Aus der Abteilung Neurodegeneration und

NeURORESTAURATIONSFORSCHUNG

(ehem. Leiter: Prof. Dr. med. J. B. Schulz)

im Zentrum Neurologische Medizin

Der Medizinischen Fakultät der Universität Göttingen

\title{
Experimentelle Untersuchungen zum neuroprotektiven Einfluss von endogenem Faim2 im murinen Fadenokklusionsmodell der zerebralen Ischämie
}

\author{
INAUGURAL-DISSERTATION \\ Zur ERLANGung Des DokTorgRAdes \\ DER MEDIZINISCHEN FAKUltäT \\ Der Georg-August-Universität Zu Göttingen
}

vorgelegt von

Christopher Spering

aus

Celle

Göttingen 2013 
I. Berichterstatter: Prof. Dr. med. J. B. Schulz

II. Berichterstatter: Prof. Dr. med. G. Trendelenburg

Tag der

mündlichen Prüfung: 07. Januar 2014 


\section{Inhaltsverzeichnis}

1 Einleitung 1

1.1 Verzögerter neuronaler Zelltod durch Apoptose . . . . . . . . . . . . . . 1

$1.1 .1 \quad$ Die Bedeutung von Apoptose für den lebenden Organismus . . 2

1.1.2 Morphologische Veränderungen apoptotischer Zellen . . . . . . 3

$\begin{array}{lll}1.1 .3 & \text { Molekularer Mechanismus des FasL/CD95L-Fas/CD95-Systems } 5\end{array}$

1.1.4 Die Bivalenz des FasL/CD95L-Fas/CD95-Systems . . . . . . . 7

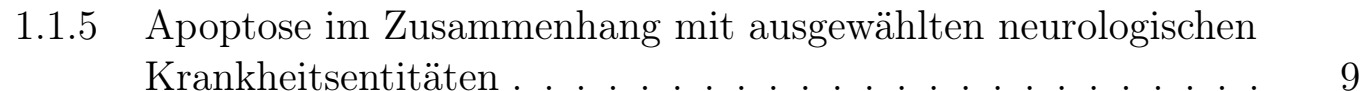

1.2 Modulation der FasL/CD95L-Fas/CD95-Transduktion durch Faim2 . 11

1.3 Der Schlaganfall . . . . . . . . . . . . . . . . . . . . 13

1.3 .1 Zerebrale Ischämie . . . . . . . . . . . . . . . . . . . . . 13

1.3 .2 Neuronaler Zelltod in der zerebralen Ischämie . . . . . . . . . 16

1.3 .3 Experimentelle Tiermodelle der zerebralen Ischämie . . . . . . 17

1.4 Herleitung der Fragestellung und experimentelle Strategie . . . . . . . 18

2 Material und Methoden $\quad 21$

2.1 Material . . . . . . . . . . . . . . . . . . . . . . . . . . . . . . . 21

2.1 .1 Apparatur . . . . . . . . . . . . . . . . . . 21

2.1 .2 Chemikalien und Bioreagenzien . . . . . . . . . . . 21

2.1 .3 Lösungen und Puffer . . . . . . . . . . . . . . . . . . . . . . 21

2.1 .4 Enzyme . . . . . . . . . . . . . . . . . . . . 23

2.1 .5 Antikörper. . . . . . . . . . . . . . . . . . 24

2.1 .6 Computersoftware . . . . . . . . . . . . . . . . . . . . . 24

2.2 Versuchstiere . . . . . . . . . . . . . . . . . . . . 25

2.2 .1 Herkunft und Haltung . . . . . . . . . . . . . . . . . . . . . . . . 25

2.2 .2 Das Faim2-null-mutant-Konstrukt. . . . . . . . . . . . . 26

2.3 Molekularbiologie . . . . . . . . . . . . . . . . . . . . . 27

2.3.1 Isolation genomischer DNA aus Schwanzspitzenbiopsie der Maus 27

$2.3 .2 \quad$ DNA-Präzipitation . . . . . . . . . . . . . . . . . . . . 27

2.3 .3 Polymerasekettenreaktion (PCR) mit genomischer DNA . . . 28 
2.3.4 Agarosegelelektrophorese von PCR-Amplifikaten . . . . . . . . 29

2.3 .5 RNA-Isolation und cDNA-Synthese . . . . . . . . . . . . 30

2.3 .6 Quantitative real time PCR . . . . . . . . . . . . . . 31

2.3 .7 Das Faim2-Lentivirus-Konstrukt . . . . . . . . . . . . . . . . 33

2.4 In-vitro-Methoden . . . . . . . . . . . . . . . . . . . . . 34

$2.4 .1 \quad$ Oxygen-glucose Deprivation (OGD) . . . . . . . . . . . 35

2.4 .2 Caspase-3- und -8-Activity-Assay . . . . . . . . . . 35

2.5 In-vivo-Methoden . . . . . . . . . . . . . . . . . . . . . . . . . 36

$2.5 .1 \quad$ Middle Cerebral Artery Occlusion (MCAo) . . . . . . . . . . . 36

2.5 .2 Stereotaktische Injektionen . . . . . . . . . . . . . . 38

2.5 .3 Zeitverlauf der Faim2- und Fas-Regulation . . . . . . . . . . . 40

2.5 .4 Caspase-3- und -8-Activity-Assay . . . . . . . . . . . . . . 41

2.5 .5 BrdU-Applikation . . . . . . . . . . . . . . . 42

2.6 Gewebeaufarbeitung der Maushirne . . . . . . . . . . . . . . . 42

2.6 .1 Einfrieren unfixierter Maushirne . . . . . . . . . . . . . . . . . 42

2.6 .2 Transkardiale Fixation des Gewebes . . . . . . . . . . . . . . . 42

2.6 .3 Schneiden der Maushirne . . . . . . . . . . . . . . . . . 42

2.6 .4 Hämatoxylin-Färbung . . . . . . . . . . . . . . . 43

2.6 .5 Messung des Infarktvolumens . . . . . . . . . . . . . . . . . 44

2.6 .6 Terminal-Desoxynucleotidyl-Transferase-mediated dUTP-biotin Nick End Labeling (TUNEL) . . . . . . . . . . . . . . . . . . . 45

$2.7 \quad$ Immunhistochemie . . . . . . . . . . . . . . . . . . . . . . . 48

$2.7 .1 \quad$ Immunhistochemie gegen BrdU . . . . . . . . . . . . . . . 48

2.7 .2 Immunfluoreszenz-Doppelfärbungen . . . . . . . . . . . . . . . 49

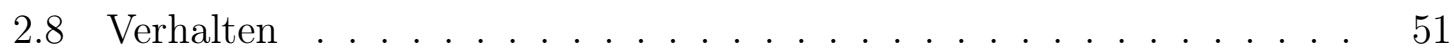

$2.8 .1 \quad S N A P$-Score-Erhebung . . . . . . . . . . . . . . . 51

2.9 Statistische Methodik . . . . . . . . . . . . . . . . . . . . . 52

\begin{tabular}{lll}
\hline 3 & Ergebnisse & 53
\end{tabular}

3.1 Charakterisierung des Proteins Faim2. . . . . . . . . . . . . . . . 53

3.1 .1 Expression von Faim2 im Organismus . . . . . . . . . . . . 53

3.1 .2 Zeitliche Regulation von Faim2 und Fas/CD95 nach zerebraler Ischämie . . . . . . . . . . . . . . . 54

3.2 Einfluss von Faim2 während milder fokaler zerebraler Ischämie . . . . 55

$3.2 .1 \quad$ Vergrößertes Infarktvolumen bei Faim2-Defizienz … . . . . 57

3.2 .2 Histologische Veränderungen im Infarktareal . . . . . . . . . . 60

3.3 Regulation der Apoptose durch Faim2 . . . . . . . . . . . . . 66 
3.4 Einfluss der Faim2- ̈̈berexpression durch viralen Gentransfer auf neuronale Zellen . . . . . . . . . . . . . . . . . . . . . . . . . . . . 67

3.4.1 Charakterisierung des viralen Vektors zur stereotaktischen Injektion vor MCA-Okklusion . . . . . . . . . . . 67

$3.4 .2 \quad$ Schutz vor Apoptose durch Überexpression von Faim2. . . . . 71

$3.5 \quad$ Klinische Bewertung der Versuchstiere nach zerebraler Ischämie . . . 75

\begin{tabular}{lll}
\hline 4 & Diskussion & 77
\end{tabular}

4.1 Faim2 im Überblick . . . . . . . . . . . . . . . . . . . . . . . . . . . 77

4.2 Die Rolle von Faim2 während der zerebralen Ischämie und Regulation der Fas/CD95-induzierten Apoptose . . . . . . . . . . . . 80

$4.2 .1 \quad$ Vergrößertes Ischämievolumen unter Faim2-Defizienz . . . . . 83

4.2 .2 Expression von Faim2 und Fas/CD95 im Organismus . . . . . 84

4.2.3 Zeitliche Regulation von Faim2 und Fas/CD95 nach zerebraler Ischämie . . . . . . . . . . . . . . . . 85

$4.2 .4 \quad$ Signaltransduktion und Caspase-Aktivität . . . . . . . . . . 86

$4.2 .5 \quad$ Klinische Symptomatik der Versuchstiere . . . . . . . . . . . . 89

$4.3 \quad$ Viraler Gentransfer von Faim2 in neuronalen Zellen als Schutz vor Apoptose - ein potentiell therapeutischer Ansatz . . . . . . . . . . . . 90

\begin{tabular}{lll}
\hline 5 & Zusammenfassung & 93
\end{tabular}

\begin{tabular}{lll}
\hline & Abkürzungsverzeichnis & 94
\end{tabular}

\begin{tabular}{lll}
\hline 7 & Literaturverzeichnis & 101
\end{tabular}

8 Anhang 115

8.1 Publikationsverzeichnis . . . . . . . . . . . . . . . . . . . . 115

$8.2 \quad$ Alternative Tiermodelle der zerebralen Ischämie . . . . . . . . . . . . 115

8.3 Apparatur . . . . . . . . . . . . . . . . . . . . 116

8.3 .1 Geräte . . . . . . . . . . . . . . . . . 116

8.3 .2 Verbrauchsmaterial . . . . . . . . . . . . . . . . 120

8.4 Chemikalien und Bioreagenzien . . . . . . . . . . . . . . . . . . . 122

8.5 PCR-Amplifikate zur Genotypisierung von LFGEIIaCre-Versuchstieren 126

8.6 Stereotaktische Injektion ． . . . . . . . . . . . . . . . . . . . 127

8.7 Position und Anatomie der Hirnsektionen . . . . . . . . . . . . . . . . 128

8.8 SNAP-Score . . . . . . . . . . . . . . . . . . . . . . . . . . . . . . . . . 129 


\section{Tabellenverzeichnis}

1.1 Apoptose in ausgewählten Krankheitsentitäten . . . . . . . . . . . . . 10

2.1 Auflistung der verwendeten Enzyme . . . . . . . . . . . . . . . . . . . 23

2.2 Auflistung der verwendeten Antikörper . . . . . . . . . . . . . . . . . 24

2.3 Auflistung der verwendeten Computersoftware . . . . . . . . . . . . . 24

2.4 PCR-Reaktionszusammensetzung . . . . . . . . . . . . . . . . . . 28

2.5 PCR-Programmablauf . . . . . . . . . . . . . . . . . . . . . . . . . . 28

$2.6 \quad$ PCR-Reaktionszusammensetzung semi-nested PCR . . . . . . . . . 29

2.7 Quantitative real time PCR: Reaktionszusammensetzung . . . . . . . 32

$2.8 \quad$ Quantitative real time PCR: Programmablauf . . . . . . . . . . . . . 32

2.9 Koordinaten für die stereotaktische Injektion . . . . . . . . . . . . . . 39

2.10 Koordinaten für den Vorversuch der stereotaktischen Injektion . . . . 39

3.1 Physiologische Parameter während MCAo . . . . . . . . . . . . . . 56

4.1 Zentrale Aussagen ausgewählter Veröffentlichungen zu Faim2 und zerebraler Ischämie . . . . . . . . . . . . . . . . . . . . . . 79

4.2 Überblick über die proximal inhibierend wirkenden Proteine der Apoptosetransduktion nach Einleitung durch FasL-Aktivierung . . . . . . 86

8.1 Tiermodelle der zerebralen Ischämie . . . . . . . . . . . . . . . . . . . 115

8.2 Auflistung der verwendeten Geräte . . . . . . . . . . . . . . . . . 116

8.3 Auflistung des verwendeten Verbrauchsmaterials . . . . . . . . . . . 120

8.4 Auflistung der verwendeten Chemikalien und Bioreagenzien . . . . . . 122

8.5 Richtlinien zur Durchführung des SNAP-Scores . . . . . . . . . . . . 130 


\section{Abbildungsverzeichnis}

$1.1 \quad$ Morphologische Veränderungen einer apoptotischen Zelle . . . . . . 4

1.2 Die extrinsische und intrinsische Apoptose-Signaltransduktion . . . 6

1.3 Funktion von FasL/CD95L-Fas/CD95 in multiplen Signaltransduk-

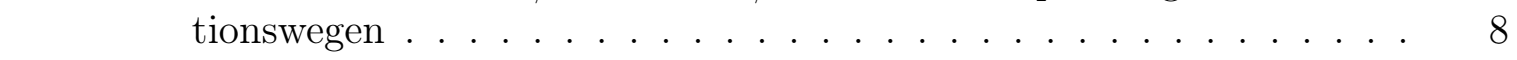

1.4 FasL/CD95L-Fas/CD95-Signaltransduktion zur Einleitung der Apoptose und dessen inhibierende Proteine. . . . . . . . . . . . . 12

$2.1 \quad$ Anatomische Verhältnisse und Positionierung von Ligaturen, Inzision, Gefäßklipp und Filament an der Karotisgabel während MCAO . 37

$2.2 \quad$ Versuchsanordnung zum Zeitverlauf der Faim2- und Fas-Regulation 40

3.1 Expression von Faim2 in verschiedenen Organen und Geweben der

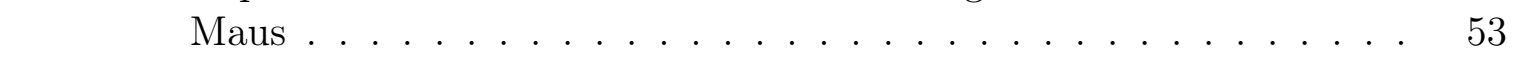

3.2 Expression von Faim2-mRNA und Fas/CD95-mRNA im zeitlichen Verlauf nach MCAO . . . . . . . . . . . . . . . 54

3.3 Makroskopische Darstellung des Infarktareals mittels HE-Färbung nach MCAO . . . . . . . . . . . . . . . . . . . 57

3.4 Infarktvolumen von Faim2 $2^{-/-}$- und Faim2 $2^{+/+}$-Tieren nach milder fokaler zerebraler Ischämie . . . . . . . . . . . . . . . . . 58

$3.5 \quad$ Vergleich der Infarktflächen der jeweiligen koronaren Sektionen . . . 59

3.6 Grafik des Infarktvolumens von Faim2 $2^{-/-}$- und Faim2 $2^{+/+}$-Tieren nach milder fokaler zerebraler Ischämie . . . . . . . . . . . . . . . 60

3.7 Darstellung des Infarktareals anhand TUNEL-positiver Zellen eines Faim2-defizienten Tieres und eines Wildtyps im Vergleich. . . . . . . 61

$3.8 \quad$ Vergleich zwischen Faim2-defizienten Tieren und Wildtypen bzgl. der Anzahl TUNEL-positiver Zellen in der infarzierten Hemisphäre und Dichte der TUNEL-positiven Zellen in der infarzierten Hemisphäre . 62

$3.9 \quad$ Vergleich zwischen Faim2-defizienten Tieren und Wildtypen bzgl. der Dichte TUNEL-positiver Zellen im Infarktareal . . . . . . . . . . . . 62

3.10 Doppelfärbung gegen TUNEL/NeuN . . . . . . . . . . . . 63

3.11 Caspase-8 und Caspase-3 in einer Doppelfärbung gegen NeuN . . . 64

3.12 BrdU-positive Zellen im Striatum . . . . . . . . . . . . . . . . . 65

3.13 Caspase-8- und -3-Aktivität im Vergleich Faim2-Defizienz und-Wildtyp 67 
3.14 Darstellung des infizierten Gewebes im Striatum am Faim2/LFGAdenovirus-Konstrukt . . . . . . . . . . . . . . 68

3.15 Darstellung der mit dem Faim2-Lentiviruskonstrukt infizierten Zellen im Striatum . . . . . . . . . . . . . . . . . . 69

3.16 Versuchsaufbau des lentiviralen Gentransfers . . . . . . . . . . . . . 71

3.17 Grafische Darstellung des Infarktvolumens von Faim2 $2^{-/-}$und Faim2 ${ }^{+/+}$ im Vergleich nach Gentransfer von Faim2 mittels eines Lentiviruskon-

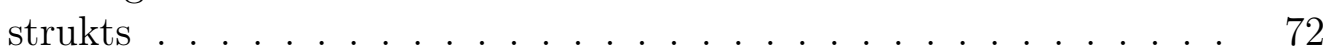

3.18 Grafische Darstellung des prozentualen Anteils überlebender Neurone nach OGD und der LDH-Freisetzung nach OGD im Vergleich Faim2 $2^{-l-}$ und Faim2 ${ }^{+/+} \ldots \ldots \ldots . \ldots 73$

3.19 Grafische Darstellung der LDH-Freisetzung nach OGD im Vergleich Faim2 $2^{-/-}$und Faim2 $2^{+/+}$in Abhängigkeit vom Virustiter $\ldots . . .974$

$3.20 \quad$ Grafische Darstellung des SNAP-Scores vor und nach MCAO . . . . 76

8.1 Agarosegelelektrophorese von PCR-Amplifikaten zur Genotypisierung von LFGEIIaCre-Versuchstieren . . . . . . . . . . . . . . . . . . . . 126

$8.2 \quad$ Versuchsaufbau der stereotaktischen Injektion . . . . . . . . . . . . 127

8.3 Anatomische Verhältnisse bei stereoktakischer Injektion mittels Bohrlochtrepanation . . . . . . . . . . . . . . . . 127

$8.4 \quad$ Position der koronaren Hirnschnitte in einer Kontrolle (sham) ohne Ischämie . . . . . . . . . . . . . . . . . . . . . . . . . 128 


\section{Einleitung}

Die vorliegende Arbeit befasst sich mit der Regulation des endogenen Zelltodmechanismus (Apoptose) nach experimenteller fokaler transienter zerebraler Ischämie in der Maus. Bei den durchgeführten Untersuchungen steht das Membranprotein Fas apoptotic inhibitory molecule 2 (Faim2) $^{1}$ im Fokus. Faim2 nimmt eine modulierende Funktion innerhalb der endogenen Fas/CD95-Signaltransduktion ein. Die durchgeführten Experimente liefern Erkenntnisse zu folgenden Mechanismen: (1) Modulation und Inhibition der Fas/CD95-induzierten Signaltransduktion zur Einleitung der Apoptose durch Faim2, (2) quantitative und zeitliche Regulation von Faim2 und Fas/CD95 während der zerebralen Ischämie und (3) Einfluss der Abwesenheit bzw. Überexpression von Faim2 auf die Zelltodprozesse nach fokaler reversibler zerebraler Ischämie. Die Beantwortung der Frage nach dem Effekt der Hochregulation von Faim2 und dessen mögliche protektive Wirkung im Rahmen der Apoptose könnte langfristig in der präklinischen und klinischen Akutbehandlung von Patienten nach einer zerebralen Ischämie durch beispielsweise medikamentöse Hochregulation von Faim2 Anwendung finden.

\subsection{Verzögerter neuronaler Zelltod durch Apoptose}

Für die Entwicklung und für die Aufrechterhaltung eines Organismus ist die Balance zwischen Leben und Tod auf zellulärer Ebene entscheidend. Programmierter neuronaler Zelltod bildet zusammen mit Zellproliferation und -regeneration die Grundlage für neuroale Plastizität. Die Apoptose spielt nicht nur bei physiologischen Prozessen wie Embryonalentwicklung und Differenzierung von Zellen und Geweben eine wichtige Rolle, sondern auch in pathophysiologischen Zusammenhängen. Neben neurodegenerativen ZNS-Erkrankungen, wie Morbus Alzheimer und Parkinson, reguliert sie auch bei akuten Erkrankungen wie zerebraler Ischämie, traumatischem Gewe-

\footnotetext{
${ }^{1}$ In früheren Studien wurde Faim2 auch Lifeguard ( $L F G$ ) (Somia et al. 1999) oder neuronal membrane protein 35 (Beier et al. 2005) genannt. In der vorliegenden Arbeit wird primär die Bezeichnung Faim2 verwendet, wobei die Faim2-defizienten Versuchstiere auch mit Faim2 $2^{-/}$und die Wildtypen mit Faim2 $2^{+/+}$abgekürzt werden.
} 
beuntergang, entzündlichen Prozessen und Neoplasien den Zelluntergang und die Regeneration/Zellproliferation (Martin-Villalba et al. 1999, Reich et al. 2008, Ribe et al. 2008, Beier und Schulz 2009). Eine der zur Apoptose führenden Signaltransduktionen wird durch das Fas/CD95-FasL/CD95L-System initiiert und stellte die Grundlage für die in der vorliegenden Arbeit untersuchte Apoptosemodulation durch Faim2 dar.

Der komplexe Ablauf der Apoptose verläuft in drei aufeinanderfolgende Phasen, die wiederum in mehrere Schritte untergliedert sind (Ellis und Horvitz 1986, Wyllie et al. 1992, Endres et al. 1998a):

Die Initiationsphase (commitment phase) ist geprägt durch Mechanismen, in denen sich die Zelle „festlegt“, das eigene Absterben zu initiieren. Auslösefaktoren sind beispielsweise Mitosezahl, Zellalter, Hormonkonzentrationen, interzelluläre Kommunikation, Fas/CD95-FasL/CD95L-vermittelter Abwehrkontakt und Noxen (Wyllie 1993, Riede et al. 2004, Reich et al. 2008).

In der Ausführungsphase (execution phase) läuft das eigentliche Zelltod-Programm ab. Dazu werden Zelltod-Proteasen (sog. Caspasen) kaskadenartig aktiviert, was wiederum zur Einleitung irreversibler Schäden und damit zur Exekution der Zelle führt.

In der Abräumphase werden nach dem Auslösen aus ihrem Zellverbund und der folgenden Kondensation die apoptotischen Zellen fragmentiert und entweder recycled oder als sog. Apoptosekörperchen phagozytiert und ohne Ausbildung einer Entzündungsreaktion beseitigt.

\subsubsection{Die Bedeutung von Apoptose für den lebenden Organismus}

Der von den Pathologen John F. R. Kerr, Andrew H. Wyllie und Alastair Robert Currie mit Apoptosis (griechisch: ảpóptosis = das Abfallen, Wegfall; aus ảpó = ab, weg und ptõsis = das Fallen (Duden 2006)) beschriebene Prozess des programmierten Zelluntergangs (Kerr et al. 1972) beschreibt einen Vorgang, bei dem die Zellbestandteile durch spezifische Kaskaden und Umbaumechanismen unter verschiedenen physiologischen und pathophysiologischen Umgebungszuständen in Kompartimente verpackt und nach Absterben der Zelle vom Körper wieder verwertet werden können (Wyllie et al. 1992, Wyllie 1993) (vgl. Abbildung 1.1 auf Seite 4).

Bei ihrer Entdeckung im Jahr 1972 konnte nur erahnt werden, welche Bedeutung die Apoptose für den lebenden Organismus darstellen würde. Heutzutage ist bekannt, 
dass Apoptose sowohl in traumatisch geschädigtem Gewebe, in der Tumorgenese und -behandlung als auch in gesundem Gewebe zur Aufrechterhaltung der Funktion und ständigen Revitalisierung eine zentrale Rolle spielt (Wyllie 2010). Im Jahr 2002 haben Sydney Brenner, Robert Horvitz und John Sulston für eben diese Aufklärung der Zusammenhänge von zelleigen programmiertem Zelltod den Nobelpreis für Medizin und Physiologie erhalten. Der Fokus ihrer Untersuchungen lag auf der Erforschung der Signaltransduktionswege am Fadenwurm Caenorhabditis elegans, die zur Einleitung der Apoptose notwendig sind (Ellis und Horvitz 1986). Die Preisträger stellten u.a. die Apoptose in Zusammenhang mit dem Zellumsatz gesunder und erkrankter Gewebe. Apoptose ist Voraussetzung für den Zellumsatz, der gewebeabhängig unterschiedlich hoch ist. Darmepithelzellen bespielsweise haben einen Lebenszyklus von ca. 36-200 Stunden, Granulozyten von vier Tagen. Ein bekanntes Bespiel ist die Lebensdauer von ca. zehn Tagen der Thrombozyten im Rahmen der Antikoagulation, Erythrozyten hingegen überleben 120 Tage. Zu den Dauergeweben gehören Nervenzellen und Zellen des Skelettsystems. Letztere überleben ca. 15-35 Jahre und traumatische Veränderungen (z.B. Fraktur, Wunde etc.) werden mit dem Ersatz durch morphologisch und funktionell minderwertiges Gewebe beantwortet (Groth 2004).

Mehr als 500 Milliarden Zellen werden im menschlichen Körper jeden Tag neu gebildet. Würde nicht auch eine entsprechend hohe Anzahl durch die Apoptose zugrunde gehen, wäre das menschliche Knochenmark innerhalb weniger Jahre Tonnen schwer und der Darm mehrere Kilometer lang (Groth 2004). Das Leben an sich und die Entwicklung des Organismus benötigt Zellteilung, Zellproliferation und Zelltod.

Während dieses Mechanismus werden durch eine spezifische Genregulation von u.a. cmyc, bcl-2, ras, p53 oder PI3-Kinase/Akt, die wiederum Proteine wie Fas/CD95 und Proteine der Fas apoptotic inhibitory molecules (Faim1-4)-Familie etc. steuern, ein reproduzierbarer Umsatz und die Regeneration kontrolliert(Ellis und Horvitz 1986, Wyllie et al. 1992, Lesne et al. 2005, Reich et al. 2008).

\subsubsection{Morphologische Veränderungen apoptotischer Zellen}

Die Apoptose wird durch ein genvermitteltes Zelltodprogramm ausgelöst und sorgt dafür, dass meist nur einzelne Zellen absterben. Hierbei kommt es zum Schrumpfen der Zelle durch die sog. Kondensation (siehe Abbildung 1.1 auf der nächsten Seite) mit anschließender Fragmentation ohne inflammatorische Begleitreaktionen. Auf Grund dieser morphologisch charakteristischen Veränderungen wird die Apoptose auch als Schrumpftod bezeichnet (Riede et al. 2004). 


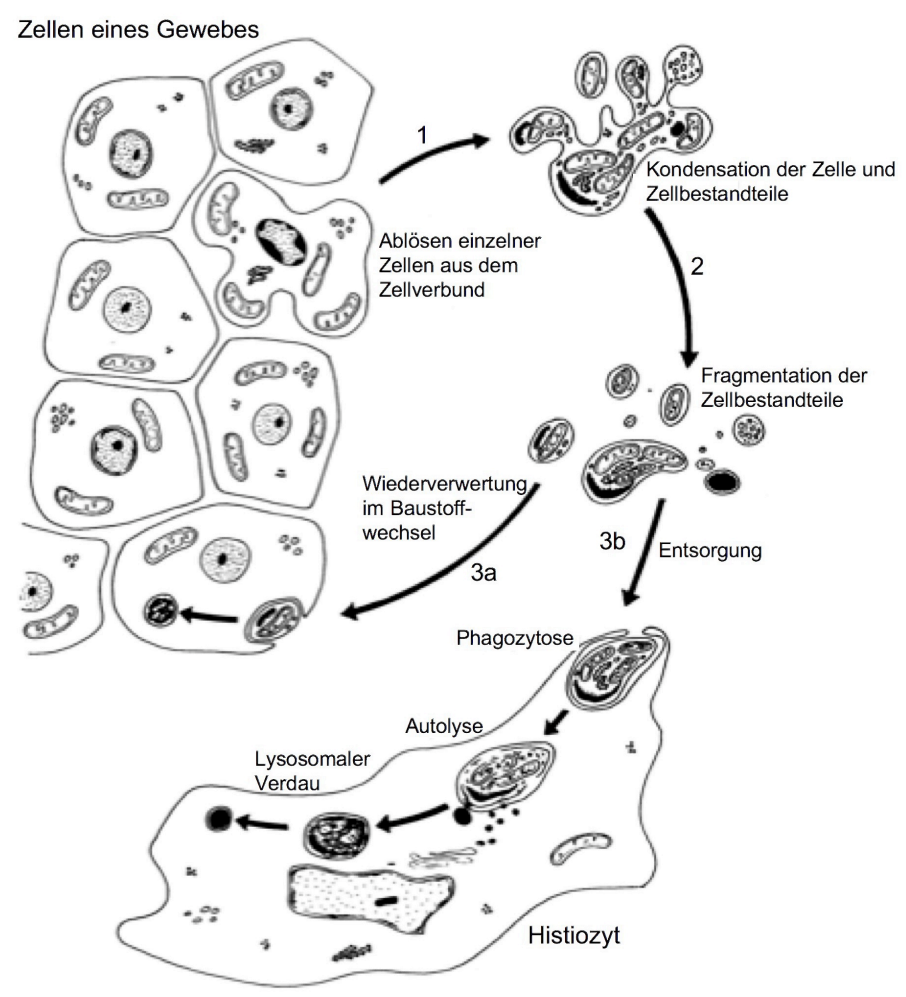

Abbildung 1.1: Flussdiagramm der morphologischen Veränderungen während der Apoptose. (1) Zunächst löst sich die apoptotische Zelle aus dem Zellverbund des Gewebes und schrumpft bis zur Kondensation. (2) Anschließend werden die Zelle selbst und die Zellbestandteile in Kompartimente verpackt, die jeweils mit Zellmembran umschlossen sind. Diese sog. Vesikel werden nun entweder zum Baustoffwechsel des menschlichen Organismus wieder verwertet (3a) oder über die Phagozytose und den lysosomalen Abbau in einem Histiozyten entsorgt (3b).

(modifiziert nach Kerr et al. 1972, Seite 242)

Demgegenüber steht der sog. Schwelltod, der akzidentelle Zelltod (Nekrose), bei dem es meist aufgrund einer irreversiblen Stoffwechselstörung zu einem erzwungenen Absterben von ganzen Zellgruppen bis hin zum Massensterben von Zellen mit konsekutiver Zellschwellung und inflammatorischer Begleitreaktion, ohne ein kontrolliertes Zelltodprogramm, kommt (Riede et al. 2004). Apoptotische Zellen befinden sich meist bereits isoliert innerhalb eines Zellverbundes und weisen histologisch kleine, ungleichmäßig sphärische bis ovale Zytoplasmafragmente auf, die zum Teil pyknotische Bestandteile der Nuclei beinhalten (Kerr et al. 1972). Nach der Kondensation und Fragmentation werden ungleich große Zellkörper gebildet, die als Vesikel mit Zellmembran umkleidet sind und je nach Differenzierung der ursprünglichen Zelle unterschiedliche Inhalte aufweisen. Diese Vesikel werden Apoptosekörperchen genannt. Sie beinhalten kondensierte Bestandteile des Nucleus und dessen kondensiertes, in dichte Granula verpacktes Chromatin, osmophile Kleinbestandteile des Nucleolus, Fragmente des 
Zytoplasmas, Zellorganellen wie Mitochondrien etc. und diverse Bindungsproteine an der Oberfläche der sie umgebenden Zellmembran (Kerr et al. 1972).

Neuronale Zellen, die sich in Apoptose befinden, können durch Markierung von internukleosomalen Spaltprodukten der DNA-Fragmente in einer apoptotischen Zelle bei Doppelfärbungen gegen TUNEL und NeuN (siehe Abschnitt 2.7.2 auf Seite 49) oder reinen TUNEL-Färbungen mittels DAB (siehe Abschnitt 2.6.6 auf Seite 45) lichtmikroskopisch visualisiert werden.

\subsubsection{Molekularer Mechanismus des FasL/CD95L-Fas/CD95- Systems}

Apoptose kann als programmierter zellulärer Selbstmord oder als programmierter zellulärer Brudermord in Erscheinung treten. Bei dem erstgenannten Prozess werden zelleigene Kaskaden durch äußere (extrinsische Apoptose-Signaltransduktion) oder innere (intrinsische Apoptose-Signaltransduktion) Einflüsse aktiviert, die schließlich das Absterben der Zelle einleiten. Dies geschieht z.B. im physiologischen Alterungsprozess, nach Entzug stimulierender Hormone, der zyklischen Abstoßung des Endometriums und toxischen Schädigungen, die dem Genom zugefügt werden, wie beispielsweise UV-Exposition der Haut (Thompson 1995, Ribe et al. 2008). Der programmierte zelluläre Brudermord hingegen wird von anderen Zellen (z.B. Abwehrzellen) desselben Organismus oder Gewebes ausgelöst. Dies geschieht beispielsweise während der Embryogenese, zytotoxischen Abwehr von Fremdzellen oder fremdgewordenen Zellen (Tumorzellen) und der Lymphopoese sowie der Ausreifung von T-Zellen (Riede et al. 2004).

Einer der zur Apoptose führenden molekularen Signaltransduktionswege stellt das FasL/CD95L-Fas/CD95-System dar. Im Rahmen dieser Apoptoseeinleitung kommen sog. Caspasen (cysteine-dependent aspartate-specific protease) zum Tragen, die kaskardenartig aktiviert werden. Dabei unterscheidet man sog. Initiationscaspasen (z.B. Caspase-8, -9, -10) von Effektorcaspasen (z.B. Caspse-3) (Tang et al. 2000).

Wie in Abbildung 1.2 auf der nächsten Seite dargestellt, kann einerseits eine intrinsische (mitochondriale) und andererseits eine extrinsische (Todesrezeptor-vermittelte) Kaskade initiiert werden. Beide beginnen mittels proteolytischer Spaltung mit der Aktivierung inaktiver Procaspasen zu Initiationscaspasen und vereinen sich schließlich in der Aktivierung von Effektorcaspasen zur Einleitung der Apoptose (Schulz et al. 1999, Tang et al. 2000, Ribe et al. 2008).

Kroemer et al. (2007) zeigen auf, dass die mitochondriale Membranpermeabilität im 
extrinsisch

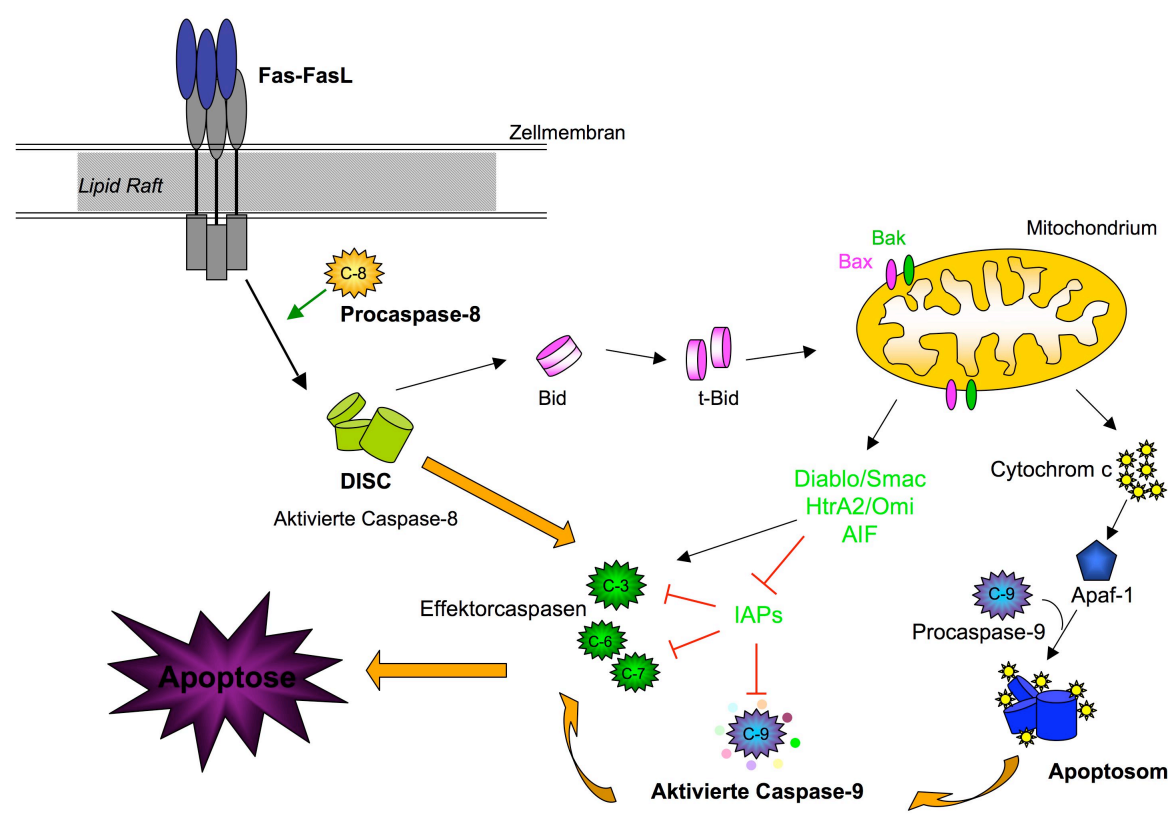

Abbildung 1.2: Die extrinsische und intrinsische Apoptose-Signaltransduktion. DISC: deathinducing signaling complex, Bid: BH3 interacting domain death agonist, t-Bid: trunkierte Form von Bid, Bak: BCL2-antagonist/killer 1, Bax: BCL2-associated X protein, Diablo: direct IAP-binding protein with low pI (Synonym Smac), Smac: second mitochondria-derived activator of caspase, AIF: apoptosis-inducing factor, HtrA2: HtrA serine peptidase 2 (Synonym Omi), Apaf-1: apoptotic protease activating factor-1, IAPs: inhibitor of apoptosis proteins

(modifiziert nach Ribe et al. 2008, Seite 167)

Rahmen der intrinsischen Signaltransduktion, welche durch zytotoxische Bedingungen wie oxidativer Stress und ionisierende Strahlung ausgelöst wird, mit folgender Translokation mitochondrialer Moleküle, einen point of no return darstellt. Dabei rekrutieren Cytochrom c, Smac/Diablo, HtrA2/Omi und AIF Initiations- und Effektorcaspasen (Tang et al. 2000, Galluzzi et al. 2009). Insbesondere das ins Zytosol abgegebene Cytochrom c kann über die Komplexbildung mit Apaf-1 und Procaspase-9 (Apoptosom) die Caspase-9 und damit die Effektorcaspasen aktivieren (Ribe et al. 2008).

In der vorliegenden Arbeit steht jedoch die extrinsische, FasL/CD95L-Fas/CD95induzierte Signaltransduktion im Vordergrund. Diese zur Apoptose führende Kaskade wird durch die sog. Todesrezeptoren eingeleitet, unter denen der zur Tumornekrosefaktor-Rezeptor(TNFR)-Superfamilie zählende Fas/CD95-Rezeptor ein wichtiger Vertreter ist. Nach Bindung mit dem Liganden FasL/CD95L bildet Fas/CD95 wiederum mit zwei weiteren FasL/CD95L-Fas/CD95-Verbindungen einen Komplex. Die Mobilität der nativen Rezeptoren und die Komplexbildung wird durch lipidhaltige Mikrodomänen, sog. lipid rafts, die sich frei in der Zellmembran bewegen können, ermöglicht 
(Fernandez et al. 2007). Durch diese Komplexbildung erfolgt die Assoziation mit dem Adaptorprotein FADD (Fas-associated death domain), welches durch eine ins Zytoplasma ragende Todesdomäne und über an dieser befindlichen Todeffektordomänen an homologe Stellen auf der Initiationscaspase (pro-Caspase-8) bindet. Unter Aktivierung regulatorischer Proteine (FLIP, Faim1 und 3, PEA-15, Btk und FAP-1 (siehe Abbildung 1.4 auf Seite 12) wird der Todessignalkomplex DISC (death-inducing signaling complex) mit aktiver Caspase- 8 geformt, um wiederum die Effektorcaspasen (Caspase-3, -6 und -7) zu aktivieren (Krammer 1998, Peter und Krammer 2003, Ribe et al. 2008, Reich et al. 2011).

Wie in den Abbildungen 1.2 auf der vorherigen Seite und 1.4 auf Seite 12 dargestellt, kann durch aktivierte Caspse-8 über die Aktivierung von Bid und die trunkierte Form (t-Bid) die Freisetzung von Cytochrom c in das Zytosol veranlasst und damit der intrinsischen Weg im Sinne einer Verstärkung (amplification loop) rekrutiert werden (Tang et al. 2000, Stegh et al. 2002, Galluzzi et al. 2009). Des Weiteren wird hierdurch über die Mobilisation von Smac/Diablo die IAPs gehemmt, welche wiederum hemmend auf die Effektorcaspasen wirken (Ribe et al. 2008).

\subsubsection{Die Bivalenz des FasL/CD95L-Fas/CD95-Systems}

Apoptose ist in der Gewebehomöostase und -differenzierung sowie einer Vielzahl an immunsystemprägenden Prozessen und pathologischen Veränderungen beteiligt (Reich et al. 2008, Sancho-Martinez und Martin-Villalba 2009) und wird u.a. durch den Todesrezeptor Fas/CD95 induziert. Fas/CD95 ist das am besten charakterisierte Protein der TNFR-Superfamilie, dessen Funktion im Rahmen der Apoptose gründlich aufgearbeitet wurde (Beier und Schulz 2009). Die Apoptoseinduktion durch das FasL/CD95L-Fas/CD95-System ist lange Zeit als einzige Funktion desselbigen angenommen worden. Die ubiquitäre Expression von Fas/CD95 im Gehirn hat Anlass dazu gegeben zu hinterfragen, ob Fas/CD95 in derart hoher Dichte in gesunden neuronalen Zellen ausschließlich für die Einleitung durch beispielsweise einen Schlaganfall induzierte Apoptose vorgehalten werden muss. Die Abbildung 1.3 auf der nächsten Seite zeigt alternative Signaltransduktionen des FasL/CD95L-Fas/CD95-Systems auf, von denen nur eine zur Apoptose führt. Corsini et al. (2009) und Sancho-Martinez und Martin-Villalba (2009) zeigten auf, dass Fas/CD95 nicht nur den Zelltod einleiten kann, sondern im Gegenteil Neurogenese im gesunden und erkrankten Gehirngewebe induziert. Des Weiteren wurde für Fas/CD95 eine Aktivierung zahlreicher alternativer Signalwege, wie mitogen-activated-protein-kinases (MAPK)-, Phosphatidylinositol-3- 
Kinase (PI3K/AKT)- und extracellular-signal-regulated-kinase (ERK)-Signalweg, beschrieben. Die Prozesse, die zur Aktivierung dieser Signalwege führen, sind noch nicht vollständig bekannt (Schulz et al. 1999, Sancho-Martinez und Martin-Villalba 2009, Corsini et al. 2009). Peter et al. (2005) beschrieben eine Tumorzellinvasion über den Fas/CD95-induzierten NF $\kappa$ B- und MAP-Kinase-Signalweg, Sancho-Martinez und Martin-Villalba (2009) eine Fas/CD95-induzierte Gliomzellproliferation über PI3K/ AKT. Die Fas/CD95-induzierte neuronale Ausdifferenzierung und Neuritenverzweigung (neuronal branching) über ERK (extracellular signal-regulated kinase) wurden von Desbarats et al. (2003) und Zuliani et al. (2006) sowie die Zellproliferation (Peter et al. 2007) und Neurogenese in adulten Neuronen von Zhao C et al. (2008) beschrieben.

Neuronale Zellen liegen im zentralen Nervensystem (ZNS) im ausdifferenzierten Sta-

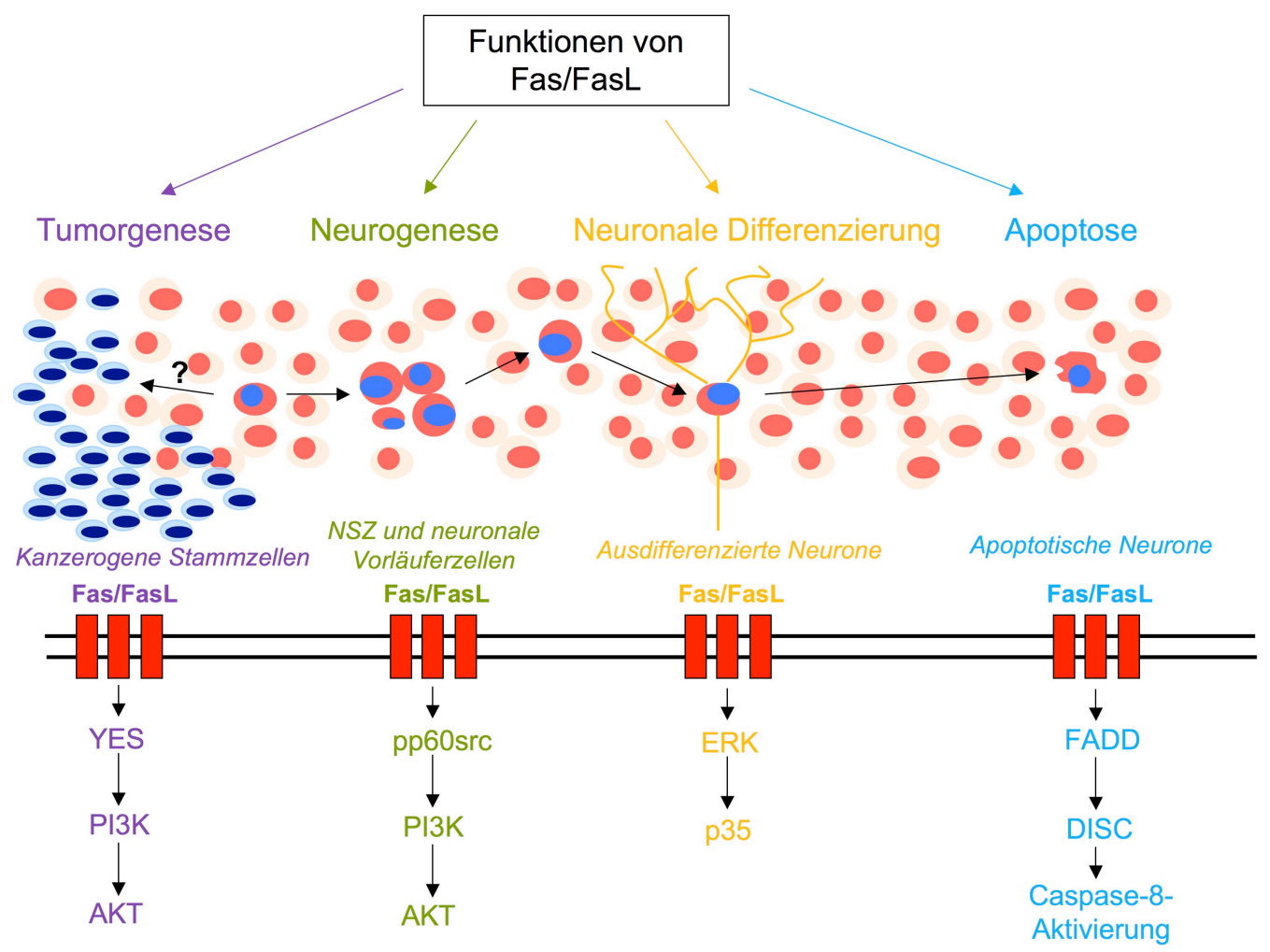

Abbildung 1.3: Funktion von FasL/CD95-Fas/CD95 in multiplen Signaltransduktionswegen. YES: v-yes-1 Yamaguchi sarcoma viral oncogene homolog 1; PI3K: Phosphatidylinositol-3-Kinase; AKT: vakt murine thymoma viral oncogene homolog 1; NSZ: neuronale Stammzellen; pp60src: v-src sarcoma (Schmidt-Ruppin A-2) viral oncogene homolog (avian) / phosphoryliertes 60-kDa-Phosphoprotein; ERK: extracellular signal-regulated kinase; p35: cyclin-dependent kinase 5 regulatory subunit 1 (p35); FADD: Fas-associated death domain; DISC: death-inducing signaling complex

(modifiziert nach Beier und Schulz 2009, Seite 129)

dium vor. Lediglich in zwei Regionen, der subventrikulären Zone (SVZ) der Seiten- 
ventrikel und der subgranulären Zone (SGZ) der Hippokampusformation des Gyrus dentatus, findet auch im adulten ZNS Neurogenese statt - sog. Stamm-Zell-Nische (Lois und Alvarez-Buylla 1994, Zhao C et al. 2008, Beier und Schulz 2009). In diesen Regionen entwickelt sich eine große Anzahl an adulten Neuronen mittels Proliferation und Differenzierung aus adulten neuronalen Stammzellen (NSZ) und migriert über den rostralen migratorischen Strom in weit entfernte Areale, wovon nur ein kleiner Teil überlebt (Zhao C et al. 2008). Einer der Auslöser für diese Proliferation und Ausdifferenzierung von NSZ mit anschließender Migration in die pathologisch veränderte Region ist die zerebrale Ischämie (Lindvall et al. 2004).

Vor dem Hintergrund, dass Fas/CD95 eine Vielzahl an biologischen Effekten beeinflusst, existieren mindestens drei Todesdomänen, die in der Lage sind Fas/CD95 mit nicht-Caspase-abhängigen Signaltransduktionen (MAPK / ERK und nuclear factor

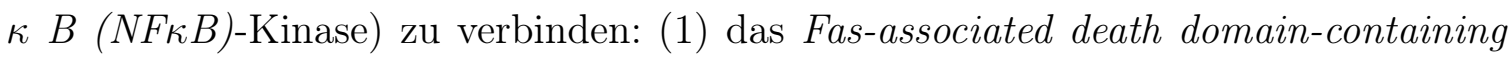
protein, FADD, (2) das death-associated protein 6, DAXX und (3) das receptorinteracting protein, RIP (Lambert et al. 2003, Wajant et al. 2003). Reich et al. (2008) stellten heraus, dass nach Analyse von knockout-Mäusen alle drei genannten Fas-assoziierten Proteine für das Überleben von Zellen essentiell, aber entbehrlich für Apoptose seien. Tran et al. (2001) wiesen sogar nach, dass die Aktivierung von ERK das proapoptotische Signal von Fas/CD95 in ein anti-apoptotisches umlenken kann, indem die Caspase-Aktivierung gehemmt wird. Derzeit ist jedoch über die Kontrollmechanismen und die molekulare Kommunikation zwischen unterschiedlichen Fas/CD95-Signalkaskaden wenig bekannt.

\subsubsection{Apoptose im Zusammenhang mit ausgewählten neurologischen Krankheitsentitäten}

Neben der Beteiligung an physiologischen Prozessen im Organismus spielt die Apoptose insbesondere bei pathologischen Veränderungen eine wichtige Rolle. Neurodegenerative Erkrankungen wie Morbus Parkinson (Landau et al. 2005), Amyotrophe Lateralsklerose (Petri et al. 2006) oder Morbus Alzheimer (Su et al. 2003), Autoimmunerkrankungen wie Multiple Sklerose (Sabelko et al. 1997, Dittel et al. 1999), akute zerebrale Schädigungen wie die zerebrale Ischämie (Rosenbaum et al. 2000, MartinVillalba et al. 2001, Reich et al. 2011) oder das Schädel-Hirn-Trauma (Beier et al. 2007) werden von durch Fas/CD95 und dessen Liganden FasL/CD95L induzierter Apoptose beeinflusst.

Grundsätzlich gelten die folgenden zwei pathophysiologischen Regulationsstörungen 
der Apoptose im Zusammenhang einer Krankheitsentität:

\section{Steigerung der zellulären Überlebensrate durch Hemmung der Apoptose}

Meist geschieht dies in Tumorzellen. Die Gewebeintegrität und -funktion wird durch ein enges interzelluläres Netzwerk aufrecht erhalten, welches der Kommunikation, Stabilität und Regulation der einzelnen Zellen dient. Maligne Zellen eines Tumors zeigen neben einer beschleunigten Stammzellerneuerung und Zellteilung eine oft verminderte Apoptoserate (Mertens et al. 1997, Bucan et al. 2010). Unter physiologischen Bedingungen würden diese Zellen durch die Induktion von Apoptose beseitigt werden (Brudermord, siehe Abschnitt 1.1.3 auf Seite 5) oder die Zelle würde durch den Verlust der interzellulären Kontrolle die Apoptose selbstständig einleiten (mitochondrialer Apoptoseweg, siehe Abschnitt 1.1.3 auf Seite 5). Im Gegensatz zu gesunden Zellen, die sich nicht unbegrenzt häufig teilen können, ist die Teilungsfähigkeit von Zellen maligner Tumore somit unkontrolliert.

Steigerung der zellulären Sterberate durch Apoptosesteigerung Durch äußere Einflüsse, wie Sauerstoffmangel, mangelhafte Nährstoffzufuhr, chemische/toxische Reize oder Verlust von rezeptorvermittelten Reizen, kann in Geweben die Apoptoserate von Zellen gesteigerten werden. Die Apoptose wird dabei, wie in Abschnitt 1.1.1 auf Seite 2 dargestellt, exogen oder endogen induziert und über die Caspase-Kaskade bis zum Exitus der Zelle vermittelt.

In der Tabelle 1.1 sind einige Beispiele knapp aufgeführt.

Tabelle: 1.1: Apoptose in ausgewählten Krankheitsentitäten

\begin{tabular}{|c|c|c|c|}
\hline Krankheit & Pathophysiologie & $\begin{array}{l}\text { FasL/CD95L-Fas/CD95- } \\
\text { Hemmung }\end{array}$ & Referenzen \\
\hline Morbus Parkinson & $\begin{array}{l}\text { gesteigerte Apoptoserate neuro- } \\
\text { melaninhaltiger dopaminerger } \\
\text { Nervenzellen in der Zona compacta } \\
\text { der Substantia nigra }\end{array}$ & $\begin{array}{l}\text { verminderter dopaminerger Zell- } \\
\text { untergang in der Substantia nigra }\end{array}$ & $\begin{array}{l}\text { Hayley et al. 2004, } \\
\text { Landau et al. } 2005\end{array}$ \\
\hline Morbus Alzheimer & $\begin{array}{l}\text { gesteigerte Apoptoserate neuro- } \\
\text { naler Zellen im Rahmen allg. } \\
\text { Hirnatrophie bei Beta-Amyloid- } \\
\text { Peptid-Ablagerungen }\end{array}$ & verminderte neuronale Toxizität & $\begin{array}{l}\text { Morishima et al. 2001, } \\
\text { Su et al. } 2003\end{array}$ \\
\hline $\begin{array}{l}\text { Amyotrophe } \\
\text { Lateralsklerose }\end{array}$ & $\begin{array}{l}\text { gesteigerte Apoptose von Motor- } \\
\text { neuronen und Axonen }\end{array}$ & $\begin{array}{l}\text { verlängertes Überleben v. Moto- } \\
\text { neuronen }\end{array}$ & $\begin{array}{l}\text { Raoul et al. 2006, Petri } \\
\text { et al. } 2006\end{array}$ \\
\hline Multiple Sklerose & $\begin{array}{l}\text { gesteigerte Apoptose im Rahmen } \\
\text { entzündlich-demyelinisierender Lä- } \\
\text { sionen im ZNS mit Verlust an Axo- } \\
\text { nen und reaktiver Gliose }\end{array}$ & $\begin{array}{l}\text { verminderter Zelluntergang und re- } \\
\text { duzierte klinische Symptomatik }\end{array}$ & $\begin{array}{l}\text { Sabelko et al. 1997, Dit- } \\
\text { tel et al. } 1999\end{array}$ \\
\hline Zerebrale Ischämie & $\begin{array}{l}\text { gesteigerte Apoptose durch } \\
\text { Ischämie und oxidativen Stress }\end{array}$ & vermindertes Infarktvolumen & $\begin{array}{l}\text { Rosenbaum et al. } 2000 \text {, } \\
\text { Martin-Villalba et al. } \\
\text { 2001, Reich et al. } 2011 \\
\end{array}$ \\
\hline Schädel-Hirn-Trauma & $\begin{array}{l}\text { gesteigerte Apoptose und Nekrose } \\
\text { durch traumatischen Zelluntergang } \\
\text { und oxidativen Stress }\end{array}$ & $\begin{array}{l}\text { vermindertes Läsionsvolumen und } \\
\text { erhöhte Regeneration von Hirn- } \\
\text { funktionen }\end{array}$ & $\begin{array}{l}\text { Beer et al. 2000, Beier } \\
\text { et al. } 2007\end{array}$ \\
\hline
\end{tabular}




\subsection{Modulation der FasL/CD95L-Fas/CD95- Transduktion durch Faim2}

Obwohl 1993 erste Funktionen des Fas/CD95-Signalwegs untersucht wurden, dauerte es nochmals 10 Jahre, bis ein Zusammenhang zwischen der Proliferation von T-Zellen im murinen lymphopenischen Syndrom und der Fas/CD95 Expression erkannt wurde (Hao et al. 2004). Desbarats und Newell (2000) beschrieben einen fulminanten Effekt in Hepatozyten nach der Injektion von Fas/CD95-spezifischen agonistischen Antikörpern. Es kam zu einem akuten Leberversagen bei Mäusen. Gleichzeitig beschleunigte allerdings diese Behandlung die Regeneration der Leber nach einer Leberteilresektion. Aber auch andere Gewebe, wie Herz, Pankreas und Kolon, weisen Aktivitäten von Fas/CD95 auf (Peter et al. 2007). Somia et al. (1999) wiesen für Faim2 eine Fas/CD95-inhibierende Funktion und damit einen Schutz vor Apoptose nach. Gleichzeitig gelang es ihnen, Faim2 in neuronalen Zellen, aber auch anderen Organen mittels mRNA-Expressionsanalyse nachzuweisen. Bucan et al. (2010) beschrieben den antiapoptotischen Effekt von Faim2 im Rahmen der Hemmung der Fas/CD95Transduktion als Bestandteil der Entstehung von Mammakarzinomen. Choi et al. (2007) wiesen die zytoprotektive Wirkung von Faim2 durch den Schutz vor Apoptose an humanen Keratinozyten nach.

Zur Regulation von Ligand-Rezeptor-Systemen, wie das FasL/CD95L-Fas/CD95-System, bestehen folgende Möglichkeiten: (1) direkte Modulation der Signaltransduktion durch regulatorisch bindende Proteine, (2) Modifizierung spezifischer intrazellulärer Rezeptorsysteme, die unterschiedliche Signalwege einleiten können und (3) Regulation des allgemeinen Aktivierungsgrades der Zelle. Alle drei Wege finden sich in der Regulation des FasL/CD95L-Fas/CD95-Systems wieder (Reich et al. 2008). Die durch Fas/CD95 induzierte Apoptose und der komplexe Regulationsmechanismus modulierend einwirkender Proteine sind bereits detailliert erforscht (Peter und Krammer 2003) und in Abbildung 1.4 auf der nächsten Seite dargestellt. Die Modulation des FasL/CD95L-Fas/CD95-Systems ist ein Beispiel des negativen Feedbacks, bei dem nicht Transduktion-aktivierende Moleküle herunter, sondern hemmende hoch reguliert werden. Neben zahlreichen gut erforschten Proteinen, die in Tabelle 4.2 .4 auf Seite 86 aufgelistet sind, sind die antiapoptotischen, inhibierenden Moleküle der Faim-Familie (Faim1, 2 und 3) zu einem frühen Zeitpunkt in der Fas/CD95Signaltransduktion hemmend wirksam. Faim2 ist dabei ein vornehmlich in Neuronen exprimiertes, 35,1 kDa schweres Membranprotein, das exklusiv vor FasL/CD95Linduziertem Zelluntergang schützend wirksam ist (Somia et al. 1999, Beier et al. 2005, 
Fernandez et al. 2007). Die Expression von Faim2 ist durch den Phosphatidylinositol 3-Kinase-AKT/Protein-Kinase B-Signalweg reguliert (Beier et al. 2005).

Die Abbildung 1.4 zeigt die Einleitung der Apoptose über die Bindung von FasL/CD95L an den Todesrezeptor Fas/CD95 auf der Zellmembran und die komplexen regulatorischen Mechanismen der weiteren Signaltransduktion. Faim2 nimmt dabei eine besondere Rolle ein, da die hemmende Wirkung bereits früh in der Initiationsphase erfolgt. Die apoptosehemmende Wirkung entfaltet Faim2 durch eine direkte Protein-ProteinBindung an Fas/CD95 (Reich et al. 2008). Während die genaue Interaktion noch nicht bekannt ist, geben Fernandez et al. (2007) Evidenz dafür, dass die Bindung von Faim2 an Fas/CD95 innerhalb der lipid rafts stattfindet und somit noch vor der Interaktion von Fas/CD95 mit FADD.

Die an den lipid rafts mobilen Fas/CD95-Rezeptoren bilden nach Bindung des Li-

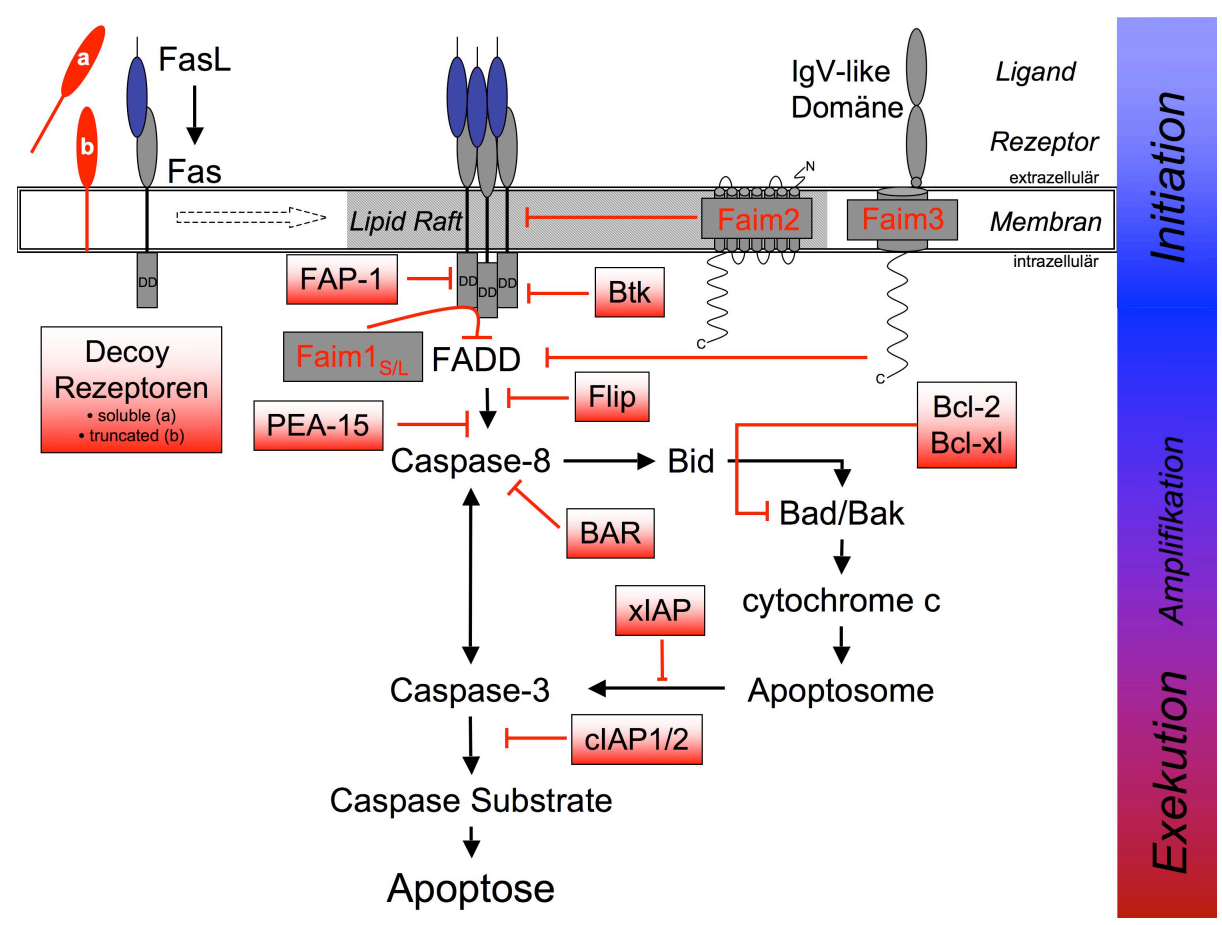

Abbildung 1.4: FasL/CD95L-Fas/CD95-Signaltransduktion zur Einleitung der Apoptose und dessen inhibierende Proteine: Bcl-2 (Bcl-XL, Bfl-1): Familie der B-Zell-Lymphom-2-Proteine; Btk: Bruton's Tyrosinkinase; c-FLIP: cellular Fas-associated death domain-like IL-1b-converting enzymeinhibitory protein (Caspase-8 und FADD-like Apoptoseregulator); Faim: Fas apoptotic inhibitory molecule (Faim1/2/3); FAP-1: Fas assoziierte Phosphatase 1; IAP: (X-linked IAP; xIAP), cellular IAP 1 und 2 (cIAP1/2): Inhibitor of apoptosis protein family; PEA-15: Phosphoprotein enriched in Astrocytes $15 \mathrm{kDa}$.

(modifiziert nach Reich et al. 2008, Seite 481)

ganden FasL/CD95L-Trimärkomplexe. Durch diese Komplexbildung erfolgt die Assoziation mit dem Adaptorprotein FADD, welches durch eine ins Zytoplasma ragende 
Todesdomäne und über an dieser befindlichen Todeffektordomänen an homologe Stellen auf der Initiator-Caspase (Procaspase-8) bindet, diese aktiviert und damit die bis zur Exekution der Zelle führende Caspase-Kaskade startet.

Ein alternativer Weg zur Apoptose verläuft direkt intrazellulär über eine Schädigung der Mitochondrien. In diesem Fall wird aus dem mitochondrialen Intermembranraum Cytochrom c oder ein spezieller Apoptosefaktor, z.B. Apoptosis-InducingFactor (AIF), freigesetzt. Das freigesetzte Cytochrom c bindet gemeinsam mit Desoxyadenosintriphosphat (dATP) an den sog. apoptotic protease activating factor-1 (Apaf-1). Dies ruft eine Konformationsänderung von Apaf-1 hervor, wodurch die sog. Caspase-Rekrutierungs-Domäne (CARD) zugänglich wird und an die CARD-Domäne der Caspase-9 binden kann. Diese Bindung ist eine Voraussetung für die autolytische Aktivierung der Caspase-9. Der gebildete Komplex aus Caspase-9, Apaf-1 und Cytochrom c wird als Apoptosom bezeichnet und kann wiederum die Caspase-Kaskade starten. Durch diese Amplifikationsschleife werden Apoptosezeiten signifkant verkürzt und schwache Signale verstärkt (Ashkenazi und Dixit 1999, Tang et al. 2000, Gerhardt et al. 2001, Reich et al. 2008). Beide Transduktionswege münden in der Aktivierung der Caspase-3, die letztlich irreversibel die Exekution der Zelle einleitet.

Die Aktivierung der Caspasen verläuft kaskadenartig, wobei bereits im Übergang von Initiationsphase zur Ausführungsphase eine Reihe an Proteinen hemmend auf die Aktivierung der Caspase-Kaskade wirken. Die Tabelle 4.2 .4 auf Seite 86 zeigt eine Übersicht über diese hemmenden Proteine und deren Eigenschaften.

\subsection{Der Schlaganfall}

Als Schlaganfall wird die Minderperfusion im Versorgungsgebiet einer Gehirnarterie nach (1) zerebraler Ischämie (80\% der Fälle) oder (2) hämorrhagischem Insult (20\%) bezeichnet. In der vorliegenden Arbeit wurde die zerebrale Ischämie durch Okklusion der Arteria cerebri media als Krankheitsmodell verwendet.

\subsubsection{Zerebrale Ischämie}

Die zerebrale Ischämie beschreibt einen Zustand eines akuten fokalen neurologischen Defizits, bei dem es aufgrund einer umschriebenen Durchblutungsstörung des Gehirns, neben der verminderten Zufuhr von Glucose und Nährstoffen, zu einem pathologischen Missverhältnis zwischen Sauerstoffbedarf und Sauerstoffzufuhr des Gehirnge- 
webes kommt (DGN 2012). Je nach Dauer dieser Imbalance entsteht eine kurzfristige, ggf. reversible neuronale Funktionsstörung oder ein irreversibler Gewebeuntergang mit permanenter Einschränkung. Die häufigste Ursache der zerebralen Ischämie ist die Minderperfusion oder Okklusion im Versorgungsgebiet der Arteria cerebri media (Poeck und Hacke 2010). Das aus dem proximalen Verschluss der A. cerebri media resultierende, charakteristische klinische Syndrom einer akuten, hochgradigen armbetonten sensomotorischen Hemisymptomatik mit Aphasie oder Neglect wird als Mediasyndrom bezeichnet und ermöglicht es, in der Notfallsituation eine bereits präklinisch rasche Verdachts- und Differentialdiagnostik mit schnellstmöglicher Zuführung optimaler Therapieoptionen einzuleiten. In der weiterführenden klinischen Untersuchung demarkieren sich meist weitere Symptome wie sensible, motorische oder sensomotorische, kontralaterale Halbseitensymptome, Störungen der Blickmotorik, Störungen der Sprechmotorik, neurophysiologische Syndrome wie Aphasien oder Apraxien und Leseoder Rechenstörungen. Die Ausprägung und Lokalisation der zerebralen Ischämie variieren stark. Häufig kann es nach einem Schlaganfall zu unspezifischen psychologischen Auffälligkeiten und ausgeprägten depressiven Verstimmungen kommen, die vermutlich durch eine postischämische Verschiebung des Neurotransmittergleichgewichts hervorgerufen werden (El Husseini et al. 2012).

Laut den aktuellen Leitlinien zur Akutbehandlung eines Schlaganfalls aus dem Jahr 2012 der Deutschen Gesellschaft für Neurologie (DGN) zählt der Schlaganfall zu den häufigsten Erkrankungen in Deutschland und ist eine der führenden Ursachen von Morbidität und Mortalität weltweit. Das Statistische Bundesamt weist dem Schlaganfall im Bericht der deutschen Todesursachenstatistik aus dem Jahr 2006 mit 65.133 Todesfällen $(7,9 \%)$ den 3 . Platz und die führende Ursache dauernder Invalidität zu, im Jahr 2010 mit 23.675 Todesfällen Platz 6 (Statistisches Bundesamt 2011). Medizinökonomisch ist die Patientengruppe mit zerebraler Ischämie in den westlichen Industrieländern die teuerste Krankheitsgruppe überhaupt und erreicht bzw. übertrifft laut Rothwell et al. (2006) sogar die Häufigkeit kardiovaskulärer Erkrankungen, wie die prospektive, populationsbezogene Oxford Vascular Study (2002-2007) zeigte. Die Inzidenz ischämischer Schlaganfälle beträgt in Deutschland 160-240/100.000 Einwohner pro Jahr (DGN 2009). Neben der Alters- und Geschlechtsabhängigkeit nimmt die Inzidenz mit steigendem Lebensalter zu, ca. $50 \%$ aller Schlaganfallpatienten sind älter als 70 Jahre. Dabei sind Männer fast allen Alters circa doppelt so häufig betroffen wie Frauen, während in der Altersgruppe der über 85-jährigen mehr Frauen erkranken und sterben (Statistisches Bundesamt 2011). Die allgemeine Mortalität innerhalb des ersten Jahres wird auf durchschnittlich $25 \%$ berechnet, wobei die je- 
weiligen Schlaganfallarten und -subtypen ausgeprägte Unterschiede in der Mortalität aufweisen.

Von den o.g. Neuerkrankungen pro Jahr versterben ca. 20\% innerhalb der ersten vier Wochen. Die überlebenden 80\% stellen derzeit eine Population von ca. 700.000 Menschen in Deutschland dar, von denen nur ein Drittel eine vollständige Genesung mit einem Leben ohne nennenswerte Einschränkungen führen kann. Von den verbleibenden zwei Dritteln werden nur 50\% wieder in der Lage sein, ein selbstständiges Leben zu führen, dies allerdings mit stark einschränkenden Lähmungen oder Symptomen, die zu einer Arbeitslosigkeit oder Frühberentung führen. Die anderen 50\% werden ab dem Zeitpunkt des Schlaganfalls dauerhaft pflegebedürftig bleiben (Poeck und Hacke 2010).

Nachdem bereits die Anerkennung als Notfall die Therapie in den vergangenen 20 Jahren signifikant verbessert hat, bildete die Einrichtung von über 200 Schlaganfallstationen, sog. Stroke Units, die stationäre Anbindung an die präklinischen Behandlungsstrategien. Da insbesondere in der präklinischen Notfalldiagnostik eine Differenzierung zwischen zerebraler Ischämie auf Grund eines möglicherweise thrombembolischen Geschehens und einer intrakraniellen Blutungssituation nicht möglich ist, gilt für die initiale Versorgung am Einsatzort nach wie vor der Grundsatz „time is brain!“ (Harraf et al. 2002).

Die Leitlinien der DGN zur Akuttherapie eines ischämischen Schlaganfalls (Rekanalisation, Lyse mittels rtPA, Prävention etc.) werden in regelmäßigen Abständen aktualisiert und orientieren sich an den Daten des SITS-MOST-Registers.

In der vorliegenden Arbeit wird eine transiente fokale zerebrale Ischämie induziert, sodass der Großteil des betroffenen Hirngewebes dem pathophysiologischen Konzept der Penumbra unterworfen ist. Unter Penumbra versteht man minderperfundiertes, aber strukturell erhaltenes Gewebe im Gegensatz zur manifesten ischämischen Nekrose mit irreversibler funktioneller und struktureller Schädigung. Die Größe der Penumbra - das durch eine zeitnahe rekanalisierende Therapie potentiell rettbare Gewebe kann mittels bildgebender CT- oder MRT-Verfahren dargestellt werden. Die zentrale Kenngröße bildet bei der Penumbra der zerebrale Blutfluss (cerebral blood flow, $C B F$ ). Die Ausdehnung ist abhängig von dem Ausmaß der regionalen CBF-Minderung, dem Ort des Gefäßverschlusses und dem Status der vaskulären Kollateralen sowie der Dauer des Perfusionsdefizits. Die Perfusion des Gehirns eines erwachsenen, gesunden Menschen liegt bei ca. $50-80 \mathrm{ml} / 100 \mathrm{~g} / \mathrm{min}$. Erst ab einer Perfusion von $33 \%$ bis $25 \%$ des Ausgangswertes (ca. $20 \mathrm{ml} / 100 \mathrm{~g} / \mathrm{min}$ ) kommt es zu neurologischen Defiziten, isoelektrischen EEG-Veränderungen und zu einem anaeroben Stoffwechsel der 
Neurone, welcher bei fehlendem Perfusionsanstieg oder weiterem Absinken des CBF auf $10-12 \mathrm{ml} / 100 \mathrm{~g} / \mathrm{min}$ zur irreversiblen Schädigung und zum Verlust der Neurotransmission führen kann (Bor-Seng-Shu et al. 2012). Hierbei ist allerdings die Zeit der Perfusionsminderung entscheidend und bestimmt somit das dynamische Konzept der Penumbra. Bereits eine grenzwertig verminderte Perfusion kann die Penumbra verkleinern, wenn eine notwendige Reperfusion nicht rechtzeitig erfolgt. Dahingegen kann für kurze Zeit auch eine stärkere Perfusionsminderung toleriert werden, sofern die Reperfusion zeitnah eingeleitet wird (Gandini et al. 2012).

In der vorliegenden Arbeit wurde die Arteria cerebri media im Mausmodell für 30 Minuten okkludiert, woraufhin der CBF auf 20\% des Ausgangswertes sank. Anschließend erfolgte die Reperfusion für 72 Stunden. Mit diesem Modell wird die maximale Ausdehnung der Penumbra erreicht und somit die höchstmögliche Anzahl potentiell apoptotischer Zellen (Endres et al. 1998a).

\subsubsection{Neuronaler Zelltod in der zerebralen Ischämie}

In zahlreichen experimentellen Fragestellungen ist die zerebrale Ischämie untersucht und in Zusammenhang mit neuronalem Zelltod gestellt worden. Dirnagl et al. (1999) arbeitete die Pathophysiologie des Schlaganfalls auf und stellte vier prinzipielle Schadensmechanismen der fokalen zerebralen Ischämie heraus:

1. Exzitotoxizität

2. Periinfarkt-Depolarisationen

3. Entzündung

4. Programmierter Zelltod (Apoptose)

Während die unter 1.-3. genannten Schadensmechanismen unmittelbar nach bzw. während der Ischämie beginnen, tritt der neuronale Zelltod als Apoptose erst verzögert ein (Du et al. 1996, Endres et al. 1998a). Wie bereits in Abschnitt 1.3.1 auf Seite 13 aufgezeigt, kommt dem verzögerten neuronalen Zelltod in dem Konzept der sog. Penumbra eine wesentliche Bedeutung zu. Die neuronalen Zellen in dieser Grenzzone gehören somit zum wiederbelebbaren Gehirngewebe (Ginsberg und Pulsinelli 1994, Fisher und Garcia 1996, Reich et al. 2011). In der vorliegenden Arbeit steht gerade diese Zone im Fokus, da hier noch eine Restperfusion und damit ein Restmetabolismus vorhanden ist. Daher könnte als therapeutischer Ansatz eine gezielte Hemmung der Apoptosesignaltransduktion die Einleitung der Apoptose hinauszögern, bis eine suffiziente Perfusion wieder erreicht wird. 


\subsubsection{Experimentelle Tiermodelle der zerebralen Ischämie}

Die Pathophysiologie und Ausprägung einer zerebralen Ischämie sind dynamische, in hohem Maße zeitabhänigige Prozesse mit deutlicher Variabilität zwischen einzelnen Patienten. Dennoch setzt eine wissenschaftliche Auswertung normierte Schlaganfallvolumina voraus, um reproduzierbare, vergleichbare und valide Daten erheben zu können. Die Entwicklung von Tiermodellen der fokalen zerebralen Ischämie und deren Anwendung wurde u.a. in Primaten (Hudgins und Garcia 1970, Garcia und Kamijyo 1974), Hunden (Molinari 1970), Ratten (Brint et al. 1988) und Mäusen (Huang et al. 1994, Endres et al. 1998a) etabliert. Um den Einfluss von Faim2 auf das Fas/CD95-Signaltransduktionssystem während und nach einer fokalen zerebralen Ischämie untersuchen zu können und um therapeutische Optionen zu testen, wurden für die vorliegende Arbeit Vorversuche zu Zeitpunkt, Länge und Intensität der arteriellen Okklusion im Fadenokklusionsmodell getestet. Die in-vivo-Modelle der zerebralen Ischämie basieren auf dem operativen Verschluss von extra- und intrakraniellen Arterien, die in-vitro-Versuche auf kontrolliertem Sauerstoff- und Glukose-Entzug primärer, neuronaler Zellkulturen.

Da die Arteria cerebri media (ACM) eine große Bedeutung bei der zerebralen Ischämie von Säugetieren hat, steht die Okklusion dieses Gefäßes im Vordergrund vieler Untersuchungen (Garcia 1984). Das am häufigsten eingesetzte und gut reproduzierbare Modell der fokalen transienten zerebralen Ischämie ist das Filamentmodell in der Maus oder Ratte. Hierbei wird durch ein silikonbeschichtetes Filament, das in die Arteria carotis interna eingeführt und bis zur Bifurkation der A. cerebri media vorgeschoben wird, eine Okklusion derselben verursacht. Die Methode der sog. Middle Cerebral Artery occlusion, MCAo, wurde in der vorliegenden Arbeit angewandt und ist in Abschnitt 2.5.1 auf Seite 36 und Abbildung 2.1 auf Seite 37 dargestellt.

Die Okklusion der ACM kann auf verschiedene Arten erfolgen. In der Tabelle 8.2 im Abschnitt 8.2 auf Seite 115 sind alternative Verfahren aufgezeigt, die jedoch bzgl. Spezifität und Reproduzierbarkeit dem Filamentmodell der transienten MCAo unterlegen sind.

Neben den zahlreichen in-vivo-Modellen wurde Ende der 80er Jahre von Choi ein invitro-Modell des Schlaganfalls entwickelt; das Verfahren des kombinierten Sauerstoffund Glukose-Entzuges, der sog. oxygen glucose deprivation (OGD) in der kortikalen neuronalen Zellkultur (Goldberg und Choi 1990, Choi et al. 2007). Dabei werden neuronale Zellen in Zellkultur transient in desoxygeniertem, glukosefreiem Medium inkubiert. 


\subsection{Herleitung der Fragestellung und experimentelle Strategie}

Apoptose stellt neben Exitotoxizität, Periinfarkt-Depolarisation und Inflammation (Dirnagl et al. 1999) einen wesentlichen Schadensmechanismus beim durch Ischämie induzierten neuronalen Zelluntergang dar. Sie kann durch zwei Signalwege induziert werden (Schulz et al. 1999): (1) den externen, durch Aktivierung von Todesrezeptoren induzierten direkten Weg, oder (2) den mitochondrialen, indirekten Weg. Im ersten Fall führt die Induktion der Todesrezeptoren zur direkten Aktivierung der InitiatorCaspase, die im Weiteren die Aktivierung von Exekutiv-Caspasen einleitet. Bei der Aktivierung des indirekten, mitochondrialen Signalweges kommt es über zelluläre Signalwege zur Freisetzung proapoptotischer Substanzen aus den Mitochondrien, die dann über das Apoptosom weitere Initiator-Caspasen aktivieren oder antiapoptotische Moleküle inhibieren (siehe Abschnitt 1.1.3 auf Seite 5 und Abbildung 1.4 auf Seite 12. Während in Tumorzellen und Lymphozyten insbesondere der exogene, todesrezeptorinitiierte Weg von Bedeutung ist, sprechen die meisten Hinweise für eine Dominanz des endogenen, mitochondrialen Apoptoseweges bei der Apoptose in postmitotischen Zellen (z.B. Neurone). Da jedoch auch Neurone Todesrezeptoren, insbesondere Fas/CD95, auf ihrer Oberfläche exprimieren (Gerhardt et al. 2001, Beier et al. 2005) und Mäuse mit defizientem Fas/CD95-Rezeptor (lpr Mäuse) oder Fas/CD95-Ligand (gld Mäuse) in verschiedenen Tiermodellen des akuten neuronalen Untergangs geschützt sind, z.B. nach Ischämie oder spinalem Trauma (MartinVillalba et al. 1999, Martin-Villalba et al. 2001, Demjen et al. 2004), stellt sich die Frage, ob unter besonderen pathologischen Bedingungen nicht doch der exogene Fas/CD95-Signalweg aktiviert wird und zum neuronalen Zelluntergang beiträgt. In einer humanen Lungenfibroblasten-Zelllinie (MRC5) wurde Fas apoptotic inhibitory molecule 2 (FAIM2)/lifeguard ( $L F G$ ) als differentiell reguliertes Molekül identifiziert, das für die Fas/CD95-Resistenz einer Subpopulation von Zellen verantwortlich ist (Somia et al. 1999). Die Autoren zeigten ferner, dass Faim2 direkt mit dem Fas/CD95Rezeptor interagierte und nicht an Fas-Adaptor Proteine band. Faim2 wird besonders im ZNS (Somia et al. 1999) und dort nur in Neuronen (Beier et al. 2005) exprimiert und die Expression wird während der Entwicklung hochreguliert. Da Faim2 bereits in der Zellmembran hemmend auf den Fas/CD95-Rezeptor wirkt, spielt es innerhalb der durch Fas/CD95-Liganden zur Apoptose führenden Signaltransduktion zu einem frühen Zeitpunkt eine wichtige Rolle.

Entwicklungsbiologisch wird die Expression von Faim2 mit der Alterung der Zellen 
zunehmend hochreguliert (Reich et al. 2008). Neurone sind auf diese Weise geschützt vor einer durch exogene Liganden, die z.B. von Entzündungszellen freigesetzt werden, induzierten Apoptose. Beier et al. (2005) stellten ferner heraus, dass die Expression von Faim2 durch den Phosphatidylinositol-3 (PI3)-Kinase/AKT-Signalweg reguliert ist. Unter pathologischen Bedingungen, z.B. nach dem ischämischen Schlaganfall, wird dieser Signalweg herunterreguliert, so dass dann möglicherweise eine Fas/CD95induzierte Apoptose der Neurone eingeleitet wird. Beier et al. (2005) konnten zeigen, dass die Expression von Faim2 der wesentliche Faktor für die Resistenz von Neuronen gegenüber Fas/CD95-Ligand war. Die Verminderung der Expression mit Hilfe von antisense- oder $R N A i$-Techniken führte zur Sensibilisierung postmitotischer Neurone gegenüber einem Fas/CD95-Ligand-Stimulus in Zellkultur.

Um die Rolle von Faim2 in krankheitsrelevanten Tiermodellen untersuchen zu können, wurde eine Faim2-defiziente Maus generiert (siehe Abschnitt 2.2.2 auf Seite 26). Diese Tiere sind lebensfähig und unterscheiden sich weder in ihrer Entwicklung noch in ihrem Verhalten oder neurologischen Status von den Wildtypkontrollen. In Kooperation mit der Experimentellen Neurologie der Charité, Universitätsmedizin Berlin, wurden an diesen Mäusen durch Verschluss der mittleren Zerebralarterie ischämische Schlaganfälle induziert und die Gehirne biochemisch, morphologisch und immunhistochemisch analysiert.

Während Exzitotoxizität nach einem ischämischen Schlaganfall dem akuten, nekrotisierenden Zelltod unterliegt, sind Apoptose und Inflammation Mechanismen, die sekundär insbesondere in der Penumbra einer ischämischen Läsion auftreten, auch nach Reoxygenierung (Endres et al. 1998a). In Tierexperimenten lässt sich durch die Wahl des ischämischen Paradigmas der Zelltodmechanismus beeinflussen. Während eine permanente Okklusion der mittleren Zerebralarterie mehrheitlich zu einem exzitotoxischen Zelltod führt, induziert eine 30-minütige Okklusion mit anschließender Reperfusion überwiegend einen apoptotischen Zelltod, sowohl in den Basalganglien als auch in kortikalen Arealen (Endres et al. 1998a). Dieses Modell schien besonders geeignet für die Untersuchung der hier aufgeworfenen Fragestellung und Hypothese. Die Induktion der Ischämie wird dabei mit dem Laser-Doppler kontrolliert. Vor und einen Tag nach Ischämie wurden Verhaltensexperimente durchgeführt. Nach Tötung der Tiere, wurden die Gehirne entnommen und anschließend histologisch und biochemisch untersucht. Es wurden Wildtypkontrolltiere mit der gleichen Anzahl von Rückkreuzungen auf den C57BL/6-Hintergrund mit den Faim2-defizienten Mäusen verglichen. Um einen möglichen Schutz vor Apoptose zu erreichen, wurde zur Hochregulation von Faim2 sowohl in den defizienten Tieren als auch in den Wildtypen, vor 
MCAo ein rekombinantes Faim2-lentivirales Konstrukt als viraler Vektor stereotaktisch in das Striatum und den Kortex injiziert. Es folgte die vergleichende Auswertung zwischen Faim2-defizienten Mäusen und Wiltypen. Die Versuche wurden primär in vivo durchgeführt. Zur Bestätigung der Ergebnisse auf zellulärer Ebene wurden in Zusammenarbeit mit der Experimentellen Neurologie der Charité, Universitätsmedizin Berlin, Faim2-defiziente neuronale Zellen mit Wildtyp Zellen in vitro unter sog. Oxygen Glucose Depriviation (OGD) in Apoptoserate, Caspaseaktivität und Überleben verglichen.

Mit dieser experimentellen Strategie sollte beantwortet werden, (1) ob Faim2-Defizienz zu einer Zunahme des Schlaganfallvolumens führt, (2) welcher Zelltodmechanismus hinter einer Zunahme des Ischämievolumens steht, (3) welche Zellen primär von der zerebralen Ischämie und der folgenden Apoptose betroffen sind, (4) welche Rolle die Caspasen in der Transduktion und Aktivierung bzw. Hemmung der Apoptose spielen, (5) ob durch Hochregulation von Faim2 ein Schutz vor Apoptose erreicht werden kann und (6) inwiefern zelluläre Beobachtungen im Vergleich von Faim2-defizienten Tieren und Wildtypen vor, während und nach der Ischämie mit neurologischen Symptomen, Verhalten und Überleben übereinstimmen. 


\section{Material und Methoden}

\subsection{Material}

Die im Folgenden gelisteten Unternehmen und Lieferanten befinden sich in Deutschland, soweit das Herkunftsland nicht anders angegeben ist.

\subsubsection{Apparatur}

\section{Geräte}

Die Auflistung der verwendeten Geräte ist im Anhang in Abschnitt 8.3 .1 auf Seite 116 zu finden.

\section{Verbrauchsmaterial}

Die Auflistung der verwendeten Verbrauchsmaterialien ist im Anhang in Abschnitt 8.3.2 auf Seite 120 zu finden.

\subsubsection{Chemikalien und Bioreagenzien}

Die Auflistung der verwendeten Chemikalien und Bioreagenzien ist im Anhang in Abschnitt 8.4 auf Seite 122 zu finden.

\subsubsection{Lösungen und Puffer}

Citratpuffer (0,01 M, pH 6,0)

Stammlösung A (0,1 M): 21,01g Citronensäure-Monohydrat $\left(\mathrm{C}_{6} \mathrm{H}_{8} \mathrm{O}_{7} \times \mathrm{H}_{2} \mathrm{O}\right)$ in $1000 \mathrm{ml}$ Aqua dest. lösen. Lagerung bei $4^{\circ} \mathrm{C}$.

Stammlösung B (0,1 M): 29, $41 \mathrm{~g}$ Natriumcitrat-Dihydrat $\left(\mathrm{C}_{6} \mathrm{H}_{5} \mathrm{Na}_{3} \mathrm{O}_{7} \times 2 \mathrm{H}_{2} \mathrm{O}\right)$ in $1000 \mathrm{ml}$ Aqua dest. lösen. Lagerung bei $4^{\circ} \mathrm{C}$.

Gebrauchsverdünnung: $18 \mathrm{ml}$ Stammlösung A und $82 \mathrm{ml}$ Stammlösung B zu $900 \mathrm{ml}$ Aqua dest. hinzugeben; pH 6,0 einstellen. 
Lysispuffer (für DNA-Isolation; $500 \mathrm{ml}$ )

$\begin{array}{ll}\text { Tris }(2 \mathrm{M}, \mathrm{pH} 8,5) & 25 \mathrm{ml} \\ \text { EDTA (0,5 M, pH 8,0) } & 5 \mathrm{ml} \\ \mathrm{NaCl}(5 \mathrm{M}-\mathrm{Lösung}) & 20 \mathrm{ml} \\ \text { Natriumdodecylsulfat (10\%) } & 10 \mathrm{ml} \\ \text { Aqua dest. } & 440 \mathrm{ml}\end{array}$

\section{NBT/BCIP Substratpuffer}

$\begin{array}{ll}\text { Tris } & 12,11 \mathrm{~g} \\ \mathrm{NaCl} & 5,84 \mathrm{~g} \\ \mathrm{MgCl}_{2} & 10,17 \mathrm{~g}\end{array}$

Auf $900 \mathrm{ml}$ mit Aqua dest. auffüllen; pH 9,5 mit $6 \mathrm{~N} \mathrm{HCl}$ einstellen; auf $1000 \mathrm{ml}$ mit Aqua dest. auffüllen.

\section{Paraformaldehyd (PFA, 4\%)}

80 g Paraformaldehyd zu $1800 \mathrm{ml}$ PBS (1x) geben; $4 \mathrm{ml} 4 \mathrm{~N} \mathrm{NaOH}$ hinzugeben und auf $40^{\circ} \mathrm{C}$ erwärmen, bis die Lösung klar wird; Lösung abkühlen lassen und pH 7,4 mit $6 \mathrm{~N} \mathrm{HCl}$ einstellen; Filtrierung und Lagerung bei $-20^{\circ} \mathrm{C}$.

PBS (10x Stammlösung, $2000 \mathrm{ml})$

$\begin{array}{ll}\mathrm{NaCl} & 160 \mathrm{~g} \\ \mathrm{KCl} & 4 \mathrm{~g} \\ \mathrm{Na}_{2} \mathrm{HPO}_{4} \times 7 \mathrm{H}_{2} \mathrm{O} & 54 \mathrm{~g} \\ \mathrm{KH}_{2} \mathrm{PO}_{4} & 4,8 \mathrm{~g}\end{array}$

Auf $1900 \mathrm{ml}$ mit Aqua dest. auffüllen; pH 7,4 einstellen; auf $2000 \mathrm{ml}$ mit Aqua dest. auffüllen; zur Herstellung der Gebrauchslösung 1:10 mit Aqua dest. verdünnen und pH neu einstellen (PBS 1x).

\section{RNA-Puffer (Angabe pro Gewebeprobe)}

TAE-Puffer $(50 x, 1000 \mathrm{ml})$

Auf $1000 \mathrm{ml}$ mit Aqua dest. auffüllen; zur Herstellung der Gebrauchslösung 1:50 mit Aqua dest. verdünnen. 
$\begin{array}{ll}\text { RLT-Puffer } & 600 \mu \mathrm{l} \\ \beta \text {-Mercaptoethanol } & 6 \mu \mathrm{l}\end{array}$

Tris $242 \mathrm{~g}$

Essigsäure (100\%) $\quad 57,1 \mathrm{ml}$

EDTA $(0,5 \mathrm{M}, \mathrm{pH} 8,0) \quad 100 \mathrm{ml}$

TBS (10x Stammlösung, $2000 \mathrm{ml}$ )

$\mathrm{NaCl} 170 \mathrm{~g}$

Tris $121 \mathrm{~g}$

Auf $1900 \mathrm{ml}$ mit Aqua dest. auffüllen; pH 7,5 mit $6 \mathrm{~N} \mathrm{HCl}$ einstellen; auf $2000 \mathrm{ml}$ mit Aqua dest. auffüllen; zur Herstellung der Gebrauchslösung 1:10 mit Aqua dest. verdünnen und ggf. pH neu einstellen (TBS 1x).

\subsubsection{Enzyme}

Tabelle 2.1: Enzyme

ABsolute $^{T M} \quad$ QPCR-SYBR ${ }^{\circledR}$-Green- Abgene, Epsom, UK

Rox-Mix

Complete $^{T M}$ Proteaseinhibitoren

Roche Diagnostics GmbH, Mannheim

PfuTurbo $^{T M}$ DNA-Polymerase

Stratagene, La Jolla, USA

Proteinase K

Roche Diagnostics GmbH, Mannheim

Taq-Polymerase

Fermentas Life Sciences, St. Leon-Rot 


\subsubsection{Antikörper}

Tabelle 2.2: Antikörper

Anti-Bromdesoxyuridin (BrdU; Abcam plc, Cambridge, UK

BU1/75[ICR1]), monoklonaler An-

tikörper (Ratte)

Anti-Caspase-3 (aktiv/gespalten), poly- Cell Signaling Technology, Danvers, klonaler Antikörper (Kaninchen) Massachusetts, USA

Anti-Caspase-8 (aktiv/gespalten), poly- Imgenex, San Diego, Kalifornien, USA klonaler Antikörper (Kaninchen)

Anti-Faim2/LFG, polyklonaler Antikörper (Ratte)

LifeSpan BioScience Inc., Seattle, WaAnti-Kaninchen $\operatorname{IgG}(\mathrm{H}+\mathrm{L})$, Alexa shington, USA

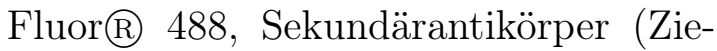

ge)

Anti-Maus IgG $(\mathrm{H}+\mathrm{L})$, Alexa Fluor@ Invitrogen, Carlsbad, Kalifornien, USA 555, Sekundärantikörper (Ziege)

Anti-Neuronal-Nuclei (NeuN), monoklo- Millipore, Billerica, Massachusetts, USA naler Antikörper (Maus)

Anti-Ratte IgG $(\mathrm{H}+\mathrm{L})$, biotinyliert, Se- Vector Laboratories, Inc., Burlingame, kundärantikörper (Kaninchen) Kalifornien, USA

\subsubsection{Computersoftware}

Tabelle 2.3: Computersoftware

Bio-Capt (Version 12.5)

BibDesk (Version 1.5.9)

GraphPad Prism (Version 5.00)

LaTeX (TeXShop, Version 2.26)

Leica Application Suite (Version 2.8.1)

Microsoft Office 2004 for MacWord (Version 11.6.3), Excel (Version 11.6.5), PowerPoint (Version 11.6.4)
Vilber Lourmat, Tory, Frankreich

LaTeX Cambridge, Massachusetts, USA

Thomson Reuters, New York City, New

York, USA

LaTeX Eugene, Oregon, USA

Leica Microsystems, Wetzlar

Microsoft, Redmond, Washington, USA 


$\begin{array}{ll}\text { MxPro - Mx3000P (Version 3.00) } & \begin{array}{l}\text { Agilent Technologies, Santa Clara, Kali- } \\ \text { fornien, USA }\end{array} \\ \text { NanoDrop ND-1000 (Version 3.5.2) } & \text { Thermo Fisher Scientific, Waltham, } \\ & \text { Massachusetts, USA } \\ \text { Photoshop CS (Version 8.0.1) } & \text { Adope Systems, San Jose, Kalifornien, } \\ & \text { USA } \\ \text { Sigma Scan Pro (Version 5.0.0) } & \text { Jandel Scientific, San Rafael, Kaliforni- } \\ & \text { en, USA } \\ \text { Stereo Investigator (Version 7.00) } & \text { MBF Bioscience, Williston, Vermont, } \\ & \text { USA }\end{array}$

\subsection{Versuchstiere}

\subsubsection{Herkunft und Haltung}

Es wurden homozygote Faim2-Wildtyp- und Nullmutanten-Mäuse (Wurfgeschwister) für die Versuche verwendet, die mithilfe eines Cre/LoxP-vermittelten Rekombinationssystems in Kooperation mit dem Max-Planck-Institut für experimentelle Medizin in Göttingen generiert worden waren (vgl. Reich et al. 2011). Vor der Verwendung in Versuchsanordnungen waren die Tiere über mehrere Generationen auf die Linie C57Bl/6 zurückgekreuzt. In den Versuchsanordnungen der MCAo und der stereotaktischen Injektion wurden ausschließlich männliche Tiere möglichst ähnlichen Alters eingesetzt. Unmittelbar vor der Verwendung in den Versuchen erfolgte die Genotypisierung mittels Polymerasekettenreaktion (PCR) aus Schwanzspitzenbiopsaten gewonnener genomischer DNA.

Die Tiere wurden unter artgerechten, standardisierten Bedingungen mit kontrollierter Raumtemperatur und Luftfeuchtigkeit in den Tierställen der Abteilung für Neurodegeneration und Neurorestaurationsforschung (Waldweg 33, 37073 Göttingen) sowie der Klinik für Neurologie der Charité - Universitätsmedizin Berlin (Campus Mitte, Charitéplatz 1, 10117 Berlin) gehalten.

Die Haltung in den Tierställen erfolgte unter Bereitstellung von Futter (pelletierte Standarddiät) mit Leitungswasser ad libitum in einem inversen Tag-Nacht-Rhythmus mit Raumbeleuchtung von 21:30 Uhr bis 9:30 Uhr. Die Identifikation im Tierstall in Göttingen erfolgte über Ohrlochmarkierungen, in Berlin über Schwanzmarkierungen. An der Stirnseite des Tierkäfigs (365x207x140 mm [LxBxH]) waren die Identifikationskarten mit Zuchtlinie, Genotyp, Tiernummern, Geschlecht, Geburtsdatum, Tiernum- 
mern der Elterntiere und Angaben über Nutzer und das genehmigte Tierversuchsvorhaben angebracht.

\subsubsection{Das Faim2-null-mutant-Konstrukt}

Die Generierung des Faim2-null-mutant-Konstrukts erfolgte in Zusammenarbeit mit dem Max-Planck-Institut in Göttingen und war nicht Bestandteil der vorliegenden Arbeit.

Von dem Gesamtgenom, das für das Protein Faim2 kodiert, wurden drei Exons als Mutationsziele identifiziert. Die Exons 3-5 (72 aa - 146 aa) bilden nicht nur ein sog. Cluster, sondern kodieren die ersten eineinhalb von insgesamt sieben Transmembrandomänen des Faim2 (Reimers et al. 2006). Um die o.g. Region auf dem Genom für die sog. Cre-Rekombinase weiterhin zu sensibilisieren, die eine Deletion der gewünschten Allele verursacht, wurde mithilfe des Vektors $p$ ConKO-True ein Zielallel produziert und die Standard-Blastozysten-Injektions-Methode für das Einbringen in das Genom verwendet (Reich et al. 2011). Die über semi-nested PCR, PCR und Southern Blotting identifizierten Genotypen wurden im Falle einer erfolgreichen Deletion der Zielallele als EIIa cre mouse bezeichnet und mit heterozygoten Nachkommen gekreuzt. Durch dieses Vorgehen konnte eine vollständige Deletion der loxP-flankierten Gensequenz und eine stabile Mutation der Folgegeneration erreicht werden (Lakso et al. 1996). Anschließend wurde auf RNA-, cDNA-, DNA- und Protein-Ebene die erfolgreiche Deletion des Faim2 nachgewiesen und in Reich et al. (2011) in Figure 1C-F publiziert. Die phänotypische Entwicklung der Faim2-null-Mutanten zeigte im Vergleich zu den Wildtypen und Hetereozygoten keine Auffälligkeiten. Sowohl die neurologische Entwicklung als auch Gewichtsverlauf und Lebenserwartung zeigten keine signifikanten Unterschiede. Sowohl in umfangreichen Verhaltenstests (open field, accelerod, tight rope test und SNAP-Score (siehe Abschnitt 3.5 auf Seite 75p) als auch makroskopisch und histologisch (NeuN und GFAP (siehe Abschnitte 3.2 .2 auf Seite 60 und 3.4 .1 auf Seite 67), Gallyas, Mac-3, APP) haben entsprechende Analysen keine signifikante Unterschiede ergeben, wie in Reich et al. (2011) in FigureS1 aufgezeigt wurde.

Die Genotypen der Mäuse wurden vor den Versuchen jeweils mittels PCR und seminested PCR getestet und bestätigt. Während der Versuche wurden nicht nur die physiologischen Parameter überwacht (siehe Abschnitt 3.2 auf Seite 55 und Tabelle 3.1 auf Seite 56), sondern es wurde auch das Verhalten vor und nach der zerebralen Ischämie getestet. 


\subsection{Molekularbiologie}

\subsubsection{Isolation genomischer DNA aus Schwanzspitzenbiopsie der Maus}

TENS Puffer für die Isolation von genomischer DNA: $100 \mathrm{mM}$ Tris-HCl, 5 mM EDTA, $200 \mathrm{mM} \mathrm{NaCl}, 0,2 \%$ SDS, pH 8,5

Die 0,2 - 0,5 cm langen Schwanzspitzenbiopsien wurden in 1,5 ml Reaktionsröhrchen gegeben und in $0,75 \mathrm{ml}$ TENS Puffer, der $0,5 \mathrm{mg} / \mathrm{ml}$ Proteinase K enthielt, im Thermomixer bei $650 \mathrm{rpm}$, bei $56^{\circ} \mathrm{C}$, inkubiert. $250 \mu \mathrm{l}$ von $4 \mathrm{M} \mathrm{NaCl}$ wurde hinzugefügt und die Proben nach dem gründlichen Mischen bei 13.000 rpm für 10 min unter RT zentrifugiert. 0,75 ml des Überstandes wurde vorsichtig in ein Reaktionsröhrchen übertragen, das 0,5 ml Isopropanol enthielt. Anschließend wurden die Proben nach gründlichem Mischen (4-6 Mal umwenden) erneut $10 \mathrm{~min}$ bei $13.000 \mathrm{rpm}$ unter RT zentrifugiert. Der entstandene Überstand wurde vorsichtig abgegossen und verworfen. Im Folgenden wurden nun die DNA pellets mit $800 \mu \mathrm{l} 70 \%$ EtOH gewaschen und bei $13.000 \mathrm{rpm}$ für $10 \mathrm{~min}$ unter RT zentrifugiert. Der Überstand wurde verworfen, die pellets für $15-20 \mathrm{~min}$ bei $42^{\circ} \mathrm{C}$ getrocknet. Anschließend wurden sie in $50 \mu \mathrm{l} \mathrm{TE}$ Puffer (10 mM Tris, 1 mM EDTA, pH 8,8) resuspendiert.

\subsubsection{DNA-Präzipitation}

Sofern eine erhöhte Reinheit und/oder eine erhöhte DNA-Konzentration in der Lösung gefordert war, wurde ein Präzipitationsschritt im Anschluss an die DNA-Extraktion durchgeführt. Hierzu wurde zunächst ein gleiches Volumen PCI (Phenol/Chloroform/ Isoamylalkohol, 25:24:1) zur DNA-Lösung hinzugefügt. Die Proben wurden kräftig für $10 \mathrm{~s}$ gemischt und bei $13.000 \mathrm{rpm}$ für $10 \mathrm{~min}$ unter RT zentrifugiert. Die obere Wasserphase wurde behutsam in ein neues Reaktionsröhrchen überführt, ohne dabei die Interphase zu berühren, und mit 100\% Isopropanol oder EtOH (70\% oder $200 \%$ jeweils des Originalvolumens) und $3 \mathrm{M} \mathrm{Na-Azetat} \mathrm{(10 \%} \mathrm{des} \mathrm{Originalvolumens)}$ vermischt. Hieran schloss sich eine 20-minütige Zentrifugation unter $4^{\circ} \mathrm{C}$ an, nach welcher der entstandene Überstand verworfen wurde. Die DNA-pellets wurden nun mit $70 \%$ EtOH gespült und erneut zentrifugiert. Das EtOH wurde vorsichtig entfernt die Präzipitate an Raumluft unter RT für 5-10 min getrocknet. Abschließend wurden die DNA-Pellets in dem geforderten Volumen entweder in $\mathrm{dd}_{2} \mathrm{O}$ oder TE-Puffer resuspendiert. 


\subsubsection{Polymerasekettenreaktion (PCR) mit genomischer DNA}

Das Verfahren der PCR (Polymerase Chain Reaction) ermöglicht es, kleinste Mengen an DNA in vitro zu amplifizieren (Saiki et al. 1985), und wurde in der vorliegenden Arbeit primär zur Genotypisierung der Versuchstiere der Zuchtreihe LFGEIIaCre und Amplifikation von komplementärer DNA (cDNA) verwendet. Vor Beginn der Amplifikation von gezielten DNA-Abschnitten wurden optimale PCR-Bedingungen durch das Einstellen der $\mathrm{MgCl}_{2}$-Konzentration, die Menge an DNA-Vorlage, die AnnealingTemperatur $\left(50-60^{\circ} \mathrm{C}\right)$ und der Einsatz von Zusätzen wie Glycerol geschaffen. Beispielhaft ist ein eingesetzter Standard-PCR Master Mix in der folgenden Tabelle 2.4 aufgezeigt.

Tabelle 2.4: Standard PCR-Reaktionszusammensetzung

\begin{tabular}{llc}
\hline Reagenz & $\begin{array}{c}\text { Finale Kon- } \\
\text { zentration }\end{array}$ & Totales Volumen $(\mu \mathrm{l})$ \\
\hline DNA-Templat (cDNA oder genomische DNA) & & variabel $(100-200 \mathrm{ng})$ \\
10x PCR Puffer & $1 \mathrm{x}$ & 2,5 \\
$\mathrm{MgCl}_{2}(25 \mathrm{mM})$ & $3 \mathrm{mM}$ & 1,5 \\
$\mathrm{dNTP}$ mix, $10 \mathrm{mM}$ jeweils & $0,4 \mathrm{mM}$ & 1,0 \\
forward Primer $(100 \mu \mathrm{M})$ & $0,2 \mathrm{mM}$ & 1,0 \\
reverse Primer $(100 \mu \mathrm{M})$ & $0,2 \mathrm{mM}$ & 1,0 \\
BioTherme Polymerase $(5 \mathrm{U} / \mu \mathrm{l})$ & & $0,25-0,5$ \\
$\mathrm{ddH}_{2} \mathrm{O}$ & & auf 25,0 auffüllen \\
\hline
\end{tabular}

Die Amplifikation wurde im Mastercycler Gradient oder im DNA engine PTC-200 Thermocycler durchgeführt. Die folgende Tabelle 2.5 zeigt die Programmabläufe im Thermocycler.

Tabelle 2.5: PCR-Programmablauf im Thermocycler

\begin{tabular}{lccc}
\hline Stufe & Temperatur $\left({ }^{\circ} \mathrm{C}\right)$ & Zeit $(s)$ & Bemerkung \\
\hline 1 & 95 & 120 & \\
2 & 95 & 30 & \\
3 & 52 & 30 & \\
4 & 72 & 30 & zurück zu Stufe 2; 35x wiederholen \\
5 & 72 & 300 & \\
6 & 20 & hold & \\
\hline
\end{tabular}

Wurde diese Amplifikation für die Genotypisierung mit den Primern Fw: 5'-TGAAA ACCACACTGCTCGAA-3'; Rv: 5'-GGGGTCAAGGTACCAGCTCT-3' eingesetzt, 
konnte damit nur die PCR-gesteuerte Identifikation von Faim2-Defizienz erreicht werden. Im Falle der Identifikation von Faim2-Wildtypen wurde die PCR als semi-nested PCR durchgeführt. Hierbei wurden folgende Primer benutzt: Fw 5'-GAGCCTCTAC CCACCTACC"C-3'; Rw1 5'-CTCCCAGGGACTCATTTGAA-3'; Rw2 5'-CTGGG TGAGACCTCAGAAGC-3'. Das Programm des Thermocyclers unterschied sich in diesem Fall lediglich in Stufe 4 (siehe Tabelle 2.5 auf der vorherigen Seite), die, anstatt für 30 Sekunden, 60 Sekunden lang dauerte. Eine Darstellung der Reaktionskomponenten befindet sich in der unten stehenden Tabelle 2.6.

Tabelle 2.6: PCR-Reaktionszusammensetzung für semi-nested PCR

\begin{tabular}{llcc}
\hline Reagenz & $\begin{array}{l}\text { Finale Kon- } \\
\text { zentration }\end{array}$ & $\begin{array}{c}\text { Totales Volumen }(\mu \mathrm{l}) \\
\text { 1. Durchlauf }\end{array}$ & $\begin{array}{c}\text { Totales Volumen }(\mu \mathrm{l}) \\
\text { 2. Durchlauf }\end{array}$ \\
\hline $\begin{array}{l}\text { DNA-Templat } \\
\text { (cDNA o. genom. DNA) }\end{array}$ & $1 \mathrm{x}$ & variabel $(100-200 \mathrm{ng})$ & 1,0 (von 1. Durchlauf) \\
$10 \mathrm{x}$ PCR Puffer & $3 \mathrm{mM}$ & 2,5 & 2,5 \\
$\mathrm{MgCl}_{2}(25 \mathrm{mM})$ & $0,4 \mathrm{mM}$ & 1,5 & 1,5 \\
$\mathrm{dNTP}$ mix, $10 \mathrm{mM}$ jeweils & $5 \mu \mathrm{M}$ & 1,0 & 1,0 \\
Primer $1(100 \mu \mathrm{M})$ & $5 \mu \mathrm{M}$ & 1,0 & 1,0 \\
Primer 2 $(100 \mu \mathrm{M})$ & $5 \mu \mathrm{M}$ & 1,0 & - \\
Primer $3(100 \mu \mathrm{M})$ & & - & 1,0 \\
BioTherme & & $0,25-0,5$ & $0,25-0,5$ \\
Polymerase $(5 \mathrm{U} / \mu \mathrm{l})$ & & auf 25,0 auffüllen & auf 25,0 auffüllen \\
ddH ${ }_{2} \mathrm{O}$ & &
\end{tabular}

\subsubsection{Agarosegelelektrophorese von PCR-Amplifikaten}

Die jeweiligen Amplifikationsprodukte wurden in 1\%igem Agarose Gel mittels DNAElektrophorese analysiert. Hierbei können DNA-Fragmente entsprechend ihrer Größe aufgetrennt und sichtbar gemacht werden. Um diese Fragmente später im UV-Licht sichtbar machen zu können, wurde der rote Phenanthridin-Farbstoff, das Ethidiumbromid, verwendet, welches in die Nukleinsäuren der DNA interkaliert und das Absorptionsspektrum verändert. Es wurden für die Darstellung der LFGEIIaCreAmplifikate 1,5- bis 2-prozentige Agarosegele (in 1xTAE-Puffer) verwendet. Nach Aufkochen der Gele in einer Mikrowelle wurden $12 \mu$ l Ethidiumbromid zu 50 ml Agarose hinzugegeben und diese anschließend auf Gelträgern in Gießschienen mit Gelkämmen zur Formung von Taschen gegossen. Die einzelnen DNA-Proben wurden 
mit 6x Loading Dye (Fermentas, Burlington, Ontario, Kanada) gemischt ( $5 \mu$ l Loading Dye zu $25 \mu$ l DNA-Amplifikat). Nach Erstarren des Gels und Übertragung in das Elektrophoresesystem wurde dieses mit 1xTAE-Puffer bedeckt und die einzelnen Geltaschen wurden mit jeweils $10 \mu \mathrm{l}$ der DNA/Loading-Dye-Mischung und zusätzlich eine Geltasche mit $5 \mu \mathrm{l}$ eines 50- bis 200-bp-Markers gefüllt. Anschließend wurden die DNA-Fragmente durch Anlegen einer Spannung von $110 \mathrm{~V}$ für $20 \mathrm{~min}$ aufgetrennt, mit einem UV-Illuminator sichtbar gemacht und fotografiert. Die Abbildung 8.1 auf Seite 126 in Abschnitt 8.5 auf Seite 126 zeigt eine derartige Darstellung zur Identifizierung von Faim2-null-Mutanten (KO-Allel) bzw. Faim2-Wildtypen (WT-Allel). Das ca. 200bp große DNA-Fragment wird als breite schwarze Bande dargestellt. Dabei weist eine einzelne Bande jeweils entweder auf einen homozygoten Wildtypen $(+/+)$ oder einen Faim2-null-Mutanten (-/-) hin. Erscheint eine Bande sowohl im WT-Allel als auch im KO-Allel, so weist dies auf ein heterozygotes Versuchstier $(+/-)$ hin. In Abbildung 8.1 auf Seite 126 ist somit der Nachweis von 3 homozygoten Faim2-nullMutanten, 4 homozygoten Wildtypen und 3 heterozygoten Versuchstieren dargestellt. Die jeweils erste Tasche der beiden dargestellten Agarosegelelektrophoresen stellt eine Wasserprobe ohne DNA-Fragmente dar und fungierte als Kontrolle.

\subsubsection{RNA-Isolation und cDNA-Synthese}

Zum Nachweis von Faim2 in verschiedenen Organen der Maus im Allgemeinen, aber insbesondere zum quantitativen Nachweis im Hirngewebe zu unterschiedlichen Zeitpunkten nach einem Ischämieereignis, wurde zunächst mit Hilfe des Quiagen-RNeasyMini-Kits (Quiagen Cat. No. 74104), dem QIAshredder (Quiagen Cat. No. 79654) und dem RNase-Free-DNase-Set (Qiagen Cat. No. 79254) mRNA isoliert und später mittels $M-M L V$ reverse Transkriptase (Promega), Oligo (dt) 15 Primer (Promega) und dNTPs (Fermentas) die Synthese von complementary DNA (cDNA) durchgeführt. Die Arbeitsschritte wurden dabei möglichst rasch und unter $15^{\circ} \mathrm{C}$ durchgeführt. Die Zentrifugentemperatur lag bei $20^{\circ} \mathrm{C}$.

Nach der Präparation von Gewebe (30 mg) wurde dieses in mit $600 \mu \mathrm{l}$ RNA-Puffer gefüllte Homogenisatorröhrchen gegeben. Hierbei wurde in dem gekühlten Homogenisator 3x für 30 Sekunden das Gewebe mechanisch homogenisiert, unterstützt durch den RNA-Puffer. Anschließend wurde 1 Volumen 70\%-Ethanol hinzugefügt. Das daraus entstandene Gemisch wurde nun auf RNeasy columns in $2 \mathrm{ml}$ Röhrchen übertragen und für $15 \mathrm{~s}$ bei ca. $8000 \mathrm{x}$ g zentrifugiert. Es folgten nun 3 Waschschritte mit den im Kit enthaltenen RW1- und RPE-Puffer und jeweils anschließender Zentrifugation für 
$15 \mathrm{~s}$ bei $8000 \mathrm{x}$ g, wobei beim letzten Waschschritt für 2 min zentrifugiert wurde. Die RNeasy column wurde in ein neues $2 \mathrm{ml}$ Röhrchen transferiert und nochmals für $1 \mathrm{~min}$ bei voller Leistungsfähigkeit der Zentrifuge für 1 Minute zentrifugiert. Daraufhin erfolgte der Elutionsschritt, zu dem die RNeasy column in ein neues 1,5 ml-Röhrchen überführt und $30 \mu \mathrm{l} R$ Nase-free Wasser hinzugeügt wurde. Es erfolgte eine erneute Zentrifugation für 1 min bei $8000 \mathrm{x}$ g. Die gewonnene RNA befand sich nun am Boden des 1,5 ml-Röhrchens.

Im Anschluss an die RNA-Isolation folgte der DNase-Verdau und die cDNA-Synthese, sofern eine quantitative Bestimmung mittels real time PCR folgen sollte. Hierzu wurde zunächst 2,5 $\mu$ l DNase I ( $1 \mu \mathrm{l}$ DNase I pro $1 \mu \mathrm{g}$ RNA) (RQ1 RNase-Free-DNase I, Promega) mit $2 \mu \mathrm{l}$ Puffer, 0,5 $\mu$ l RNase-Inhibitor (RNasin, Promega), $15 \mu \mathrm{l}$ der zuvor gewonnenen RNA (max. 2,5 $\mathrm{g}$ ) gemischt. Dieses Gemisch wurde für 30 Minuten bei $37^{\circ} \mathrm{C}$ inkubiert. Anschließend wurde $1 \mu \mathrm{l}$ Stop Solution (Promega) hinzugefügt und nochmals für $10 \mathrm{~min}$ bei $65^{\circ} \mathrm{C}$ inkubiert. Im Folgenden wurden $2 / 3$ Volumen Isopropanol und 1/10 Volumen Ammoniumacetat hinzugefügt und bei $4^{\circ} \mathrm{C}$ für 20 Minuten zentrifugiert. Der Überstand wurde vorsichtig abgenommen und verworfen. $80 \mu$ l Ethanol (70\%ig) wurden hinzugegeben und nochmals für 20 Minuten bei $4^{\circ} \mathrm{C}$ zentrifugiert. Der Überstand wurde daraufhin vorsichtig abgenommen, verworfen und das Pellet am Boden des Rörchens kurz getrocknet. Danach wurde es in $15 \mu$ l Wasser aufgenommen. Mit der gewonnenen RNA in Lösung wurde nun die cDNA-Synthese durchgeführt. Zunächst wurde die RNA-Konzentration mittels Photometer (PeqLab, NanoDrop) bestimmt. In 0,5 ml-Reaktionsröhrchen wurde daraufhin 2,5 $\mu \mathrm{g}$ RNA (max. 14,7 $\mu \mathrm{l}$ ) in $4 \mu \mathrm{l}$ Puffer $(5 \mathrm{x}), 0,5 \mu \mathrm{l} \mathrm{dNTP}(10 \mathrm{mM})$ und $0,4 \mu \mathrm{l}$ Oligo dt Primer $(100 \mu \mathrm{M})$ gegeben und bei $70^{\circ} \mathrm{C}$ für 2 Minuten mit $70^{\circ} \mathrm{C}$ Deckelheizung im Thermocycler reagiert. Im Anschluss erfolgte die Zugabe von $0,4 \mu \mathrm{l}$ reverse Transkriptase auf Eis. Dieses Gemisch wurde zur Reaktion für 60 Minuten bei $42^{\circ} \mathrm{C}$ in den Thermocycler gegeben. Das gewonnene Produkt wurde entweder unmittelbar für die real time PCR eingesetzt oder bei $-20^{\circ} \mathrm{C}$ gelagert.

\subsubsection{Quantitative real time PCR}

Quantitative real time PCR (qPCR) wurde mittels der interkalierenden, fluoreszie-

renden SYBR ${ }^{\circledR}$-Green-Farbe durchgeführt. Zunächst wurde hierfür in einem ersten Schritt unter Benutzung des RNeasy-Mini-Kits (Qiagen) laut Herstelleranleitung RNA isoliert (vgl. Abschnitt 2.3.5 auf der vorherigen Seite). Die dabei gewonnene RNA-Konzentration wurde mithilfe des Nanodrop-Spektrometers (Nano- 
tech) bestimmt. Im Folgenden wurde die RNA von RQ1-RNase-Free-DNase (Promega) verdaut und gegen RNasen geschützt, indem $20 \mathrm{U}$ des RNase-Inhibitors RNasin (Promega) hinzugefügt wurden. Insgesamt wurden $2,5 \mu \mathrm{g}$ der RNA für die reverseTranskriptase-PCR (M-MLV; Promega) benutzt. Anschließend wurde die cDNA im Verhältnis 1:5 gelöst. Für alle Reaktionsschritte wurde stets HPLC Wasser eingesetzt, ebenso auch für die Lösung der cDNA. Die qPCR selbst wurde mittels $A B s o l u t e^{T M_{-}}$ QPCR-SYBR ${ }^{\circledR}$ _Green-ROX-Mix (ABgene) vorbereitet. Die hierzu eingesetzten Primer sind unten aufgeführt.

Die qPCR wurde im Stratagene-Mx3000P-Realtime-Gerät (Stratagene) durchgeführt

Tabelle 2.7: Quantitative real time PCR: Reaktionszusammensetzung

\begin{tabular}{llc}
\hline Reagenz & $\begin{array}{l}\text { Finale Kon- } \\
\text { zentration }\end{array}$ & Totales Volumen $(\mu \mathrm{l})$ \\
\hline DNA Vorlage (cDNA abgeleitet aus RNA) & & 2,0 \\
SYBR ${ }^{\circledR}$-Green-ROX-Mix & $70 \mathrm{nM}$ & 12,5 \\
forward Primer $(5 \mu \mathrm{M})$ & $70 \mathrm{nM}$ & 0,35 \\
reverse Primer $(5 \mu \mathrm{M})$ & & 0,35 \\
HPLC-grade $\mathrm{H}_{2} \mathrm{O}$ & 9,8 \\
\hline
\end{tabular}

und, wie in der unten stehenden Tabelle 2.8 gezeigt ist, programmiert:

Die Fluoreszenz wurde detektiert und in real time gemessen. Dessen geometrische

Tabelle 2.8: Programmablauf der real time PCR im Stratagene-Mx3000P-Realtime-Gerät

\begin{tabular}{lccc}
\hline Stufe & Temperatur $\left({ }^{\circ} \mathrm{C}\right)$ & Zeit $(s)$ & Anzahl der Cycles \\
\hline 1 - Enzymaktivierung & 95 & 900 & 1 \\
\hline 2 - Denaturierung & 95 & 15 & 40 \\
3 - Primer Annealing & primer $\mathrm{T}_{m}$ & 30 & \\
4 - Extension & 72 & 30 & 1 \\
\hline 5 - Schmelzkurve & 95 & 30 & \\
& 60 & 30 & \\
\end{tabular}

Zunahme in Verbindung mit der exponentiellen Zunahme des Produkts wurde zum Ermitteln des threshold cycle (CT) einer jeden Reaktion benutzt. Der Wert der CT zeigt denjenigen Cycle an, in dessen Zunahme die Fluoreszenzzunahme zum ersten 
Mal signifikant höher ist als die Hintergrundfluoreszenz. Glyceraldehyd-3-PhosphatDehydrogenase (GAPDH) der Maus wurde als Kontrollgen eingesetzt.

Die Auswertung der qPCR erfolgte mithilfe der $2^{-\Delta \Delta C t}$-Methode. Hierfür wurde neben dem Zielgen ein sogenanntes Housekeeping-Gen mit vorausgesetzter konstanter Expression (Glycerinaldehyd-3-phosphat-Dehydrogenase; GAPDH) mitamplifiziert und die Expression des Zielgens auf das Housekeeping-Gen mit der Berechnung des sogenannten $\Delta$ Ct-Wertes normalisiert:

$$
\Delta C t_{\text {Zielgen } / \text { Kalibrator }}=C t_{\text {Zielsequenz }}-C t_{\text {Housekeeping-Gen }}
$$

Kontrollgruppen der jeweiligen Experimente (cDNA NaCl-injizierter-Versuchstiere) dienten als relative Referenz (Kalibrator), deren Expression als 1 definiert wurde. Die $\Delta$ Ct-Werte der Kontrollgruppe wurden gemittelt und anschließend der $\Delta \Delta$ CtWert für jede einzelne Probe des Zielgens berechnet:

$$
\Delta \Delta C t=\Delta C t_{\text {Zielgen }}-\Delta C t_{\text {Kalibrator }}
$$

Anschließend konnte die relative Expression des Zielgens als ein Vielfaches der Expression des Kalibrators berechnet werden: Relative mRNA-Expression $=2^{-\Delta \Delta C t}$

Es wurden folgende Primer verwendet:

\section{Fas-Expression :}

Fw: 5'-CTGCGATGAAGAGCATGGTTT-3'

Rv: 5'-CCATAGGCGATTTCTGGGAC-3'

\section{Faim2-Expression :}

Fw: 5'-AGAAGACATCATGACCCAGGG-3'

Rv: 5'-CTTTCTGGTCATCCCAGCTG-3'

\section{GAPDH-Expression :}

Fw: 5'-TGGCAAAGTGGAGATTGTTGCC-3'

Rv: 5'AAGATGGTGATGGGCTTCCCG-3'

\subsubsection{Das Faim2-Lentivirus-Konstrukt}

Sowohl das Faim2-Lentivirus als auch das Faim2-Adenovirus wurden in Kooperation mit Frau Dr. Ellen Gerhard im Labor Prof. J. B. Schulz konstruiert und generiert. 
Mäusliche Full-length-Faim2-cDNA (Faim2full length) (Klon: MGC:40667 (IMAGE:54 00222), Klon Sequenz: BC032278.1, Vektor: pCMV-SPORT6, RZPD German Resource Center for Genome Research, Berlin) und eine trunkierte Version, die lediglich die ersten 104 aa kodiert (Faim2truncated), wurden in lentivirale Drittgenerationsvektoren (pRRLSIN.cPPT.PGK/GFP.WPRE, Tronolab, Lausanne, Schweiz) subkloniert, wobei die green-fluorescence-protein (GFP)-Genkassette belassen und ein N-terminales FLAG tag (common forward: 5'-GCGGATCCATGGATTACAAGG ATGACGACGATAAGACCCAGGGAAAGCTCTCTGTGG-3', reverse (Faim2full length): 5'-CCGCTCGAGTCATTCCCGGTTGGTGCCAA-3', reverse (Faim2 truncated): 5'-CCGCTCGAGTCACTTTCTGATGAAGAGCC-3') hinzugefügt wurde. Das GFP-exprimierende Virus diente als Kontrolle. Die korrekte Zusammensetzung, Überlebensfähigkeit und Funktionsweise aller Klonsequenzen wurde mittels automated sequencing (Metabion, Martinsried) bestätigt. Die Generierung und transgene Expression der Drittgenerationslentiviruspartikel wurde wie in Dull et al. (1998) beschrieben durchgeführt. Die weitere Aufarbeitung erfolgte wie in Reich et al. (2011) dargestellt.

Die dabei entstandene relative Kopienanzahl der lentiviralen Konstrukte wurde mittels mRNA durch real time PCR ermittelt und als Quotient von WPRE (Woodchuck hepatitis virus post-transcription regulatory element)-Molekülen pro 10.000 AktinMolekülen/ $\mu$ l ausgedrückt. Der Quotient betrug 697 für das full-length-Faim2-Proteinexprimierende lentivirale Konstrukt (LV-Faim2full length), 1208 für das an aa 1-105 trunkierte Faim2-Protein-exprimierende lentivirale Konstrukt (LV-Faim2truncated) und 1973 für das green-fluorescence-Protein-exprimierende lentivirale Konstrukt ( $L V$ $G F P)$. Das Virus wurde in allen Versuchen äquimolar verwendet und während der stereotaktischen Injektionen auf Eis gekühlt. Zu Lagerungszwecken wurde das Lentiviruskonstrukt bei $-80^{\circ} \mathrm{C}$ tiefgefroren

Im Rahmen der in-vitro-Versuchsreihen mittels OGD wurden zwei unterschiedliche Titer verwendet: hohe (high) (2100 WPRE/10000 Aktin-Molekülen/ $\mu \mathrm{l}$ ) und niedrige (low) (697 WPRE/10000 Aktin-Molekülen/ $\mathrm{ll}$ ) Lentivirus-Titer.

\subsection{In-vitro-Methoden}

Die in-vitro-Versuche wurden im Labor der Klinik für Neurologie der Charitè Universitätsmedizin Berlin in Zusammenarbeit mit Christoph Harms durchgeführt. Die primären murinen kortikalen Neurone wurden von Mausembryonen (embryonaler Tag 16, E16) der Linie C57Bl/6 sowohl von Faim2-defizienten Versuchstieren als auch von 
Wildtypen entnommen. Die Zellen wurden bei $36,5^{\circ} \mathrm{C}, 95 \%$ Luft, $5 \% \mathrm{CO}_{2}$ und $95 \%$ Luftfeuchtigkeit im Züchtungsmedium, das aus dem neurobasalen Medium mit B27Zusatz (Life Technologies/BRL, Eggenstein), 100 U/ml Penizillin-Streptomyzin und 0,5 mM L-Glutamin (Biochrom KG, Berlin) bestand, gehalten. Ab dem 4. Tag in vitro wurde zwei Mal pro Woche ein Mediumwechsel durchgeführt, wobei die Hälfte verworfen und der Rest wieder aufgefüllt wurde.

Bevor die kortikalen Neurone für Experimente verwendet werden konnten, mussten sie 10 Tage in o.g. Medium in vitro gereift sein. Anschließend wurde der virale Gentransfer durch das Faim2-full-length- sowie das Faim2-truncated-Lentiviruskontrukt durchgeführt. Zusätzlich wurden die Zellen entweder vor oder nach Gentransfer einem Sauerstoff-Glukose-Entzug mittels oxygen-glucose deprivation (OGD), analog zu einer zerebralen Ischämie, unterzogen.

\subsubsection{Oxygen-glucose Deprivation (OGD)}

Bei der oxygen-glucose deprivation werden den Zellen in vitro gleichzeitig Sauerstoff und Glukose entzogen. Dies hat zur Folge, dass sie zur Apoptose angeregt werden. Um den Zellen zunächst die Glukose zu entziehen, wurde unmittelbar vor dem Experiment das Züchtungsmedium entfernt. Anschließend wurden sie in PBS gewaschen und die Kulturen zum Sauerstoffentzug für 90 Minuten in der glukosefreien Salzlösung in die Hypoxiekammer (Anaerobierkammer Concept 400, Ruskinn Ltd, GB) mit einem Sauerstoffpartialdruck von $\mathrm{pO}_{2}<2 \mathrm{mmHg}$ plaziert. Nach 90 Minuten wurde die glukosefreie Elektrolytlösung wieder gegen das Züchtungsmedium ausgetauscht und die normoxischen Bedingungen wiederhergestellt.

Bei den Kontrollkulturen wurde zur 90-minütigen Inkubation unter normoxischen Bedingungen eine Salzlösung mit 20 mM D-Glukose verwendet. Das Ausmaß der Apoptose wurde über die Messung der ins Medium freigesetzten Laktat-Dehydrogenase (LDH) ermittelt (Harms et al. 2007). Die LDH-Konzentration wurde über den kinetischen LDH-Test bestimmt. Um zusätzlich eine Aussage über den zellulären Schaden machen zu können, wurden die Zellen parallel über das Phasenkontrastmikroskop (Leitz, Wetzlar) evaluiert und repräsentative Mikrophotographien angefertigt.

\subsubsection{Caspase-3- und -8-Activity-Assay}

Die Aktivitätsmessung von cleaved Caspase-3 und -8 in der Zellkultur von primären murinen kortikalen Neuronen wurde analog zu dem Activity-Assay aus in-vivo-gewonnenem Hirngewebe durchgeführt (siehe 2.5.4 auf Seite 41). 


\subsection{In-vivo-Methoden}

\subsubsection{Middle Cerebral Artery Occlusion (MCAo)}

Die Tierexperimente wurden in strenger Einhaltung der Richtlinien zu den gültigen Tierschutzbestimmungen in Zusammenarbeit mit Prof. Dr. M. Endres (Charitè, Universitätsmedizin Berlin) und Prof. Dr. J. B. Schulz (Universitätsmedizin Göttingen) durchgeführt (Tierversuchsantrag Nr. G 0240/07 (LAGeSo (Landesamt für Gesundheit und Soziales) Berlin) und Nr. 33.11.42502-04.030/09 (Göttingen)). Alle operativen Eingriffe wurden an tief anästhesierten Tieren vorgenommen. Männliche Faim2defiziente Mäuse und littermate Faim2-Wildtypen der Black-Six-Linie wurden mit Isofluran im $\mathrm{N}_{2} \mathrm{O}-\mathrm{O}_{2}$-Gasgemisch $\left(70 \% \mathrm{~N}_{2} \mathrm{O}\right.$ und $\left.30 \% \mathrm{O}_{2}\right)$ anästhesiert. Die Narkose wurde mit 2,0\% Isofluran eingeleitet und mit 1,0\% aufrecht erhalten. Hierzu wurden die Tiere auf dem OP-Tisch in Rückenlage gelagert und über eine Gesichtsmaske ventiliert. Während der Narkose wurde ein EKG zum Kreislaufmonitoring abgeleitet und über den beheizbaren OP-Tisch und eine rektal eingeführte Temperatursonde mittels Feedback-Temperatur-Regler die Körperkerntemperatur bei $36,5 \pm 0,5{ }^{\circ} \mathrm{C}$ konstant gehalten. Die Narkosedauer betrug ca. 8-10 Minuten.

Nach dem Prüfen der Narkosetiefe und dem Erlöschen von Reaktionen auf Schmerzreize erfolgte zunächst eine ca. $1 \mathrm{~cm}$ lange Inzision links paramedian auf Höhe der Karotisgabel. Im Folgenden wurde das subkutane Fett- und Bindegewebe sowie ggf. Schilddrüsengewebe stumpf nach medial und lateral präpariert, sodass das Trigonum caroticum mit der A. carotis communis, der Karotisgabel mit A. carotis interna und externa sowie der $N$. vagus sauber dargestellt werden konnten. Zunächst wurden nun die A. carotis communis und externa jeweils mit einer Ligatur versehen. Hierzu wurde ein 5-0 Polyviolene-Faden der Firma Harvard Apparatus verwendet. Zur Vorbereitung der folgenden Einbringung des Monofilaments zur Okklusion der A. cerebri media wurde eine Ligatur um die A. carotis interna gelegt, allerdings nicht zugezogen. Während nun mit Hilfe einer Präzisionsschere die A. carotis interna eröffnet wurde, erfolgte zeitgleich die Insertion des mit Silikon beschichteten Monofilaments. Unter Darstellung des Verlaufs der A. carotis interna bis zum Abgang der A. occipitalis, an dessen Abgang das Filament vorbeigesteuerten werden musste, wurde nun das Filament bis in die A. cerebri media vorgeschoben, um die fokale zerebrale Ischämie zu induzieren. Das verwendete Monofilament bestand aus einem monofilen 8-0 Nylonfaden, der mit einem Silikon-Resin-Gemisch (Xantopren M Mucosa and Activator NF Optosil Xantopren, Heraeus Kulzer, Wehrheim) beschichtet wurde. Der Faden wurde bis zum Abgang der A. cerebri anterior am Circulus Willisii eingeführt. Auf diese 
Weise konnten die A. cerebri media und A. choroidea anterior okkludiert werden. Sobald die korrekte Platzierung mittels Flussmessung bestätigt werden konnte, wur-

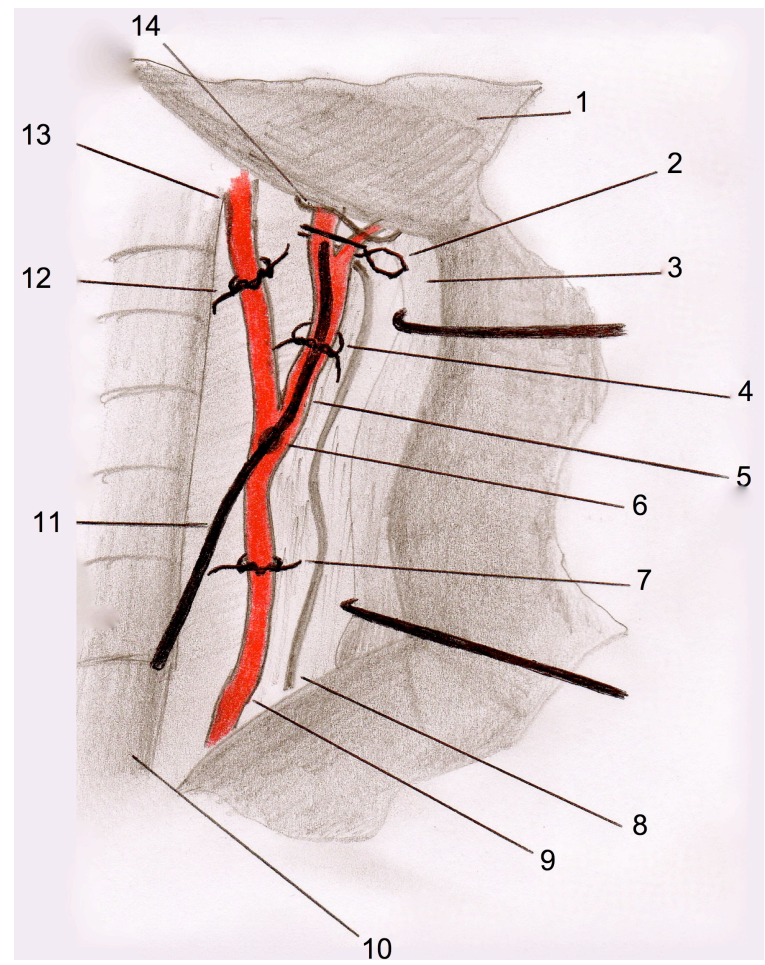

Abbildung 2.1: Anatomische Verhältnisse und Positionierung von Ligaturen, Inzision, Gefäßklipp und Filament an der Karotisgabel während MCAo. (1) Fell, Kutis und Subkutis; (2) Gefäßklipp; (3) Drüsengewebe; (4) 3. Ligatur (offen); (5) A. carotis interna; (6) Inzision in A. carotis communis; (7) 1. Ligatur (gechlossen); (8) Nervus vagus; (9) A. carotis communis; (10) Trachea; (11) In die A. carotis interna eingeführtes Filament bis zum geschlossenen Gefäßklipp, nach Öffnen des Gefäßklipps, Vorschieben bis A. cerebri media; (12) 2. Ligatur (geschlossen); (13) A. carotis externa; (14) Nervenast

de das Filament mit der zuvor gelegten Ligatur fixiert, die Narkose langsam beendet und die Wunde verschlossen. Die Mäuse wurden während der Okklusionszeit von insgesamt 30 Minuten auf einer Wärmeplatte gelagert und anschließend zum Entfernen des Filaments erneut kurz narkotisiert. Während das Filament aus der A. carotis interna zurückgezogen wurde, erfolgte gleichzeitig das Zuziehen der um die A. carotis interna zuvor locker gelegten Ligatur. Zum Beweis der erfolgreichen Reperfusion wurde ein Reflux aus der A. carotis interna zunächst abgewartet. So war nach 30minütiger Okklussion die Reperfusion des Versorgungsgebiets der A. cerebri media und der A. choroidea anterior gewährleistet. Um den regionalen zerebralen Blutfluss ermitteln zu können und sowohl die Minderperfusion als auch die Reperfusion zu dokumentieren, wurde erneut die Laser-Doppler-Flussmetrie (Peri Flux 4001 Master, Perimed, Stockholm, Schweden) angewendet. Dabei fiel der regionale zerebrale Blut- 
fluss im Versorgungsgebiet der A. cerebri media auf ca. 20\% des Ausgangswertes ab und erreichte den Ausgangspunkt vor Okklusion innerhalb von 5 Minuten nach dem Wiederöffnen des Gefäßes. Es erfolgte nun der endgültige Wundverschluss mittels Einzelknopfnähte.

Vorbeiströmendes Narkosegas und ausgeatmete Gasvolumina wurden über eine Absaugvorrichtung entfernt. Im Anschluss an den operativen Eingriff wurden die Tiere mit einer Wärmeplatte auf Körpertemperatur gehalten und mit einer subkutanen Injektion von $1 \mathrm{ml} 5 \%$ Glukose (Braun) und 0,9\% $\mathrm{NaCl}$ (Diaco) im Verhältnis 1:1 versorgt. Des Weiteren wurde das Futter mit Wasser getränkt und in den Käfig platziert. Zur fortgesetzten Analgesie erhielten die Tiere $3,2 \mathrm{mg} / \mathrm{ml}$ Nocaminsulfon (Ratiopharm) in das Trinkwasser gemischt.

Stichprobenartig wurde in einigen Tieren die linke A. femoralis punktiert und der mittlere arterielle Blutdruck und eine Blutgasanalyse durchgeführt. Als Kontrolle wurden sog. Sham Mäuse auf dem OP Tisch gelagert, anästhesiert und die Karotisgabel frei präpariert. Bevor das Filament eingeführt werden sollte, wurde die Narkose jedoch beendet und die Tiere wurden somit nicht einer unilateralen, zerebralen Ischämie unterzogen. Nach 30 Minuten erfolgte nochmals eine kurze Narkose und der definitive Wundverschluss.

Nach einer 72-stündigen Reperfusionszeit wurden die Versuchstiere, wie in Abschnitt 26 auf Seite 42 dargestellt, tief narkotisiert und dekapitiert, um anschließend das Gehirn zu präparieren und entsprechend aufzuarbeiten.

\subsubsection{Stereotaktische Injektionen}

In Vorbereitung auf die stereotaktischen Injektionen wurden die Mäuse durch eine intraperitoneale Injektion von $150 \mathrm{mg} / \mathrm{kg}$ KG Ketamin (Ketanest S, Pfizer) und $15 \mathrm{mg} / \mathrm{kg}$ KG Xylazin (Xylazin 2\%, Riemser) analgosediert. Nach dem Testen von Reflexen (Lidschlussreflex, Schmerzreflex an den Extremitäten) wurden die Mäuse flach, auf dem Bauch liegend, in den stereotaktischen Rahmen (World Precision Instruments, Berlin, Germany) eingespannt. Die offenstehenden Augen wurden mit Bepanthen Augen- und Nasensalbe (Dexpanthenol, Bayer) bedeckt.

Eine mit Mineralöl gefüllte Glaskapillare wurde in den Nanoliter2000 Microinjector (Word Precision Instruments) gespannt und anschließend mit der benötigten Menge an Virus befüllt. Es erfolgte dann der ca. $0,5 \mathrm{~cm}$ lange, saggital geführte, paramediane Hautschnitt über der Schädelkalotte. Nach der Präparation der Schädelkalotte wurde die Injektionsposition mittels standarisierter Koordinaten relativ zum Bregma 
ermittelt. Die verwendeten Koordinaten befinden sich in der untenstehenden Tabelle 2.9. An dieser Position wurde ein Bohrloch mit $1 \mathrm{~mm}$ Durchmesser gesetzt. Die Abbildung 8.2 in Abschnitt 8.6 auf Seite 127 zeigt den Versuchsaufbau und die Positionierung der Maus während der stereotaktischen Injektion. Die Injektion des Virus (Lentivirus, 697 Moleküle pro 10000 Aktin-Molekülen/ $\mu$ l) erfolgte in zwei Höhen entlang des durch die Injektionsnadel geschaffenen Kanals mit je $1 \mu$ und einer Rate von $250 \mathrm{nl} / \mathrm{min}$. Die Abbildung 8.3 in Abschnitt 8.6 auf Seite 127 stellt die anatomischen Lagebeziehungen dar.

Tabelle 2.9: Koordinaten für die stereotaktische Injektion

\begin{tabular}{lccc}
\hline Anatomische Struktur & $\begin{array}{c}\text { anterior } \\
(\mathrm{mm})\end{array}$ & $\begin{array}{c}\text { lateral (links) } \\
(\mathrm{mm})\end{array}$ & $\begin{array}{c}\text { ventral (ab Kalotte) } \\
(\mathrm{mm})\end{array}$ \\
\hline \multirow{2}{*}{ Striatum } & $+0,20$ & $+2,0$ & $+3,75$ \\
& $+0,20$ & $+2,0$ & $+2,75$ \\
\hline
\end{tabular}

Für die Injektion selbst wurde zunächst eine Zeit von 2 min nach dem Einführen der Kanüle in das Hirnparenchym abgewartet. Anschließend wurde die Injektion mit $250 \mathrm{nl} /$ min gestartet. Nach der Injektion wurde die Kanüle zunächst in dieser Position für 2 min belassen, bevor die tiefere Koordinate eingestellt wurde. Nach erfolgter Virusinjektion von $2 \mu \mathrm{l}$ Gesamtvolumen in das Striatum links wurde die Kanüle nach 5-minütiger Pause aus dem Hirnparenchym wieder entfernt.

Die postoperative Versorgung wurde analog zur Versorgung nach MCAo durchgeführt. Hierzu wurde die Wunde mit Histoacryl (Braun) verschlossen, die Körpertemperatur der Tiere mithilfe einer Wärmeplatte gewährleistet und Glukose (5\%, Braun) / $\mathrm{NaCl}$ (0,9\%, Diaco) Mix (1:1) subkutan verabreicht. Zur Analgesie erhielten die Mäuse $3,2 \mathrm{mg} / \mathrm{ml}$ Novaminsulfon (Ratiopharm) in das Trinkwasser gemischt.

Tabelle 2.10: Koordinaten für den Vorversuch der stereotaktischen Injektion

\begin{tabular}{llccc}
\hline & $\begin{array}{l}\text { Anatomische Struktur } \\
(\mathrm{je} 1 \mu \mathrm{l})\end{array}$ & $\begin{array}{c}\text { anterior } \\
(\mathrm{mm})\end{array}$ & $\begin{array}{c}\text { lateral (links) } \\
(\mathrm{mm})\end{array}$ & $\begin{array}{c}\text { ventral (ab Kalotte) } \\
(\mathrm{mm})\end{array}$ \\
\hline \multirow{2}{*}{ 1. Bohrloch } & Kortex & $+0,05$ & $+0,20$ & $+0,15$ \\
& Striatum & $+0,05$ & $+0,20$ & $+0,33$ \\
\hline \multirow{2}{*}{ 2. Bohrloch } & Kortex & $-0,94$ & $+0,25$ & $+0,15$ \\
& Striatum & $-0,94$ & $+0,25$ & $+0,30$ \\
\hline
\end{tabular}

Die stereotaktischen Injektionen wurden zunächst zum Vergleich des Infektionsradius mit Adeno- und Lentiviren durchgeführt und immunhistologisch mittels anti-GFP- 
und anti-Faim2-Färbungen aufgearbeitet. Nach Identifikation des Lentivirus als das geeignetere von beiden, wurde ein Vorversuch zur Menge und zur Lokalisation der Injektion aufgenommen. Die hierbei verwendeten Koordinaten sind in der Tabelle 2.10 auf der vorherigen Seite aufgezeigt. Hierbei wurden zwei Bohrlöcher gesetzt und durch die jeweils zweimalige Injektion von $1 \mu \mathrm{l}$ ein Gesamtvolumen von $4 \mu \mathrm{l}$ injiziert. Im Folgenden wurden dann jedoch die weniger traumatischen lentiviralen Injektionen wie in Tabelle 2.9 auf der vorherigen Seite aufgeführt drei Wochen vor der MCAo appliziert.

\subsubsection{Zeitverlauf der Faim2- und Fas-Regulation}

Zur Darstellung der nach Ischämie zeitabhängigen Regulation von Faim2 und Fas wurde, wie in Abbildung 3.2 auf Seite 54 aufgezeigt, zu den Zeitpunkten 0, 3, 18 und 48 Stunden nach MCAo Hirngewebe aufgearbeitet und mittels RNA-Isolation und real time PCR die relative Menge an Faim2 und Fas im ischämischen Hirngewebe ermittelt.

Hierzu wurde zunächst, wie in Abschnitt 2.5.1 auf Seite 36 beschrieben, die MCAo

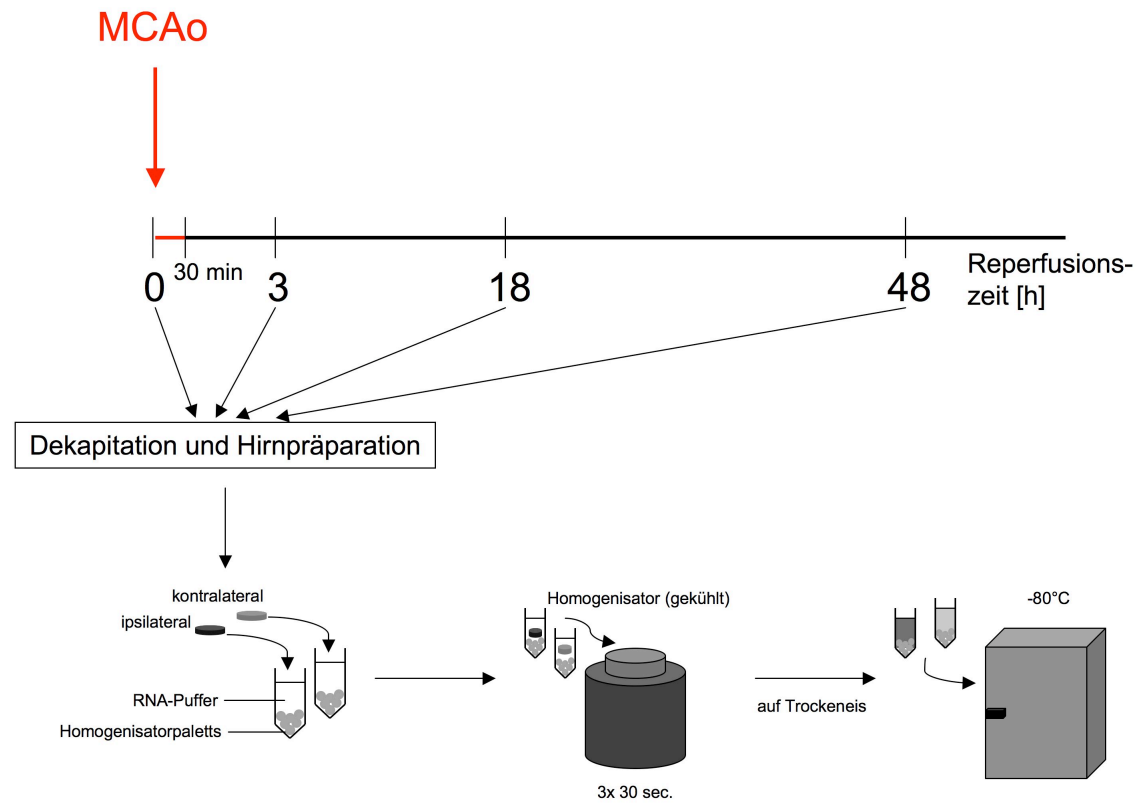

Abbildung 2.2: Versuchsanordnung zum Zeitverlauf der Faim2- und Fas-Regulation

durchgeführt. Anstelle der 72-stündigen Reperfusionszeit wurde nun jedoch nur 0, 3, 18 oder 48 Stunden Reperfusionszeit eingehalten und die Mäuse wurden zu diesen Zeitpunkten jeweils nach tiefer Narkose dekapitiert und die Gehirne entsprechend 
präpariert. Direkt nach der Präparation aus dem Schädel, wurden die Gehirne entlang der Falx cerebri in ipsilateral (ischämisches Hirnareal im Mediastromgebiet) und kontralateral (Kontrolle) geteilt. Anschließend wurden die jeweiligen Striata in $30 \mathrm{mg}$ Blöcke geteilt und in $2 \mathrm{ml}$ Homogenisatorröhrchen mit $600 \mu \mathrm{l}$ RNA-Puffer gegeben. Im gekühlten Homogenisator wurden die Proben anschließend für 3x 30 s homogenisiert, um dann unmittelbar auf Trockeneis gefroren und bis zur Weiterverarbeitung bei $-80^{\circ} \mathrm{C}$ eingefroren zu werden. Die weitere Aufarbeitung erfolgte schließlich mittels RNA-Isolation, cDNA-Synthese und real time PCR wie in Abschnitten 2.3.5 auf Seite 30 und 2.3 .6 auf Seite 31 beschrieben.

\subsubsection{Caspase-3- und -8-Activity-Assay}

Zur sicheren Detektion apoptotischer Vorgänge in einer Zelle ist die Messung der Aktivität der in Abschnitt 1.1 .3 auf Seite 5 bereits dargestellten Initiatorcaspase (Caspase-8) als Startpunkt der Caspasenkaskade und der Effektorcaspase (Caspase3) als Endpunkt der Caspasenkaskade und Bestandteil des Apoptosoms, mittels eines Activity-Assays möglich. Dabei werden jeweils die aktivierten Formen der Caspasen (cleaved) gemessen. Die flourometrisch ermittelte Kozentration von cleaved Caspase3 und -8 ist dabei proportional zur Aktivität von Caspase-3 und -8. Diese Aktivität wurde sowohl in ischämischen Hirnarealen der Faim2-defizienten Mäuse und deren Kontrollen als auch in neuronalen Zellkulturansätzen gemessen. Die neuronalen Zellen waren zuvor durch Sauerstoffentzug ebenfalls zur Apoptoseinduktion angeregt worden. Zur Messung der Caspase-3- und -8-Aktivität wurde ein Kit der Firma Roche Diagnostics, Mannheim verwendet, das auf der Basis des Enzyme Linked Immunosorbent Assay (ELISA) beruht.

Das Gehirngewebe wurde zunächst in Lysispuffer homogenisiert und anschließend bei $4^{\circ} \mathrm{C}$ zentrifugiert. Der Überstand wurde mit Reaktionspuffer und 0,5 $\mu$ l DTT gemischt. Entsprechende Kontrollen ohne AFC bzw. mit $1 \mu \mathrm{l}$ Fas-Inhibitor wurden angesetzt und die Proben für 30 min auf Eis inkubiert. Das Caspase-Substrat wurde hinzugefügt und für $60 \mathrm{~min}$ bei $37^{\circ} \mathrm{C}$ inkubiert. Anschließend erfolgte die Messung mittels flourometrischer Bestimmung des proteolytisch freigesetzten AFC.

Die neuronalen Zellen aus der Zellkultur wurden nach Sauerstoffentzug analog aufbereitet und die Caspase-Aktivität wurde flourometrisch ermittelt. 


\subsubsection{BrdU-Applikation}

5-Bromo-2'-Deoxy-Uridin (BrdU, Sigma) wurde in 1\% 1M NaOH in PBS (Konzentration $20 \mathrm{mg} / \mathrm{ml}$ ) aufgelöst. Es wurde die pulsatile Verabreicherungsmethode eingesetzt, wobei täglich ab $72 \mathrm{~h}$ vor MCAo intraperitoneale Injektionen $(50 \mathrm{mg} B r d U / k g$ Körpergewicht) verabreicht wurden. Alle Experimente, die eine in-vivo-Applikation von BrdU beinhalteten, wurden im Laboratorium der Klinik für Neurologie der Charité Universitätsmedizin Berlin durchgeführt.

\subsection{Gewebeaufarbeitung der Maushirne}

\subsubsection{Einfrieren unfixierter Maushirne}

Die Tiere wurden mit Isofluran tief narkotisiert und mit einer Schere dekapitiert. Die Hirne wurden rasch entnommen und es wurden, vor dem Einfrieren in Methylbutan bei $-40^{\circ} \mathrm{C}$ auf Trockeneis, sichtbare Gefäße und Hirnhautreste entfernt. Bis zur weiteren Verarbeitung wurden die Gehirne bei $-80^{\circ} \mathrm{C}$ aufbewahrt.

\subsubsection{Transkardiale Fixation des Gewebes}

Die Tiere wurden mit 10\% Chloralhydrat in PBS $(6,25 \mathrm{ml} / \mathrm{kg}$ KG intraperitoneal) nach 72-stündiger Reperfusionszeit nach MCAo tief analgosediert. Das vordere und mittlere Mediastinum wurde von ventral her eröffnet. Der rechte Vorhof wurde eröffnet und anschließend der linke Ventrikel kanüliert. Die transkardiale Perfusion erfolgte mit Hilfe einer Pumpe (Flussrate $5 \mathrm{ml} / \mathrm{min}$ ). Zuerst wurde mit ca. $5 \mathrm{ml}$ kaltem PBS perfundiert, bis die aus dem Herzvorhof herausströmende Flüssigkeit weitestgehend frei von Blut war. Anschließend wurden mit ca. $50 \mathrm{ml}$ 4\% PFA in PBS (pH-Wert 7,2 - 7,4) transkardial perfundiert. Die Gehirne wurden dann nach Aufschneiden der Kalotte und Abziehen der Meningen vorsichtig entnommen und noch weitere 8 Stunden in $4 \%$ PFA bei $+4{ }^{\circ} \mathrm{C}$ postfixiert.

\subsubsection{Schneiden der Maushirne}

Abhängig von der späteren Aufarbeitungs- und Färbemethode, wurden die Gehirne unterschiedlich sektioniert, wobei die Position der koronaren Schnitte im Gehirn immer gleich blieb. Diese Sektionen sind in der Abbildung 8.4 in Abbschnitt 8.7 auf Seite 128 dargestellt und die anatomischen Positionen relativ zum Bregma angegeben. 
Der Fokus lag beim Aufarbeiten der Gehirne auf dem Versorgungsgebiet der Arteria cerebri media, im Speziellen dem Striatum und dem das Striatum umgebenden Kortex.

\section{Free-Floating-Schnitte}

Die mit 4\% PFA transkardial fixierten Gehirne wurden am Vibratom (Technical Products, St. Louis, USA) geschnitten, wobei $40 \mu \mathrm{m}$ starke koronare Schnitte angefertigt wurden. Die Schnitte wurden dann ca. $24 \mathrm{~h}$ in 30\%iger Glukoselösung (in PBS) kryoprotektiert und anschließend entweder bei $-20^{\circ} \mathrm{C}$ gelagert oder bei $4^{\circ} \mathrm{C}$ bis zur weiteren Verarbeitung aufbewahrt.

\section{Kryoschnitte}

Die unfixiert eingefrorenen Gehirne (fresh frozen) wurden am Kryostat (Microm, Heidelberg) geschnitten. 10-20 $\mu \mathrm{m}$ starke koronare Sektionen wurden auf kurz vorgewärmte Objektträger (Menzel Gläser, Braunschweig) aufgenommen. Anschließend wurden diese bei $-80^{\circ} \mathrm{C}$ gelagert.

\section{Paraffin-Schnitte}

Zunächst wurden die Gehirne für 24 Stunden in vierprozentiger Paraformaldehydlösung fixiert, mit Hilfe eines Gewebeinfiltrationsautomaten paraffiniert und anschließend an einer Paraffinausgießstation in Paraffinblöcke eingegossen. Von den Paraffinblöcken wurden $4 \mu \mathrm{m}$ starke Schnitte angefertigt, in einem Wasserbad bei $50^{\circ} \mathrm{C}$ geglättet, auf Objektträgern aufgezogen und anschließend in einem Ofen bei $37^{\circ} \mathrm{C}$ getrocknet.

\subsubsection{Hämatoxylin-Färbung}

Die Hämatoxylin-Färbung färbt Chromatin in den Zellkernen blau (Hämatoxylin). Zunächst erfolgte eine Entparaffinierung und Reinigung der Schnitte, indem Letztere sequentiell dreimal in Xylol für 10 min und anschließend für 3 min zweimal in 100\%und jeweils einmal in 96\%-, 70\%- sowie 50\%-Ethanol und zweimal für 5 min in Aqua dest. rehydriert wurden. Nach jeweils siebenminütiger Färbung in Hämalaunlösung und anschließender fließender Wässerung (Bläuung) wurden sie kurz in Aqua dest. gespült und nachfolgend in einer aufsteigenden Reihe (jeweils 4 mal Eintauchen in 50\%-, 70\%-, 96\%-Ethanol; 5 min in 100\%-Ethanol; 2 mal 10 min Xylol) dehydriert und mit Entellan eingedeckelt. 


\subsubsection{Messung des Infarktvolumens}

Nach einer Reperfusionszeit von $72 \mathrm{~h}$ wurden die Mäuse tief narkotisiert und mit einer Schere dekapitiert. Die Gehirne wurden im Ganzen mit Kleinhirn und Bulbi olfactories nach Entfernung der sichtbaren Gefäß- und Hirnhautrückstände zügig entnommen und in Methylbutan bei $-40^{\circ} \mathrm{C}$ auf Trockeneis schockgefroren. Im Verlauf wurden daraufhin die Gehirne am Kryostaten (Microm, Heidelberg) koronar alle $200 \mu \mathrm{m}$ in 10-20 $\mu \mathrm{m}$ starke Scheiben geschnitten und auf Objektträger (Menzel Gläser, Braunschweig) aufgenommen. Die fünf verschiedenen Koronarschnitte sind in Abbildung 8.4 auf Seite 128 dargestellt und stellten bei der Messung jeweils repräsentativ das o.g. $200 \mu \mathrm{m}$ Intervall dar. Nachdem die auf die Objektträger aufgenommenen Schnitte über Nacht getrocknet waren, wurde eine Hämatoxylin-Färbung (Merck, Darmstadt, Germany) druchgeführt. Nach erneuter Trocknung wurden die Schnitte am Computer eingescannt und die Infarktareale mittels Sigma Scan Pro quantifziert und das Volumen berechnet. Grundsätzlich wurde vorausgesetzt, dass beide Hemisphären gleich groß waren. Wegen des Ödemeffekts wurde die volumetrische Messung ein Schnitt anterior und ein Schnitt posterior des Ischämieareals begonnen bzw. beendet. Um die ödematöse Hirnschwellung von der Berechnung weiterhin auszuschließen, wurde die gesamte kontralaterale (nicht-infarzierte Hemisphäre) von der gesamten ipsilateralen (infarzierte) Hemisphäre subtrahiert. Folgende Parameter wurden jeweils an den Hirnschnitten a1 bis a5 (siehe Abb. 8.4 auf Seite 128) gemessen:

1. Fläche der gesamten ipsilateralen (ischämischen) Hemisphäre in $\mathrm{mm}^{2}$ : il $\mathrm{l}_{\text {gesamt }}$

2. Fläche des nicht ischämischen Areals der ipsilateralen (ischämischen) Hemisphäre in $\mathrm{mm}^{2}$ : $\mathrm{il}_{\text {gesund }}$

3. Fläche der kontralateralen (nicht-ischämischen) Hemisphäre in $\mathrm{mm}^{2}$ : cl

Zur Ermittlung des direkten Infarktvolumens $\left(\mathrm{Z}_{\text {dir }}\right)$ ergibt sich folgende Formel:

$$
Z_{\text {dir }} m m^{3}=\left(\left(\mathrm{il}_{\text {gesamt }} m m^{2}-\mathrm{il}_{\text {gesund }} m m^{2}\right) \cdot 0,2 \mathrm{~mm}\right)_{a 1}+(\ldots)_{a 2}+\ldots+(\ldots)_{a 5}
$$

Zur Ermittlung des indirekten Infarktvolumens $\left(\mathrm{V}_{\text {ind }}\right)$ ergibt sich folgende Formel:

$$
V_{\text {ind }} \%=\frac{\left(\left(\mathrm{il}_{\text {gesund }} \mathrm{mm}^{2} \cdot 0,2 \mathrm{~mm}\right)_{a 1}+(\ldots)_{a 2}+\ldots+(\ldots)_{a 5}\right)}{\left(\left(\mathrm{cl} m m^{2} \cdot 0,2 \mathrm{~mm}\right)_{a 1}+(\ldots)_{a 2}+\ldots+(\ldots)_{a 5}\right)} \cdot 100
$$

$\mathrm{V}_{\text {ind }}$ stellt dabei den prozentualen Anteil des Gehirns dar, der vom Infarkt verschont blieb. Der Vorteil der indirekten Volumetrie besteht insbesondere darin, dass der Störfaktor durch die ödematöse Schwellung nahezu auf 0 reduziert werden kann. 
Das Ödem selbst kann durch die Berechnung des Ödemindex $\mathrm{E}_{\text {Index }}$ wie folgt berechnet werden:

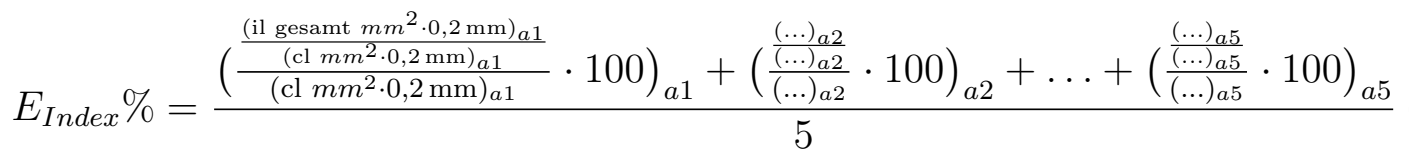

$\mathrm{E}_{\text {Index }}$ stellt den Mittelwert aus den prozentualen Ödemanteilen der jeweiligen Hirnabschnitte dar. Damit weist $E_{\text {Index }}>0$ auf ein Ödem hin, $E_{\text {Index }}<0$ gibt Anhalt auf eine Hirnatrophie durch z.B. ein chronisches Stadium einer Ischämie (Lin et al. 1993). Die Berechnungen und die Interpretation der errechneten Volumina erfolgten analog zu den von Lin et al. (1993) veröffentlichten Auswertungen zum Effekt des Hirnödems auf das Infarktvolumen im Rattenmodel der fokalen zerebralen Ischämie.

Präparate von Tieren ohne Infarkt oder einem nur sehr kleinen Infarktareal in der Hippokampusregion wurden von den Messungen ausgeschlossen, da hier von einer insuffizienten zerebralen Ischämie ausgegangen werden musste. Im Folgenden wurden die Infarktgrößen der jeweiligen Gruppen (Faim2-Defizienz, Faim2-Wildtyp) jeweils mit passenden Geschlechts- und Alterstrukturen verglichen. Zur statistischen Auswertung wurde der Mann-Whitney-U-Test verwendet.

\subsubsection{Terminal-Desoxynucleotidyl-Transferase-mediated dUTP-biotin Nick End Labeling (TUNEL)}

Wie erstmalig durch (Gavrieli et al. 1992) beschrieben, können die beim Vorgang der Apoptose durch internukleosomale Spaltung entstehenden DNA-Fragmente in einer Zelle durch die TUNEL-Färbung (TdT-mediated dUTP-biotin nick end labeling) markiert und dargestellt werden. Die Terminale Desoxynucleotidyl Transferase (TdT) katalysiert als Enzym bei der Färbung die Verknüpfung von mit Digoxigenin markierten Desoxyribonukleotidtripohsphaten (dNTP: DIG-DNA) mit den 3'-HydroxylEnden der fragmentierten Einzel- und Doppelstrang-DNA-Moleküle. Die Farbreaktion wird nun über das Hinzugeben von gegen Digoxigenin gerichteten Primärantikörpern erzeugt. Dabei werden diese entweder an alkalische Phosphatase (Lichtmikroskopie; NBT/BCIP-Entwicklung) oder an Rhodamin (Fluoreszenzmikroskopie) gekoppelt.

Die Bearbeitung und Vorbereitung der Schnitte war abhängig von der vorangegangenen Fixierungs- und Schneidemethode. Wurden die Gehirne mittels Kryoschnitte (siehe Abschnitt 2.6.3 auf Seite 43) aufgearbeitet, tauten und trockneten die Objektgläser zunächst bei Raumtemperatur auf. Anschließend wurden der erste und fünfte von den 5 auf den Objektträger aufgezogenen Schnitten entfernt und die ver- 
bliebenen drei mit einem Fettstift umkreist. Alle weiteren Schritte erfolgten in dem dadurch gebildeten Reservoir. Zunächst wurden die Schnitte in 4\%-igem PFA bei einem $\mathrm{pH}$ von 7,5 für 15 min vorbehandelt. Anschließend wurde dreimalig mit TBS gewaschen. Die Objektträger wurden daraufhin auf Eis gelegt und die Schnitte für 2 min mit Citratpuffer bedeckt. Es folgte erneut dreimaliges Waschen. Im Folgenden wurde auf jeden Objektträger mit den drei umkreisten Schnitten $100 \mu$ l Tailingmix gegeben, der aus $90 \mu \mathrm{l}$ Label Solution (69 $\mu \mathrm{l}$ Reaktionspuffer, $14 \mu \mathrm{l} \mathrm{CoCl}_{2}, 7 \mu \mathrm{l}$ DIGDNA) und $10 \mu \mathrm{l}$ TdT bestand und für $2 \mathrm{~h}$ bei $37^{\circ} \mathrm{C}$ in einer Feuchtkammer inkubiert. Nach erneutem dreimaligem Waschen und 30-minütigem Blocken mit 10\% FCS in TBS bei Raumtemperatur folgte eine 90-minütige Inkubation mit dem Primärantikörper (Anti-Digoxigenin-Alkalische-Phosphatase [1:250 verdünnt in 10\% FCS in TBS] oder Anti-Digoxigenin-Rhodamin [1:20 verdünnt in 10\% FCS in TBS]). Anschließend wurde fünfmalig mit TBS gewaschen. Das daraufhin verwendete Chromagen wurde abhängig von der gewünschten Auswertungsmethode gewählt (siehe unten). Wurden die Gehirne mittels Paraffin-Schnitttechnik (siehe Abschnitt 2.6.3 auf Seite 43) aufgearbeitet, wurde zunächst eine enzymatische Vorbehandlung mit $20 \mu \mathrm{g} / \mathrm{ml}$ (gelöst in TBS $/ 2 \mathrm{mM} \mathrm{CaCl}_{2}$ ) rekombinanter Proteinase $\mathrm{K}$ (Roche Diagnostics, Mannheim) für 15 Minuten bei $37^{\circ} \mathrm{C}$ durchgeführt. Die für Immunfluoreszenz-Doppelfärbungen vorgesehenen Schnitte wurden hitzeinduziert demaskiert. Die Schnitte wurden daraufhin dreimalig mit TBS gewaschen und für 5 Minuten in TBS auf Eis zur Inaktivierung der Proteinkinase K abgekühlt. Das weitere Prozedere erfolgte wie oben beschrieben. Waren die Schnitte noch nicht auf Objektträger aufgezogen (siehe Abschnitt 2.6.3 auf Seite 43), erfolgte zuvor das Auftragen und Trocknen der Schnitte auf Objektträger. Die weiteren Schritte erfolgten wie oben beschrieben. Die Objektträger wurden $10 \mathrm{Mi}$ nuten in $0,1 \mathrm{M} \mathrm{PO}_{4}$ inkubiert und anschließend mit Immu-Mount eingedeckelt. Waren die Schnitte als Doppelfärbung mit NeuN, aktiver Caspase-3 oder aktiver Caspase8 Hoechst 33258 (Invitrogen GmbH; Karlsruhe, Germany) immunfluoreszenzgefärbt, wurden sie mit Aqua dest. gespült und abschließend mit Immu-Mount eingedeckelt. Das Enzym TdT wurde für die Negativkontrolle bei ansonsten identischem Färbeprotokoll weggelassen. Die Quantifizierung der TUNEL-positiven Zellen und damit derjenigen Zellen, die Apoptose eingeleitet hatten, erfolgte mittels des Stereo-Investigators 7 der Firma Leica (MicroBrightField Bioscience, Williston, USA) oder dem Stereomikroskop SMZ645 (Nikon Corporation, Tokio, Japan). 


\section{TUNEL mit 3,3'-Diaminobenzidin (DAB) als Chromagen}

Gefrierschnitte wurden aus dem Gefrierfach entnommen und für 10 Minuten bei Raumtemperatur aufgetaut und getrocknet. Die folgenden Schritte erfolgten analog zu dem oben beschriebenen Protokoll:

1. Fixation in $4 \%$ PFA für 10 min bei Raumtemperatur

2. dreimaliges Waschen der Schnitte je 5 min im TBS

3. Umranden der Schnitte mit PAP-Pen (hydrophobic slide marker)

4. Citratpuffer auf Schnitte für 2 min auf Eis

5. dreimaliges Waschen der Schnitte je 5 min im TBS

6. Inkubation im Equilibration buffer für 1 min bei Raumtemperatur (ca. $20 \mu \mathrm{l}$ pro Schnitt)

7. Inkubation mit $450 \mu \mathrm{l}$ Label Solution und $50 \mu \mathrm{l}$ Enzyme Solution in einer Feuchtkammer bei $37^{\circ} \mathrm{C}$ für $120 \mathrm{~min}$

8. Waschen in der Stop solution für $10 \mathrm{~min}$

9. dreimaliges Waschen der Schnitte je 5 min im TBS

10. Inkubation mit HRP-konjugiertem Antikörper (12 $\mu \mathrm{l}$ pro Schnitt) in einer Feuchtkammer bei Raumtemperatur für $60 \mathrm{~min}$

11. dreimaliges Waschen der Schnitte je 5 Minuten im TBS

12. Inkubation mit $0,05 \% \mathrm{DAB} / 0,01 \% \mathrm{H}_{2} \mathrm{O}_{2}$ in $40 \mathrm{ml}$ TBS mit $200 \mu \mathrm{l} \mathrm{NiCl}$ für $8 \mathrm{~min}$

13. Waschen in destilliertem $\mathrm{H}_{2} \mathrm{O}$ für 5 min

14. dreimaliges Waschen der Schnitte je 5 min im TBS

15. Vor Eindeckeln mit Immu Mount $10 \mathrm{~min}$ in $0,1 \mathrm{M} \mathrm{PO}$.

\section{TUNEL mit Fluorescein als Chromagen}

1. Fixation in 4\% PFA für 10 min bei Raumtemperatur

2. dreimaliges Waschen der Schnitte je 5 min im TBS

3. Umranden der Schnitte mit PAP-Pen (hydrophobic slide marker)

4. Citratpuffer auf Schnitte für 2 min auf Eis

5. dreimaliges Waschen der Schnitte je 5 min im TBS

6. Inkubation im Equilibration buffer für 1 min bei Raumtemperatur (ca. $20 \mu \mathrm{l}$ pro Schnitt)

7. Inkubation mit $450 \mu \mathrm{l}$ Label Solution und $50 \mu \mathrm{l}$ Enzyme Solution in einer Feuchtkammer bei $37^{\circ} \mathrm{C}$ für $120 \mathrm{~min}$

8. Waschen in der Stop solution für $10 \mathrm{~min}$ 
9. dreimaliges Waschen der Schnitte je 5 min im TBS

10. Inkubation mit HRP-konjugiertem Antikörper (12 $\mu \mathrm{l}$ pro Schnitt) in einer Feuchtkammer bei Raumtemperatur für $60 \mathrm{~min}$

11. dreimaliges Waschen der Schnitte je 5 min im TBS

12. Inkubation mit FITC-konjugiertem Antikörper (12 $\mu$ l pro Schnitt, Intergen) in einer Feuchtkammer bei Raumtemperatur für 30 min

13. dreimaliges Waschen der Schnitte je 5 min im TBS

14. Eindeckeln in Immu-Mount.

\subsection{Immunhistochemie}

\subsubsection{Immunhistochemie gegen BrdU}

Das Protokoll der Färbung:

1. Blockierung der endogenen Peroxidase durch Inkubation der Schnitte in $3 \%$ $\mathrm{H}_{2} \mathrm{O}_{2}$ in $\mathrm{ddH}_{2} \mathrm{O}$ für 15 min bei Raumtemperatur

2. zweimaliges Waschen in PBS für 5 min bei Raumtemperatur

3. Denaturieren der DNA durch Inkubation in $2 \mathrm{M} \mathrm{HCl}$ für $60 \mathrm{~min}$ bei $+37^{\circ} \mathrm{C}$

4. zweimaliges Waschen im PBS für 5 min bei Raumtemperatur

5. Inkubation mit 5\%-igem Kaninchenserum/ 0,3\% Triton X-100 in PBS für 30 min bei Raumtemperatur

6. Inkubation der Schnitte mit anti-BrdU (monoklonal, hergestellt in Ratte; Titer 1:200 in $5 \%$ Kaninchenserum in PBS) für $18 \mathrm{~h}$ bei $+4^{\circ} \mathrm{C}$

7. dreimaliges Waschen in PBS

8. Inkubation mit biotinyliertem anti-Ratte-IgG (1:250) für $60 \mathrm{~h}$ bei Raumtemperatur

9. dreimaliges Waschen der Schnitte je 5 min im PBS

10. Inkubation im Avidin-Biotin-Komplex (ABC-Peroxidase-EliteKit) für $1 \mathrm{~h}$ bei Raumtemperatur

11. dreimaliges Waschen der Schnitte je 5 min im PBS

12. Reaktion mit $0,05 \%$ DAB-Lösung in $0,003 \% \mathrm{H}_{2} \mathrm{O}_{2}$ (in PBS)

13. Stoppen der DAB-Reaktion mit dd $\mathrm{H}_{2} \mathrm{O}$

14. dreimaliges Waschen der Schnitte je 5 min im PBS

15. Eindeckeln in Immu-Mount. 


\subsubsection{Immunfluoreszenz-Doppelfärbungen}

Um die in den Einfachfärbungen ermittelten quantitativen Ergebnisse qualitativ zu belegen, wurden Immunfluoresezenz-Doppelfärbungen durchgeführt. Hierbei wurde einerseits die Fragestellung der neuronenspezifischen Reaktionen durch Doppelfärbungen gegen NeuN (Neuronal nuclear protein) bearbeitet, andererseits wurden durch Doppelfärbungen mit TUNEL (Terminale Desoxynucleotidyl Transferase dUTP Nick End Labeling) die apoptotischen Abläufe spezifiziert. Da die Doppelfärbungen für die qualitative Aufarbeitung der zuvor quantitativ dargestellten Unterschiede zwischen Faim2-defizenten Versuchstieren und Wildtypen genutzt wurde, erfolgte hier keine stereologische Erhebung der Absolutzellzahlen.

\section{Aktive Caspase-3/TUNEL und Aktive Caspase-8/TUNEL}

Zur qualitativen Darstellung der durch Caspase-Aktivierung gesteuerten apoptotischen Vorgänge im endogenen Caspase-Signalweg wurden Immunfluoreszenz-Doppelfärbungen mit gegen aktive Caspase- 3 und aktive Caspase- 8 gerichteten Primärantikörpern in Kombination mit TUNEL-Färbung durchgeführt. Hierzu wurde zunächst die im Abschnitt 2.5.1 auf Seite 36 beschriebene zerebrale Ischämie bei Faim2-nullMutanten und Wildtypen induziert und anschließend wurden die Hirne sowohl für das Färbeverfahren mittels Free-Floating (siehe Abschnitt 2.6.3 auf Seite 43) als auch als Paraffinschnitte aufgearbeitet. Es erfolgte zunächst die Vorbereitung der Schnitte in den Waschkammern und das Aufziehen auf Objektträger bzw. eine Entparaffinierung der Schnitte mit anschließendem zweimaligen Waschen in Aqua dest. für 5 min. Die Paraffinschnitte wurden dann einer hitzeinduzierten Antigendemaskierung in der Mikrowelle unterzogen, indem die Schnitte in mit Citratpuffer $(0,01 \mathrm{M}, \mathrm{pH} 6,0)$ gefüllten Plastikküvetten gestellt und anschließend einmal für 5 min und vier Mal für 10 min bei voller Geräteleistung in der Mikrowelle gekocht wurden. In den Pausen wurde die Plastikküvette mit Aqua dest. nachgefüllt. Nach einstündigem Abkühlen der Schnitte in einem Eisbad erfolgte ein dreimaliger Waschschritt für 5 min in Aqua dest. Das anschließende einmalige Waschen in TBST für 5 min und die einstündige Inkubation mit Blockierungslösung (10\% FCS in TBST) wurde an beiden Schnittarten durchgeführt. Im Folgenden wurde der jeweilige Primärantikörper aufgetragen (Anti-Caspase-3, aktiv/gespalten [1:200 verdünnt in 10\% FCS in TBST] und AntiCaspase-8, aktiv/gespalten [1:1000 verdünnt in 10\% FCS in TBST]) und jeweils über Nacht bei $4^{\circ} \mathrm{C}$ inkubiert. Nach erneutem dreimaligen Waschen in TBST wurde der

Sekundärantikörper (Anti-Kaninchen IgG [H+L], Alexa Fluor ${ }^{\circledR}$ 488; 1:200 verdünnt 
in 10\% FCS in TBST) aufgetragen und für zwei Stunden bei Raumtemperatur inkubiert. Nach dreimaligem Waschen in TBST erfolgten nun die Gegenfärbung nach der TUNEL-Methode (vgl. Abschnitt 2.6.6 auf Seite 47), eine Kernfärbung mit Hoechst 33258 für 10 min, Spülen in Aqua dest. und anschließend die Eindeckelung mit ImmuMount. Für Negativkontrollen wurde der Primärantikörper bei ansonsten identischem Protokoll weggelassen.

\section{TUNEL/NeuN}

Die Doppelfärbung von TUNEL und NeuN erfolgte analog zum vorgenannten Prozedere. Ziel war es zu identifizieren, ob es sich bei den apoptotischen Zellen auch tatsächlich um neuronale Zellen handelte. Hierzu wurde gegen ein neuronales Kernprotein gefärbt. Die verwendeten Gehirnschnitte waren zuvor mittels Paraffinschnittechnik aufgearbeitet worden (vgl. Abschnitt 2.6.3 auf Seite 43). Die Entparaffinierung, hitzeinduzierte Antigendemaskierung, Inkubation in Blockierungslösung, Kernfärbung mit Hoechst 33258, Eindeckelung und die jeweiligen Waschschritte entsprachen der bereits zuvor geschilderten Vorgehensweise. Es erfolgte zuerst die TUNEL-Färbung wie in Abschnitt 2.6.6 auf Seite 47 mit Fluorescein als Chromagen beschrieben. Nach Lagerung bei $4^{\circ} \mathrm{C}$ über Nacht, wurde mit dem Primärantikörper gegen NeuN (1:100 verdünnt in 10\% FCS in TBST) 90 min bei Raumtemperatur inkubiert und für die Farbentwicklung ein Sekundärantikörper (Anti-Maus IgG [H+L], Alexa Fluor@ 555, 1:200 verdünnt in 10\% FCS in TBST; 120 min Inkubation bei Raumtemperatur) eingesetzt. Für Negativkontrollen wurde der Primärantikörper bei ansonsten identischem Protokoll weggelassen.

\section{Aktive Caspase 3/NeuN und Aktive Caspase 8/NeuN}

Sowohl die Färbeprotokolle als auch die verwendeten Antikörper sind analog zu den beiden vorgenannten Doppelfärbungen verwendet worden. Es wurde zunächst die Caspase-Färbung durchgeführt und als Gegenfärbung die NeuN-Färbung.

\section{GFP/NeuN-, GFP/GFAP- und GFP/Iba-1-Doppelfärbungen an Adeno- und Lentiviruskonstrukten im Vergleich}

Zur Identifizierung sowohl des geeigneten Viruskonstrukts als auch der notwendigen Viruskonzentration im Injektionsvolumen der stereotaktischen Injektion wurden neuronale Zellen im Striatum durch das Faim2-Adenvirus-Konstrukt und Faim2Lentivirus-Konstrukt (vgl. Reich et al. 2011) mittels stereotaktischer Injektion (siehe 
Abschnitt 2.5.2 auf Seite 38 mit dem Faim2-Virus-Konstrukt infiziert und die Schnitte mit drei Doppelfärbungen aufgearbeitet. Dabei wurde zunächst mittels einer NeuN Doppelfärbung mit dem grün-fluoreszierenden Protein (GFP-pAd bzw. GFP-pLenti) das Virus in den neuronalen Zellen nachgewiesen. Anschließend wurde zur Kontrolle GFP-pAd bzw. GFP-pLenti mit dem gliazellenspezifischen Protein GFAP ( Glial fibrillary acidic protein) gegengefärbt. Ebenfalls zur Kontrolle wurde mit dem mikrogliaund makrophagenspezifischen Iba-1 (Ionized calcium binding adaptor molecule 1) gegengefärbt, um die spezifische Infektion der Neuronen zu bestätigen. Abschließend erfolgte eine Färbung mit dem Faim2-Antikörper der Firma LifeSpan BioScience Inc., Seattle, USA.

Die Abbildungen 3.14 auf Seite 68 und 3.15 auf Seite 69 zeigen die jeweiligen Ergebnisse der zuvor genannten Färbungen. Dabei zeigt sich im Vergleich zwischen Lentiund Adenovirus eine signifikant stärkere Destruktion des Hirngewebes allein durch die Aggressivität des Adenovirus. Auf Grund dieser Ergebnisse wurden die weiteren Färbungen nur noch mit dem Faim2-Lentivirus-Konstrukt durchgeführt.

\subsection{Verhalten}

Die Induktion eines einseitigen Ischämieareals sollte nicht nur histologisch nachgewiesen, sondern auch klinisch erfasst werden. Dazu wurde der von Herrn Shirley B. Shelton im Jahr 2008 veröffentlichte sog. SNAP-Score verwendet. SNAP steht für Simple Neuroassessment of Asymmetric Impairment. Hierdurch konnten die klinischen Auffälligkeiten vor und nach der Ischämie erhoben werden. Zeigte ein Tier keine oder nur geringe Unterschiede zwischen den beiden Zeitpunkten, war die zerebrale Ischämie in der Regel nicht erfolgreich eingetreten.

\subsubsection{SNAP-Score-Erhebung}

Wie von Shelton et al. (2008) beschrieben, eignet sich der SNAP-Score, um effizient und sensitiv ein einseitiges neurologisches Defizit klinisch zu dokumentieren. Hierzu wurden die Tiere unmittelbar vor und 2 Stunden nach Ende der Isofluran-Narkose wie in Tabelle 8.5 auf Seite 131 im Anhang in Abschnitt 8.8 detailliert aufgezeigt, klinisch beurteilt. Ein Tier ohne neurologisches Defizit sollte einen SNAP Score von 0 erreichen, ab einem Score von 2-5 war ein neurologisches Defizit zu erwarten (Shelton et al. 2008). 


\subsection{Statistische Methodik}

Die erhobenen Daten wurden zunächst in Excel 2004 zusammengefasst und aufgearbeitet. Die statistische Aufarbeitung erfolgte mittels GraphPad Prism (Version 5.00) und graphisch als Säulendiagramme mit errechnetem Mittelwert sowie Standardfehler des Mittelwerts (standard error of the mean, SEM) angegeben.

In den meisten Fällen wurden zwei Gruppen analysiert. Hierbei wurde der Student's t-Test für unverbundene Stichproben verwendet. In Einzelfällen wurden durch Varianzanalysen mehr als zwei Gruppen miteinander verglichen. Im Falle eines zu untersuchenden Faktors wurde der One-way ANOVA, bei zwei zu untersuchenden Faktoren der Two-way ANOVA, mit anschließendem post-hoc-Test für multiple Vergleiche zum Nachweis von Gruppenunterschiedlichkeiten verwendet. Um die Kontrollgruppen mit den Interventionsgruppen zu vergleichen, wurde bei einfaktorieller Varianzanalyse der Dunnett's post-hoc-Test und nach zweifaktorieller Varianzanalyse bei verbundenen Stichproben der Bonferroni bzw. beim Vergleich von überspannten Mittelwerten der Tukey post-hoc-Test angewendet. Im Falle der Signifikanzanalyse des ordinalskalierten SNAP-Scores wurde zunächst die Kruskal-Wallis-one-way-Analyse angewendet, gefolgt vom Dunn's-Multiple-Comparison-Test.

Als signifikant wurden $p-$ Werte $<0,05$ angenommen $\left({ }^{*} p<0,05 ;{ }^{* *} p<0,01\right)$, soweit nicht anders angegeben. 


\section{Ergebnisse}

\subsection{Charakterisierung des Proteins Faim2}

\subsubsection{Expression von Faim2 im Organismus}

Im Rahmen seiner antiapoptotischen Funktion greift Faim2 in hemmender Wirkung des Fas/CD95-Signalwegs in die endogenen Regulationsmechanismen neuronaler Zellen ein. Wie in Abschnitt 1.2 auf Seite 11 aufgezeigt, wurde von mehreren Autoren jedoch Faim2 auch in anderen Organen und Zellen nachgewiesen und ihm dort die hemmende Wirkung des Fas/CD95-Transduktionssystems zugeschrieben. Während Somia et al. (1999) mittels Northern-Blotting Faim2-mRNA in multiplen humanen Organen nachweisen konnten, zeigten Fernandez et al. (2007) mittels quantitativer RT-PCR die Expression von Faim2 primär nur in neuronalen Zellen auf.

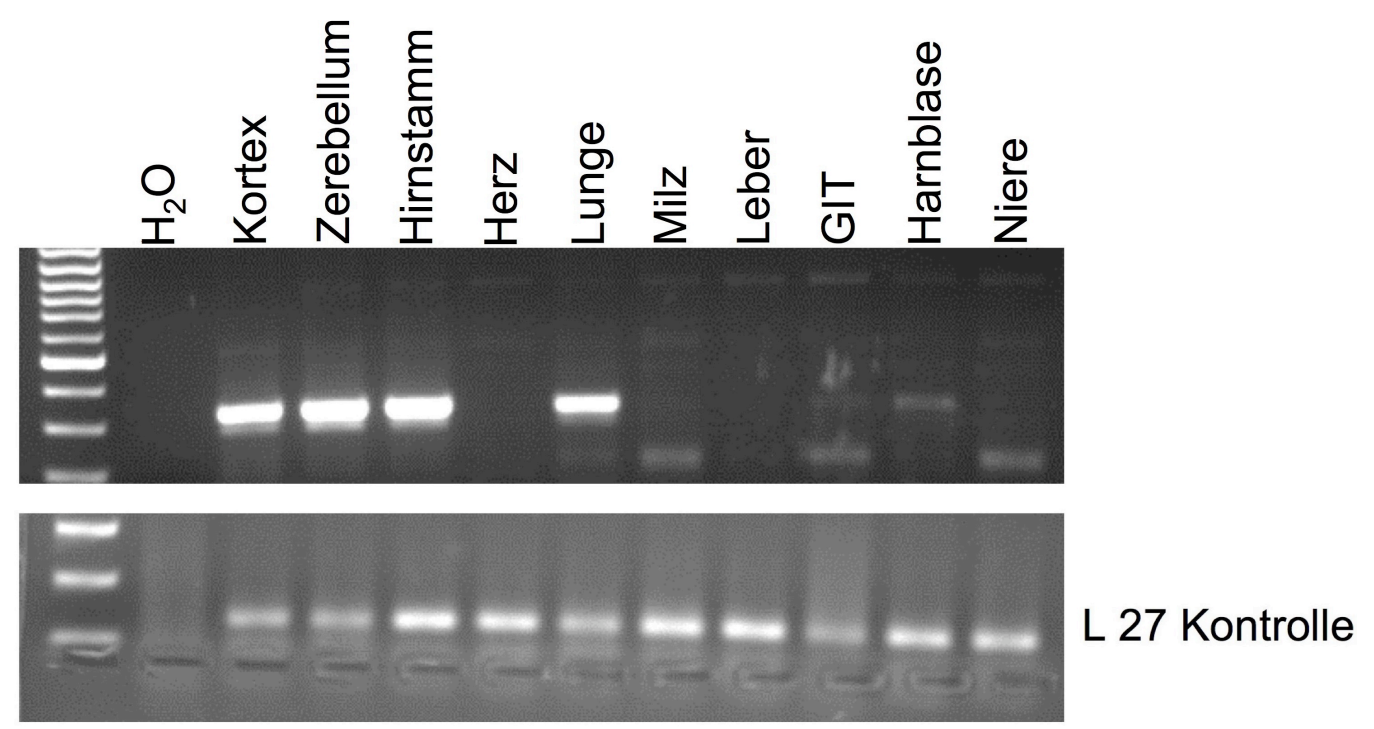

Abbildung 3.1: Expression von Faim2 in verschiedenen Organen und Geweben der Maus. Mittels RT-PCR wurde die RNA amplifiziert. Als Kontrolle diente das in den Mitochondrien lokalisierte ribosomale Protein L 27. Eindeutig gelang der Nachweis von Faim2 im zerebralen Kortex, Zerebellum, Hirnstamm und der Lunge. Ein sehr schwaches Signal konnte in der Harnblase erfasst werden, das fraglich schwache Signal im GIT konnte in repetitiven Versuchen ausgeschlossen werden. In Herz, Milz, Leber und Niere war Faim2 nicht nachweisbar. 
Auf Grund dieser Zusammenhänge haben wir neben neuronalem Gewebe multiple Gewebeproben in der Maus auf Faim2-Expression untersucht. Die Abbildung 3.1 zeigt die basale Expression von Faim2 in verschiedenen Geweben und Organen ohne Einfluss durch eine Ischämie. Dabei gelang mittels quantitativer RT-PCR ein sicherer Nachweis von Faim2 im zerebralen Kortex, Zerebellum, Hirnstamm und der Lunge. Schwächere Signale konnten ebenfalls in der Harnblase und im Gastro-Intestinal-Trakt (GIT) erfasst werden, welche jedoch in repetitiven Versuchen nicht mehr nachweisbar waren. In Herz, Milz, Leber und Niere war Faim2 nicht nachweisbar.

\subsubsection{Zeitliche Regulation von Faim2 und Fas/CD95 nach zerebraler Ischämie}

Die Regulation des Fas/CD95-Rezeptors und die Regulation von Faim2 wurde mittels Expressionsanalyse durch quantitativer real time PCR nach zerebraler fokaler Ischämie untersucht. Dazu wurde zunächst eine MCAo durchgeführt und das ischämische Hirngewebe an den Zeitpunkten 0, 3, 18 und 48 Stunden nach 30-minütiger Ischämie entsprechend aufbereitet und anschließend mittels real time PCR analysiert.

Faim2

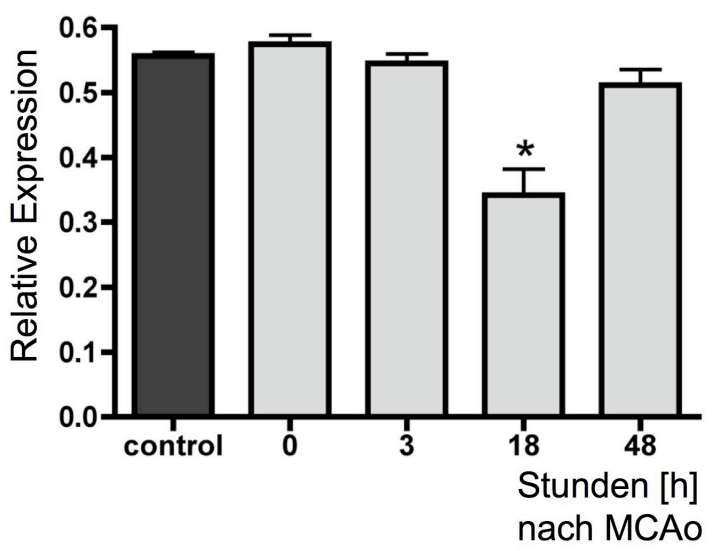

Fas/CD95

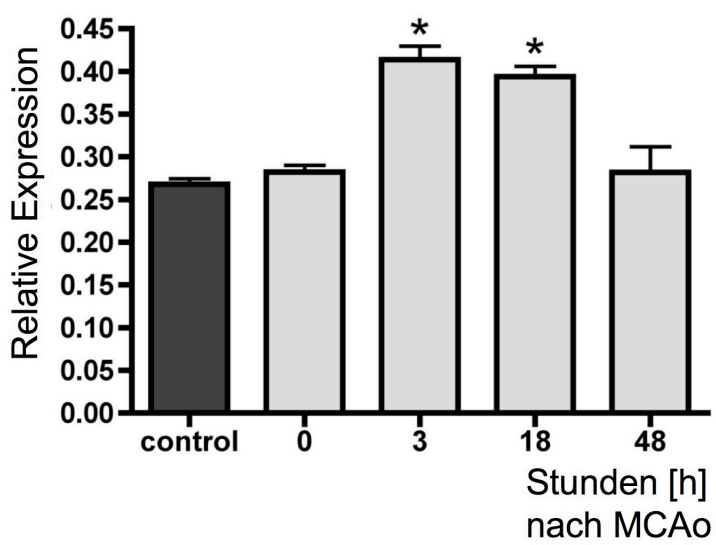

Abbildung 3.2: Expression von Faim2- und Fas/CD95-mRNA im zeitlichen Verlauf nach 30minütiger MCAo. Das Hirngewebe wurde nach 3-, 18-, und 48-stündiger Reperfusion entnommen und mittels real time PCR analysiert. Dabei diente die kontralaterale (nicht-infarzierte Hirnhemisphäre) als Kontrolle. Die Grafiken zeigen eine signifikante Hochregulation von Fas/CD95 während 3 bis 18 Stunden nach fokaler zerebraler Ischämie. Gleichzeitig wird Faim2 in der Zwischenzeit signifikant herunter reguliert und erreicht ein Minimum bei 18 Stunden nach fokaler zerebraler Ischämie. Nach 48 Stunden erreichen beide Moleküle wieder den Ausgangswert. 5 Versuchstiere wurden pro Zeitpunkt untersucht und jeweils drei wiederholende Messungen durchgeführt. Die Daten sind als Mittelwerte $\left( \pm\right.$ SEM) dargestellt. Signifikanzanalyse: ${ }^{*} p<0,001$ ipsilaterale Hemisphäre vs. Kontrolle (Zeitpunkte $18 \mathrm{~h}$ bzw. $3 \mathrm{~h}$ und $18 \mathrm{~h}$ ). 
Die Abbildung 3.2 auf der vorherigen Seite gibt die aus dieser Untersuchung erhobene inverse Regulation von Faim2 und Fas/CD95 wieder. Dabei ist zu erkennen, dass der Fas/CD95-Rezeptor zwischen 3 und 18 Stunden nach 30-minütiger zerebraler Ischämie um ca. $50 \%$ hochreguliert ist, während Faim2 zum Zeitpunkt von 18 Stunden nach Ischämie signifikant herunter reguliert ist. Faim2 verbleibt bis einschließlich drei Stunden nach dem Ischämieereignis auf dem Ausgangsniveau und lässt erst zwischen 3 und 18 Stunden nach MCAo eine Änderung der Expression erkennen. Zum Zeitpunkt von 48 Stunden Reperfusionszeit nach Ischämie erreichen beide Proteine erneut nahezu den Ausgangswert. Als Kontrolle diente in diesem Versuch die kontralaterale, von der Ischämie nicht beeinflusste Gehirnhemisphäre.

\subsection{Einfluss von Faim2 während milder fokaler zerebraler Ischämie}

Zunächst wurden Faim2-defiziente Versuchstiere und Wildtypen der 30-minütigen Okklusion der A. cerebri media (sog. milde Ischämie) unterzogen, um folgend das topisch-anatomische, das zeitliche und das histologische Profil des Infarktareals zu untersuchen. Durch Vorarbeiten von Endres et al. (1998a) war bekannt, dass in der milden Ischämie nach 30-minütiger Okklusionszeit der maximale Zelluntergang nach einer Reperfusionszeit von 72 Stunden zu beobachten ist. Hinsichtlich der Quantität apoptotischer Zellen spielt insbesondere das direkt um die Infarktzone liegende Areal, die sog. Penumbra, eine wichtige Rolle, während zu späteren Zeitpunkten auch in diesem Areal die Anzahl apoptotischer Zellen wieder abnimmt (Endres et al. 1998a). Aufgrund dieser Vorüberlegungen wurde das Reperfusionszeitintervall nach MCAOkklusion auf 72 Stunden festgelegt.

Stichprobenartig wurden jeweils 2 von 8 Versuchstieren während der Versuchsreihen auf physiologische Parameter untersucht, sodass ein Unterschied in arteriellem Blutdruck, Herzfrequenz, Temperatur, pH-Wert, Sauerstoffpartialdruck $\left(\mathrm{pO}_{2}\right)$ und Kohlenstoffdioxidpartialdruck $\left(\mathrm{pCO}_{2}\right)$ zwischen Faim2 $2^{-/-}$und Faim2 ${ }^{+/+}$ausgeschlossen werden konnte (siehe Tabelle 3.1 auf der nächsten Seite. Es ist zu erkennen, dass zwischen den Versuchsgruppen zu keinem Zeitpunkt signifikante Unterschiede bzgl. der Hämodynamik, respiratorischen Funktion und des pH-Wertes bestanden.

Das zeitliche Profil des Einflusses von Faim2 während der fokalen zerebralen Ischämie wurde in Abschnitt 3.1 .2 und Abbildung 3.2 auf der vorherigen Seite beschrieben.

Zur topisch-anatomischen Untersuchung wurden die Gehirne zunächst nach Ablauf 
Tabelle 3.1: Physiologische Parameter der Faim2 $2^{-/-}$- und Faim2 $2^{+/{ }^{-}}$Versuchstiere im Vergleich

\begin{tabular}{lll}
\hline & Faim2 $^{+/+}$ & Faim2 $^{-/-}$ \\
\hline art. Blutdruck (basal) & $90,8 \pm 1,9$ & $93,4 \pm 4,0$ \\
art. Blutdruck (MCAo) & $95,3 \pm 3,7$ & $92,1 \pm 4,3$ \\
pH (MCAo) & $7,3 \pm 0,01$ & $7,31 \pm 0,02$ \\
$\mathrm{pCO}_{2}(M C A o)$ & $41,4 \pm 2,9$ & $41,7 \pm 2,2$ \\
$\mathrm{pO}_{2}(M C A o)$ & $97,9 \pm 7,4$ & $94,4 \pm 5,0$ \\
\hline
\end{tabular}

der 72-stündigen Reperfusion in $20 \mu \mathrm{m}$ starke koronare Sektionen mit dem Kryostaten geschnitten und anschließend mittels HE-Färbung (vgl. Abschnitt 2.6 .4 auf Seite 43 aufgearbeitet. Bereits makroskopisch ist mit dieser Methode das Ischämieareal zu erkennen (Abbildung 3.3 auf der nächsten Seite). Um das Infarktareal weiter zu charakterisieren und die Größe zu quantifizieren, wurde eine computergestützte Volumetrie durchgeführt (vgl. Abschnitt 2.6.5 auf Seite 44).

Ein wichtiger Faktor bei der Auswertung der Infarktgröße war der Ödemindex, da die ischämische (ipsilaterale) Hirnhemisphäre proportional zur Infarktgröße ödematös aufgetrieben ist. Um die ödematöse Schwellung des Hirngewebes jedoch nicht in die Volumetrie des Infarkts einzubeziehen, fungierte die kontralaterale Hirnhemisphäre als Referenz. Der daraus errechnete Ödemindex $\mathrm{E}_{\text {Index }}$ ermöglichte die Darstellung des tatsächlichen Infarktvolumens ohne Ödemanteil. Die Berechnung ist in Formel 2.5 in Abschnitt 2.6.5 auf Seite 44 dargestellt.

Die weitere histologische Aufarbeitung erfolgte zum einen über bekannte zelluläre Marker wie TUNEL-Färbung, 5-Bromo-2'-desoxy-Uridin (BrdU) und Caspase-8 und -3 , die jeweils spezifisch unterschiedliche Stadien der zellulären Aktivität bzw. Abschnitte in der Apoptose-Transduktion anzeigen und zum anderen über neuronenspezifische Marker wie das Neuron-specific nuclear protein (NeuN). Während des stereotaktischen lentiviralen Gentransfers mit einem rekombinanten Lentivirus wurden zur Bestätigung der selektiven neuronalen Infektion zusätzlich zytologische Marker, wie das mikroglia- und makrophagenspezifische Iba-1 (Ionized calcium binding adaptor molecule 1) oder das gliazellenspezifische Protein GFAP (Glial fibrillary acidic protein), verwendet. 

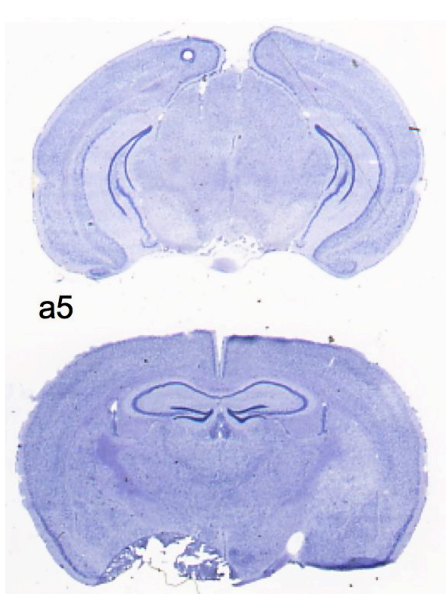

a4

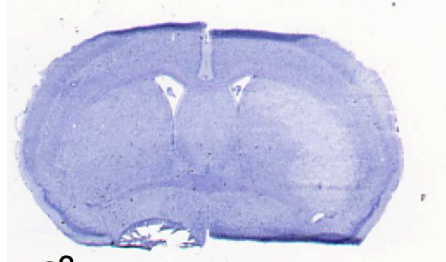

a3

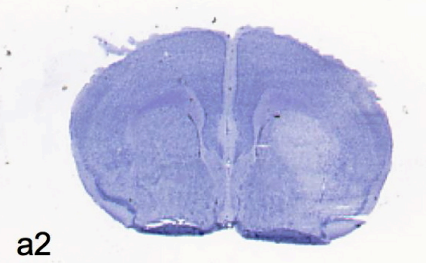

a1

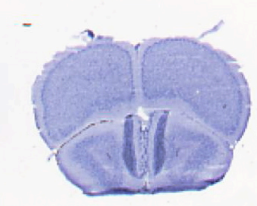

Abbildung 3.3: Makroskopische Darstellung des Infarkareals mittels HE-Färbung nach MCAo. In der linken Hemisphäre ist ab a2 bis a4 das Ischämieareal (aufgehellter Bereich) im Striatum bis in den Kortex (a3 und a4) reichend zu erkennen.

\subsubsection{Vergrößertes Infarktvolumen bei Faim2-Defizienz}

Nach milder zerebraler fokaler Ischämie zeigte sich, nach dem Schneiden der Gehirne im Kryostaten und anschließender Aufarbeitung der Hirnschnitte mittels HEFärbung, in der computergesteuerten Volumetrie bei den Faim2-defizienten Tieren $(n=11)$ im Vergleich zu den Wildtypen $(n=8)$ ein signifikant größeres Infarktareal. In wiederholten Versuchsreihen (jeweils $n=9$ ) bestätigte sich das signifikant größere 
Infarktvolumen bei Faim2-Defizienz. Die Abbildung 3.4 zeigt den bereits makroskopisch erkennbaren Unterschied zwischen Faim2 $2^{-/-}$und Faim ${ }^{+/+}$. Mit der Größe des

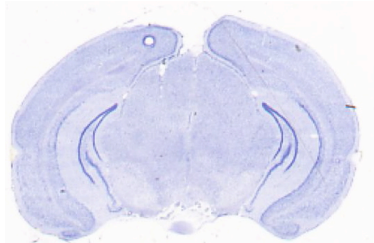

a5
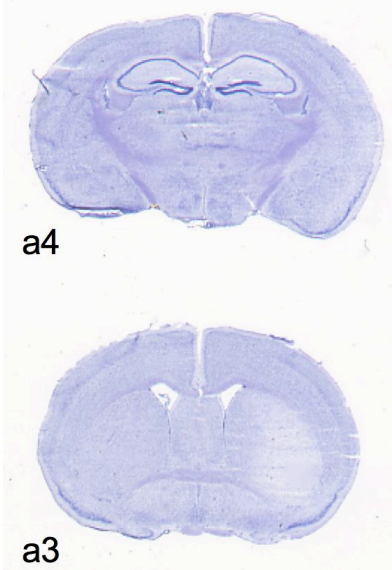

a3

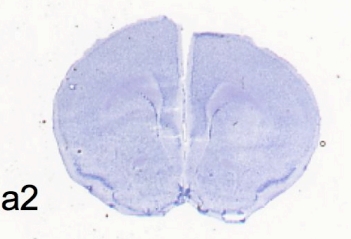

a1

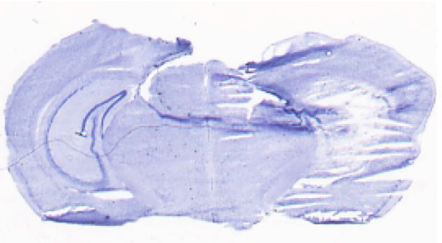

a5
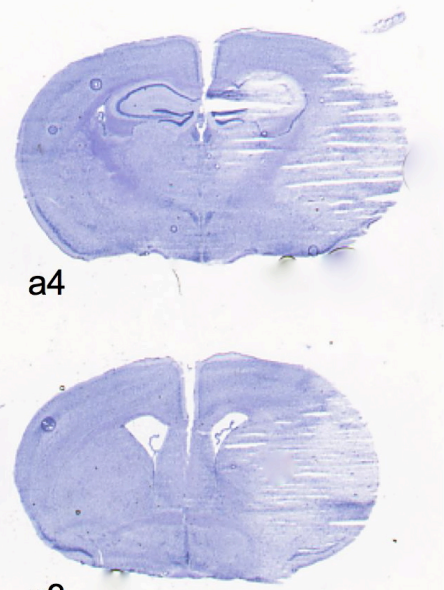

a3

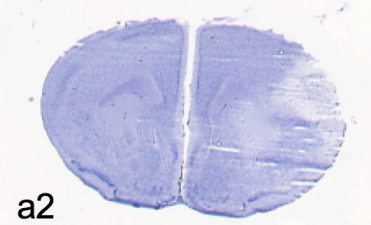

a1

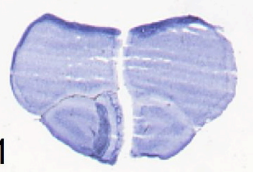

Abbildung 3.4: Infarktvolumen von Faim2 $2^{+/+_{-}}$(links) und Faim2 $2^{-/-}$-Versuchstieren (rechts) nach milder fokaler zerebraler Ischämie. Das Ausmaß des Infarktareals ist bei Faim2-/- stärker ausgeprägt. Die Gewebetextur wird aufgrund des ebenfalls ausgeprägteren Ödems weicher und lockerer, daher erscheinen insbesondere die Sektionen a4 und a5 zum Teil zerrissen. Die Ausbreitung des Infarkts in den umliegenden Kortex ist zu erkennen. Weiterhin zeigt sich eine Ausbreitung in die Hippokampusregion.

(modifiziert publiziert in Reich et al. 2011, S. 230)

Infarktvolumens stieg auch der Umfang des Ödems und die damit verbundene Schwellung der infarzierten Gehirnhemisphäre. Dies ist an der Gewebetextur in den gezeigten Schnitten, insbesondere Sektionen a4 und a5, zu erkennen. Die ödembedingte 
Vulnerabilität des Gewebes erschwerte die histologische Aufarbeitung, sodass teilweise Geweberisse beim Schneiden mit dem Kryostaten auftraten. Die makroskopische Ausbreitung des Infarkts in den umliegenden Kortex war bei den Faim2-defizienten Versuchstieren zu erkennen, während eine derartige Infarktausdehnung bei den Wildtypen nicht beobachtet werden konnte. Weiterhin zeigte sich eine Ausbreitung in die Hippokampusregion, die normalerweise zumindest zusätzlich von der A. cerebri posterior versorgt wird. Die Ausbreitung des Schlaganfalls bis in die Hippokampusregion konnte bei ca. der Hälfte der Faim2-/-_Mäuse beobachtet werden.

Die Infarktflächen auf den jeweiligen koronaren Sektionen a1-a5 (vgl. Abbildung 8.4 in Abbschnitt 8.7 auf Seite 128 weisen deutliche Unterschiede bzgl. der Ausdehung und Größe auf. Signifikant größer ist die Infarktfläche bei Faim2 ${ }^{-/}{ }^{-}$-Versuchstieren $(p=0,001)$ auf Sektionsebene in Sektion a2 (Abbildung 3.5). Vergleicht man die-

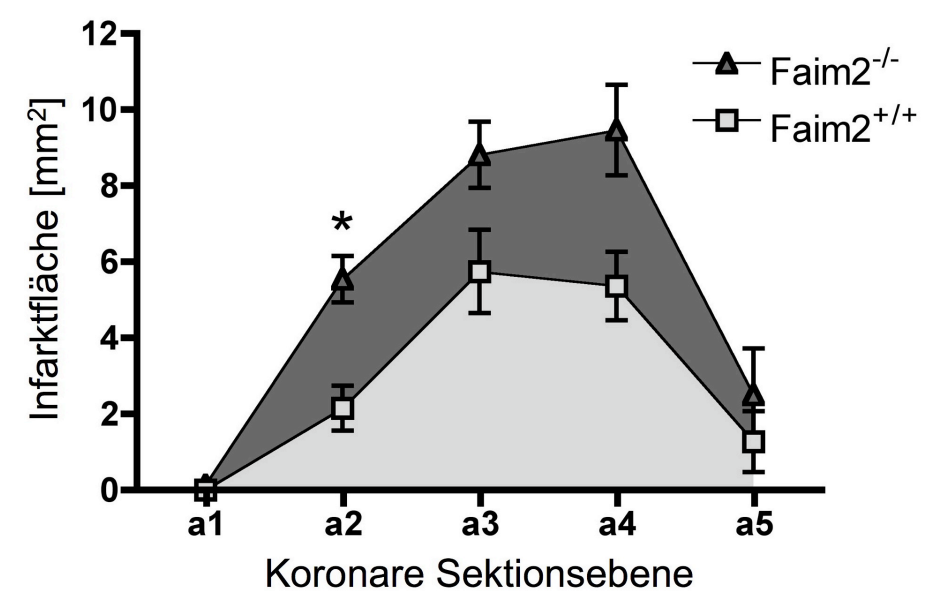

Abbildung 3.5: Vergleich der Infarktflächen der jeweiligen koronaren Sektionen bei Faim2 $2^{+/+}$ $(n=11)$ und Faim $2^{-/}$-Versuchstieren $(n=9)$ nach milder fokaler zerebraler Ischämie. Bei der Signifikanzanalyse mittels One-way ANOVA wird in Sektion a2 eine Signifikanz $\left({ }^{*} p=0,01\right)$ errechnet. Für die restlichen Sektionen wird eine deutliche Tendenz, aber keine Signifikanz erreicht.

se Beobachtungen mit den Beobachtung des Infarktareals bei ansonsten vollständig gesunden Tieren aus Versuchsreihen zu unterschiedlichen Okklusionszeiten von der Arbeitsgruppe von Prof. M. Endres der Klinik für Neurologie der Charitè Universitätsmedizin Berlin, ist das Ausmaß der Infarktgröße bei Tieren, die einer 30-minütige Okklusionszeit der A. cerebri media und anschließend 72 Stunden Reperfusion unterzogen worden sind, äquivalent mit denen des Faim2-Wildtypen. Eine Ausbreitung in die Hippokampusregion und in den Kortex wurde bei 30-minütiger Okklusionszeit in großen Wildtypkontrollkollektiven nicht beobachtet. Bei längeren Okklusionszeiten der A. cerebri media, die im Rahmen von Vorversuchen der vorliegenden Arbeit 
durchgeführt worden sind, zeigte sich nur bei 1 von 5 Versuchstieren ein derartig ausgeprägtes Infarktareal, nachdem das Filament für 72 Stunden (bis zur Dekapitation) in der Position an der A. cerebri media belassen und somit die Ischämiezeit von 30 Minuten auf 72 Stunden erhöht worden war (Modell der permanenten Okklusion). Die restlichen 4 Tiere wiesen zwar vergrößerte Infarktareale auf, diese waren jedoch nahezu vollständig auf das Striatum und nur teilweise den umgebenden Kortex in Sektion a3 beschränkt. Die ödematöse Hirnschwellung der infarzierten Hemisphäre war ebenfalls vergrößert.

Die Grafik 3.6 zeigt den signifikanten Unterschied $(p=0,0009)$ der Infarktvolumina mit einem Mittelwert von $20,81 \mathrm{~mm}^{3} \pm 2,97$ bei Faim2 ${ }^{+/+}$-Versuchstieren und $42,21 \mathrm{~mm}^{3} \pm 3,99$ bei Faim2 $2^{-/-}$-Tieren.

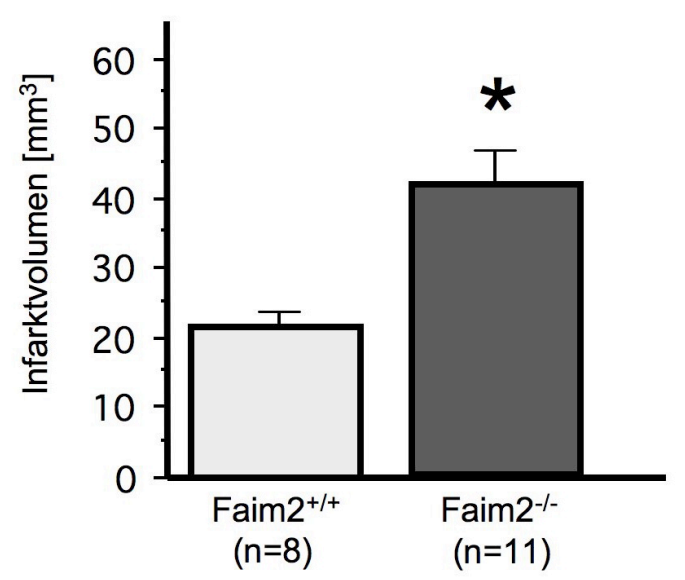

Abbildung 3.6: Grafik des Infarktvolumens von Faim $2^{-/-}-(n=11)$ und Faim $2^{+/+_{-} \text {Tieren }}(n=8)$ nach milder fokaler zerebraler Ischämie; Signifikanzanalyse: ${ }^{*} p=0,0009$

\subsubsection{Histologische Veränderungen im Infarktareal}

Als Marker für die Ausarbeitung des histologischen Profils im ischämisch-geschädigten Infarktareal, wurde die in-situ-Markierung der nukleären DNA-Fragmentation mit TUNEL-Färbung (siehe Abschnitt 2.6.6 auf Seite 47) gewählt. Hierdurch können Doppelstrangbrüche in der DNA detektiert werden (Gavrieli et al. 1992) und insbesondere bei der Detektion des verzögerten Zellschadens valide Daten zur Darstellung von in Apoptose befindlichen Zellen erhoben werden (Du et al. 1996, Endres et al. 1998a). Da diese Methode eine breite Anwendung zur Detektion von ischämisch-bedingtem Zellschaden findet, wurde sie in einer Reihe von Studien kritisch evaluiert (CharriautMarlangue und Ben-Ari 1995, Labat-Moleur et al. 1998). In den vorliegenden Aus- 
wertungen wurden lediglich Zellen mit einem starken nukleären TUNEL-Signal sowie kondensiertem Chromatin als positiv gewertet. Zellen mit fehlendem oder einem schwachen zytoplasmatischen bzw. schwachen nukleären Signal wurden als TUNELnegativ gewertet.

Die Abbildung 3.7 zeigt den Vergleich der Infarktausdehnung zwischen Faim2-defizienten Versuchstieren und Wildtypen hinsichtlich TUNEL-positiver Zellen. Bei Faim2Defizienz ist eine deutlich größere Ausdehnung des Apoptoseareals zu erkennen, welches sich über das Striatum hinausreichend bis in den umliegenden Kortex erstreckt.
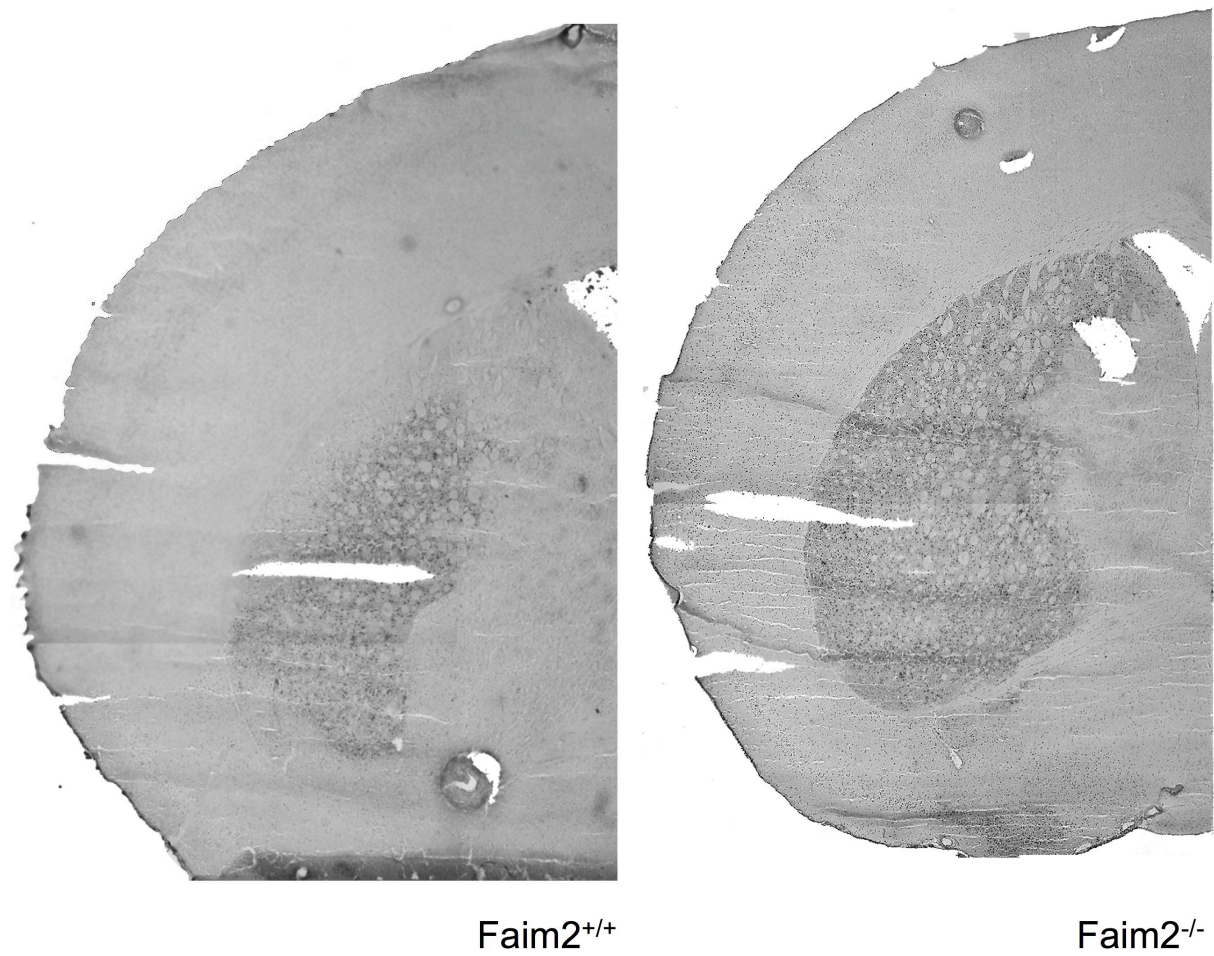

Abbildung 3.7: Darstellung des Infarktareals anhand TUNEL-positiver Zellen eines Faim2defizienten Tieres und eines Wildtyps im Vergleich. Mittels DAB sind die TUNEL-positiven Zellen sichtbar gemacht worden. Die schwarzen punktförmigen Strukturen weisen auf eine TUNEL-positive Zelle hin. Bei Faim2-Defizienz ist eine deutlich größere Anzahl und vergrößerte Ausdehnung (bis in den umliegenden Kortex reichend) des apoptotischen Areals zu erkennen.

Die absolute Anzahl und die Dichte der apoptotischen Zellen in der infarzierten Hemisphäre (inkl. Kortex) wurde stereologisch bestimmt und ist in Abbildung 3.8 auf der nächsten Seite dargestellt. Diese beschreibt den signifikanten Unterschied im Vergleich zwischen Faim2-defizienten Tieren und Wildtypen. Danach leiten signifikant mehr Zellen die Apoptose ein, wenn Faim2 als Inhibitor der Apoptose-Signaltransduktion fehlt. 
In den Abbildungen 3.8 und 3.9 ist die Dichte der TUNEL-positiven Zellen im In-
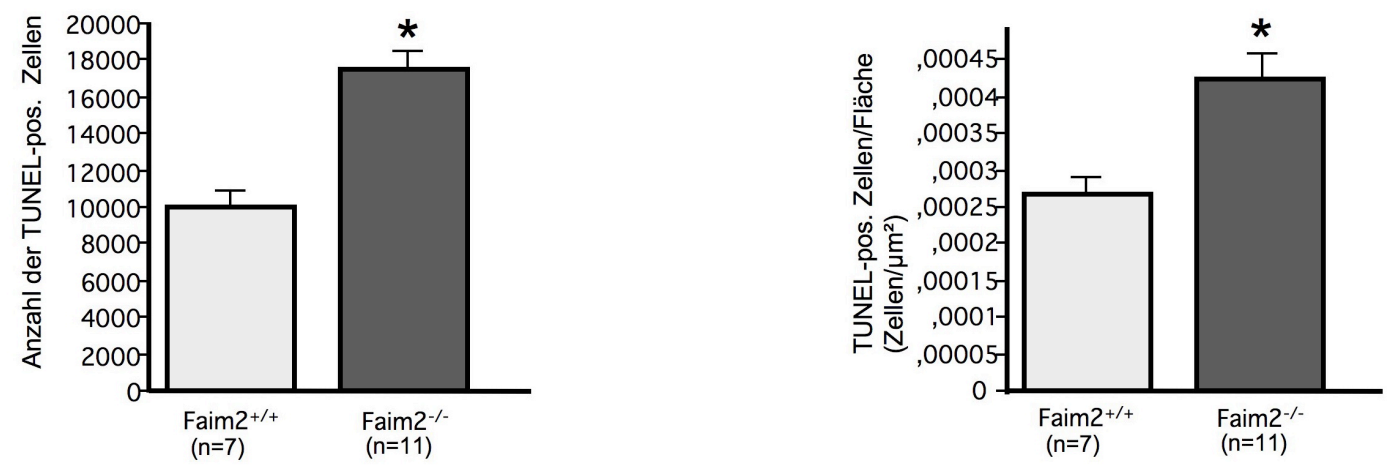

Abbildung 3.8: Vergleich zwischen Faim2-defizienten Tieren und Wildtypen bzgl. der absoluten Anzahl TUNEL-positiver Zellen in der infarzierten Hemisphäre (Grafik links) und Dichte der TUNEL-positiven Zellen in der infarzierten Hemisphäre (Grafik rechts). TUNEL-positive Zellen/Hemisphäre: Faim2 ${ }^{+/+}: 10030 \pm 815,1(\mathrm{n}=7)$, Faim2 ${ }^{-/-}: 17550 \pm 890,3(\mathrm{n}=11)$; Signifikanzanalyse: ${ }^{*} p<0,0001$ (Grafik links); ${ }^{*} p=0,003$ (Grafik rechts)

farktareal dargestellt. Die bereits oben angesprochene signifikant erhöhte Dichte apoptotischer Zellen im Infarktareal der Faim2-defizienten Versuchstiere im Vergleich zu den Wildtypen, ist hier deutlich zu erkennen. Somit ist die stereologisch gemessene

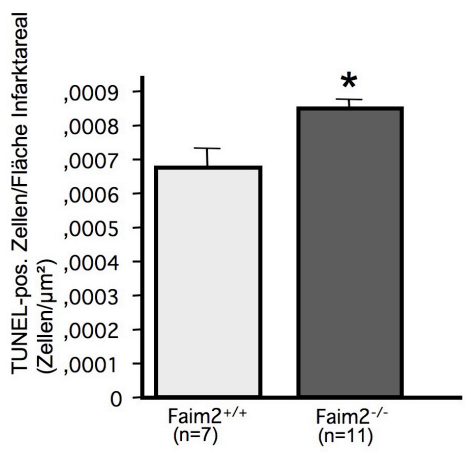

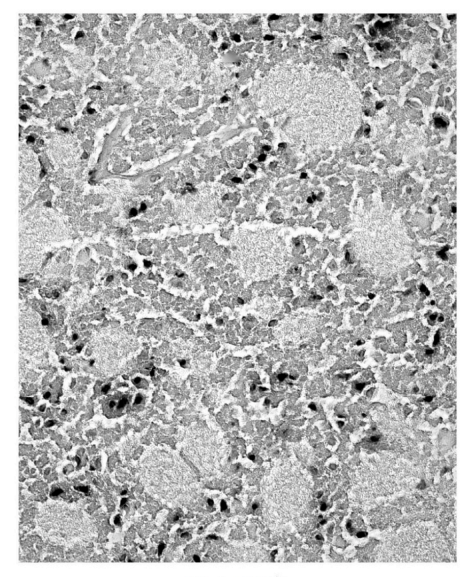

Faim $2^{+/+}$

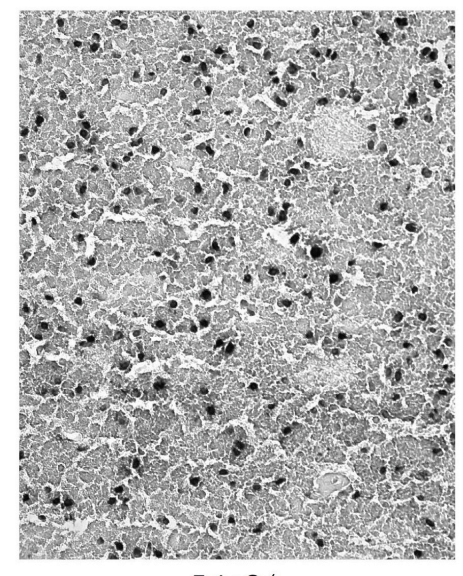

Faim $2^{-1-}$

Abbildung 3.9: Vergleich zwischen Faim2-defizienten Tieren und Wildtypen bzgl. der Dichte TUNEL-positiver Zellen im Infarktareal. Die Grafik links zeigt den signifikanten Dichteunterschied apoptotischer Zellen im Infarktareal. Die beiden Bildausschnitte rechts geben die Dichte im Striatum des Infarktareals wieder. Mittels DAB wurden hier die TUNEL-positiven Zellen schwarz eingefärbt. TUNEL-positive Zellen $/ \mathrm{mm}^{3}$ Infarkt x 104: Faim $2^{+/+}: 0,3364 \pm 0,0287(\mathrm{n}=7)$, Faim2 $2^{-/-}: 0,4252$ $\pm 0,0129(\mathrm{n}=11)$, Signifikanzanalyse: ${ }^{*} p=0,0057$

absolute Anzahl apoptotischer Zellen nicht nur aufgrund der Ausbreitung der Fläche 
in der infarzierten Hemisphäre bei Faim2-Defizienz erhöht, sondern auch aufgrund ihrer Dichte innerhalb des Infarktareals.

Zur genaueren Untersuchung des Ausmaßes der Schädigung und zur Charakterisierung des Zellprofils wurden die Schnitte weiter histologisch und immunhistochemisch aufgearbeitet. Um den Zelltyp der apoptotischen Zellen zu identifizieren, wurden Doppelfärbungen gegen TUNEL und einen zellspezifischen Marker verwendet. Für den Nachweis von Neuronen kam dabei das in adulten Neuronen exprimierte Neuronspecific nuclear protein (NeuN) zum Einsatz. Die Abbildung 3.10 zeigt die Doppelfärbung gegen TUNEL/NeuN im Vergleich Faim2-defizienter Tiere und Wildtypen. In den beiden unteren Bildabschnitten sind Neurone mittels NeuN grün angefärbt.

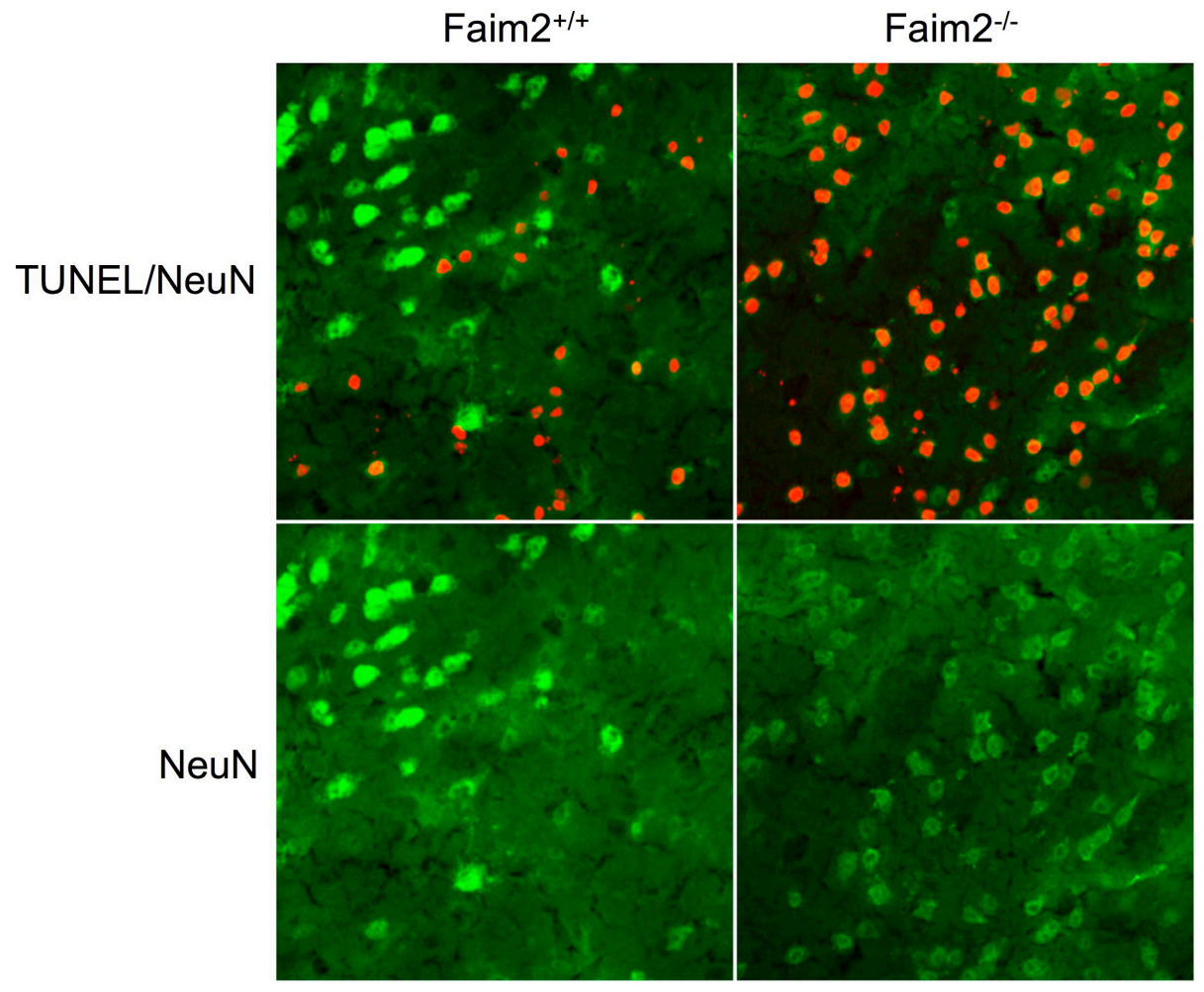

Abbildung 3.10: Doppelfärbung gegen TUNEL/NeuN im Vergleich Faim2 ${ }^{-/{ }_{-}}$und Faim2 $2^{+/+_{-}}$ Versuchstiere. In den beiden unteren Bildabschnitten ist NeuN grün angefärbt, die Neurone sind deutlich zu erkennen. In den beiden oberen Bildabschnitten sind TUNEL-positive Zellen rot markiert. Eine Überlagerung von rotem und grünem Farbstoff markiert ein TUNEL-positives Neuron und weist damit auf einen neuronenspzifischen Zellschaden hin.

(modifiziert publiziert in Reich et al. 2011, S. 230)

In den beiden oberen Bildabschnitten sind TUNEL-positive Zellen rot markiert. Eine Überlagerung von rotem und grünem Farbstoff markiert ein TUNEL-positives Neuron und weist damit auf einen neuronenspezifischen Zellschaden hin. Im Vergleich zwischen Faim2 $2^{-/-}$- und Faim2 $2^{+/+}$-Versuchstieren ist der quantitative Unterschied und 
die höhere Dichte an TUNEL-positiven Zellen bei Faim2-Defizienz zu erkennen.

Es wurden des Weiteren Doppelfärbungen gegen NeuN und aktivierte Caspase- 8 und
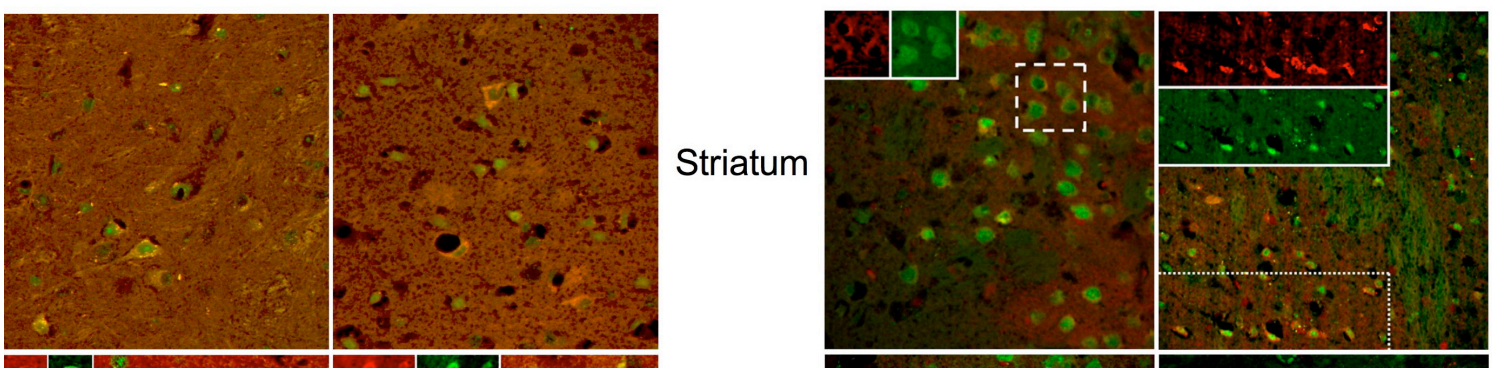

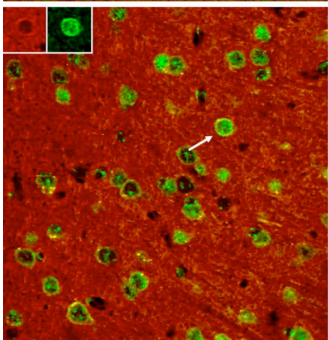

Faim2 $2^{+/+}$

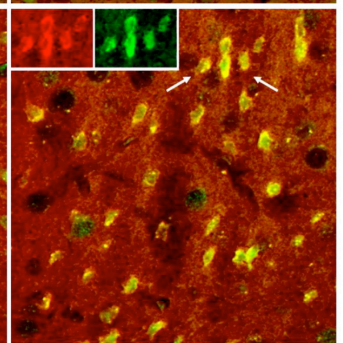

Faim2-/-

Caspase 8

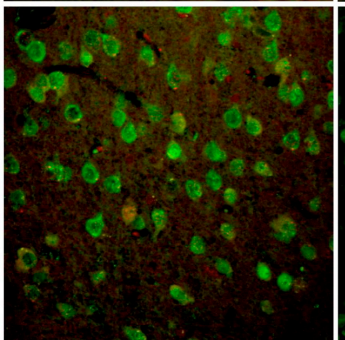

Faim2 $2^{+/+}$

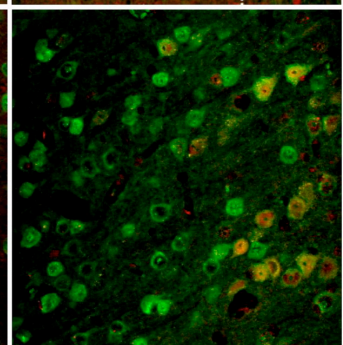

Faim2 $2^{-1-}$

\section{Caspase 3}

Abbildung 3.11: Konfokale Immunofluoreszenz 16 Stunden nach 30-minütiger MCAo. Caspase-8 (links) (Doppelfärbung von NeuN (grün) und aktivierter Caspase-8 (rot); Bildgröße: $200 \times 200 \mu \mathrm{m}$ ) und Caspase-3 (rechts) (Doppelfärbung von NeuN (grün) und aktivierte Caspase-3 (rot); Bildgröße: $275 \times 275 \mu \mathrm{m}$ ). Vergleichend Faim2-defiziente Versuchstiere und Faim2-Wildtypen, ist jeweils ein Bildausschnitt aus dem Striatum als Infarktzentrum bei der MCAo und ein Bildausschnitt aus dem umgebenden Kortex als Penumbra dargestellt. Es zeigen sich deutlich die Formunregelmäßigkeiten, pyknotischen Zellen und das Zelldebridement der neuronalen Zellen bei Faim2-Defizienz als Hinweis auf einen erhöhten Zelluntergang.

(modifiziert publiziert in Reich et al. 2011, S. 231)

-3 durchgeführt, um sowohl die Zellspezifität als auch den Status der Zelle innerhalb der Caspase-Kaskade in Richtung Apoptose zu identifizieren. Aktivierte Caspasen sind durch proteolytische Spaltung und Dimerisierung einer Procaspase in einen aktivierten Zustand versetzte Proteasen (Tang et al. 2000). In der Abbildung 3.11 sind diese Doppelfärbungen nach einer Reperfusionszeit von 16 Stunden, nach vorangegangener 30-minütiger Ischämie, mit deutlichen Signalunterschieden zwischen Faim2defizienten Versuchstieren und Wildtypen dargestellt. Es ist zu erkennen, dass sich bereits zu diesem Zeitpunkt im Zentrum des Ischämieareals (Striatum) die Signalstärke allgemein verschlechterte, während sie in der Penumbra (umgebender Kortex) noch ausgeprägt war. Da eine Quantifizierung der Caspase-8- und -3-positiven Zellen nicht möglich war, standen hier die morphologischen Veränderungen im Vordergrund. Hierbei zeigte sich in einer qualitativen Untersuchung eine deutliche Mehrzahl an Zel- 
len mit Formunregelmäßigkeiten und pyknotischem Erscheinungsbild der NeuN- und Caspase-positiven Zellen bei Faim2-Defizienz.

Die vor der MCA-Okklusion verabreichte i.p. Injektion von 5-Bromo-2'-desoxy-Uridin (BrdU) (Injektionsprotokoll siehe Abschnitt 2.5.5 auf Seite 42 bereitete die im Anschluss an die Reperfusionsphase durchgeführte Färbung gegen BrdU vor. Durch die BrdU-Markierung werden teilungsaktive Zellen im reaktiven Zeitfenster des ischämischen Schadens markiert. 5-Bromo-2'-desoxy-Uridin dient als ein Thymidinanalogon und wird in die replizierende DNA eingebaut. Während der physiologischen Funktionen einer Zelle geht man davon aus, dass diese den Zellzyklus beendet hat und insbesondere Neurone nicht in der Lage sind den Zellzyklus wieder aufzunehmen - sog. G0Phase/Ruhephase (Tixier-Vidal 1994). Allerdings zeigten vermehrt Untersuchungen, dass insbesondere in der Penumbra Neurone auch nach Abschluss der Embryonalentwicklung eine Aktivierung und Wiederexpression von zellzyklusrelevanten Genen aufweisen (Cramer und Chopp 2000). Innerhalb der 4 Zyklen des Zellzyklus (G1-, S-, G2- und M-Phase) wird DNA nur während der S-Phase repliziert. Somit gilt BrdU als ein Marker der S-Phase des Zellzyklus und der immunhistochemische Nachweis von BrdU gilt als Marker für DNA-Replikation sowohl im embryonalen als auch adulten Nervensystem (Thomaidou et al. 1997, Kornack und Rakic 1999). Der Proliferationsmarker BrdU wird daher auch als Marker für Neurogenese verwendet (Kempermann et al. 1998). Die Abbildung 3.12 zeigt quantitativ die Unterschiede BrdU-positiver

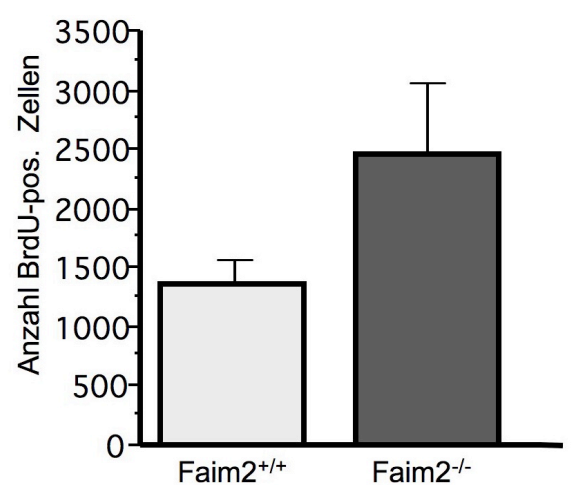

Abbildung 3.12: BrdU-positive Zellen im Infarktareal und Penumbra (Striatum). Es zeigt sich ein nicht-signifikanter $(p=0,0974)$ Unterschied mit jedoch deutlichem Trend an BrdU-positiven Zellen im Infarktareal und der umgebenden Penumbra im Vergleich zwischen Faim2 $2^{-/-}$und Faim2 $2^{+/+}$ (jeweils $\mathrm{n}=9$ ).

Zellen im Infarktareal und der Penumbra zwischen Faim2-defizienten Tieren und Wildtypen auf. Zwar konnte eine Signifikanz nicht erhoben werden ( $p=0,0974)$, 
es zeigte sich jedoch bei kleiner Fallzahl (jeweils $n=9$ ) ein deutlicher Trend.

\subsection{Regulation der Apoptose durch Faim2}

Wie bereits dargestellt unterliegt die Apoptose komplexen Regulationsmechanismen. Über den Fas/CD95-Rezeptor und seinen Liganden wird nach der Komplexbildung die Aktivierung der Caspase-Kaskade eingeleitet, sofern diese Aktivierung nicht verhindert wird. Während die Familie der Fas apoptotic inhibitory melecules 1, 2 und 3 ihre hemmende Wirkung direkt am Fas/CD95-Rezeptor entfalten, wirken weitere Proteine regulatorisch in der Initiations- bzw. Amplifikationsphase. Damit greift das in der vorliegenden Arbeit im Fokus stehende Protein Faim2 noch vor der Aktivierung des Fas-associated death-domain-containing protein (FADD) ein (Fernandez et al. 2007, Somia et al. 1999), sodass die Aktivierung der Caspase-8 als wichtiger Einleitungsschritt der weiteren Apoptose-Kaskade nicht erreicht wird. Während die Caspase-8-Aktivierung innerhalb der Initiationsphase eine frühe und wegweisende Rolle spielt, markiert die Aktivierung der Caspase-3 das Ende der Amplifikationsphase und damit die Einleitung der irreversiblen Exekutionsphase.

Zur Evaluation des proximal-inhibitorischen Effekts von Faim2 auf die apoptotische Fas/CD95-Signalkaskade wurden neben der TUNEL-Reaktivität (vgl. Abschnitt 3.2 .2 auf Seite 60) auch postischämische Caspase-8- und -3-Aktivität (in vitro) bzw. Spaltprodukte als Aktivierungsmarker genotypabhängig untersucht.

Die Aktivierung der Caspase-Kaskade gilt als wichtiger Nachweis Fas/CD95-induzierter Apoptose. Die Darstellung von aktivierter Caspase-8 und -3 gibt Hinweis darauf, ob die Apoptose-Signaltransduktion erfolgreich eingeleitet worden ist. Dabei wurde aufgrund der bereits beschriebenen örtlichen bzw. zeitlichen Unterschiede von Caspase-8 und -3 innerhalb der Caspase-Kaskade zunächst jeweils ein sog. activity assay ex vivo durchgeführt (vgl. Reich et al. 2011). Hierbei wurden Faim2 $2^{-/-}$- und Faim2 $2^{+/+}$-Mäuse (jeweils $n=3$ ) nach 30-minütiger MCAo und unterschiedlichen Reperfusionszeitpunkten $(3 \mathrm{~h}, 8 \mathrm{~h}, 10 \mathrm{~h}, 20 \mathrm{~h}$ und $40 \mathrm{~h})$ unter Analgosedierung perfundiert und anschließend aus Schnitten der ipsilateralen (ischämischen) Hirnhemisphäre die jeweilige CaspaseAktivität bestimmt. Nach 20 Stunden Reperfusion konnte eine signifikant erhöhte Aktivität von Caspase-8 und-3 in den Faim2-defizienten Versuchstieren nachgewiesen werden (Abbildung 3.13 auf der nächsten Seite). Die kontralateralen Hirnhemisphären fungierten als Kontrolle.

Auch in der Doppelfärbung gegen NeuN/aktivierte Caspas- 8 bzw. NeuN/aktivierte 

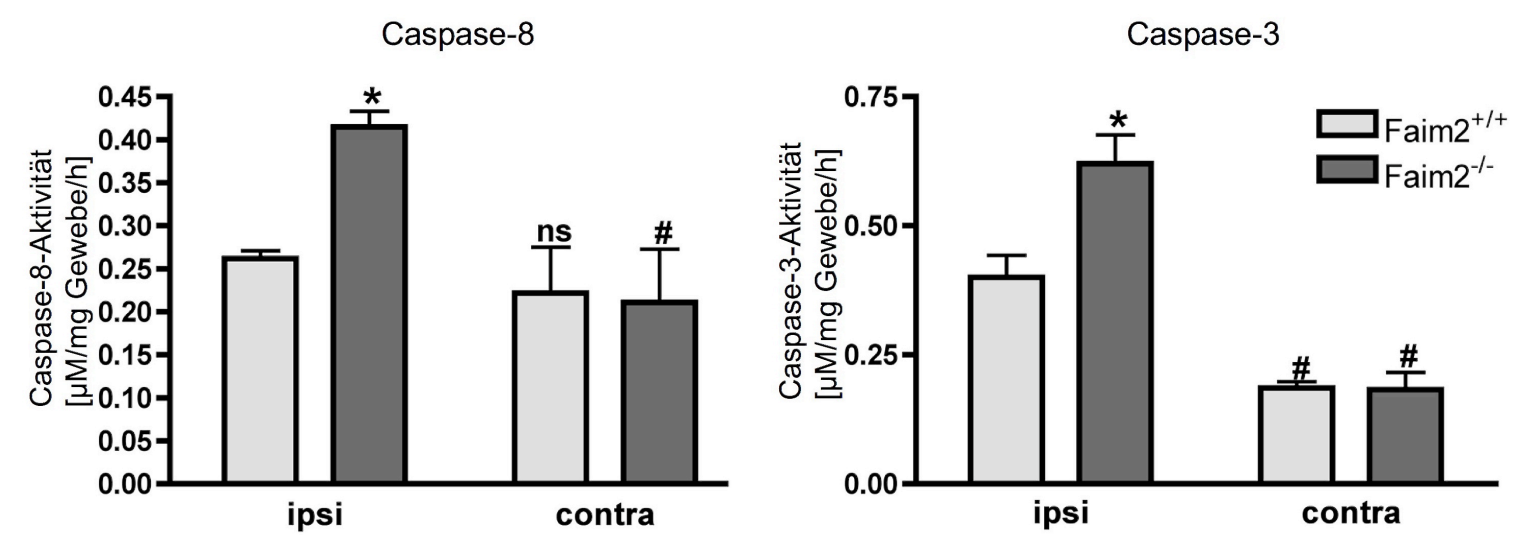

Abbildung 3.13: Caspase-8- und -3-Aktivität im Vergleich von Faim2-Defizienz und -Wildtyp $20 \mathrm{~h}$ nach 30-minütiger MCAo. Als Kontrolle diente jeweils die kontralaterale (contra) Hirnhemisphäre, während die ipsilaterale (ipsi) diejenige mit einem Infarktareal darstellt. Die Daten sind als Mittelwerte \pm SEM aus jeweils $\mathrm{n}=3$ dargestellt. Signifikanzanalyse mittels Two-way ANOVA, gefolgt von Tukey posthoc Analyse ergibt für Caspase- $8:{ }^{*} p=0,004$ bei ipsilateral Faim2 ${ }^{+/+}$vs. Faim2 $2^{-/-}$ und ${ }^{\sharp} p=0,01$ bei entsprechendem Vergleich ipsilateral vs. contralateral bei Faim2 $2^{-/-}$. n.s. $=$not significant bei ipsilateral vs. contralateral Faim $2^{+/+}$. Für Caspase-3: ${ }^{*} p=0,033$ bei ipsilateral Faim $2^{+/+}$vs. Faim $2^{-/-}$und ${ }^{\sharp} p=0,009$ bei entsprechendem Vergleich ipsilateral vs. contralateral bei Faim $2^{-/-}$und Faim2 $2^{+/+}$.

(modifiziert publiziert in Reich et al. 2011, S. 231)

Caspase-3 waren deutliche Unterschiede zu erkennen. Die qualitativen Signalunterschiede mit ungleicher Ausbreitung vom Striatum ausgehend bis in den umgebenden Kortex reichend sind in Abbildung 3.11 auf Seite 64 aufgezeigt. Insbesondere die Mehrzahl an Zellen mit Formunregelmäßigkeiten und pyknotischem Erscheinungsbild stellt die höhere Apoptoserate bei Faim2-Defizienz heraus.

\subsection{Einfluss der Faim2-Überexpression durch viralen Gentransfer auf neuronale Zellen}

\subsubsection{Charakterisierung des viralen Vektors zur stereotaktischen Injektion vor MCA-Okklusion}

Durch die stereotaktische Injektion eines geeigneten Virus als Vektor für Faim2 in das Striatum und den Kortex konnte bei Nullmutanten Faim2 wieder lokal exprimiert bzw. überexprimiert und bei Wildtypen überexprimiert werden. Dies bedingte eine Reihe an Vorversuchen, um (1) ein geeignetes Virus (Adenovirus oder Lentivirus) zu wählen, (2) das optimale Zeitintervall zwischen Injektion und MCA-Okklusion zu 
finden, (3) die Menge und Dosierung des zu injizierenden Virus zu bestimmen und (4) die genaue Lokalisation der Injektionsstelle zu identifizieren. Hinzu kommt, dass die stereotaktische Injektion bereits mit einem lokalen zerebralen Trauma einhergeht und die sich anschließende MCAo nochmals traumatisch auf das Hirngewebe wirkt.

Zur Testung eines geeigneten Virus wurde sowohl ein Adenovirus- als auch ein Lentiviruskontrukt für Faim2 entwickelt. Die ersten Versuche wurden mit einem Adenovirus durchgeführt. Die Versuchstiere wiesen, wie in Abbildung 3.14 dargestellt,
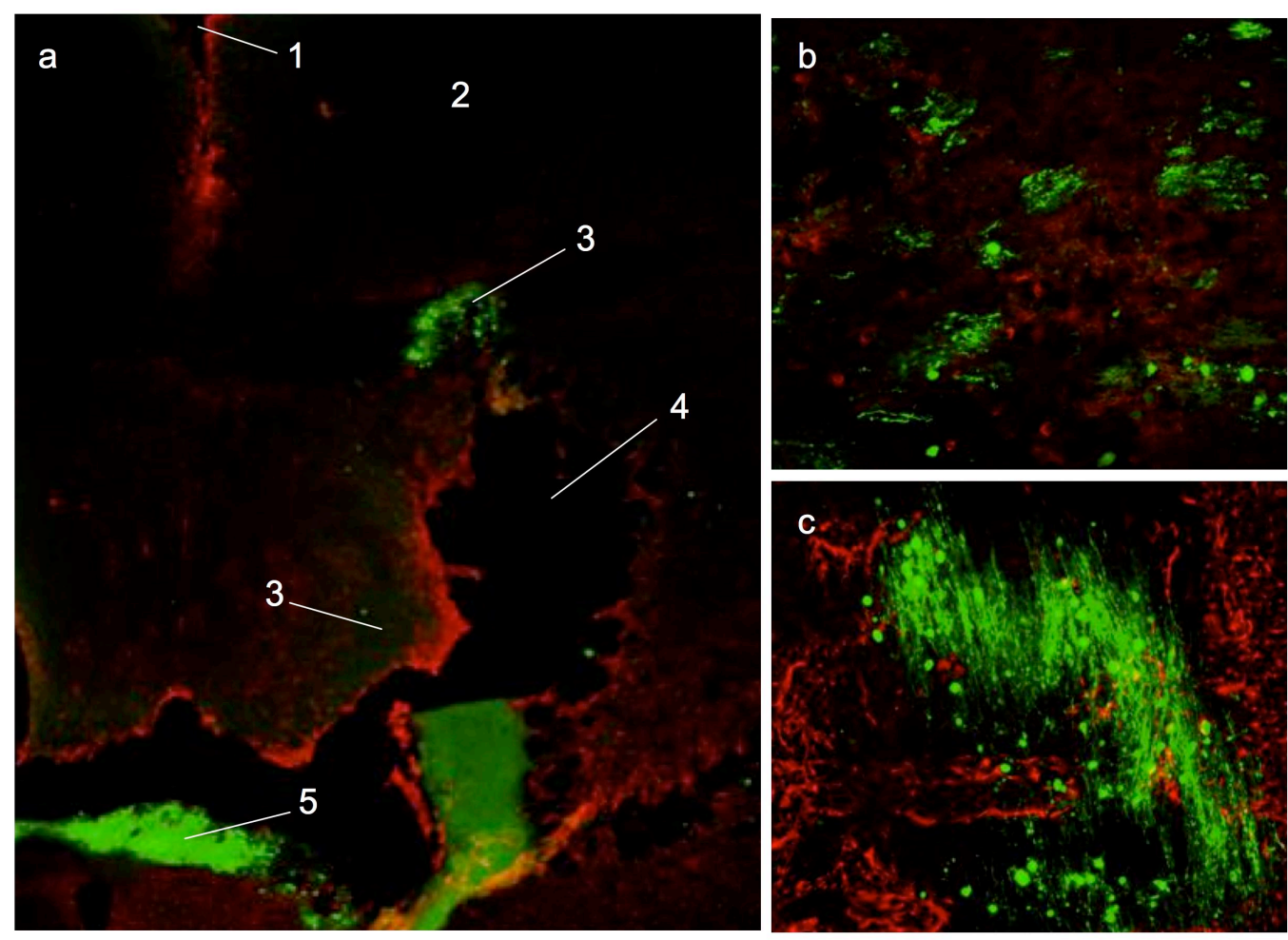

Abbildung 3.14: Darstellung des infizierten Gewebes im Striatum am Faim2/LFG-AdenovirusKonstrukt - a GFP-pAdeno/GFAP-Doppelfärbung: 1 Linker Ventrikel; 2 gesundes Striatum; 3 im Striatum infizierte Zellen; 4 Destruktion durch Adenovirus; 5 freie Virusreste; b GFP-pAdeno/NeuNDoppelfärbung; c GFP-pAdeno/Iba-1-Doppelfärbung

einen erheblichen Gewebeschaden auf. Dargestellt sind in $\boldsymbol{a}$ Doppelfärbung GFPpAdeno/GFAP, in $\boldsymbol{b}$ GFP-pAdeno/NeuN Doppelfärbung und in $\boldsymbol{c}$ GFP-pAdeno/Iba-1 Doppelfärbung. Neben dem Ergebnis der erheblichen Destruktion durch das Adenovirus wurde durch die vorliegenden Färbungen auch nachgewiesen, dass eine neuronenspezifische Infektion nicht ausreichend erzielt werden konnte. 
Aufgrund dieser destruktiven Eigenschaften des Adenovirus war ein zweites operatives Trauma durch die MCA-Okklusion nicht denkbar, da ansonsten die Auswertungen der Versuche allein durch das Ausmaß des Traumas verfälscht worden wären. Das Lentiviruskonstrukt erwies sich als weitaus weniger aggressiv gegenüber den infizierten Zellen. Die Abbildung 3.15 zeigt die Infektion durch das gewebeschonendere Lentivirus. In diesem Versuch wurde mittels Einfach- und Doppelfärbungen gegen $\boldsymbol{a}$ GFP,

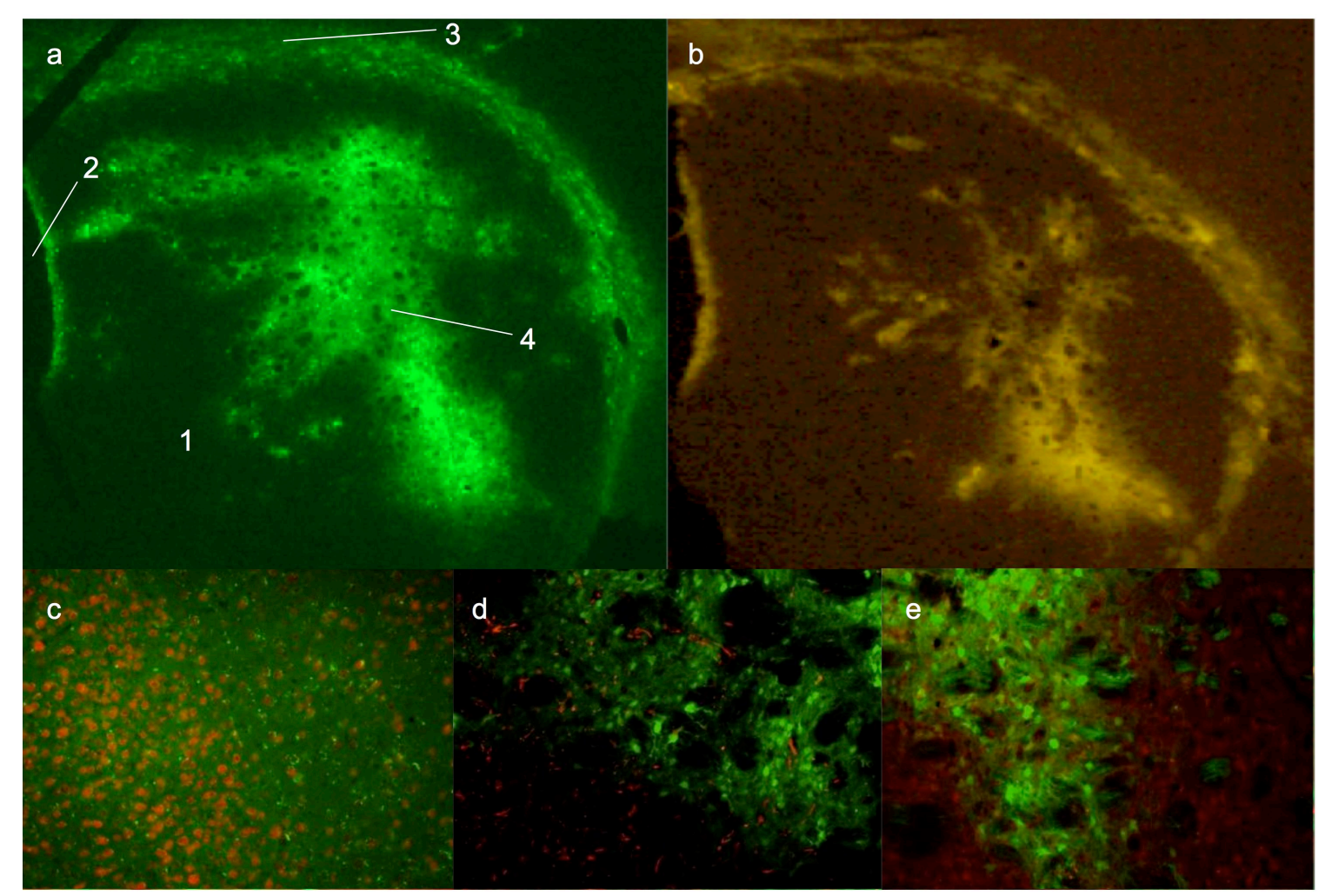

Abbildung 3.15: Darstellung der mit dem Faim2-Lentiviruskonstrukt infizierten Zellen im Striatum. a GFP-Färbung: 1 gesundes Striatum; 2 Linker Ventrikel; 3 Corpus Callosum; 4 mit Faim2Lentivirus infiziertes Areal im Striatum; b Faim2-Färbung; c NeuN/GFP-pLenti-Doppelfärbung; d GFP/Iba-1-Doppelfärbung; e GFP/GFAP-Doppelfärbung.

(modifiziert publiziert in Reich et al. 2011, Supplemental Material)

$\boldsymbol{b}$ Faim2-Antikörper, $\boldsymbol{c}$ NeuN/GFP-pLenti, $\boldsymbol{d}$ GFP/Iba-1 und $\boldsymbol{e}$ GFP/GFAP eine neuronenspezifische Infektion durch das Lentivirus nachgewiesen. Weder in der Doppelfärbung mit dem gliazellenspezifischen Protein GFAP noch in der Doppelfärbung mit dem mikroglia- und makrophagenspezifischen Iba-1 konnte ein Überlagern des grünen Signals (GFP-pLenti) mit dem jeweils roten Signal beobachtet werden. Nur in der Doppelfärbung mit dem neuronenspezifischen NeuN mit GFP-pLenti wurde 
eine Überlagerung der beiden farblich markierten Marker beobachtet und somit auf eine neuronenspezifische Infektion durch das Lentiviruskonstrukt geschlossen werden. In den Vorversuchen wurde das Lentivirus demnach als geeigneter für die Doppelbelastung einer stereotaktischen Injektion und folgender MCA-Okklusion identifiziert. Mithilfe des viralen Vektors sollte die Implementierung der genomischen Information zur Synthese von Faim2 in den neuronalen Zellen erreicht werden. Hierzu wird die Zelle auf herkömmlicher Art und Weise vom Virus infiziert und das Virusplasmid in die Zell-DNA integriert. Insbesondere Lentiviren haben sich als effizient im in-vivo-Gentransfer erwiesen und weisen eine hohe Spezifität für die Donorzelle auf (Dull et al. 1998). Die Abbildung 3.15 auf der vorherigen Seite belegt nicht nur die neuronenspezifische und gewebeschonende Infektion durch das Lentiviruskonstrukt, sondern auch eine im Verhältnis zur injizierten Virusmenge effiziente Infektionsrate und Ausbreitung im striatalen Infarktareal. Die beiden Bildabschnitte $\boldsymbol{a}$ und $\boldsymbol{b}$ der Abbildung 3.15 zeigen die flächige Ausbreitung des Viruskonstrukts innerhalb des Striatums. Der Gentransfer durch das Lentiviruskonstrukt erwies sich allerdings nicht nur im in-vivo- sondern auch im in-vitro-Versuch als erfolgreich (siehe Abschnitt 3.4 .2 auf der nächsten Seite).

Nachdem das geeignete Virus identifiziert worden war, musste im 2. Schritt das geeignete Zeitintervall zwischen Injektion des Virus und Ischämie mittels MCA-Okklusion erarbeitet werden. Gleichzeitig wurden unterschiedliche Injektionsmengen und anatomische Injektionslokalisationen des Virus ermittelt. Dazu wurden 10, 15 und 20 Tage nach stereotaktischer Injektion des Virus die MCA-Okklusionen durchgeführt. Parallel dazu wurde eine Versuchsgruppe mit $1 \mu \mathrm{l}$ pro Injektionslokalisation und eine mit $2 \mu \mathrm{l}$ pro Injektionslokalisation des Virus (jeweils 697 WPRE-Moleküle/10.000 AktinMoleküle/ $\mu \mathrm{l}$ ) bei gleicher Injektionsgeschwindigkeit an zwei Lokalisationen innerhalb des Striatums infiziert. Zur Auswertung der korrekten anatomischen Lokalisation der Injektionshöhe wurden diese beiden Versuchsgruppen wiederum in eine Gruppe an Tieren, die eine oberflächlichere Injektion in den Kortex und eine zweite tiefere Injektion in das Striatum erhielten, und eine zweite Gruppe, die jeweils nur eine tiefere Injektion in das Striatum erhielten, aufgeteilt. Die Ergebnisse dieser Versuchsreihe zeigten die geringste Anzahl an während und nach der MCA-Okklusion verstorbenen Tiere bei einer Erholungsphase von 20 Tagen nach stereotaktischer Injektion. Die Injektion von Virus in den Kortex und in das Striatum rief eine wiederum zu große gewebliche Destruktion hervor. Bezüglich der zu injizierenden Menge wiesen $2 \mu \mathrm{l}$ keinen Vorteil und kein vergrößertes Infektionsareal gegenüber einer Injektion von nur $1 \mu \mathrm{l}$ auf. Daher wurde das möglichst schonende Verfahren gewählt. Hierbei 
wurde jeweils $1 \mu \mathrm{l}$ des Lentivirus an zwei Lokalisationen stereotaktisch direkt in das Striatum injiziert (siehe Tabelle 2.9 auf Seite 39). Im Anschluss wurde nach 20 Tagen die MCA-Okklusion durchgeführt und nach 72-stündiger Reperfusionszeit das Hirngewebe entsprechend aufgearbeitet und ausgewertet (siehe Abbildung 3.16 für den Versuchsablauf).

\section{Stereotaktische Injektion}

LV-Faim2/LV-GFP (je $n=10$ )

\section{MCAo}

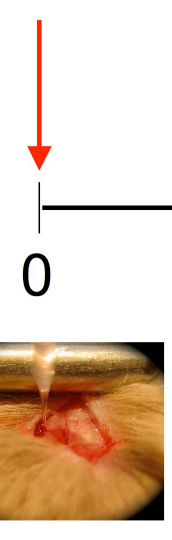

\section{2 striatale Injektionen} mit je $1 \mu$ L Lentivirus

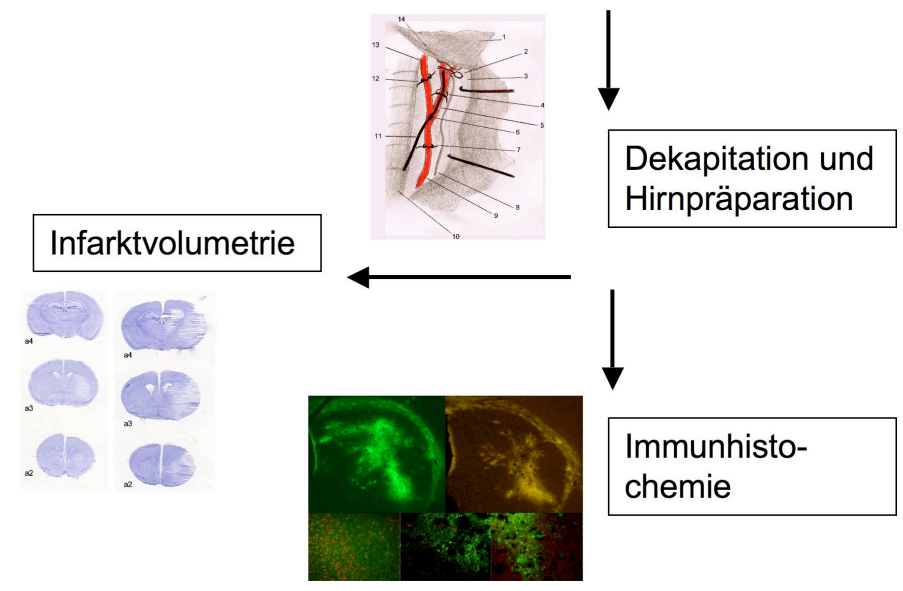

Abbildung 3.16: Versuchsaufbau des lentiviralen Gentransfers

\subsubsection{Schutz vor Apoptose durch Überexpression von Faim2}

Nach der stereotaktischen Injektion von lentiviralem Faim2 (LV-Faim2) wurde anschließend nach 20 Tagen die zerebrale fokale Ischämie mittels MCA-Okklusion induziert. Während in der volumetrischen Auswertung nach MCAo bei Versuchstieren ohne lentivirale Injektion ein signifikant größeres Infarktvolumen bei den Faim2defizienten Versuchstieren als bei den Wildtypen zu beobachten war, konnte nach der vorherigen Injektion von LV-Faim2 ein im Vergleich zur Injektion lentiviraler Kontrollvektoren signifikant verkleinertes Infarktvolumen beobachtet werden. Die Abbil- 
dung 3.17 zeigt die Ergebnisse von Faim2-defizienten Versuchstieren und Wildtypen im Vergleich bei lentiviralem Gentransfer von Faim2. Als Kontrolle diente LentivirusGFP (LV-GFP). Dabei war zu erkennen, dass im Vergleich zur Kontrolle das Infarktvolumen nach lentiviralem Gentransfer von Faim2 bei beiden Genotypen in vivo verringert ist. Sowohl die Wildtypen als auch die Faim2-defizienten Versuchstiere wiesen durch die lentivirusinduzierte Faim2-Überexpression ein signifkant verringertes Infarktvolumen in Ausdehnung und Zellzahl apoptotischer Zellen auf. Die absolute Anzahl der apoptotischen Zellen wurde in vivo nicht quantifiziert, da jeweils nur eine lokale Expression von Faim2 durch den lentiviralen Gentransfer erreicht werden konnte.

Während in der Volumetrie ein geringeres Ausmaß des Schlaganfalls zu beboachten

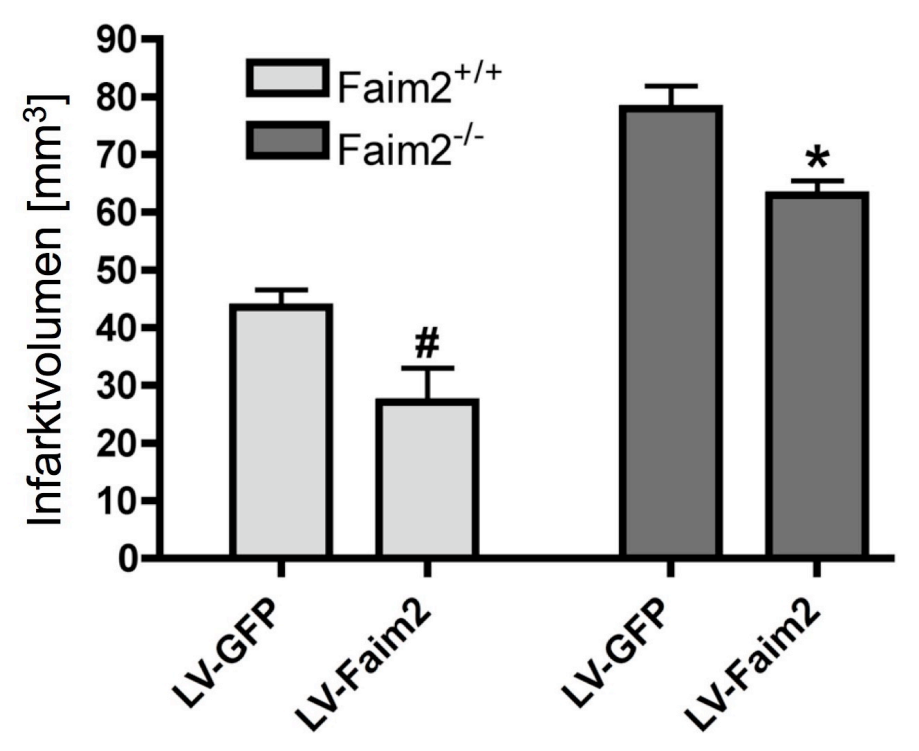

Abbildung 3.17: Grafische Darstellung des Infarktvolumens von Faim $2^{-/-}$und Faim $2^{+/+}$im Vergleich nach Gentransfer von Faim2 mittels eines Lentiviruskonstrukts und MCAo 20 Tage nach stereotaktischer Injektion. Die Signifikanzanalyse mittels Two way ANOVA gefolgt von einem ungepaarten t-Test, zeigt ein signifikant kleineres Infarktvolumen nach Gentransfer von Faim2 sowohl bei Faim2 $2^{-/-}$als auch bei Faim2 ${ }^{(+/+)}$. Die Daten sind als Mittelwerte \pm SEM aus jeweils $n=5-8$ pro Gruppe dargestellt. Infarktvolumen: Faim2 $2^{-/-}$vs. Faim2 $2^{+/+} p<0,0001 ;$ LV-GFP vs. LV-Faim2 ${ }^{*} p=0,0013$; Faim $2^{+/+}$vs. LV-GFP ${ }^{\sharp} p=0,0218$; Faim $2^{-/-}$vs. LV-GFP ${ }^{*} p=0,0126$.

(modifiziert publiziert in Reich et al. 2011, S. 230)

war, konnte in der in-vitro-Versuchsreihe auch ein erhöhtes Überleben der neuronalen Zellen beobachtet werden. Die in-vitro-Versuche wurden im Labor der Klinik für Neurologie der Charitè Universitätsmedizin Berlin in Zusammenarbeit mit Christoph Harms durchgeführt. Dabei wurden primäre kortikale Neurone in Zellkulturansätzen durch sog. oxygen-glucose deprivation (OGD) unter oxidativen Stress versetzt. In der 
Abbildung 3.18 ist zu erkennen, dass signifikant mehr Wildtyp-Zellen (Faim2 ${ }^{+/+}$) überlebt haben als Zellen von Faim2-defizienten Versuchstieren (Faim2 ${ }^{-/-}$) (linke Grafik). Die rechte Grafik zeigt die Freisetzung von Laktatdehydrogenase (LDH) während des Zelluntergangs im Rahmen des oxidativen Stress. LDH ist ein Marker für den Zelluntergang, da es als essentielles Enzym im Rahmen des Energiestoffwechsels einer jeden Zelle bei deren Untergang freigestzt wird (Katchanov et al. 2001). Im Medium der neuronalen Zellen aus der Faim2 ${ }^{-/}-$Zelllinie war ein signifkant erhöhter LDH-Spiegel zu erheben. Daraus ist zu schlussfolgern, dass signifikant mehr Zellen der Faim2-defizienten Versuchstiere die Apoptose einleiteten.

Nach der Transduktion der neuronalen Zellen in vitro mit Faim2-Lentivirus und dem
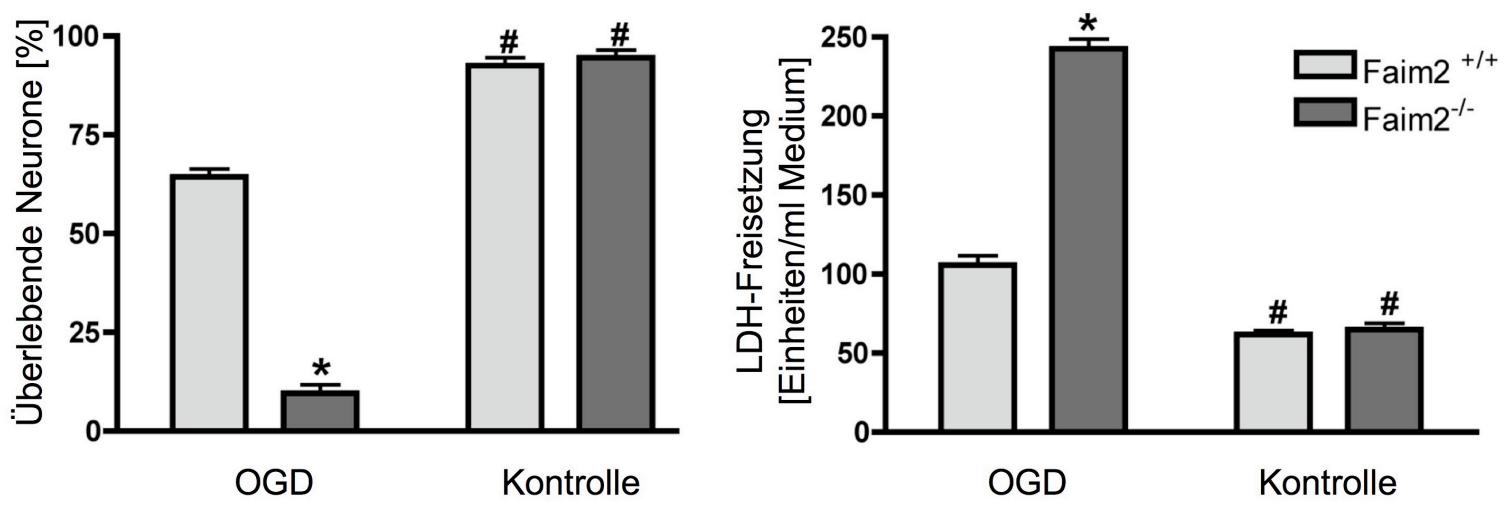

Abbildung 3.18: Grafische Darstellung des prozentualen Anteils überlebender primärer kortikaler Neurone nach OGD (linke Grafik) und der LDH-Freisetzung nach OGD (rechte Grafik) im Vergleich von Faim2 $2^{-/-}$- und Faim2 $2^{+/+}$-Versuchstieren. Es wurden ca. 500 Neurone pro Versuchskondition bzgl. der Viabilität in mindestens 8 mikroskopischen Gesichtsfeldern analysiert und in unabhängigen Versuchsansätzen wiederholt. Die Signifikanzanalyse erfolgte mittels Two-way ANOVA gefolgt von einer Tukey post-hoc-Analyse: Faim $2^{-/-}$vs. Faim2 $2^{+/+}{ }^{*} p<0,001$; jeweils Kontrolle vs. Faim2 $2^{-/-}$ bzw. Faim $2^{+/+}{ }^{\sharp} p<0,001$; Der LDH-Spiegel wurde $24 \mathrm{~h}$ nach OGD bestimmt. Die Daten sind als Mittelwerte \pm SEM aus 4 unabhängigen Versuchsansätzen. Die Signifikanzanalyse erfolgte mittels Two-way ANOVA gefolgt von einer Tukey post-hoc-Analyse: LDH-Konzentration nach OGD Faim2 $2^{-/-}$vs. Faim $2^{+/+}{ }^{*} p<0,001$; jeweils Kontrolle (LDH in neuronaler Zellkultur von Faim2 $2^{-/-}$bzw. Faim $2^{+/+}-$Versuchstieren) vs. Faim $2^{-/-}$bzw. Faim2 ${ }^{+/+} \sharp p<0,001$;

(modifiziert publiziert in Reich et al. 2011, S. 228)

damit verbundenen Gentransfer, zeigte sich auch auf zellulärer Ebene ein signifikant verringerter Zelluntergang nach OGD. Hierbei wies die Faim2 $2^{-/-}$-Zelllinie primärer kortikaler Neurone, die von E16 Embryos der Faim2-defizienten Versuchstiere und Wildtypen stammend für 10 Tage in vitro kultiviert worden waren, nach Gentrasfer sowohl durch das Faim2-full length-als auch das Faim2-truncated-Lenitviruskonstrukt, wenn auch nicht so effektiv, einen signifkanten Rückgang des Zelluntergangs im Vergleich zur Kontrollzelllinie ohne viralen Gentransfer auf. Die Abbildung 3.19 zeigt 


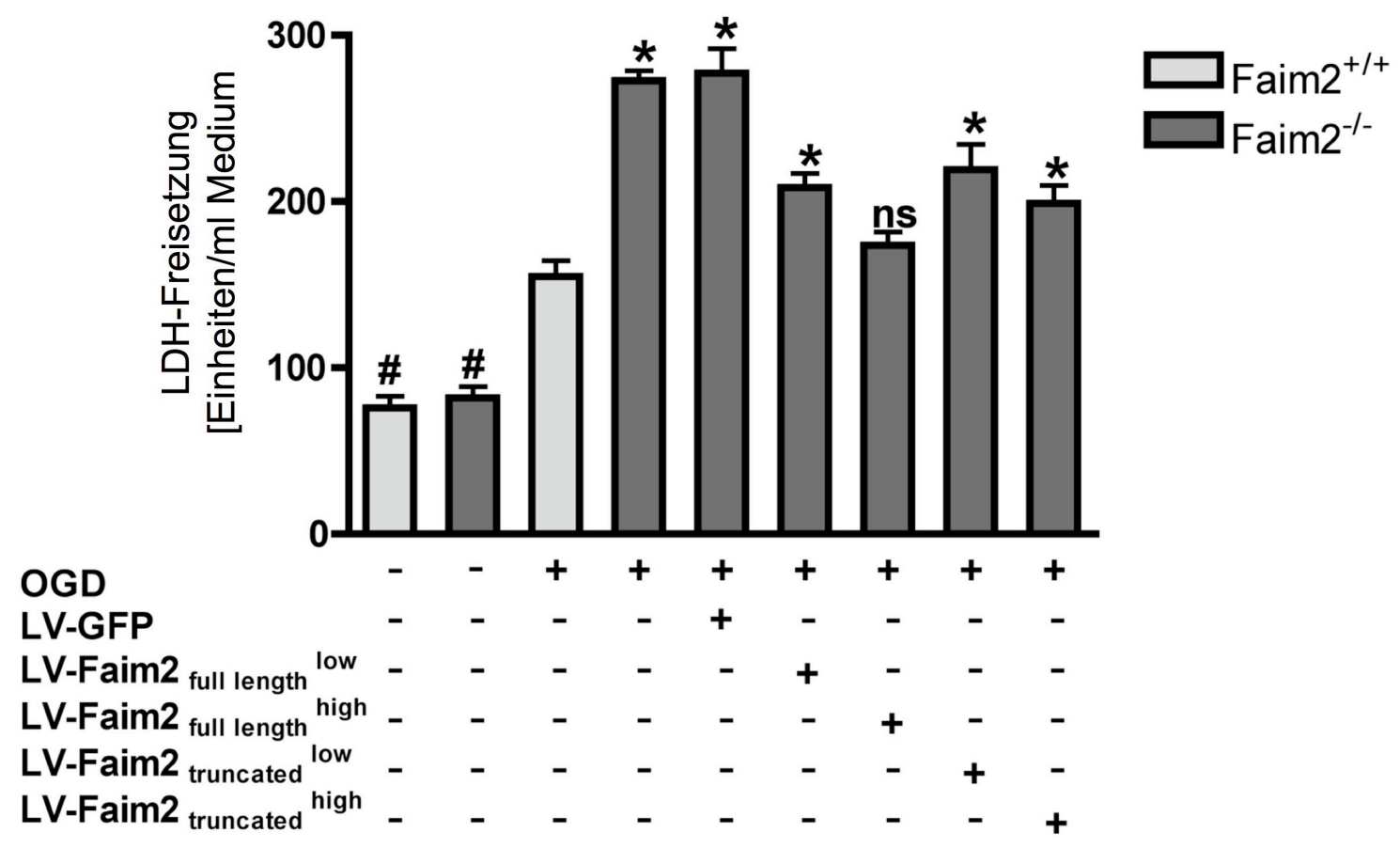

Abbildung 3.19: Grafische Darstellung der LDH-Freisetzung aus primären murinen kortikalen neuronalen Zellen in Zellkultur nach OGD im Vergleich von Faim2 $2^{-/-}$- und Faim2 $2^{+/+}$-Versuchstieren und Abhängigkeit vom Titer des zugeführten Lentiviruskonstrukts. Die Neurone wurden 3 Tage nach Beginn des in-vitro-Ansatzes mit Viruspartikeln transduziert. Dabei wurde entweder ein hoher oder ein niedriger Virustiter (bzgl. des mRNA-Levels) verwendet. Die LDH-Konzentration wurde $24 \mathrm{~h}$ nach 2,5-stündiger OGD ermittelt. Die Daten sind als Mittelwerte \pm SEM aus n=6-8 in dreifach unabhängigen Versuchsansätzen. Die Signifikanzanalyse erfolgte mittels One-way ANOVA gefolgt von einer Tukey posthoc Analyse: OGD-Faim $2^{-/-}$mit unterschiedlichem Virustiter vs. OGD-Faim $2^{+/+}$ ${ }^{*} p<0,05$; nicht signifikant (n.s.) Faim2 $2^{-/-}$full length ${ }^{h i g h}$ vs. OGD-Faim2 ${ }^{+/+}$; jeweils Kontrolle (LDH in neuronaler Zellkultur von Faim $2^{-/-}$- bzw. Faim $2^{+/+}$-Versuchstieren) vs. Faim $2^{-/-}$bzw. Faim $2^{+/+}{ }^{\sharp} p<0,01$.

(modifiziert publiziert in Reich et al. 2011, S. 228)

diese Versuchsreihen für neuronale Zelllinien unter OGD mit Gentransfer unterschiedlicher Virusunterformen mit hohen (high) (2100 WPRE/10000 Aktin-Molekülen/ $\mu \mathrm{l}$ ) und niedrigen (low) (697 WPRE/10000 Aktin-Molekülen/ $\mu$ l) Titern des Lentiviruskonstrukts. Hierbei wurde nach 2,5-stündiger OGD mit 24-stündiger Reoxygenierung (Harms et al. 2007) der LDH-Spiegel gemessen und das neuronale Überleben mittels Propidiumiodid (PI)-Gegenfärbung quantifiziert (Reich et al. 2011). Dabei wurden jeweils mindestens 2000 Neurone pro Versuchsanordnung ausgezählt und dieses jeweils 3 -fach wiederholt. Die ischämische Toleranz von Faim2 $2^{-/}$kortikalen Neuronen war signifikant niedriger als bei den Wildtypen. Um einen Dosiseffekt zu untersuchen, wurden die Zellen mit unterschiedlich hohen Virus-Titern (siehe oben) transduziert. Hieraus resultierte eine dosisabhängige LDH-Freisetzung, die bei dem Einsatz von Faim2-/-full length ${ }^{\text {high }}$ und Faim2-/- full length ${ }^{\text {low }}$ besonders deutlich wird. Wäh- 
rend sich die LDH-Freisetzung bei der Verwendung von Faim2-/- full length ${ }^{\text {high }}$ den Wildtypenkonditionen anglich und keinen signifikanten Unterschied mehr aufwies, reduzierte sich zwar die LDH-Freisetzung unter Verwendung des Faim2 ${ }^{-/-}$full length ${ }^{\text {low }}$ als Vektor, der Unterschied zu den Wildtypkontrollen war jedoch weiterhin noch signifikant.

Bei den primären kortikalen neuronalen Zellen aus Wildtypen resultierte die Infektion mit hohen und niedrigen Faim2-Lentivirus-Titern ebenfalls dosisabhängig in einer signifikanten Reduktion des Zelluntergangs, gemessen in der Auszählung von mindestens 2000 mit Propidiumiodid gefärbten Neuronen pro Versuchsansatz, wie von Harms et al. (2007) und Reich et al. (2011) beschrieben.

Insgesamt lässt sich beobachten, dass der Gentransfer mittels Faim2-Lentivirus sowohl makroskopisch in vivo als auch auf zellulärer Ebene in vitro das Schlaganfallvolumen und den zellulären Untergang bei Faim2-/-_Versuchstieren signifikant verringert sowie bei den Faim2 $2^{+/+}$-Versuchstieren reduziert.

\subsection{Klinische Bewertung der Versuchstiere nach zerebraler Ischämie}

Zur klinischen Evaluation eines einseitigen neurologischen Defizits eignet sich der sog. SNAP-Score (Simple Neuroassessment of Asymmetric Impairment) (Shelton et al. 2008). Die Versuchtstiere wurden jeweils 10 Minuten vor der MCAo und 2 Stunden nach Beginn der Reperfusionszeit klinisch untersucht. Die Abbildung 3.20 auf der nächsten Seite zeigt die Untersuchung der Versuchstiere im Rahmen der Versuchsreihe nach stereotaktischer Injektion des Faim2-Lentivirus und anschließender MCAOkklusion 20 Tage später. Vor der MCA-Okklusion erreichten die Tiere maximal einen Score von 1, was die Abwesenheit eines neurologischen Defizits anzeigt. Diese Eingangsvoraussetzungen in die operative MCA-Okklusion war besonders wichtig, da die Tiere 20 Tage zuvor durch die stereotaktische, striatale Virusinjektion bereits ein potentielles zerebrales Trauma erlitten hatten. Tiere, die in der Voruntersuchung vor der MCA-Okklusion einen SNAP-Score > 2 erreicht hätten, wären spätestens an dieser Stelle aus dem Versuch ausgeschlossen worden.

Die Abbildung 3.20 auf der nächsten Seite zeigt auf, dass nach MCAo ein signifikant größeres neurologisches Defizit bzgl. einer neuropathologischen Asymmetrie besteht. In den Untersuchungen wiesen die Faim2 $2^{-/-}$-Versuchstiere signifikant höhere Testergebnisse als die Wildtypen auf. Außerdem zeigte sich beim Vergleich von Faim2 $2^{-/}$- 


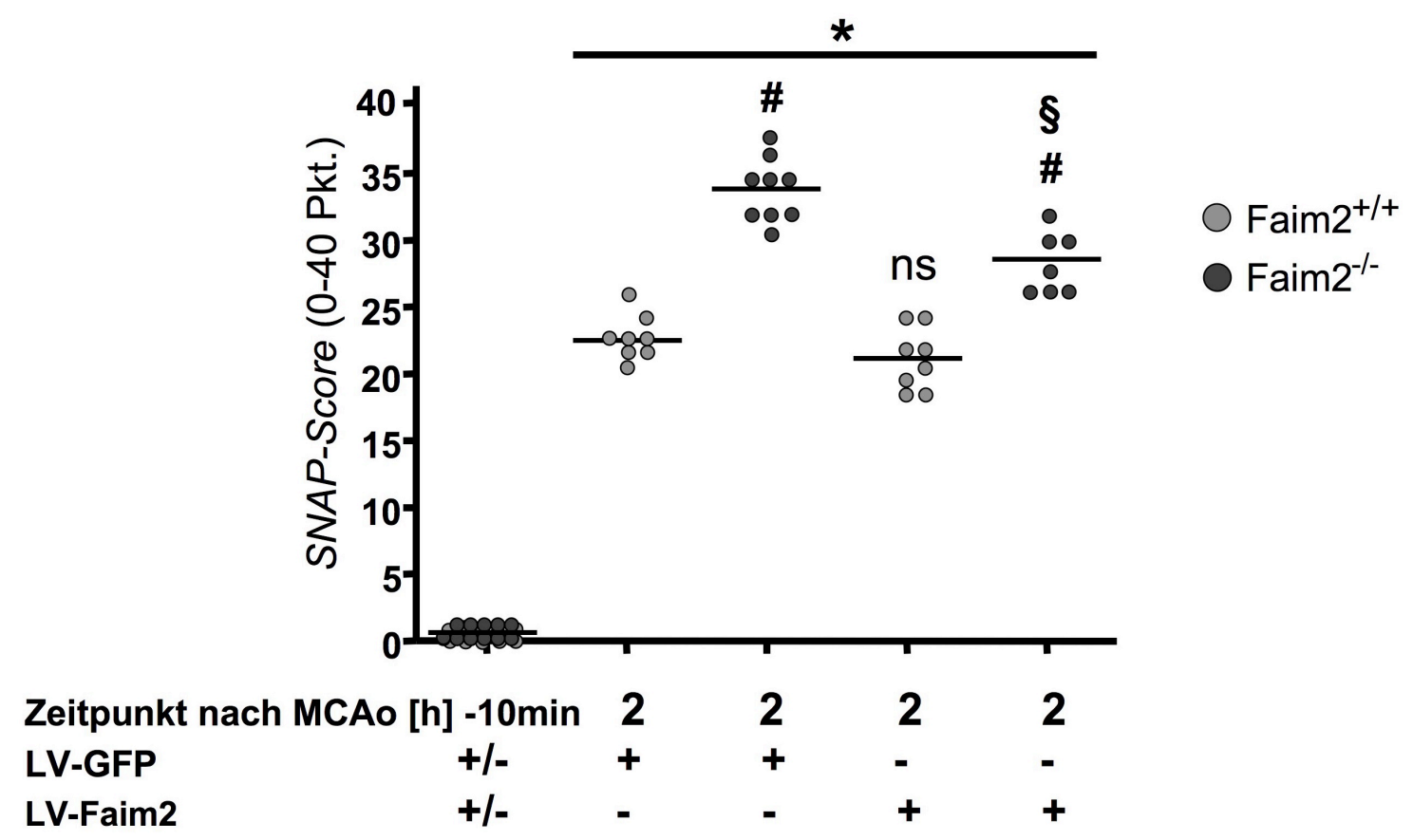

\begin{abstract}
Abbildung 3.20: Grafische Darstellung des SNAP-Scores 10 Minuten vor MCAo und 2 Stunden nach Beginn der Reperfusionszeit an Versuchstieren, die 20 Tage vor der Ischämie eine stereotaktische Injektion von Faim2-Lentivirus bzw. Lentivirus-GFP als Kontrolle (sham-Tiere) erhalten hatten (jeweils $n=7-9$ ). Dabei erreichen die sham-Tiere (LV-GFP) nach MCAo im Median 22 Pkt. (Faim2 $2^{+/+}$) und 34 Pkt. (Faim2 $2^{-/-}$), die Versuchstiere (LV-Faim2) nach MCAo im Mittel 21 Pkt. $\left(\right.$ Faim $\left.2^{+/+}\right)$und 27 Pkt. (Faim2 $2^{-/-}$). Die Signifikanzanalyse erfolgte mittels Kruskal-Wallis-oneway-Analyse gefolgt von einem Dunn's-Multiple-Comparison-Test: $2 \mathrm{~h}$ nach Beginn der Reperfusion vs. $10 \mathrm{~min}$ vor MCAo ${ }^{*} p<0,001$; Faim $2^{-/-}$LV-GFP bzw. LV-Faim2 vs. Faim2 $2^{+/+}$LV-GFP bzw. LV-Faim $2{ }^{\sharp} p<0,001$; Faim $2^{-/-}$LV-GFP vs. Faim $2^{-/-}$LV-Faim $2{ }^{\S} p<0,01$; nicht signifikant (ns) Faim $^{+/+}$LV-GFP vs. Faim2 ${ }^{+/+}$LV-Faim2
\end{abstract}

Tieren mit LV-Faim2, dass ein signifikant geringeres neurologisches Defizit nach der MCA-Okklusion als bei den sham-Tieren (Faim2-/--LV-GFP) besteht. Somit korrelieren die Ergebnisse der vorgenannten Effekte von Faim2-Defizienz auf die zerebrale Ischämie bzw. die lentivirale Überexpression von Faim2 mit den Ergebnissen der klinischen Bewertung des neurologischen Defizits nach MCAo unter Faim2-Defizienz und Faim2-Überexpression. Bei den Faim2 $2^{+/+}$-Tieren konnte in der klinischen Untersuchung des neurologischen Defizits in der vergleichenden Analyse kein Unterschied durch die Überexpression von Faim2 beobachtet werden. 


\section{Diskussion}

\subsection{Faim2 im Überblick}

Die in der vorliegenden Arbeit dargestellten und in Reich et al. (2011) veröffentlichten Daten und Ergebnisse zu dem neuroprotektiven Membranprotein Faim2 belegen erstmalig in vivo seinen signifikanten Einfluss während und nach der akuten Phase der transienten fokalen zerebralen Ischämie und die Bedeutung seiner Expression und Regulation. Betrachtet man die Häufigkeit und die gesundheitlichen, ökonomischen und psychischen Folgen einer zerebralen Ischämie beim Menschen (vgl. Abschnitt1.3.1 auf Seite 13) in Verbindung mit der evolutionären Stärke von Faim2, wird die Bedeutung des therapeutischen Potentials dieses endogenen neuroprotektiven Proteins deutlich. Obgleich nicht ausgeschlossen werden kann, dass der Organismus mit all seinen komplexen Regelkreisläufen und Kontrollinstanzen andere Mechanismen kompensatorisch hoch- oder herunterreguliert, um den Verlust von Faim2 in den Faim2-defizienten Tieren auszugleichen, belegen die dargestellten Ergebnisse, dass Faim2 protektiv auf das Überleben einer neuronalen Zelle wirkt und den programmierten Zelltod verhindern kann. Gleichzeitig geben sie Anhalt darauf, dass nicht nur eine hohe neuronale Spezifität für Faim2 besteht sondern auch, dass im Rahmen der zeitlichen Regulation von Faim2 und Fas/CD95 nach zerebraler Ischämie potentiell neuronale Regeneration über das FasL/CD95L-Fas/CD95-System gefördert und damit auch von Proteinen wie Faim2 kontrolliert werden kann. Zuliani et al. (2006) schrieben erstmalig Fas/CD95 gegensätzliche Fähigkeit zur Apoptoseinduktion - reverse signaling - zu. Mit dieser Eigenschaft des FasL/CD95L-Fas/CD95-Systems belegten sie, dass Fas/CD95 nicht nur Apoptose in kortikalen und hippokampalen Neuronen, sondern auch regenerative und differenzierende Prozesse wie neuronal branching induzierte und kontrollierte.

Ein möglicher therapeutischer Ansatz bestünde analog zur viralen Hochregulation in der medikamentös induzierten Hochregulation über den PI3-Kinase-Akt/ProteinKinase-B-abhängigen Signalweg, über den Faim2 reguliert wird (Beier et al. 2005). Siren et al. (2001) beispielsweise beschrieben die antiapoptotischen Eigenschaften von Erythropoietin in zerebralem Gewebe, wobei gleichzeitig von Zhao W et al. (2006) 
aufgezeigt wurde, dass Erythropoietin über PI3-Kinase-Akt phosphorylierend wirkte und dessen Konzentration erhöhte. Damit wäre eine potentielle Hochregulation von Faim2 nach zerebraler Ischämie mittels Erythropoietin innerhalb der Akutbehandlung denkbar.

Katchanov et al. (2001) haben gezeigt, dass im Mausmodell der transienten zerebralen Ischämie mittels MCAo reliable und signifikante Daten bzgl. der Untersuchung von verspätetem neuronalem Zelltod im Striatum erzeugt werden können und dieses Modell zuverlässig die fokale zerebrale Ischämie beim Menschen repräsentiert. Die Ausprägung der Nekrose mit direktem Zelluntergang neuronaler Zellen durch den Verlust an Energiezufuhr ist abhängig von der Länge der Ischämiezeit und der Zeit bis zur Reperfusion sowie dessen Ausprägung. Gleichzeitig sind jedoch die Zellen der Region um die zentrale Nekrose herum, die Penumbra, einer Vielzahl an Noxen und Signalen, wie beispielsweise Nachbarzellen (Brudermord), Glutamat-Exitotoxizität, reaktive Sauerstoffradikale, Entzündungsreaktion, Kommunkationsverlust durch die Ankermoleküle, Metalloproteinasen und Endotheline, ausgesetzt (Ferrer und Planas 2003). Weiterhin stellten Ferrer und Planas (2003) die Apoptose als ursächlich für die komplexen Abläufe des ischämischen neuronalen Zelltods innerhalb der Penumbra dar. Daher wurde in der vorliegenden Arbeit durch die Ischämiezeit von 30 Minuten eine milde Ischämieform ohne Nekrose gewählt und beides untersucht, die frühe Phase der apoptotischen Ischämiefolgen im Zentrum des Schlaganfalls und die verspätete Pathophysiologie der Penumbra. Hierbei konnte ein signifikanter Unterschied bei Faim2-defizienten Versuchstieren in der Dichte und Anzahl der die Apoptose einleitenden Zellen, im Schlaganfallvolumen und in der Caspase-Aktivität gezeigt werden. Dass Fas/CD95 von großer Bedeutung für die apoptoseeinleitende Signaltransduktion nach zerebraler Ischämie ist, wurde bereits in unterschiedlichen Mausmodellen der zerebralen Ischämie gezeigt. Eine signifikante Reduktion des Ischämieareals konnte z.B. bei direkter Signalunterbrechung durch genetische Veränderungen von Fas/CD95 (Graham et al. 2004, Martin-Villalba et al. 2001, Rosenbaum et al. 2000) oder antikörpervermittelte Neutralisation von FasL (Martin-Villalba et al. 2001) erreicht werden. Die genetische Faim2-Defizienz der in dieser Arbeit untersuchten Tiere führte nun zu dem gegenteiligen Effekt, nämlich zur signifikanten Erhöhung des Infarktvolumens und Zelluntergangs nach transienter fokaler zerebraler Ischämie, da nun die physiologische, intrinsische Hemmung der Apoptose während der Signaltransduktion ausgeschaltet war. Dass dieser Effekt durch die Hochregulation von Faim2 mittels viralem Lenitivirusvektor im Striatum rückläufig war und bei Überexpression sogar zu einer signifikanten Reduktion führte, belegt die hohe Spezifität dieser Signalüber- 
tragung über Faim2 und Fas/CD95.

Die hier vorliegend erarbeiteten Ergebnisse weisen dem Membranprotein Faim2 eine wichtige Rolle in der Regulation der Apoptose innerhalb einer Zelle zu. Neben der reinen Regulation der zur Apoptose führenden Signaltransduktion, um beispielsweise ein unkontrolliertes Absterben von Zellen zu verhindern, ist Faim2 damit an der Entscheidung zwischen Absterben und Regeneration einer Zelle beteiligt. Ob im Umkehrschluss demnach die Regeneration von Zellen durch Überexpression von Faim2 beschleunigt oder induziert und ob geschädigtes Gewebe durch Faim2 zur Gesundung, Proliferation und Regeneration angestoßen werden kann, ist mit den Ergebnissen der vorliegenden Arbeit jedoch ebenso noch nicht sicher zu beantworten, wie mögliche Zusammenhänge der apoptosehemmenden Wirkung von Faim2 mit weiteren Krankheitsentitäten neben der zerebralen Ischämie.

In der Tabelle 4.1 ist eine Auswahl an aktuellen Arbeiten zu Faim2 im Zusammenhang mit Apoptoseregulation aufgezeigt. Es wird dabei deutlich, dass die Charakterisierung von Faim2 nicht nur eine relativ junge Geschichte hat, sondern auch, dass dieses neuroprotektive Membranprotein bereits in verschiedenen Zusammenhängen und Fragestellungen untersucht worden ist. Auffallend ist, dass es durch die Ergebnisse der vorliegenden Arbeit erstmalig gelang, Faim2 an defizienten Mäusen in vivo zu untersuchen. Die im Mausmodell der zerebralen Ischämie erhobenen, signifikanten Ergebnisse im Vergleich zwischen Faim2-defizienten Mäusen und Wildtypen, unterstreichen die zuvor in vitro entwickelten Funktionsweisen dieses antiapoptotischen Proteins.

Tabelle: 4.1: Zentrale Aussagen ausgewählter Veröffentlichungen zu Faim2 und zerebraler Ischämie

\begin{tabular}{|c|c|c|c|}
\hline Titel & Autor & Inhalt & $\begin{array}{l}\text { Art der } \\
\text { Studie }\end{array}$ \\
\hline $\begin{array}{l}\text { LFG: an anti-apoptotic gene that provides } \\
\text { protection from Fas-mediated cell death. }\end{array}$ & Somia et al. 1999 & $\begin{array}{l}\text { Erstmalige Darstellung der antiapoptotischen } \\
\text { Wirkung von Lifeguard (LFG)/Faim2 im Rah- } \\
\text { men eines genetischen Screenings zur Inhibi- } \\
\text { tion von Apoptose. Eine besonders hohe Ex- } \\
\text { pression des Proteins konnte in der Hippokam- } \\
\text { pusregion nachgewiesen werden. }\end{array}$ & in vitro \\
\hline $\begin{array}{l}\text { FasL }(C D 95 L / A P O-1 L) \text { resistance of neu- } \\
\text { rons mediated by phosphatidylinositol 3- } \\
\text { kinase-Akt/protein kinase B-dependent ex- } \\
\text { pression of lifeguard/neuronal membrane } \\
\text { protein } 35 .\end{array}$ & Beier et al. 2005 & $\begin{array}{l}\text { Die Expression des antiapoptotischen Pro- } \\
\text { teins membrane protein 35/LFG/Faim2 } \\
\text { wird durch Phosphatidylinositol-3-kinase } \\
\text { (PI3-kinase)-Akt/Protein-Kinase-B reguliert } \\
\text { und kann durch in-vitro -Überexpression in } \\
\text { Gliomazellen diese vor Apoptose schützen. }\end{array}$ & in vitro \\
\hline
\end{tabular}


4.2. Die Rolle von Faim2 während der zerebralen Ischämie und Regulation der Fas/CD95-

\begin{tabular}{lll} 
Zentrale Aussagen ausgewählter Veröffentlichungen zu Faim2 und zerebraler Ischämie Fortsetzung \\
\hline Titel & Autor & Inhalt \\
\hline $\begin{array}{l}\text { Inhibition of apoptosis by expression of an- } \\
\text { tiapoptotic proteins in recombinant human }\end{array}$ & Choi et al. 2007 & $\begin{array}{l}\text { Die immunologischen Untersuchungen an hu- } \\
\text { Studie }\end{array}$ \\
keratinocytes. & & $\begin{array}{l}\text { manen Keratinozyten zeigen, dass eine Ab- } \\
\text { stoßungsreaktion durch Hochexpression von }\end{array}$ \\
& antiapoptotischen Proteinen wie LFG/Faim2 \\
& verringert werden kann und die Zellen selte- \\
ner in Apoptose gehen.
\end{tabular}

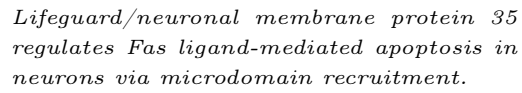

Lifeguard/neuronal membrane protein 35 regulates Fas ligand-mediated apoptosis in neurons via microdomain recruitment.

Fernandez et al. 2007
The anti-apoptotic protein lifeguard is expressed in breast cancer cells and tissues.

Fas/CD95 regulatory protein Faim2 is neuroprotective after transient brain ischemia.
Bucan et al. 2010 (1)

Reich et al. 2011
FasL/Fas und damit auch LFG/Faim2 spielen eine zentrale Rolle in der Apoptoseregulation und in neurodegenerativen Erkrankungen. Das anitapoptotische Protein kann kortikale Zellen vor Apoptose schützen und reguliert die Caspaseaktivität herab. Es ist in den sog. $l i$ pid rafts lokalisiert, besitzt sieben Membrandomänen und ist an einer sehr frühen und wichtigen Position im Signaltransduktionsweg der Apoptoseaktivierung hemmend wirksam.

Das apoptosehemmende Protein LFG/Faim2 ist insbesondere in hoher Konzentration in epithelialen Brustkrebszellen exprimiert. Die hohe Expression korreliert mit der sinkenden Sensitivität der malignen Zellen gegenüber Fas und damit der Malignität des Tumors.

Erstmals Nachweis von Schutz vor Apoptose in einer Faim2-defizienten Mauslinie in vivo. Auch die in-vitro-Daten bestätigen die signifikant höhere Apoptoserate nach zerebraler Ischämie bzw. oxygen-glucose deprivation (OGD). Ein Schutz vor Apoptose wird durch Hochexpression mittels viralem Gentransfer erreicht. in vitro

in vitro

\subsection{Die Rolle von Faim2 während der zerebralen Ischämie und Regulation der Fas/CD95- induzierten Apoptose}

Dem Membranprotein Faim2 können durch die vorliegenden Ergebnisse eine Reihe an wichtigen Eigenschaften zugeordnet werden: (1) hohe zelluläre Spezifität (siehe Abbildungen 3.1 auf Seite 53 und 3.10 auf Seite 63), (2) zentrale Positionierung innerhalb der Signaltransduktionskaskade an den sog. lipid rafts in der Zellmembran (Fernandez et al. 2007) in unmittelbarer Nähe zu den Todesrezeptoren/Todesdomäne (FADD) (siehe Abbildung 1.4 auf Seite 12 und der Caspase-8 mit frühem regulatorischen Einfluss auf die Caspasen-Aktivierung (vgl. Abbildung 3.11 auf Seite 64 und Abschnitt 3.3 auf Seite 66), (3) stabile und signifikante antiapoptotische Eigenschaften über Inhibition von Fas/CD95 direkt, sowohl in vivo als auch in vitro, 
(4) regulatives Expressionslevel während der zerebralen Ischämie (siehe Abbildung 3.2 auf Seite 54 mit Herabregulation in der postakuten Ischämiephase zur möglicherweise Fas-induzierten Regeneration (siehe alternative Funktionen von Fas/CD95, Abschnitt 1.1.4 auf Seite 7) sowie (5) Regulierbarkeit über viralen Gentransfer und damit potentiell auch medikamentös über Erythropoietin (Siren et al. 2001, Beier et al. 2005, Zhao W et al. 2006) zur signifkanten Reduktion des Zelluntergangs und des Infarktvolumens.

Frühere Studien zu Faim2 beschreiben bereits einen Teil dieser Eigenschaften in vitro (siehe Tabelle 4.1 auf Seite 79). Dass Faim2 apoptosehemmende Eigenschaften hat, stellten bereits Somia et al. (1999) heraus. Beier et al. (2005) brachten jedoch Faim2 erstmals direkt in einen Zusammenhang mit Apoptose und Caspase-Aktivierung. Sie konnten in mehreren Zellreihen, u.a. Glioma-Zellreihen, die nicht Faim2 exprimierten, nachweisen, dass diese eine erhöhte Apoptoserate aufwiesen. Analog zu dem in der vorliegenden Arbeit durchgeführten viralen Gentransfer gelang es ihnen schließlich Faim2 auch in diesen Zellen zu exprimieren und damit die Apoptoserate zu senken. Fernandez et al. (2007) gelang es neben dem erneuten Nachweis der antiapoptotischen Eigenschaften von Faim2, eine nähere mikroskopische Charakterisierung durchzuführen. So stellten sie fest, dass Faim2 in den sog. lipid rafts und damit in unmittelbarer Nähe zu den FasL/CD95L-Fas/CD95-Komplexen und den Todesdomänen (FADD) lokalisiert ist. Diese Positionierung stellte eine zentrale Eigenschaft für die Untersuchungen in der vorliegenden Arbeit der Caspase-Aktivität in vivo dar. Wobei Somia et al. 1999 bereits zuvor herausgefunden hatten, dass Faim2 weder direkt die Bindungsfähigkeit von Fas/CD95 mit FADD noch die Verbindung von FasL/CD95L zu Fas/CD95 beeinflusst. Bucan et al. (2010) stellten die Zellproliferation von Zellen in einem Mammakarzinom in Zusammenhang mit Faim2. Sie konnten nachweisen, dass Faim2 in Zelllinien eines Mammakarzinoms signifikant höher exprimiert ist als in gesunden Zellen und damit die Karzinomzellen weniger sensitiv auf Fas-induzierte Apoptosesignale reagierten.

Durch die vorliegende Arbeit ist es erstmals gelungen an zuvor generierten Faim2defizienten Mäusen zunächst das Resultat aus dem Verlust sowie die Relevanz des Vorhandenseins von Faim2 in vivo zu untersuchen. In einem zweiten Schritt wurde Faim2 durch einen lentiviralen Vektor direkt stereotaktisch striatal wieder zugeführt bzw. überexprimiert und anhand dessen die Funktionsweise des Proteins im zerebralen Gewebe untersucht und konnte anhand von in-vitro-Versuchen bestätigt werden. Dabei konnten in einem experimentellen Modell der zerebralen Ischämie antiapoptotische Eigenschaften von Faim2 nachgewiesen werden. Ferner ist die Expression von 
Faim2 nach einer zerebralen Ischämie reguliert. Durch eine verminderte Expression von Faim2 nach zerebraler Ischämie scheint die apoptotische Vulnerabilität von Neuronen erhöht. Die signifikanten Ergebnisse belegen die hohe Spezifität, mit der Faim2 antiapoptotisch wirksam ist. Nicht auszuschließen bleiben dabei regulatorische Kompensationsmechanismen, die bei Faim2-Defizienz in einem Organismus wirksam werden. Jedoch konnte sowohl durch die deutliche Signifikanz der erhobenen Daten bzgl. Infarktvolumen, Apoptoserate und -dichte und Caspase-Aktivität als auch durch den erfolgreichen Schutz vor Apoptose durch die Überexpression von Faim2 in neuronalen Zellen des Striatums und Caudoputamens, die wichtige Rolle von Faim2 für die Apoptoseregulation belegt werden.

Neben dem Aspekt der kontrollierten Apoptoseinduktion durch Fas/CD95 und den hemmenden Eigenschaften von Faim2 lassen sowohl die zeitliche Regulation (vgl. Abbschnitte 3.1.2 auf Seite 54 und 4.2.3 auf Seite 85 dieser beiden Proteine als auch die hohe Expression von Faim2 im ZNS (vgl. Abbschnitt 3.1.1 auf Seite 53) weitere Funktionen vermuten. Vor dem Hintergrund der erstmaligen Darstellung durch Zuliani et al. (2006), dass Fas/CD95 Neuroregeneration in Form von neuronal branching induzierte, nahmen Beier et al. (2007) dies als Grundlage zur Annahme, dass durch Fas/CD95 Neuroplastizität, dessen Voraussetzung Dendritenwachstum (neuronal branching) ist, nach Schädel-Hirn-Trauma induziert werden kann. Durch in-vivoVersuche im Mausmodell des akuten Schädel-Hirn-Traumas konnten sie die in-vitroErgebnisse von Zuliani et al. (2006) insofern bestätigen, als dass durch Fas/CD95 sowohl das Läsionsvolumen verringert als auch die kognitiven Hirnleistungen sowie die Gedächtnisleistungen erhöht werden. Durch die verstärkte Expression von Fas/CD95 und verminderte Expression von Faim2 nur wenige Stunden nach der zerebralen Ischämie erhöht sich die zerebrale apoptotische Vulnerabilität. Die in dieser Arbeit in vivo dargestellte antiapoptotische Wirkung von Faim2 schützt vor dem neuronalen Zelluntergang. Nach einer ersten Phase mit gesteigertem Zelluntergang schließst sich eine Phase der Regeneration und Plastizität an. Experimentelle Studien, die diesen Zeitraum untersuchen, legen nahe, dass zur Verbesserung der Plastizität vermutlich eine verstärkte Aktivität des Fas/CD95-Signalwegs vorteilhaft ist. Im Zusammenhang mit den Ergebnissen der vorliegenden Arbeit lässt dies die Vermutung zu, dass Faim2 und andere Fas/CD95-regulierende Proteine die Fähigkeit besitzen, nicht nur hemmend auf die Apoptoseinduktion, sondern auch indirekt oder gar direkt aktivierend auf Neuroregeneration und Neuroplastizität im weiteren Verlauf einer akuten Erkrankung wie dem Schädel-Hirn-Trauma und dem Schlaganfall zu wirken. Ein möglicher Erklärungsansatz liegt in einer geänderten downstream-Signalpräferenz 
von Fas/CD95. Damit wird Faim2 zu einem wertvollen Ziel für therapeutische Ansätze. Gleichzeitig geben allerdings Beier und Schulz (2009) zu bedenken, dass der therapeutische Ansatz am FasL/CD95L-Fas/CD95-System und damit auch Faim2, nicht ungefährlich ist. Die Bivalenz von Fas/CD95 und Faim2 mit den bisher noch wenig bekannten, komplexen Regulationsmechanismen innerhalb der Zellen, ermöglicht einerseits einen therapeutischen Ansatz bei zahlreichen neurologischen Erkankungen (vgl. Abbschnitt 1.1.5 auf Seite 9), birgt andererseits aber die Gefahr der Stimulation von Apoptoseinduktion, neurogenem Wachstum oder gar Tumorinduktion. Daher muss dieser hochpotente und zugleich gefährliche therapeutische Ansatz des regulatorischen Netzwerks von Fas/CD95 und dessen modulierende Proteine, wie Faim2, spezifischer untersucht, die Transduktionskaskade genauer indentifiziert und Möglichkeiten erarbeitet werden, Signale entlang der neuroregenerativen Eigenschaften $\mathrm{zu}$ induzieren, während die proapoptotischen Eigenschaften umgangen werden können (Beier und Schulz 2009). Dieser noch unbekannte switch (Umschaltpunkt) von Faim2, der über Apoptoseinduktion oder Überleben und ggf. Regeneration der Zelle entscheidet, bleibt auch durch die Daten der vorliegenden Arbeit weiterhin unbekannt.

\subsubsection{Vergrößertes Ischämievolumen unter Faim2-Defizienz}

Sowohl die Beobachtung des vergrößerten Infarktareals und Hirnödems als auch die Ausbreitung des Ischämieareals bis hin in den umgebenden Kortex (siehe Abbildungen 3.4 auf Seite 58 und 3.7 auf Seite 61 , ist bei den Tieren in der klinischen Untersuchung durch den SNAP-Test bestätigt worden. Wie durch die Anzahl TUNELpositiver neuronaler Nuklei und der neuronalen Caspase-3-Aktivität gezeigt wurde, weist nicht nur die volumetrische Ausdehnung des Infarktareals einen signifikanten Unterschied, sondern auch die Dichte apoptotischer neuronaler Zellen bei den Faim2defizienten Versuchstieren eine signifikante Zunahme auf. Diese Beobachtung belegt die qualitative und quantitative Verschiebung sterbender, gefährdeter oder überlebender neuronaler Zellen weg von potentiell rettbaren neuronalen Zellen in der Penumbra in Richtung ischämischem Zelltod bei Faim2-Defizienz.

Aufgrund dieser signifikanten Unterschiede im Infarktareal Faim2-defizienter Tiere muss jedoch kritisch eine Gefäßanormalität diskutiert werden. Der Circulus arteriosus (cerebri) Willisi ist bei Säugetieren als extrazerebrale Anastomosen des Gehirns ähnlich aufgebaut, weist jedoch starke interindividuelle Variationen bzgl. des Gefäßverlaufs, der Gefäß̊durchmesser und der Versorgungsgebiete auf (Hillen et al. 1991). 
Das im Filamentmodell der MCAo verwendete Silokonfilament wird durch die $A$. carotis interna an der A. ophthalmica vorbei bis distal der Bifurkation von A cerebri media und anterior vorgeschoben. Somit kann durch die Anastomosen das restliche Gewebe weiter versorgt werden, nur die A. cerebri media ist vollständig vom Blutfluss getrennt. Mit dieser Positionierung verschließt das Filament ebenfalls den Zufluss der A. communicans posterior, welcher wiederum in die A. cerebri posterior mündet. Letztere Arterie versorgt dorsale Gehirnanteile wie die Hippokampusregion und anteilig den Kortex. Um das vergrößerte Infarktareal durch eine Gefäßmalformation erklären zu können, müsste bei den Faim2-defizienten Tieren eine Fehlfunktion der Anastomosen im Circulus arteriosus (cerebri) Willisi bestehen. Der Blutfluss von der kontralateralen Arteria cerebri posterior und der Arteria basilaris müsste unterbrochen oder unzureichend sein oder die Arteria communicans posterior insuffizient mit gleichzeitiger Vergrößerung des Versorgungsgebietes der Arteria cerebri media. Eine Malformation der A. communicans posterior bestehen bei ca. 6-21\% der Bevölkerung und induziert insbesondere unter ipsilateral bestehender Okklusion der $A$. cerebri media eine fokale zerebrale Ischämie im Hypothalamus (Chuang et al. 2008). Bei 1-2 Versuchstieren mit einem derart stark ausgedehnten Infarktareal pro Versuchsansatz werden die vorgenannten 6-21\% nicht erreicht, weshalb nicht von einem erhöhten Malformationsrisiko auszugehen ist. Auch die in den Faim2-defizenten Tieren beobachtete Ausdehnung des Ischämieareals in den Kortex erschien nicht durch eine Gefäßmalformation erklärbar zu sein, da die Flussmessung während der MCAo und die chirurgische Präparation während der Ischämieinduktion keine Auffälligkeiten ergaben. Es wurde daher auf eine gesonderte Gefäßdarstellung der zerebralen Blutversorgung verzichtet.

\subsubsection{Expression von Faim2 und Fas/CD95 im Organismus}

Während die Apoptose an sich als Regulator für Zellwachstum und Kontrollinstanz für die physiologische Funktionsweise der Zellen gilt, muss zwingender Weise auch die Apoptose selbst reguliert werden. Da dieses Phänomen nicht nur in vereinzelten Geweben im Organismus stattfindet, sondern ubiquitär in jeder Zelle potentiell ablaufen kann, wäre Faim2 in jeder Zelle zu erwarten. Die Abbildung 3.1 auf Seite 53 zeigt die Expression von Faim2 im Organismus. Hierbei fällt auf, dass Faim2 auf mRNA-Ebene lediglich in neuronalem Gewebe (Kortex, Zerebellum, Hirnstamm) und in der Lunge sicher nachzuweisen war. Der Nachweis im Gastrointestinaltrakt und Harnblase gelang in repetitiven Versuchsanordnungen nur schwach bis gar nicht. 
Somia et al. (1999) hingegen konnten in einer mRNA-Expressionsanalyse multipler humaner Organe mittels Northern-Blot Faim2 auch in nicht-neuronalem Gewebe nachweisen (z.B. Harnblase, Uterus, Niere, Zervix, Ovarien etc.). Die höchste Expression wiesen sie jedoch ebenfalls im neuronalen Gewebe, insbesondere in den Körnerzellschichten des Hippokampus und Zerebellums nach. Auch Fernandez et al. (2007) kamen im Rahmen einer Expressionsstudie zu diesem Ergebnis und wiesen eine hohe Expression von Faim2 mittels quantitativer RT-PCR in hippokampalen Zellen und Neuronen des Kleinhirns nach. Fas/CD95 dahingegen war von mehreren Autoren zuvor in nahezu allen Organen nachgewiesen worden: Desbarats und Newell (2000) (Hepatozyten), Peter et al. (2007) (Herz, Pankreas und Kolon), Bucan et al. (2010) (Mammakarzinomzellen), Choi et al. (2007) (Keratinozyten). Die Ergebnisse der vorliegenden Arbeit weisen darauf hin, dass Faim2 hingegen nahezu ausschließlich in neuronalem Gewebe exprimiert ist.

Neben dem Nachweis von Faim2 auf RNA-Ebene gelang nur zweimalig der Nachweis auf Proteinebene. Hierzu wurden verschiedene Antikörper herangezogen, von denen letztlich nur der Antikörper der Firma Lifespan einen erfolgreichen Nachweis von Faim2 im Viruskonstrukt aufwies. Eine regelrechte Expressionsstudie war somit auf Proteinebene nicht erfolgreich. Eine mögliche Erklärung dafür könnte in der Aufarbeitung der Proteinproben liegen, im Rahmen derer die Proteine durch die mechanische und chemische Auflösung des Gewebes zum Teil denaturieren.

\subsubsection{Zeitliche Regulation von Faim2 und Fas/CD95 nach zerebraler Ischämie}

Neben der longitudinalen Expression von Faim2 in unterschiedlichen Geweben ist insbesondere auch die zeitliche Expression von Faim2 im Vergleich zu Fas von großem Interesse. Fernandez et al. (2007) wiesen nach, dass Faim2 in der postnatalen Entwicklungsphase und im Erwachsenenalter hochreguliert wird. Für die Expressionsstudie der vorliegenden Arbeit wurde eine leicht modifizierte Fragestellung gewählt. Der Fokus lag dabei mehr auf dem zeitlichen Expressionsverlauf von Faim2 und Fas/CD95 während und nach der zerebalen Ischämie. Da Faim2 in unmittelbarem Zusammenhang mit Fas/CD95 steht, wurde dieser vergleichend ebenfalls in die Expressionsstudie eingeschlossen. Die Abbildung 3.2 auf Seite 54 zeigt die Herabregulation von Faim2 ab ca. 3-18 Stunden nach MCAo, während Fas/CD95 bereits ab 3 Stunden signifikant hochreguliert war und zwischen der 18. und 48. Stunde wieder fast bis auf das Grundniveau abfiel. Faim2 ist 48 Stunden nach MCAo wieder nahezu beim Ausgangswert 
angekommen.

Die unverändert hohen Konzentrationen an Faim2 innerhalb der Akutphase (3 Stunden nach MCAo) der zerebralen Ischämie in Verbindung mit der zuvor nachgewiesenen hohen Spezifität für neuronale Zellen, lassen auf ein hohes neuroprotektives Potential des Membranproteins Faim2 schließen. Während Faim2 in der Akutphase auf einem hohen Level exprimiert bleibt, wird es in der postakuten Phase (18 Stunden nach MCAo) signifikant herunterreguliert und könnte damit alternative Fas/CD95Signaltransduktionen (vgl. Abschnitt 1.1.4 auf Seite 7) zulassen. Dieses würde beispielsweise Neuroregeneration ermöglichen. Initial den Zelltod fördernd, gleichzeitig aber die vorgenannte Vermutung unterstützend verhält sich Fas/CD95 in der postischämischen Phase. In der akuten Phase nach Ischämie, in der Zelltod initiiert wird, wird Fas/CD95 signifikant hochreguliert, während Faim2 im Verlauf abfällt. Anschließend verbleibt es in der postakuten Phase (18 Stunden nach MCAo), in der regenerative Prozesse eingeleitet werden, auf einem hohen Expressionsniveau. Ob diese $\mathrm{Zu}-$ sammenhänge und damit Faim2 tatsächlich die entscheidende Rolle in der Umschaltung von Apoptose zu neuroregenerativen Prozessen durch alternative Fas/CD95Transduktionen spielen, bleibt spekulativ und ist in der vorliegenden Arbeit nicht weiter bearbeitet worden, sollte aber in Folgestudien berücksichtigt werden.

Ein Schwachpunkt dieser Expressionsstudie sind die relativ weit gewählten Zeitabstände. Dadurch ist nicht genau zu beurteilen, in welchem Zeitraum ein Minimum bzw. Maximum der Regulation erreicht ist.

\subsubsection{Signaltransduktion und Caspase-Aktivität}

Um die Aktivität von Faim2 während der Apoptoseeinleitung einordnen und detailliert untersuchen zu können, sind sowohl die Kenntnis über die genaue Lokalisation des Proteins selbst als auch die Kenntnis über andere an dem Vorgang beteiligte Proteine notwendig. In der Tabelle 4.2 sind die in der Signaltransduktion beteiligten, inhibierenden Proteine dargestellt und deren Funktion sowie Literaturreferenzen aufgelistet. Die Abbildung 1.4 auf Seite 12 zeigt die aufgelisteten Moleküle im Zusammenhang der Apoptosetransduktion graphisch.

Tabelle: 4.2: Überblick über die proximal inhibierend wirkenden Proteine der Apoptosetransduktion nach Einleitung durch FasL-Aktivierung

\begin{tabular}{lllll}
\hline Bezeichnung & Gewebeexpression & Lokalisation & Funktion & Referenz \\
\hline \hline Faim1 (Fas apopto- & vorranging neu- & Zyoplasma & Hemmung des FADD direkt & (Sole et al. 2004, Segura et al. \\
tic inhibitory mole- & ronal & & & 2007) \\
cule 1) & & &
\end{tabular}


4.2. Die Rolle von Faim2 während der zerebralen Ischämie und Regulation der Fas/CD95induzierten Apoptose

Überblick über die proximal inhibierend wirkenden Proteine der Apo-ptosetransduktion nach Einleitung durch FasL-Aktivierung Fortsetzung

\begin{tabular}{|c|c|c|c|c|}
\hline Bezeichnung & Gewebeexpression & Lokalisation & Funktion & Referenz \\
\hline $\begin{array}{l}\text { Faim2/LFG (Fas } \\
\text { apoptotic inhibitory } \\
\text { molecule 2) }\end{array}$ & neuronal & Membran & $\begin{array}{l}\text { Hemmung der Komplexbildung } \\
\text { von Fas-Ligand/Fas-Rezeptor- } \\
\text { Komplex an den sog. lipid rafts } \\
\text { innerhalb der Zellmembran di- } \\
\text { rekt }\end{array}$ & $\begin{array}{l}\text { Schweitzer et al. 1998, Somia } \\
\text { et al. 1999, Schweitzer et al. } \\
2002 \text {, Beier et al. 2005, Fern- } \\
\text { andez et al. 2007, Davis et al. } \\
2007 \text { ) }\end{array}$ \\
\hline $\begin{array}{l}\text { Faim3 (Fas apopto- } \\
\text { tic inhibitory mole- } \\
\text { cule } 3 \text { ) }\end{array}$ & lymphoidal & Membran & Hemmung des FADD direkt & (Song und Jacob 2005) \\
\hline $\begin{array}{l}\text { Btk (Bruton's Tyro- } \\
\text { sinkinase) }\end{array}$ & hämatopoietisch & Zytoplasma & Hemmung des FADD direkt & $\begin{array}{l}\text { (Vassilev et al. 1999, Vassilev } \\
\text { und Uckun 2004) }\end{array}$ \\
\hline $\begin{array}{l}\text { FAP-1 (Fas assozi- } \\
\text { ierte Phosphatase 1) }\end{array}$ & ubiqitär & Zytoplasma & Hemmung des FADD direkt & (Foehr et al. 2005) \\
\hline $\begin{array}{l}\text { PEA-15 (Phospho- } \\
\text { protein enriched in } \\
\text { Astrocytes } 15 \mathrm{kDa})\end{array}$ & ubiquitär & Zytoplasma & $\begin{array}{l}\text { Hemmung der Aktivierung von } \\
\text { Caspase- } 8\end{array}$ & $\begin{array}{l}\text { (Ricci-Vitiani et al. } 2004 \text {, Ren- } \\
\text { ganathan et al. 2005, Eckert } \\
\text { et al. 2008) }\end{array}$ \\
\hline $\begin{array}{l}\text { c-FLIP (cellular } \\
\text { Fas-associated } \\
\text { death-domain-like } \\
\text { IL-1b-converting } \\
\text { enzyme-inhibitory } \\
\text { protein) }\end{array}$ & ubiquitär & Zytoplasma & $\begin{array}{l}\text { Hemmung der Aktivierung von } \\
\text { Caspase- } 8\end{array}$ & $\begin{array}{l}\text { (Raoul et al. 1999, Graham } \\
\text { et al. 2004, Taoufik et al. 2007, } \\
\text { Safa et al. 2008) }\end{array}$ \\
\hline $\begin{array}{l}\text { Bcl-2 (Familie der } \\
\text { B-Zell-Lymphom-2- } \\
\text { Proteine) }\end{array}$ & ubiquitär & Zytoplasma & $\begin{array}{l}\text { Hemmung der Aktivierungs- } \\
\text { und Freilassungsproteine von } \\
\text { Cytochrom c }\end{array}$ & $\begin{array}{l}\text { (White et al. 1998, Deveraux } \\
\text { et al. 2001, Henshall et al. 2002) }\end{array}$ \\
\hline $\begin{array}{l}\text { IAP (Inhibitor of } \\
\text { apoptosis protein } \\
\text { family) }\end{array}$ & neuronal & Zytoplasma & $\begin{array}{l}\text { direkte Hemmung der Ak- } \\
\text { tivierung von Caspase-3 } \\
\text { durch das Caspase-9/Apaf- } \\
1 / \text { Cytochrome } c-\text { Apoptosom }\end{array}$ & $\begin{array}{l}\text { (Gerhardt et al. 2001, Ferrer } \\
\text { und Planas 2003) }\end{array}$ \\
\hline
\end{tabular}

Der entscheidende Punkt bei der Signaltransduktion ist, wie in Abschnitt 1.1.3 auf Seite 5 ausführlich dargestellt, die Aktivierung der Caspase-8 (Initiatorcaspase) als Beginn der Caspasenkaskade und schließlich die Aktivierung der Caspase-3 (Effektorcaspase) als Einleitung der Exekution. Deshalb stand bei der vorliegenden Arbeit die Messung von aktivierter Caspase-8 und -3 neben Faim2 im Vordergrund. In der Abbildung 3.13 auf Seite 67 ist der signifikante Unterschied der Faim2-defizienten Tiere gegenüber den Wildtypen bzgl. der Aktivierung von Caspase- 8 und -3 dargestellt. Dieses Ergebnis des sog. Caspase activity assay belegt ex vivo die bereits aufgestellte Vermutung, dass die Faim2-Defizienz zu einem signifikanten Anstieg der Apoptoserate der Zellen führt. Das Assay wurde 20 Minuten nach MCAo durchgeführt und liefert wichtige Aussagen über die Apoptoseaktivität der Zelle im zeitlichen Verlauf. Nach 20-minütiger Reperfusion nach zerebraler Ischämie wird der bekannte Höhepunkt der Initiatorcaspase, Caspase-8, erreicht, während die Aktivität der in der 
4.2. Die Rolle von Faim2 während der zerebralen Ischämie und Regulation der Fas/CD95-

Kaskade später angesiedelte Effektorcaspase, Caspase-3, erst später beginnt (Velier et al. 1999). Entsprechend ebbt die gemessene Caspase-8-Aktivität bereits ab und erreicht schließlich den Ausgangspunkt, während die Caspase-3-Aktivität erst noch steigt. Im Vergleich von Faim2-defizienten Tieren mit Wildtypen konnte im zeitlichen Verlauf weiterhin gezeigt werden, dass Tiere mit Faim2-Defizienz nicht nur eine höhere Caspase-Aktivität sowohl von Caspase- 8 als auch -3 aufweisen sondern auch eine verlängerte Aktivität der Initiator-Caspase-8 (vgl. Abbildung 3.11 auf Seite 64 . Die verlängerte Aktivität wurde aufgrund der morphologischen Veränderungen der neuronalen Zellen im Kortex 16 Stunden nach MCAo beobachtet. Hierbei ist kritisch anzumerken, dass nicht auszuschließen ist, dass allein durch diese verlängerte Aktivität vermehrt Zellen aus der Penumbra den Zelltod einleiten und sich die Penumbra im Zentrum verkleinert, das Gesamtvolumen jedoch in die Peripherie ausbreitet. In der Abbildung 3.11 auf Seite 64 ist eine quantitative Darstellung von Caspase-8- und -3-NeuN-Doppelfärbungen dargestellt. Es ist zu erkennen, dass nicht nur signifikant mehr Neurone eine Caspaseaktivität in den Faim2-defizienten Tieren aufweisen als die Wildtypen, sondern auch das Zelldebridement und die Ausbreitung der Penumbra in den Kortex stark zugenommen hat. Diese Beobachtung steht in Analogie zu den TUNEL-Färbungen der apoptotischen Zellen im Vergleich Faim2-defizienter Versuchstiere und Wildtypen im infarzierten Hirnareal, siehe Abbildung: 3.7 auf Seite 61 . Um das Ausmaß der Penumbra und der dortigen Zellaktivitäten im unmittelbaren zeitlichen Verlauf nach zerebraler Ischämie verfolgen zu können, wäre eine MRT-Diagnostik notwendig. Um dabei die zelluläre Ebene beurteilen zu können, müsste eine zeitlichqualitative Aufarbeitung der Caspase-Aktivität erfolgen, welches im Rahmen der vorliegenden Arbeit nicht möglich war.

Die hier dargestellte Betrachtung der Caspasenaktivität und -regulation durch Faim2 ist ein wichtiger Bestandteil im Verständnis über die Funktionsweisen der apoptosemodulierenden Proteine, wie Faim2 eines ist. Dennoch konnte nach wie vor genaue Interaktion von Faim2 mit dem Rezeptor Fas/CD95 nicht geklärt werden. Somia et al. (1999) stellten für Faim2 bereits eine apoptoseinhibierende Funktion fest, belegten aber gleichzeitig, dass Faim2 weder die direkte Aktivierung von FADD durch Fas/CD95 noch die Bindung des Liganden FasL/CD95L an Fas/CD95 beeinflussen konnte. Es bleibt zu vermuten, dass Faim2 beispielsweise die Trimärbildung von FasL/CD95L-Fas/CD95 an den lipid rafts (vgl. Abschnitt 1.2 auf Seite 11) verhindert, da Faim2 auch hier lokalisiert ist (Fernandez et al. 2007). Somit bleiben der genaue molekulare Mechanimus, über den Faim2 durch Hemmung von Fas/CD95 modulierend auf die Caspasenaktivität wirkt, und der genaue Angriffspunkt innerhalb der 
lipid rafts am Fas/CD95 Rezeptor unbekannt.

\subsubsection{Klinische Symptomatik der Versuchstiere}

Die erhobenen Ergebnisse zu den zellulären Veränderungen nach einer zerebralen Ischämie spiegeln sich in den klinischen Untersuchungen der Versuchstiere wider. Alle in den Schlaganfallversuchen eingesetzten Versuchstiere wurden 10 Minuten vor der MCAo und 2 Stunden nach Beginn der Reperfusion mittels SNAP Score auf neurologische Defizite untersucht. Die Versuchstiere mit viralem Gentransfer wurden 20 Tage zuvor stereotaktisch operiert.

Nach erfolgtem Gentransfer von Faim2 war eine signifikante Verbesserung der erreichten Punktzahl (postoperativ) für die Faim2-defizienten Versuchstiere im Vergleich Lentivirus zu Plazebo zu beobachten. Vergleicht man die Wildtypen postoperativ zwischen verabreichtem Lentivirus und Plazebo, ergibt sich zwar eine Tendenz in Richtung Milderung der klinischen Symptomatik nach Virusinfektion, allerdings keine statistische Signifikanz. Es ist daher kritisch zu hinterfragen, ob eine Hochregulation oder gar Überexpression von Faim2 tatsächlich auch in den Wildtypen einen klinischen Effekt bei zerebraler Ischämie erreichen kann. Der Vergleich zwischen in-vitroVersuchsansatz und klinischer Symptomatik kann jedoch nur bedingt herangezogen werden, da in vitro mit ca. 90\% Infektionseffektivität durch den Faim2-Gentransfer nahezu physiologische Zelltod-Level in den Faim2-defizienten neuronalen Zellen erreicht werden konnte. Bei den Faim2-kompetenten Zellen wurde ein zusätzlicher neuroprotektiver Effekt gemessen. In vivo hingegen wird das ischämische Areal nur anteilig infiziert. Durch die stereotaktische Injektion in das Caudoputamen/Striatum und nicht in den Kortex wird lediglich das Zentrum der zerebralen Ischämie erreicht, die kortikalen, peripheren Anteile des Ischämieareals werden dabei nicht infiziert. Somit ist eine fehlende Signifikanz bezüglich der klinischen Symptomatik in den Wildtypen, bei denen ein zusätzlicher neuroprotektiver Effekt, anders als auf in-vitro-Ebene, nicht eintritt, nicht überraschend. Um einen möglichen therapeutischen Ansatz in den medizinischen Alltag zu übertragen, müsste gesichert sein, dass sowohl die Expression von Faim2 ubiquitär und nicht nur punktuell im ZNS erhöht wird als auch Wildtypen von der Aktivierung/Hochexpression von Faim2 profitieren, da Faim2-Defizienz in der Bevölkerung nicht zu erwarten ist.

Insgesamt können die erhobenen Daten der klinischen Beurteilung mittels SNAPScore lediglich einen weiteren Anhaltspunkt und eine Bestätigung der Versuchsreihen zur zellulären Erhebung darstellen. Ferner ist kritisch zu hinterfragen, ob der gewähl- 
te Zeitpunkt mit 10 Minuten vor MCAo und 2 Stunden nach Beginn der Reperfusion den Höhepunkt des postischämischen Apoptoseschadens überhaupt erreicht. Die erhobenen Daten aus der zeitlichen Regulation von Fas/CD95 und Faim2 nach MCAo (vgl. Abschnitte 3.1.2 auf Seite 54 und 4.2.3 auf Seite 85) weisen deutliche Expressionsänderungen von Faim2 und Fas/CD95 innerhalb der ersten 48 Stunden nach Reperfusionsbeginn nach. Insbesondere Fas/CD95 zeigt zum Zeitpunkt 3 Stunden und 18 Stunden nach MCAo eine signifikante Hochregulation, während Faim2 zunächst auf hohem Niveau exprimiert bleibt und erst bei dem Zeitpunkt 18 Stunden nach MCAo signifikant herabreguliert ist. Damit ist zwar eine klinische Hemisymptomatik 2 Stunden nach MCAo zu erwarten, gerade aber die zu diesem Zeitpunkt weiter ansteigende Fas/CD95-Konzentration lässt eine weitere Zunahme der apoptotischen Zellen vermuten. Endres et al. (1998b) konnten 24 Stunden nach 30-minütiger MCAo keine ischämischen Veränderungen in mit Triphenyltetrazoliumchlorid (TTC) und HE-Färbungen aufgearbeiteten Kryoschnitten nachweisen. Erst zu dem Zeitpunkt 72 Stunden nach MCAo waren ischämische Veränderungen auf diese Weise detektierbar. Die klinischen, neurologischen Tests wurden hier 24, 30 und 72 Stunden nach MCAo durchgeführt. Der Höhepunkt der ischämischen Veränderungen war bis zur 72. Stunde nach Schlaganfall zu erheben (Endres et al. 1998b).

Somit ist die o.g. fehlende Signifikanz bei den Faim2-Wildtypen sicherlich auch mit dem Zeitpunkt von nur 2 Stunden nach MCAo zu erklären, andererseits zeigt sich aber bereits zu diesem Zeitpunkt eine signifikante Verbesserung der klinischen Symptomatik nach MCAo und lentiviralem Faim2-Gentransfer bei den Faim2-defizienten Versuchstieren. Weitere klinische Untersuchungen zu späteren Zeitpunkten nach Beginn der Reperfusion nach 30-minütiger MCAo wären notwendig, um diese Beobachtung zu klären.

\subsection{Viraler Gentransfer von Faim2 in neuronalen Zellen als Schutz vor Apoptose - ein potentiell therapeutischer Ansatz}

Durch die Defizienz an Faim2, einem frühen Regulator der Fas-induzierten Apoptoseinduktion und Hemmer der FasL/CD95-Fas/CD95-Komplexbildung, erlitten die Versuchtiere eine signifikant größere zerebrale Ischämie und in der Zellkultur gingen signifikant mehr Neurone in die Apoptose. Durch die Infektion in vitro, mit ca. 90\% Infektionsrate der Neurone, konnte durch Faim2-Gentransfer das physiologische Level 
an unter OGD absterbenden Zellen in mutierten Neuronen wieder erreicht werden. Des Weiteren konnten Fernandez et al. (2007) nachweisen, dass bei Überexpression von Faim2 in Zellkultur primärer kortikaler Neurone die Caspasenaktivierung sank, was sie durch die Reduktion der FasL-induzierten Apoptose erklärten.

in vivo wurden nur die Areale um die stereotaktische Infektionsstelle um den Nucleus caudatus vom Lentivirus infiziert. Daraus resultierte eine partielle Reduktion des Infarktvolumens sowohl in Faim2-defizienten Versuchstieren als auch in den Wildtypen innerhalb der zentralen Ischämiezone, dem Caudatoputamen. Sowohl die Dosierung (Virustiter) als auch die Anzahl der Injektionsstellen und die Injektion selbst stellen bereits ein relevantes zerebrales Trauma dar. Durch eine Verdopplung der Dosis oder der Injektionsstellen innerhalb des Striatums und ggf. auch Kortex, könnte eine höhere Infektionsrate in vivo erreicht werden. Es wäre jedoch zu hinterfragen, welche Neurone aufgrund der Ischämie und welche durch das Injektionstrauma die Apoptose eingeleitet haben. Insofern kann das hohe therapeutische Potential der vorliegenden Ergebnisse nur dann genutzt werden, wenn durch eine medikamentöse Manipulation und Hochregulation von Faim2 in den betroffenen Neuronen kein sekundärer Schaden entsteht und eine ausreichend hohe Faim2-Expression erzielt werden kann.

Bei der Göttinger Epo Stroke Study aus den Jahren 1997 - 2001 konnte Frau Prof. Dr. Dr. H. Ehrenreich vom Max-Planck-Institut Göttingen bereits eine signifikant höhere neurologische Leistungsfähigkeit unter Erythropoietinsubstitution bei Radiochemotherapie von Glioblastompatienten, gemessen an der NIHSS (National Institute of Health Stroke Scale) nachweisen. Daraus ergab sich eine deutschlandweite Multicenter-Studie in den Jahren 2003-2008 in Krankenhäusern und Kliniken in Aachen, Berlin, Braunschweig, Bremen, Celle, Dresden, Erlangen, Essen, Göttingen, Hannover und Leipzig. Hierbei wurde Patienten mit einem Schlaganfall in der Notaufnahme Erythropoietin (Epoetin-alpha, Eprex ${ }^{\circledR}$; 40000 Internationale Einheiten als Kurzinfusion) verabreicht und am Tag 2, 3 und 90 wiederholt. Die Ergebnisse waren ernüchternd. Der Vegleich zu Patienten mit Plazebo oder rtPA ergab für Erythropoietin insgesamt ein tendenziell schlechteres Ergebnis. Bei Patienten, die mit rtPA therapiert worden waren, erhöhte sich das Komplikationsrisiko für Versterben, Blutung, Ödemen und thrombembolischen Geschehen (Ehrenreich et al. 2009, Sirén et al. 2009).

Dass Erythropoietin weiterhin jedoch ein hohes neuroprotektives Potential hat, stellten Garcia-Rodriguez und Sosa-Teste (2009) sowie Subirós et al. (2012) heraus. Von einer sicheren Anwendung bei Menschen zur Hochregulation von Faim2 und Ersatz der im Mausmodell der stereotaktischen Injektion angewandten Infektion der Neu- 
4.3. Viraler Gentransfer von Faim2 in neuronalen Zellen als Schutz vor Apoptose - ein potentiell therapeutischer Ansatz

rone mit einem Faim2-Lentivirus, scheinen wir derzeit jedoch noch weit entfernt zu sein. Dass Faim2 über PI3-kinase/AKT aktiviert und hochreguliert werden kann, haben bereits Beier et al. (2005) gezeigt. Dieses wiederum wird durch Erythropoietin aktiviert (Zhao W et al. 2006) und könnte somit theoretisch den neuroprotektiven Effekt, der Erythropoietin zugeschrieben wird, erklären. 


\section{Zusammenfassung}

Apoptose und dessen Signaltransduktion spielen eine zentrale Rolle in der Entstehung und Pathophysiologie von diversen neurologischen Erkrankungen. Um neuartige therapeutische Möglichkeiten auszuschöpfen oder zu erforschen, ist das Verständnis über die Regulationsprozesse im Rahmen der zur Apoptose führenden Signaltransduktion essentiell. In der vorliegenden Arbeit wurde das antiapoptotische Membranprotein Fas apoptotic inhibitory molecule 2 (Faim2) im Rahmen der Fas/CD95 induzierten Apoptose im Mausmodell der zerebralen Ischämie untersucht. Faim2 ist ein in der Evolution stabiler und zugleich neuronenspezifischer Inhibitor der über Fas/CD95-induzierten Apoptose. Um Faim2 näher untersuchen zu können, wurden Faim2-defiziente Versuchstiere generiert. Diese wiesen phänotypisch keinerlei Auffälligkeiten auf und zeigten ein regelrechtes Fortpflanzungsmuster. Im Rahmen der durchgeführten MCAo zur Induktion der zerebralen Ischämie im Versorgungsgebiet der Arteria cerebri media rief die Faim2-Defizienz ein signifkant größeres Schlaganfallvolumen hervor. In der neuronalen Zellkultur gingen signifikant mehr Faim2-defiziente Zellen nach kombinierter oxygen glucose deprivation in Apoptose als Wildtypzellen. Durch die stereotaktische Injektion eines rekombinanten Faim2-Lentivirus-Konstrukts und den damit verbundenen Gentransfer von Faim2 konnte das Schlaganfallvolumen in vivo bzw. die Apoptoserate in vitro signifikant gesenkt werden. Die zeitlich abhängige Regulation von Caspasenaktivierung und Fas/CD95 sowie Herabregulation von Faim2 nach einer zerebralen Ischämie geben neben den vorgenannten Schlaganfallvolumina Evidenz dafür, dass Faim2 als neuroprotektives Protein im Kontext der zerebralen Ischämie eine wichtige Rolle übernimmt und einen potentiellen therapeutischen Ansatz darstellt. Gleichzeitig deuten die zeitliche Herabregulation von Faim2 und erhöhte Expression von Fas/CD95 auch auf alternative Signaltransduktionswege, wie beispielsweise Fas-induzierte Neuroregeneration und -plastizität, hin und räumen damit möglicherweise Faim2 eine komplexe intrazellulär modulierende Stellung ein. 


\section{Abkürzungsverzeichnis}

A.

Aa.

Abb.

$\mathrm{ACM}$

$\mathrm{AFC}$

AIF

AKT

$\mathrm{Al}_{2}\left(\mathrm{SO}_{4}\right)_{3}$

Apaf-1

Aqua dest.

Bak

Bax

BCIP

Bcl-2

$\mathrm{BH}$

Bid

bp

BrdU

Btk

bzgl.

bzw.

${ }^{\circ} \mathrm{C}$

CARD

$\mathrm{CBF}$

cDNA

$\mathrm{CoCl}_{2}$

com.
Arteria

Arteriae

Abbildung

Arteria cerebri media

7-amino-4-trifluoromethyl coumarin

apoptosis-inducing factor

v-akt murine thymoma viral oncogene

homolog 1

Aluminiumsulfat

apoptotic protease activating factor-1

destilliertes Wasser

Bcl-2-antagonist/killer

Bcl-2-associated $X$ protein

5-Brom-4-chlor-3-indoxylphosphat, 4-Toluidin-Salz (BCIP)

B-cell lymphoma 2

Bcl-2 homology

BH3 interacting domain death agonist

Basenpaare

5-Bromo-2-Deoxyuridin

Bruton's Tyrosinkinase

bezüglich

beziehungsweise

Grad Celsius

Caspase-Rekrutierungs-Domäne

cerebral blood flow

komplementäre DNA

Cobalt(II)-chlorid

communis 
Ct

$\mathrm{CT}$

DAB

dATP

DAXX

DGN

Diablo

DIG

DISC

DNA

DNase I

DTT

dNTP

dUTP

EDTA

EEG

ELISA

ERK

EtOH

FADD

Faim1/2/3

Faim $2^{-/-}$

Faim $2^{+/+}$

FAP-1

f.c.

FCS

FITC

FLIP/cFLIP

$g$

G
Threshold-Cycle

Computertomographie

3,3'-Diaminobenzidin

Desoxyadenosintriphosphat

death-associated protein 6

Deutsche Gesellschaft für Neurologie

direct IAP-binding protein with low $p I$

Digoxigenin

death-inducing signaling complex

Desoxyribonukleinsäure (Deoxyribo-

nucleic acid)

Desoxyribonuklease I

Dithiothreitol

Desoxyribonukleosid-Triphosphat

Desoxyuridin-Triphosphat

Ethylendiamintetraessigsäure

Elektroenzephalographie

Enzyme Linked Immunosorbent Assay

extracellular signal-regulated kinase

Ethanol

Fas-associated death domain

Fas apoptotic inhibitory molecule 1, 2 oder 3

Faim2-Defizienz

Faim2-Wildtypen

Fas assoziierte Phosphatase 1

final concentration; Endkonzentration

fetal calf serum

Fluoresceinisothiocyanat

(cellular) Fas-associated death domainlike IL-1b-converting enzyme-inhibitory protein (Caspase-8 und FADD-like Apoptoseregulator)

Gramm

Gauge; Maß des Kanülenaußendurchmessers 


\begin{tabular}{|c|c|}
\hline GIT & Gastro-Intestinal-Trakt \\
\hline GFAP & Glial fibrillary acidic protein \\
\hline GFP & Grün fluoreszierendes Protein \\
\hline ggf. & gegebenenfalls \\
\hline $\mathrm{HCl}$ & Salzsäure \\
\hline $\mathrm{HE}$ & Hämatoxylin-Eosin \\
\hline HRP & $\begin{array}{l}\text { Meerrettichperoxidase (horseradish per- } \\
\text { oxidase) }\end{array}$ \\
\hline HtrA2 & HtrA serine peptidase 2 \\
\hline $\mathrm{H}_{2} \mathrm{O}$ & Wasser \\
\hline $\mathrm{H}_{2} \mathrm{O}_{2}$ & Wasserstoffperoxid \\
\hline IAP & inhibitor of apoptosis protein \\
\hline Iba-1 & $\begin{array}{l}\text { Ionized calcium binding adaptor mole- } \\
\text { cule } 1\end{array}$ \\
\hline Inc. & Incorporated \\
\hline i.p. & intraperitoneal \\
\hline $\mathrm{KCl}$ & Kaliumchlorid \\
\hline$k g$ & Kilogramm \\
\hline KG & Körpergewicht \\
\hline $\mathrm{KH}_{2} \mathrm{PO}_{4}$ & Kaliumhydrogenphosphat \\
\hline $\mathrm{KO}$ & knockout / Faim2-null-Mutant \\
\hline KU & Kunitz Units; Kunitz-Einheiten \\
\hline$l$ & Liter \\
\hline $\mathrm{L} \times \mathrm{B} \times \mathrm{H}$ & Länge mal Breite mal Höhe \\
\hline $\mathrm{LDH}$ & Lactatdehydrogenase \\
\hline LFG & Lifeguard (Synonym: Faim2) \\
\hline LV & Lentivirus \\
\hline$M$ & mol \\
\hline MAP & mitogen-activated protein \\
\hline MCA & $\begin{array}{l}\text { Middle cerebral artery, Arteria cerebri } \\
\text { media }\end{array}$ \\
\hline MCAo & Middle cerebral artery occlusion \\
\hline$m g$ & Milligramm \\
\hline $\mathrm{MgCl}_{2}$ & Magnesiumchlorid \\
\hline$m l$ & Milliliter \\
\hline$m m$ & Millimeter \\
\hline
\end{tabular}


mRNA

MRT

$\mu \mathrm{g}$

$\mu \mathrm{l}$

$\mathrm{n}$

N

$\mathrm{NaCl}$

$\mathrm{Na}_{2} \mathrm{HPO}_{4}$

$\mathrm{NaOH}$

NBT

NeuN

$\mathrm{NF} \kappa \mathrm{B}$

NIHSS

NMP35

n.s.

NSZ

OGD

$\mathrm{p}$

p35

pAdeno

PBS

$\mathrm{pCO}_{2}$

PCR

PEA-15

PFA

$\mathrm{pH}$

PI

PI3-Kinase-Akt

pLenti

$\mathrm{pO}_{2}$ messenger RNA; Boten-Ribonukleinsäure

Magnetresonanztomographie

Mikrogramm

Mikroliter

Anzahl

Äquivalentkonzentration

Natriumchlorid

Dinatriumhydrogenphosphat

Natriumhydroxid

Nitroblau-Tetrazoliumchlorid

Neuron-specific nuclear protein

nuclear factor kappa-light-chainenhancer of activated B-cells

National Institute of Health Strocke Scale

Neuronal membrane protein 35 (Synonym: Faim2)

nicht signifikant

Neuronale Stammzellen

oxygen-glucose deprivation (OGD)

Wahrscheinlichkeit

cyclin-dependent kinase 5 regulatory subunit 1 (p35)

Faim2-Adenoviruskonstrukt

Phosphatgepufferte Salzlösung

Kohlenstoffdioxidpartialdruck

Polymerasekettenreaktion

Phosphoprotein enriched in Astrocytes $15 k D a$

Paraformaldehyd

pondus/potentia Hydrogenii

Propidiumiodid

Phosphatidylinositol-3-Kinase-Akt

Faim2-Lentiviruskonstrukt

Sauerstoffpartialdruck 
pp60src

qPCR

RIP

RLT-Puffer

RNA

rpm

RT

RT-PCR

$s$

s.c.

SDS

SEM

Smac

SNAP

sog.

SVZ

TAE-Puffer

TBS

TBST

TdT

TE-Puffer

TENS-Puffer

TNFR

Tris

TTC v-src sarcoma (Schmidt-Ruppin A-2) viral oncogene homolog (avian) / phosphoryliertes 60-kDa-Phosphoprotein quantitative real time polymerase chain reaction

receptor-interacting protein

Guanidin-Thiocyanat enthaltender Lysispuffer

Ribonucleic acid; Ribonukleinsäure

rounds per minute (Umdrehungen pro Minute)

reverse Transkriptase

Reverse-Transkriptase-PCR

Sekunde

subkutan

Sodium Dodecyl Sulfate (Natriumdodecylsulfat)

Standardfehler des Mittelwerts (standard error of the mean)

second mitochondria-derived activator of caspase

Simple Neuroassessment of Asymmetric Impairment

sogenannt

Subventrikuläre Zone

Tris-Acetat-EDTA-Puffer

Tris-Buffered Saline

Tris-Buffered Saline and Tween 20

Terminale desoxynucleotidyl Transferase

Tris-EDTA-Puffer

Tris-EDTA-NaCl-SDS-Puffer

Tumornekrosefaktor-Rezeptor

Tris(hydroxymethyl)-aminomethan

Triphenyltetrazoliumchlorid 
TUNEL

$U$

UV

WPRE

WT

YES

ZNS
Terminal-Deoxynucleotidyl-Transferase-

mediated dUTP-biotin Nick End

Labeling

Unit

Ultraviolett

Woodchuck hepatitis virus posttranscription regulatory element

Wildtyp

v-yes-1 Yamaguchi sarcoma viral oncogene homolog 1

Zentrales Nervensystem 
Verwendete SI-Einheiten und -Präfixe:

Symbol SI-Einheit Präfix Faktor

\begin{tabular}{llll}
\hline$c$ & & centi & $10^{-2}$ \\
$g$ & Gramm & & - \\
$h$ & Stunde & & - \\
$k$ & & kilo & $10^{3}$ \\
$\mu$ & & mikro & $10^{-6}$ \\
$m$ & & milli & $10^{-3}$ \\
min & Minute & & - \\
mol & Mol & & - \\
$n$ & & nano & $10^{-9}$ \\
$s$ & Sekunde & & -
\end{tabular}




\section{Literaturverzeichnis}

Ashkenazi, A und Dixit, VM (1999): Apoptosis control by death and decoy receptors. Curr Opin Cell Biol 11 [Nr. 2] 255-60.

Beer, R, Franz, G, Schöpf, M, Reindl, M, Zelger, B, Schmutzhard, E, Poewe, W und Kampfl, A (2000): Expression of Fas and Fas ligand after experimental traumatic brain injury in the rat. J Cereb Blood Flow Metab 20 [Nr. 4] 669-77.

Beier, CP und Schulz, JB (2009): CD95/Fas in the brain-not just a killer. Cell Stem Cell $\underline{5}$ [Nr. 2] 128-130.

Beier, CP, Wischhusen, J, Gleichmann, M, Gerhardt, E, Pekanovic, A, Krueger, A, Taylor, V, Suter, U, Krammer, PH, Endres, M, WelLER, M und Schulz, JB (2005): FasL (CD95L/APO-1L) resistance of neurons mediated by phosphatidylinositol 3-kinase-Akt/protein kinase B-dependent expression of lifeguard/neuronal membrane protein 35. J Neurosci $\underline{25}$ [Nr. 29] $6765-74$.

Beier, CP, Kolbl, M, Beier, D, Woertgen, C, Bogdahn, U und BrawanSKI, A (2007): CD95/Fas mediates cognitive improvement after traumatic brain injury. Cell Res $\underline{17}$ [Nr. 8] 732-4.

Bor-Seng-Shu, E, Kita, WS, Figueiredo, EG, Paiva, WS, Fonoff, ET, TeiXeIRA, MJ Und PANERAI, RB (2012): Cerebral hemodynamics: concepts of clinical importance. Arq Neuropsiquiatr $\underline{70}$ [Nr. 5] 352-6.

Brint, S, Jacewicz, M, Kiessling, M, Tanabe, J und Pulsinelli, W (1988): Focal brain ischemia in the rat: methods for reproducible neocortical infarction using tandem occlusion of the distal middle cerebral and ipsilateral common carotid arteries. J Cereb Blood Flow Metab $\underline{8}$ [Nr. 4] 474-85.

Buchn, V, Reimers, K, Choi, CY, Eddy, MT und Vogt, PM (2010): The 
anti-apoptotic protein lifeguard is expressed in breast cancer cells and tissues. Cell Mol Biol Lett 15 [Nr. 2] 296-310.

Charriaut-Marlangue, C und Ben-Ari, Y (1995): A cautionary note on the use of the TUNEL stain to determine apoptosis. Neuroreport $\underline{7}$ [Nr. 1] 61-4.

Chen, ST, Hsu, CY, Hogan, EL, Maricq, H und Balentine, JD (1986): A model of focal ischemic stroke in the rat: reproducible extensive cortical infarction. Stroke 17 [Nr. 4] 738-43.

Choi, CYU, Reimers, K, Allmeling, C, Kall, S, Choi, YH und Vogt, PM (2007): Inhibition of apoptosis by expression of antiapoptotic proteins in recombinant human keratinocytes. Cell Transplant 16 [Nr. 6] 663-674.

Chuang, YM, Liu, CY, PAn, PJ und Lin, CP (2008): Posterior communicating artery hypoplasia as a risk factor for acute ischemic stroke in the absence of carotid artery occlusion. J Clin Neurosci $\underline{15}$ [Nr. 12] 1376-81.

Corsini, NS, Sancho-Martinez, I, Laudenklos, S, Glagow, D, Kumar, S, Letellier, E, Koch, P, Teodorczyk, M, Kleber, S, Klussmann, S, Wiestler, B, Brüstle, O, Mueller, W, Gieffers, C, Hill, O, Thiemann, M, Seedorf, M, Gretz, N, Sprengel, R, Celikel, T und MartinVillalbA, A (2009): The death receptor CD95 activates adult neural stem cells for working memory formation and brain repair. Cell Stem Cell $\underline{\underline{5}}$ [Nr. 2] 178-90.

Cramer, SC und Chopp, M (2000): Recovery recapitulates ontogeny. Trends Neurosci 23 [Nr. 6] 265-71.

Davis, AR, Lotocki, G, Marcillo, AE, Dietrich, WD und Keane, RW (2007): FasL, Fas, and death-inducing signaling complex (DISC) proteins are recruited to membrane rafts after spinal cord injury. J Neurotrauma $\underline{24}$ [Nr. 5] 823-34.

Demuen, D, Klussmann, S, Kleber, S, Zuliani, C, Stieltues, B, Metzger, C, Hirt, UA, Walczak, H, Falk, W, Essig, M, Edler, L, Krammer, PH und Martin-Villalba, A (2004): Neutralization of CD95 ligand promotes regeneration and functional recovery after spinal cord injury. Nat Med $\underline{10}$ [Nr. 4] 389-95.

Desbarats, J und Newell, MK (2000): Fas engagement accelerates liver regeneration after partial hepatectomy. Nat Med $\underline{6}$ [Nr. 8] 920-3. 
Desbarats, J, Birge, RB, Mimouni-Rongy, M, Weinstein, DE, Palerme, JS UND NEWELL, MK (2003): Fas engagement induces neurite growth through ERK activation and p35 upregulation. Nat Cell Biol $\underline{5}$ [Nr. 2] 118-25.

Deveraux, QL, Schendel, SL und Reed, JC (2001): Antiapoptotic proteins. The bcl-2 and inhibitor of apoptosis protein families. Cardiol Clin $\underline{19}$ [Nr. 1] $57-74$.

DGN: Akuttherapie des ischämischen Schlaganfalls - Leitlinie der Deutschen Gesellschaft für Neurologie (DGN) und der Deutschen Schlaganfallgesellschaft (DSG) in der Deutschen Gesellschaft für Neurologie. Deutsche Gesellschaft für Neurologie e.V., Berlin 2009.

DGN: Akuttherapie des ischämischen Schlaganfalls - Leitlinie der Deutschen Gesellschaft für Neurologie (DGN) und der Deutschen Schlaganfallgesellschaft (DSG) in der Deutschen Gesellschaft für Neurologie. Deutsche Gesellschaft für Neurologie e.V., Berlin 2012.

Dirnagl, U, Iadecola, C und Moskowitz, MA (1999): Pathobiology of ischaemic stroke: an integrated view. Trends Neurosci 22 [Nr. 9] 391-7.

Dittel, BN, Merchant, RM und Janeway, CA (1999): Evidence for Fasdependent and Fas-independent mechanisms in the pathogenesis of experimental autoimmune encephalomyelitis. J Immunol 162 [Nr. 11] 6392-400.

Du, C, Hu, R, Csernansky, CA, Hsu, CY und Choi, DW (1996): Very delayed infarction after mild focal cerebral ischemia: a role for apoptosis? J Cereb Blood Flow Metab $\underline{16}$ [Nr. 2] 195-201.

Duden: Das Herkunftswörterbuch: Etymologie der deutschen Sprache. (Duden 07) Bibliographisches Institut, Mannheim 2006.

Dull, T, Zufferey, R, Kelly, M, Mandel, RJ, Nguyen, M, Trono, D und NALDINI, L (1998): A third-generation lentivirus vector with a conditional packaging system. J Virol 72 [Nr. 11] 8463-8471.

Eckert, A, Bock, BC, Tagscherer, Ke, HaAs, TL, Grund, K, Sykora, J, Herold-Mende, C, Ehemann, V, Hollstein, M, Chneiweiss, H, WiestLer, OD, Walczak, H und Roth, W (2008): The PEA-15/PED protein protects glioblastoma cells from glucose deprivation-induced apoptosis via the ERK/MAP kinase pathway. Oncogene 27 [Nr. 8] 1155-66. 
Ehrenreich, H, Weissenborn, K, Prange, H, Schneider, D, Weimar, C, Wartenberg, K, Schellinger, PD, Bohn, M, Becker, H, Wegrzyn, M, Jähnig, P, Herrmann, M, Knauth, M, Bähr, M, Heide, W, Wagner, A, Schwab, S, Reichmann, H, Schwendemann, G, Dengler, R, Kastrup, A, Bartels, C und EPO Stroke Trial Group (2009): Recombinant human erythropoietin in the treatment of acute ischemic stroke. Stroke 40 [Nr. 12] e64756.

El Husseini, N, Goldstein, LB, Peterson, ED, Zhao, X, Pan, W, Olson, DM, Zimmer, LO, Williams, JR, JW, Bushnell, C und Laskowitz, DT (2012): Depression and antidepressant use after stroke and transient ischemic attack. Stroke $\underline{43}$ [Nr. 6] 1609-16.

Ellis, HM Und HoRvitz, HR (1986): Genetic control of programmed cell death in the nematode C. elegans. Cell $\underline{44}$ [Nr. 6] 817-29.

Endres, M, KAPs, M und Moskowitz, MA (1998a): [Apoptosis and ischemic infarct]. Nervenarzt $\underline{69}$ [Nr. 6] 459-64.

Endres, M, Namura, S, Shimizu-Sasamata, M, Waeber, C, Zhang, L, Gómez-Isla, T, Hyman, BT und Moskowitz, MA (1998b): Attenuation of delayed neuronal death after mild focal ischemia in mice by inhibition of the caspase family. J Cereb Blood Flow Metab 18 [Nr. 3] 238-47.

Fernandez, M, Segura, MF, Sole, C, Colino, A, Comella, JX und Cena, V (2007): Lifeguard/neuronal membrane protein 35 regulates Fas ligand-mediated apoptosis in neurons via microdomain recruitment. J Neurochem 103 [Nr. 1] 190-203.

Ferrer, I Und Planas, AM (2003): Signaling of cell death and cell survival following focal cerebral ischemia: life and death struggle in the penumbra. J Neuropathol Exp Neurol $\underline{62}$ [Nr. 4] 329-39.

Fisher, M Und GARCIA, JH (1996): Evolving stroke and the ischemic penumbra. Neurology 47 [Nr. 4] 884-8.

Foehr, ED, Lorente, G, Vincent, V, Nikolich, K und Urfer, R (2005): FAS associated phosphatase (FAP-1) blocks apoptosis of astrocytomas through dephosphorylation of FAS. J Neurooncol $\underline{74}$ [Nr. 3] 241-8. 
Galluzzi, L, Blomgren, K und Kroemer, G (2009): Mitochondrial membrane permeabilization in neuronal injury. Nat Rev Neurosci 10 [Nr. 7] 481-94.

Gandini, R, Pampana, E, Del Giudice, C, Massari, F, Spano, S, AssaKo Ondo, EP, Salvatori, E, Sallustio, F, Koch, G, Stanzione, P und Simonetti, G (2012): Acute stroke treatment using the Penumbra endovascular mechanical thrombolysis device: a single-centre experience. Radiol Med 117 [Nr. 7] 1199-214.

Garcia, JH (1984): Experimental ischemic stroke: a review. Stroke 15 [Nr. 1] 5-14.

Garcia, JH und Kamijyo, Y (1974): Cerebral infarction. Evolution of histopathological changes after occlusion of a middle cerebral artery in primates. $J$ Neuropathol Exp Neurol 33 [Nr. 3] 408-21.

Garcia-Rodriguez, JC und Sosa-Teste, I (2009): The nasal route as a potential pathway for delivery of erythropoietin in the treatment of acute ischemic stroke in humans. SciWorldJ $\underline{9}$ 970-81.

Gavrieli, Y, Sherman, Y und Ben-Sasson, SA (1992): Identification of programmed cell death in situ via specific labeling of nuclear DNA fragmentation. J Cell Biol $\underline{119}$ [Nr. 3] 493-501.

Gerhardt, E, Kugler, S, Leist, M, Beier, C, Berliocchi, L, Volbracht, C, Weller, M, Bahr, M, Nicotera, P und Schulz, JB (2001): Cascade of caspase activation in potassium-deprived cerebellar granule neurons: targets for treatment with peptide and protein inhibitors of apoptosis. Mol Cell Neurosci $\underline{17}$ [Nr. 4] 717-31.

Ginsberg, MD und Pulsinelli, WA (1994): The ischemic penumbra, injury thresholds, and the therapeutic window for acute stroke. Ann Neurol $\underline{36}$ [Nr. 4] 553-4.

GoldBerg, MP UND CHoi, DW (1990): Intracellular free calcium increases in cultured cortical neurons deprived of oxygen and glucose. Stroke 21 [Nr. 11 Suppl] III $75-7$.

Graham, Em, Sheldon, RA, Flock, DL, Ferriero, DM, Martin, LJ, O'Riordan, DP und Northington, FJ (2004): Neonatal mice lacking functional Fas death receptors are resistant to hypoxic-ischemic brain injury. Neurobiol Dis 17 [Nr. 1] 89-98. 
Groth, J: Meine Moleküle. Deine Moleküle. Rhombos-Verlag, Berlin 2004 (Kapitel Der programmierte Zelltod (Apoptose), Seiten 69-72).

HaO, Z, Hampel, B, Yagita, H und Rajewsky, K (2004): T cell-specific ablation of Fas leads to Fas ligand-mediated lymphocyte depletion and inflammatory pulmonary fibrosis. J Exp Med 199 [Nr. 10] 1355-65.

Harms, C, Albrecht, K, Harms, U, Seidel, K, Hauck, L, Baldinger, T, Hübner, D, Kronenberg, G, An, J, Ruscher, K, Meisel, A, Dirnagl, U, von Harsdorf, R, Endres, M und Hörtnagl, H (2007): Phosphatidylinositol 3-Akt-kinase-dependent phosphorylation of p21(Waf1/Cip1) as a novel mechanism of neuroprotection by glucocorticoids. J Neurosci $\underline{27}$ [Nr. 17] $4562-71$.

Harraf, F, Sharma, AK, Brown, Mm, Lees, KR, Vass, RI und Kalra, L (2002): A multicentre observational study of presentation and early assessment of acute stroke. BMJ $\underline{325}$ [Nr. 7354] 17.

Hayley, S, Crocker, SJ, Smith, PD, Shree, T, JaCkson-Lewis, V, Przedborski, S, Mount, M, Slack, R, Anisman, H und Park, DS (2004): Regulation of dopaminergic loss by Fas in a 1-methyl-4-phenyl-1,2,3,6tetrahydropyridine model of Parkinson's disease. J Neurosci 24 [Nr. 8] 2045-53.

Henshall, DC, Araki, T, Schindler, CK, Lan, JQ, Tiekoter, KL, Taki, W Und Simon, RP (2002): Activation of Bcl-2-associated death protein and counter-response of Akt within cell populations during seizure-induced neuronal death. J Neurosci 22 [Nr. 19] 8458-65.

Hillen, B, Hoogstraten, HW, Van Overbeeke, JJ und Van der Zwan, A (1991): Functional anatomy of the circulus arteriosus cerebri (WillisII). Bull Assoc Anat (Nancy) 75 [Nr. 229] 123-6.

Huang, Z, Huang, Pl, Panahian, N, Dalkara, T, Fishman, MC und MosKOWITZ, MA (1994): Effects of cerebral ischemia in mice deficient in neuronal nitric oxide synthase. Science 265 [Nr. 5180] 1883-5.

Hudgins, WR und GaRCIA, JH (1970): Transorbital approach to the middle cerebral artery of the squirrel monkey: a technique for experimental cerebral infarction applicable to ultrastructural studies. Stroke $\underline{1}$ [Nr. 2] 107-11. 
Katchanov, J, Harms, C, Gertz, K, Hauck, L, Waeber, C, Hirt, L, Priller, J, von Harsdorf, R, Bruck, W, Hortnagl, H, Dirnagl, U, BhiDE, PG Und EndREs, M (2001): Mild cerebral ischemia induces loss of cyclindependent kinase inhibitors and activation of cell cycle machinery before delayed neuronal cell death. J Neurosci 21 [Nr. 14] 5045-53.

Kempermann, G, Kuhn, HG und Gage, FH (1998): Experience-induced neurogenesis in the senescent dentate gyrus. J Neurosci 18 [Nr. 9] 3206-12.

Kerr, JF, Wyllie, AH und Currie, AR (1972): Apoptosis: a basic biological phenomenon with wide-ranging implications in tissue kinetics. $\operatorname{Br} J$ Cancer 26 [Nr. 4] 239-57.

Kofler, B, Bulleyment, A, Humphries, A und Carter, DA (2002): Id-1 expression defines a subset of vimentin/S-100beta-positive, GFAP-negative astrocytes in the adult rat pineal gland. Histochem $J \underline{34}$ [Nr. 3-4] 167-71.

Kornack, DR und RAKIC, P (1999): Continuation of neurogenesis in the hippocampus of the adult macaque monkey. Proc Natl Acad Sci U S A $\underline{96}$ [Nr. 10] $5768-73$.

Krammer, PH (1998): The CD95(APO-1/Fas)/CD95L system. Toxicol Lett 102-103 $131-7$.

Kroemer, G, Galluzzi, L und Brenner, C (2007): Mitochondrial membrane permeabilization in cell death. Physiol Rev $\underline{87}$ [Nr. 1] 99-163.

Labat-Moleur, F, Guillermet, C, Lorimier, P, Robert, C, Lantuejoul, S, Brambilla, E und Negoescu, A (1998): TUNEL apoptotic cell detection in tissue sections: critical evaluation and improvement. J Histochem Cytochem $\underline{46}$ [Nr. 3] 327-34.

Lakso, M, Pichel, JG, Gorman, JR, Sauer, B, Okamoto, Y, Lee, E, Alt, FW Und WestPHAL, H (1996): Efficient in vivo manipulation of mouse genomic sequences at the zygote stage. Proc Natl Acad Sci U S A 93 [Nr. 12] 5860-5.

Lambert, C, LAndau, AM und Desbarats, J (2003): Fas-beyond death: a regenerative role for Fas in the nervous system. Apoptosis $\underline{8}$ [Nr. 6] 551-62.

Landau, AM, Luk, KC, Jones, ML, Siegrist-Johnstone, R, Young, YK, Kouassi, E, Rymar, VV, Dagher, A, Sadikot, AF und Desbarats, J 
(2005): Defective Fas expression exacerbates neurotoxicity in a model of Parkinson's disease. J Exp Med 202 [Nr. 5] 575-81.

Lesne, S, Gabriel, C, Nelson, DA, White, E, Mackenzie, Et, Vivien, D UND BuIsson, A (2005): Akt-dependent expression of NAIP-1 protects neurons against amyloid-beta toxicity. J Biol Chem 280 [Nr. 26] 24941-7.

Lin, TN, He, YY, Wu, G, Khan, M und Hsu, CY (1993): Effect of brain edema on infarct volume in a focal cerebral ischemia model in rats. Stroke 24 117-121.

Lindvall, O, Kokaia, Z und Martinez-Serrano, A (2004): Stem cell therapy for human neurodegenerative disorders-how to make it work. Nat Med 10 Suppl S42-50.

Lois, C und Alvarez-Buylla, A (1994): Long-distance neuronal migration in the adult mammalian brain. Science 264 [Nr. 5162] 1145-8.

Martin-Villalba, A, Herr, I, Jeremias, I, Hahne, M, Brandt, R, Vogel, J, Schenkel, J, Herdegen, T und Debatin, KM (1999): CD95 ligand (FasL/APO-1L) and tumor necrosis factor-related apoptosis-inducing ligand mediate ischemia-induced apoptosis in neurons. J Neurosci 19 [Nr. 10] 3809-17.

Martin-Villalba, A, Hahne, M, Kleber, S, Vogel, J, Falk, W, Schenkel, J Und KRAmmer, PH (2001): Therapeutic neutralization of CD95-ligand and TNF attenuates brain damage in stroke. Cell Death Differ $\underline{8}$ [Nr. 7] 679-86.

Mertens, F, Johansson, B, Hoglund, M und Mitelman, F (1997): Chromosomal imbalance maps of malignant solid tumors: a cytogenetic survey of 3185 neoplasms. Cancer Res $\underline{57}$ [Nr. 13] 2765-80.

Molinari, GF (1970): Experimental cerebral infarction. I. Selective segmental occlusion of intracranial arteries in the dog. Stroke 1 [Nr. 4] 224-31.

Morishima, Y, Gotoh, Y, Zieg, J, Barrett, T, Takano, H, Flavell, R, Davis, RJ, Shirasaki, Y und Greenberg, ME (2001): Beta-amyloid induces neuronal apoptosis via a mechanism that involves the c-Jun N-terminal kinase pathway and the induction of Fas ligand. J Neurosci 21 [Nr. 19] 7551-60.

Peter, ME und Krammer, PH (2003): The CD95(APO-1/Fas) DISC and beyond. Cell Death Differ 10 [Nr. 1] 26-35. 
Peter, ME, Legembre, P und Barnhart, BC (2005): Does CD95 have tumor promoting activities? Biochim Biophys Acta 1755 [Nr. 1] 25-36.

Peter, Me, Budd, RC, Desbarats, J, Hedrick, SM, Hueber, AO, Newell, MK, Owen, LB, Pope, RM, Tschopp, J, Wajant, H, Wallach, D, WiltROUT, RH, ZÖRNIG, M UND LYNCH, DH (2007): The CD95 receptor: apoptosis revisited. Cell $\underline{129}$ [Nr. 3] 447-50.

Petri, S, Kiaei, M, Wille, E, Calingasan, NY und Beal, MF (2006): Loss of Fas ligand-function improves survival in G93A-transgenic ALS mice. J Neurol Sci 251 [Nr. 1-2] 44-9.

Poeck, K und Hacke, W: Neurologie. Springer, Berlin 2010 (Kapitel Zerebrale Durchblutungsstörungen: Ischämische Infarkte, Seiten 164-222).

Pulsinelli, WA und Brierley, JB (1979): A new model of bilateral hemispheric ischemia in the unanesthetized rat. Stroke 10 [Nr. 3] 267-72.

Raoul, C, Henderson, CE und Pettmann, B (1999): Programmed cell death of embryonic motoneurons triggered through the Fas death receptor. J Cell Biol 147 [Nr. 5] 1049-62.

Raoul, C, Buhler, E, Sadeghi, C, Jacquier, A, Aebischer, P, Pettmann, B, Henderson, CE und HaAse, G (2006): Chronic activation in presymptomatic amyotrophic lateral sclerosis (ALS) mice of a feedback loop involving Fas, Daxx, and FasL. Proc Natl Acad Sci U S A 103 [Nr. 15] 6007-12.

Reich, A, Spering, C und Schulz, JB (2008): Death receptor Fas (CD95) signaling in the central nervous system: tuning neuroplasticity? Trends Neurosci $\underline{31}$ [Nr. 9] 478-486.

Reich, A*, Spering, C*, Gertz, K, Harms, C, Gerhardt, E, Kronenberg, G, Nave, KA, Schwab, M, Tauber, SC, Drinkut, A, Harms, K, Beier, CP, Voigt, A, GöbBels, S, Endres, M und Schulz, JB (2011): Fas/CD95 regulatory protein Faim2 is neuroprotective after transient brain ischemia. $J$ Neurosci 31 [Nr. 1] 225-33 (* Reich, A und Spering, C equally contributed, shared first authorship).

Reimers, K, Choi, CYU, Mau-Thek, E und Vogt, PM (2006): Sequence analysis shows that Lifeguard belongs to a new evolutionarily conserved cytoprotective family. Int J Mol Med $\underline{18}$ [Nr. 4] 729-734. 
Renganathan, H, Vaidyanathan, H, Knapinska, A und Ramos, JW (2005): Phosphorylation of PEA-15 switches its binding specificity from ERK/MAPK to FADD. Biochem J $\underline{390}$ [Nr. Pt 3] 729-35.

Ribe, EM, Serrano-Saiz, E, Akpan, N und Troy, CM (2008): Mechanisms of neuronal death in disease: defining the models and the players. Biochem $J \underline{415}$ [Nr. 2] 165-82.

Ricci-Vitiani, L, Pedini, F, Mollinari, C, Condorelli, G, Bonci, D, Bez, A, Colombo, A, Parati, E, Peschle, C und Maria, RD (2004): Absence of caspase 8 and high expression of PED protect primitive neural cells from cell death. J Exp Med $\underline{200}$ [Nr. 10] 1257-66.

Riede, UN, Werner, M und Schaefer, HE: Allgemeine und spezielle Pathologie. Thieme, Stuttgart 2004.

Rosenbaum, DM, Gupta, G, D’Amore, J, Singh, M, Weidenheim, K, Zhang, H Und Kessler, JA (2000): Fas (CD95/APO-1) plays a role in the pathophysiology of focal cerebral ischemia. J Neurosci Res $\underline{61}$ [Nr. 6] 686-92.

Rothwell, PM, Buchan, A und Johnston, SC (2006): Recent advances in management of transient ischaemic attacks and minor ischaemic strokes. Lancet Neurol $\underline{5}$ [Nr. 4] 323-31.

Sabelko, KA, Kelly, KA, Nahm, MH, Cross, AH und Russell, JH (1997): Fas and Fas ligand enhance the pathogenesis of experimental allergic encephalomyelitis, but are not essential for immune privilege in the central nervous system. J Immunol $\underline{159}$ [Nr. 7] 3096-9.

SAFA, AR, DAY, TW und Wu, CH (2008): Cellular FLICE-like inhibitory protein (C-FLIP): a novel target for cancer therapy. Curr Cancer Drug Targets 8 [Nr. 1] $37-46$.

Saiki, RK, Scharf, S, Faloona, F, Mullis, KB, Horn, GT, Erlich, HA und ARnheim, N (1985): Enzymatic amplification of beta-globin genomic sequences and restriction site analysis for diagnosis of sickle cell anemia. Science $\underline{230}$ [Nr. 4732] 1350-4.

Sancho-Martinez, I und Martin-Villalba, A (2009): Tyrosine phosphorylation and CD95: a FAScinating switch. Cell Cycle $\underline{8}$ [Nr. 6] 838-42. 
Schulz, JB, Weller, M und Moskowitz, MA (1999): Caspases as treatment targets in stroke and neurodegenerative diseases. Ann Neurol 45 [Nr. 4] 421-9.

Schweitzer, B, Taylor, V, Welcher, AA, McClelland, M und Suter, U (1998): Neural membrane protein 35 (NMP35): a novel member of a gene family which is highly expressed in the adult nervous system. Mol Cell Neurosci 11 [Nr. 5-6] 260-73.

Schweitzer, B, Suter, U und TAylor, V (2002): Neural membrane protein 35/Lifeguard is localized at postsynaptic sites and in dendrites. Brain Res Mol Brain Res 107 [Nr. 1] 47-56.

Segura, MF, Sole, C, Pascual, M, Moubarak, RS, Perez-Garcia, MJ, Gozzelino, R, Iglesias, V, Badiola, N, Bayascas, JR, Llecha, N, Rodriguez-Alvarez, J, Soriano, E, Yuste, VJ und Comella, JX (2007): The long form of Fas apoptotic inhibitory molecule is expressed specifically in neurons and protects them against death receptor-triggered apoptosis. $J \mathrm{Neu}-$ rosci 27 [Nr. 42] 11228-41.

Shelton, SB, Pettigrew, DB, Hermann, AD, Zhou, W, Sullivan, PM, Crutcher, KA und Strauss, KI (2008): A simple, efficient tool for assessment of mice after unilateral cortex injury. J Neurosci Methods $\underline{168}$ [Nr. 2] $431-42$.

Siemkowicz, E und Hansen, AJ (1978): Clinical restitution following cerebral ischemia in hypo-, normo- and hyperglycemic rats. Acta Neurol Scand $\underline{58}$ [Nr. 1] $1-8$.

Sirén, Al, Fratelli, M, Brines, M, Goemans, C, Casagrande, S, LewcZuk, P, Keenan, S, Gleiter, C, Pasquali, C, Capobianco, A, Mennini, T, Heumann, R, Cerami, A, Ehrenreich, H und Ghezzi, P (2001): Erythropoietin prevents neuronal apoptosis after cerebral ischemia and metabolic stress. Proc Natl Acad Sci U S A $\underline{98}$ [Nr. 7] 4044-9.

Sirén, AL, Fasshauer, T, Bartels, C und Ehrenreich, H (2009): Therapeutic potential of erythropoietin and its structural or functional variants in the nervous system. Neurotherapeutics $\underline{6}$ [Nr. 1] 108-27.

Smith, ML, Bendek, G, Dahlgren, N, Rosén, I, Wieloch, T und Siesjö, 
BK (1984): Models for studying long-term recovery following forebrain ischemia in the rat. 2. A 2-vessel occlusion model. Acta Neurol Scand $\underline{69}$ [Nr. 6] 385-401.

Sole, C, Dolcet, X, Segura, MF, Gutierrez, H, Diaz-Meco, MT, Gozzelino, R, Sanchis, D, Bayascas, JR, Gallego, C, Moscat, J, Davies, AM und Comella, JX (2004): The death receptor antagonist FAIM promotes neurite outgrowth by a mechanism that depends on ERK and NF-kapp B signaling. J Cell Biol 167 [Nr. 3] 479-92.

Somia, NV, Schmitt, MJ, Vetter, DE, Van Antwerp, D, Heinemann, SF UND VERMA, IM (1999): LFG: an anti-apoptotic gene that provides protection from Fas-mediated cell death. Proc Natl Acad Sci U S A 96 [Nr. 22] 12667-12672.

Song, Y Und JACOB, CO (2005): The mouse cell surface protein TOSO regulates Fas/Fas ligand-induced apoptosis through its binding to Fas-associated death domain. J Biol Chem 280 [Nr. 10] 9618-26.

Statistisches-Bundesamt: Todesursachen in Deutschland. Statistisches Bundesamt, Wiesbaden 2011 (Fachserie 12, Reihe 4).

Stegh, AH, Barnhart, BC, Volkland, J, Algeciras-Schimnich, A, Ke, N, REED, JC Und PETER, ME (2002): Inactivation of caspase-8 on mitochondria of Bcl-xL-expressing MCF7-Fas cells: role for the bifunctional apoptosis regulator protein. J Biol Chem 277 [Nr. 6] 4351-60.

Subirós, N, Del Barco, DG und Coro-Antich, RM (2012): Erythropoietin: still on the neuroprotection road. Ther Adv Neurol Disord $\underline{5}$ [Nr. 3] 161-73.

Su, JH, Anderson, AJ, Cribbs, DH, Tu, C, Tong, L, Kesslack, P und CotMAN, CW (2003): Fas and Fas ligand are associated with neuritic degeneration in the AD brain and participate in beta-amyloid-induced neuronal death. Neurobiol Dis $\underline{12}$ [Nr. 3] 182-93.

Tamura, A, Graham, Di, McCulloch, J und Teasdale, GM (1981): Focal cerebral ischaemia in the rat: 1 . Description of technique and early neuropathological consequences following middle cerebral artery occlusion. J Cereb Blood Flow Metab 1 [Nr. 1] 53-60.

TANG, D, LAhti, JM Und Kidd, VJ (2000): Caspase-8 activation and bid cleavage contribute to MCF7 cellular execution in a caspase-3-dependent manner during staurosporine-mediated apoptosis. J Biol Chem $\underline{275}$ [Nr. 13] 9303-7. 
Taoufik, E, Valable, S, Müller, GJ, Roberts, Ml, Divoux, D, Tinel, A, Voulgari-Kokota, A, Tseveleki, V, Altruda, F, lassmann, H, Petit, E UND PROBERT, L (2007): FLIP(L) protects neurons against in vivo ischemia and in vitro glucose deprivation-induced cell death. J Neurosci 27 [Nr. 25] 663346.

Thomaidou, D, Mione, MC, Cavanagh, JF und Parnavelas, JG (1997): Apoptosis and its relation to the cell cycle in the developing cerebral cortex. $J$ Neurosci 17 [Nr. 3] 1075-85.

Thompson, CB (1995): Apoptosis in the pathogenesis and treatment of disease. Science 267 [Nr. 5203] 1456-62.

TIXIER-VIDAL, A (1994): Cell division and differentiation of central nervous system neurons. Ann N Y Acad Sci 733 56-67.

Tran, SE, Holmstrom, TH, Ahonen, M, Kahari, VM und Eriksson, JE (2001): MAPK/ERK overrides the apoptotic signaling from Fas, TNF, and TRAIL receptors. J Biol Chem $\underline{276}$ [Nr. 19] 16484-90.

Vassilev, AO Und UCKun, FM (2004): Therapeutic potential of inhibiting Bruton's tyrosine kinase, (BTK). Curr Pharm Des 10 [Nr. 15] 1757-66.

Vassilev, A, Ozer, Z, Navara, C, Mahajan, S und UCkun, FM (1999): Bruton's tyrosine kinase as an inhibitor of the Fas/CD95 death-inducing signaling complex. J Biol Chem $\underline{274}$ [Nr. 3] 1646-56.

Velier, JJ, Ellison, JA, Kikly, KK, Spera, PA, Barone, FC und FeuerSTEIN, GZ (1999): Caspase-8 and caspase-3 are expressed by different populations of cortical neurons undergoing delayed cell death after focal stroke in the rat. J Neurosci $\underline{19}$ [Nr. 14] 5932-41.

Wajant, H, Pfizenmaier, K und Scheurich, P (2003): Non-apoptotic Fas signaling. Cytokine Growth Factor Rev 14 [Nr. 1] 53-66.

Watson, BD, Dietrich, WD, Busto, R, Wachtel, MS und Ginsberg, MD (1985): Induction of reproducible brain infarction by photochemically initiated thrombosis. Ann Neurol $\underline{17}$ [Nr. 5] 497-504.

White, CA, McCombe, PA und Pender, MP (1998): The roles of Fas, Fas ligand and Bcl-2 in T cell apoptosis in the central nervous system in experimental autoimmune encephalomyelitis. J Neuroimmunol 82 [Nr. 1] 47-55. 
Wyllie, AH (1993): Apoptosis (the 1992 Frank Rose Memorial Lecture). Br J Cancer $\underline{67}$ [Nr. 2] 205-8.

Wyllie, AH (2010): Where, O death, is thy sting? A brief review of apoptosis biology. Mol Neurobiol $\underline{42}$ [Nr. 1] 4-9.

Wyllie, AH, Arends, MJ, Morris, RG, Walker, SW und Evan, G (1992): The apoptosis endonuclease and its regulation. Semin Immunol $\underline{4}$ [Nr. 6] 389-97.

Zhao, C, Deng, W und Gage, FH (2008): Mechanisms and functional implications of adult neurogenesis. Cell $\underline{132}$ [Nr. 4] 645-60.

Zhao, W, Kitidis, C, Fleming, MD, Lodish, HF und Ghaffari, S (2006): Erythropoietin stimulates phosphorylation and activation of GATA-1 via the PI3-kinase/AKT signaling pathway. Blood $\underline{107}$ [Nr. 3] 907-15.

Zuliani, C, Kleber, S, Klussmann, S, Wenger, T, Kenzelmann, M, Schreglmann, N, Martinez, A, del Rio, JA, Soriano, E, Vodrazka, P, Kuner, R, Groene, HJ, Herr, I, Krammer, PH und Martin-Villalba, A (2006): Control of neuronal branching by the death receptor CD95 (Fas/Apo1). Cell Death Differ $\underline{13}$ [Nr. 1] 31-40. 


\section{Anhang}

\subsection{Publikationsverzeichnis}

Ergebnisse der vorliegenden Arbeit wurden an folgenden Stellen veröffentlicht:

\section{Originalarbeit}

Reich, A.*, Spering, C.*, Gertz, K., Harms, C., Gerhardt, E., Kronenberg, G., Nave, K. A., Schwab, M., Tauber, S. C., Drinkut, A., Harms, K., Beier, C. P., Voigt, A., Göbbels, S., Endres, M. und Schulz, J. B. (2011): Fas/CD95 regulatory protein Faim2 is neuroprotective after transient brain ischemia. J Neurosci 31 [Nr. 1] 225-33.

*Die Erstautorenschaft wird von Reich, A. und Spering, C. als equally contributed geteilt.

\section{Übersichtsarbeit}

Reich, A., Spering, C. und Schulz, J. B. (2008): Death receptor Fas (CD95) signaling in the central nervous system: tuning neuroplasticity? Trends Neurosci 31 [Nr. 9] $478-486$.

\section{Posterbeitrag}

Reich A, Spering C, Gertz K, Harms C, Gerhardt E, Kronenberg G, Nave KA, Schwab M, Tauber SC, Drinkut A, Harms K, Voigt A, Göbbels S, Endres M und Schulz JB (2010): Fas/CD95 Regulatory Protein Faim2 Is Neuroprotective after Transient Brain Ischemia. Neurowoche, P 713, Mannheim, Deutschland, 21. - 25.09.2010.

\subsection{Alternative Tiermodelle der zerebralen Ischämie}

Tabelle: 8.1: Tiermodelle der zerebralen Ischämie

\begin{tabular}{llllc}
\hline Tiermodell & Verfahren & Vorteile & Nachteile & Referenzen \\
\hline \hline $\begin{array}{l}\text { Permanente } \\
\text { proximale MCAo }\end{array}$ & $\begin{array}{l}\text { permanente } \\
\text { durch proximalen Verschluss Aa. } \\
\text { cerebri mediae beidseits }\end{array}$ & $\begin{array}{l}\text { einmaliger, einfacher } \\
\text { operativer Eingriff }\end{array}$ & $\begin{array}{l}\text { Ischämie im Kortex und } \\
\text { Caudoputamen }\end{array}$ & Garcia et al. \\
1984
\end{tabular}


Tiermodelle der zerebralen Ischämie Fortsetzung

\begin{tabular}{|c|c|c|c|c|}
\hline Tiermodell & Verfahren & Vorteile & Nachteile & Referenzen \\
\hline $\begin{array}{l}\text { Temporäre } \\
\text { distale MCAo }\end{array}$ & $\begin{array}{l}\text { distale Okklusionsvariante, mit Ver- } \\
\text { schluss ACM über der Fissura } \\
\text { rhinalis durch Ligatur + Ver- } \\
\text { schluss A. carotis com. beidseits } \\
\text { temporär }\end{array}$ & $\begin{array}{l}\text { signifikante Reduktion } \\
\text { des Blutflusses über } \\
\text { dem Versorgungsgebiet } \\
\text { der ACM rechts mit } \\
\text { moderatem Infarkt im } \\
\text { frontoparietalen Kortex }\end{array}$ & $\begin{array}{l}\text { kein Infarkt im Caudo- } \\
\text { putamen }\end{array}$ & $\begin{array}{l}\text { Chen et al. } \\
1986\end{array}$ \\
\hline $\begin{array}{l}\text { Permanenter } \\
\text { Gefäßverschluss } \\
\text { durch Elektro- } \\
\text { kauterisation }\end{array}$ & $\begin{array}{l}\text { Gezielte Elektrokauterisation von } \\
\text { gehirnversorgenden Gefäßen }\end{array}$ & $\begin{array}{l}\text { einfache Durchführbar- } \\
\text { keit }\end{array}$ & $\begin{array}{l}\text { Mangelhafte Präzision } \\
\text { und Kontrollierbarkeit }\end{array}$ & $\begin{array}{l}\text { Tamura et } \\
\text { al. } 1981\end{array}$ \\
\hline $\begin{array}{l}\text { Globalischämie } \\
\text { durch } \quad \text { Neck } \\
\text { tornique }\end{array}$ & $\begin{array}{l}\text { mit aufpumpbarem Neck Torni- } \\
\text { que Dekapitation simuliert, an- } \\
\text { schließend Reperfusion nach Entfer- } \\
\text { nen der Druckmanschette }\end{array}$ & $\begin{array}{ll}\text { Dekapiation } & + \text { Re- } \\
\text { perfusion; } & \text { einfache } \\
\text { Methode } & \end{array}$ & $\begin{array}{l}\text { Kompression } \\
\text { wichtiger Strukten } \\
\text { im Halsbereich (Nervus } \\
\text { vagus, Glandula thy- } \\
\text { roidea, Vv. jugulares } \\
\text { etc.) + inkomplette } \\
\text { Globalischämie da Aa. } \\
\text { vertebrales im Schutz } \\
\text { der Halswirbelsäule }\end{array}$ & \begin{tabular}{lr}
\multicolumn{2}{c}{ Siemkowicz } \\
und Hansen \\
1978
\end{tabular} \\
\hline $\begin{array}{l}\text { Globalischämie } \\
\text { durch Kardio- } \\
\text { plegie }\end{array}$ & $\begin{array}{l}\text { kardioplege Lösung mit folgendem } \\
\text { kardialen Arrest und zerebraler } \\
\text { Globalischämie }\end{array}$ & einfache Methode & $\begin{array}{l}\text { Ischämie auch für den } \\
\text { restlichen Organsimus }\end{array}$ & $\begin{array}{l}\text { Kofler et al. } \\
2002\end{array}$ \\
\hline $\begin{array}{l}\text { Globalischämie } \\
\text { durch das 4- } \\
\text { Gefäßverschluss- } \\
\text { Modell }\end{array}$ & $\begin{array}{l}\text { Tag 1: atraumatische Gefäß- } \\
\text { klammern locker um die Aa. } \\
\text { carotides communes angebracht } \\
\text { und die Aa. vertebrales durch die } \\
\text { Foramina alares des Atlas verödet; } \\
\text { Tag 2: Ischämieinduktion durch } \\
\text { temporären Verschluss der beiden } \\
\text { zuvor gesetzten Arterienklemmen }\end{array}$ & $\begin{array}{l}\text { auch an wachen, nicht } \\
\text { narkotisierten, sich frei } \\
\text { bewegenden Tieren } \\
\text { durchführbar }\end{array}$ & $\begin{array}{l}\text { komplexe und aufwen- } \\
\text { dige OP, schwer repro- } \\
\text { duzierbar }\end{array}$ & $\begin{array}{l}\text { Pulsinelli } \\
\text { und Brierley } \\
1979\end{array}$ \\
\hline $\begin{array}{l}\text { 2-Gefäß- } \\
\text { verschluss-Modell }\end{array}$ & $\begin{array}{l}\text { Aa. carotides communes okklu- } \\
\text { diert + medikamentöse systemische } \\
\text { Hypotension; zerebraler Blutfluss } \\
\text { (CFU) im Kortex sinkt auf 5\%, } \\
\text { im Thalamus und Mittelhirn noch } \\
\text { mehr }\end{array}$ & $\begin{array}{l}\text { komplexe OP und } \\
\text { Management }\end{array}$ & $\begin{array}{l}\text { nur Ischämie-induktion } \\
\text { des Vorderhirns }\end{array}$ & $\begin{array}{l}\text { Smith et al. } \\
1984\end{array}$ \\
\hline $\begin{array}{l}\text { Photochemische } \\
\text { Induktion von } \\
\text { Thromben }\end{array}$ & $\begin{array}{l}\text { Vorbereitung: photosensitive Sub- } \\
\text { stanz Bengalrosa i.v. injiziert. An- } \\
\text { schließend durch gezielte Bestrah- } \\
\text { lung mit Licht von } 560 \mathrm{~nm} \text { Wellen- } \\
\text { länge Bildung von Sauerstoffradika- } \\
\text { len angeregt, dies ruft mikrovasku- } \\
\text { läre Thrombozytenaggregation her- } \\
\text { vor }\end{array}$ & $\begin{array}{l}\text { präzise Positionierung } \\
\text { der Infarktareale im } \\
\text { Kortex }\end{array}$ & $\begin{array}{l}\text { Schädigung der mikro- } \\
\text { vaskulären Strombahn } \\
\text { durch die photochemi- } \\
\text { sche Reaktion, Beein- } \\
\text { trächtigung der Blut- } \\
\text { Hirn-Schranke und Ent- } \\
\text { stehung von vasogenen } \\
\text { Ödemen }\end{array}$ & $\begin{array}{l}\text { Watson et } \\
\text { al. } 1985\end{array}$ \\
\hline $\begin{array}{l}\text { Embolische } \\
\text { Modelle }\end{array}$ & $\begin{array}{l}\text { intraarterielle Blutklümpchen } \\
\text { durch Katheter in A. carotis } \\
\text { communis eingebracht oder direkt } \\
\text { visköses Silikon positioniert }\end{array}$ & $\begin{array}{l}\text { einfache Durchführbar- } \\
\text { keit }\end{array}$ & $\begin{array}{lr}\text { mangelhafte } & \text { Kon- } \\
\text { trollierbarkeit } & \text { und } \\
\text { potentielle } & \text { Streuung } \\
\text { von Mikropartikeln }\end{array}$ & $\begin{array}{l}\text { Multiple } \\
\text { Modelle } \\
\text { beschrieben }\end{array}$ \\
\hline
\end{tabular}

\subsection{Apparatur}

\subsubsection{Geräte}

Tabelle 8.2: Auflistung der verwendeten Geräte

Anästhesie Work Station (table top / Harvard Apparatus, Holliston, Mastwo gases)

Adapter für key-fill Vaporizer - Isofluran Harvard Apparatus, Holliston, Massachusetts, USA

Aufbewahrungsboxen für Reaktionsge- GLW@ Storing Systems, Würzburg fäße

Elektrophoresekammer für Agarose Gels Bio-Rad Laboratories GmbH, München Mini Sub Cell GT

Elektrophoresesystem (Gelgrößen: 7 x PEQLAB Biotechnologie GmbH, Erlan$8 \mathrm{~cm}, 9 \times 11 \mathrm{~cm})$ gen 
Färbeglaskästen

Färbegestell

Färbetrog (Kunststoff)

Feuchte Kammer

Flockeneisbereiter (Modell: AF-20)

Gefrierschrank (Modell: MDF-U537)

Gefrierschrank (Modell: HFU 586 Top)

Gel-Gießschienen

Gelkämme (1,0 und 1,5 mm; 8, 10, 12 14 Zähne)

Gelträger

Gel-Videodokumentationssystem (BioVision)

Gewebehomogenisator Precellys 24

Glaswaren (Gefäße und Flaschen; $25 \mathrm{ml}$, $50 \mathrm{ml}, 100 \mathrm{ml}, 250 \mathrm{ml}, 500 \mathrm{ml}, 1000 \mathrm{ml}$, $2000 \mathrm{ml})$

Homogenisator Precellys 24-Dual

Hämodynamische Messeinheit, incl. Hugo Sachs Elektronik - Harvard Blutdruck, EKG, HF, Blutfluss, pH und Apparatus GmbH, March-Hugstetten $\mathrm{pO}_{2}$

Heizplatte $H I$ 1220

Kaltlichtquelle KL 1500 LCD

Kammerasystem für OP Mikroskop Leica M651 (Modell: Leica 2D)
PEQLAB Biotechnologie GmbH, Erlangen

Heinemann Labortechnik GmbH, Duderstadt

Heinemann Labortechnik GmbH, Duderstadt

Heinemann Labortechnik GmbH, Duderstadt

Kartell spa, Noviglio, Italien

Scotsman Ice Systems, Vernon Hills, Illinois, USA

Sanyo Electric Co., Ltd., Moriguchi, Osaka, Japan

Thermo Fisher Scientific, Waltham, Massachusetts, USA

PEQLAB Biotechnologie GmbH, Erlangen gen

PEQLAB Biotechnologie GmbH, Erlangen gen

PEQLAB Biotechnologie GmbH, Erlangen

Schott AG, Mainz

Leica Microsystems, Wetzlar

Schott AG, Mainz

Leica, Microsystems, Wetzlar 
Kompaktwaage CS200

Kühlschränke Premium No Frost

Magnetrührer MR 3000

Messpipetten (25 ml)

Messpipetten ( $5 \mathrm{ml} ; 10 \mathrm{ml}$ )

Mess-/Mischzylinder, Größen: $2000 \mathrm{ml}$, $1000 \mathrm{ml}, 500 \mathrm{ml}$

Mikroinjektor Nanoliter2000 microinjector Micro4 smart controller unit

Mikrokühlzentrifuge Sigma 1-15 K

Mikrooperationsbesteck

Mikrowelle (Micromaxx ${ }^{\circledR}$ MM 41580)

Mikroskop (Modell: Axioskop 2 mot plus)

Mikroskop (Modell: DMI6000 B)

Nahtmaterial Monofilament Nylon

(Größen: 4-0, 5-0, 8-0, 9-0)

Nahtmaterial Polyviolene LOOK $^{\circledR}$

(Größen: 4-0, 5-0)

Narkosegasabsaugung Flouvac System,

VAC 240

Operationsmikroskop (Modell: M651 MSD)

Operationstisch (Modell: size 1H Type $872 / 3 \mathrm{H})$

Paraffinausgießstation

Histocentre 2)

PCR-Thermozykler Mastercycler ${ }^{\circledR}$

gradient

pH-Meter (Typ: CG 842)

(Shandon

Pipetten $m L I N E^{\circledR}$, Größen: $10 \mu \mathrm{l}, 20$ $\mu \mathrm{l}, 200 \mu \mathrm{l}, 1000 \mu \mathrm{l}$

Pipetten Pipetman ${ }^{\circledR}$, Größen: $10 \mu \mathrm{l}, 20$ Gilson, Middleton, Wisconsin, USA $\mu \mathrm{l}, 100 \mu \mathrm{l}, 200 \mu \mathrm{l}, 1000 \mu \mathrm{l}$
Ohaus Corp., Pine Brook, New Jersey, USA

Liebherr, Bulle, Schweiz

Heidolph Instruments, Schwabach

Brand, Wertheim

HBG Henneberg-Sander GmbH, Gießen

Brand (Plastibrand ${ }^{\circledR}$ ), Wertheim und

Kartell spa, Noviglio, Italien

WPI (World Precision Instruments),

Berlin

Sartorius, Göttingen

Harvard Apparatus, Holliston, Massachusetts, USA

Medion AG, Essen

Carl Zeiss AG, Oberkochen

Leica Microsystems, Wetzlar

Harvard Apparatus, Holliston, Massachusetts, USA

Harvard Apparatus, Holliston, Massachusetts, USA

Harvard Apparatus, Holliston, Massachusetts, USA

Leica Microsystems, Wetzlar

Hugo Sachs Elektronik - Harvard Apparatus GmbH, March-Hugstetten

Thermo Fisher Scientific, Waltham, Massachusetts, USA

Eppendorf, Hamburg

Schott AG / SI Analytics GmbH, Mainz

Biohit Oyj, Helsinki, Finnland 
Pipettierhelfer $\left(a c c u-j e t^{\circledR}\right)$

Präparatekästen

Präparationsbesteck

Präzisionswaage

(Modell: Kern EW 4200-2NM)

Real-Time PCR System (Stratagene $\mathrm{Mx} 3000 \mathrm{P}^{T M}$ )

Reinstwassersystem arium $^{\circledR} 611$

Rotationsmikrotom (Leica RM2245)

SDS-PAGE- und Blotting-Apparatus Mini-PROTEAN ${ }^{\circledR} \quad$ II-ElektrophoreseSystem PROTEAN ${ }^{\circledR} \quad$ II $\quad$ xi- $^{-}$

Elektrophorese-System

Sigma 1-15 Mikrozentrifuge

Spannungsgeräte(Elektrophorese): PowerPac Basic ${ }^{T M}$

Spektrophotometer NanoDrop ${ }^{\circledR} \quad N D$ 1000

Standautoklav (vertikal) 5075 ELV

Stereo Investigator 7

Stereotaktischer Rahmen

Stereomikroskop SMZ645

Stoppuhren SKT338N

Thermomixer Comfort

Tierkäfige Mäuse

Tischkühlzentrifuge Sigma 6 K15

Vaporizer - Isofluran

VideoMot2 - Video Tracking System Vortex Genie 2
Brand, Wertheim

Heinemann Labortechnik GmbH, Duderstadt

Karl Hammacher GmbH, Solingen

Kern \& Sohn GmbH, Balingen

Agilent Technologies, Santa Clara, Kalifornien, USA

Sartorius, Göttingen

Leica Microsystems, Wetzlar

Bio-Rad Laboratories GmbH, München

Vitaris AG, Baar, Schweiz

Bio-Rad, Hercules, Kalifornien, USA

Thermo Fisher Scientific, Waltham, Massachusetts, USA

Systec GmbH, Wettenberg

MicroBrightField Bioscience, Williston, USA

WPI (World Precision Instruments), Berlin

Nikon Corporation, Tokio, Japan

Oregon Scientific, Tualatin, Oregon, USA

Eppendorf, Hamburg

Tecniplast, Buguggiate, Italien

Sartorius, Göttingen

Harvard Apparatus, Holliston, Massachusetts, USA

TSE Systems GmbH, Bad Homburg neoLab Migge Laborbedarf GmbH, Heidelberg 
Wärme- und Trockenschrank Heraeus Thermo Fisher Scientific, Waltham, Function Line T 20 Massachusetts, USA

Western Blot Imaging Fluor Chem Q proteinsimple, Santa Clara, California, USA

Zentrifuge $5415 D$

Eppendorf, Hamburg

\subsubsection{Verbrauchsmaterial}

Tabelle 8.3: Auflistung des verwendeten Verbrauchsmaterials

Deckgläser für die Mikroskopie Größen: Menzel, Braunschweig / Thermo Fis$18 \mathrm{x} 18 \mathrm{~mm}, 24 \mathrm{x} 40 \mathrm{~mm}, 24 \mathrm{x} 60 \mathrm{~mm}$ her Scientific, Waltham, Massachusetts, USA

Eindeckmittel Entellan Merck, Darmstadt

Eindeckmittel Shandon Immu-Mount ${ }^{T M}$ Thermo Fisher Scientific, Waltham, Massachusetts, USA

Einbettkassetten (Rotilabo ${ }^{\circledR}$ ) Roth, Karlsruhe

Einmalspritzen (Omnifix ${ }^{\circledR} ; 5 \mathrm{ml}, 10 \mathrm{ml}$, B. Braun Melsungen AG, Melsungen $20 \mathrm{ml}$ )

Einmalspritze $\left(B D\right.$ Plastipak $\left.{ }^{T M} ; 1 \mathrm{ml}\right) \quad$ Becton Dickinson and Company, Franklin Lakes, New Jersey, USA

Filtrierpapiere Macherey-Nagel GmbH \& Co. KG, Düren

Gel blotting paper Type GB3000

Whatman GmbH, Dassel

Injektionskanülen (100 Sterican ${ }^{\circledR}$; Grö-

B. Braun Melsungen AG, Melsungen ßen: $18 \mathrm{G}, 26 \mathrm{G}, 27 \mathrm{G}$ )

Keramik-Kügelchen (Precellys; 1, $4 \mathrm{~mm}$ ) Labortücher (KIMTECH Science) peqlab Biotechnologie GmbH, Erlangen Latex-Untersuchungshandschuhe (pu- Paul Hartmann AG, Heidenheim derfrei), Peha-soft ${ }^{\circledR}$

Nitril-Untersuchungshandschuhe (pu- Ansell Limited, Richmond, Australia derfrei), Nitra-Tex ${ }^{\circledR}$ EP

Nitrocellulosemembran $0,45 \mu \mathrm{m}$ Bio-Rad Laboratories GmbH, München Nitrocellulose Transfermembran Whatman GmbH, Dassel PROTRAN ${ }^{\circledR}$ 
Objektträger Menzel-Gläser Menzel, Braunschweig / Thermo Fis-

Superfrost ${ }^{\circledR}$ Plus

PAP pen $(\mathrm{ab} 2601)$

PCR-Gefäße (0, 2 ml; 8er-Streifen)

Pipettenspitzen, Größen: $10 \mu \mathrm{l}, 200 \mu \mathrm{l}$, Sarstedt, Nümbrecht

$1000 \mu \mathrm{l}$

Pipettenspitzen (steril; RNase-, DNase-, nerbe plus, Winsen/Luhe

Pyrogen-, DNA-frei), Größen: $10 \mu \mathrm{l}, 20$

$\mu \mathrm{l}, 100 \mu \mathrm{l}, 200 \mu \mathrm{l}, 1000 \mu \mathrm{l}$

Precellys Keramik-Kit 1,4 mm mit $2 \mathrm{ml}$

Homogenisatorröhrchen

Reagiergefäße (1,5 ml; $2 \mathrm{ml})$ mit Deckel- Sarstedt, Nümbrecht

verschluß

Reagiergefäße (2 ml) mit Schraubver- Heinemann Labortechnik GmbH, Duschluss

Röhren, Größen: $50 \mathrm{ml}, 15 \mathrm{ml}$

Skalpellklingen

Sterile Skalpellklingen

Sterile Spritzen und Kanülen

Unterlagen MoliNea $^{\circledR}$ plus L $(40$ x Paul Hartmann AG, Heidenheim $60 \mathrm{~cm})$

Vernichtungsbeutel

Sarstedt, Nümbrecht derstadt

Sarstedt, Nümbrecht

Heinz Herenz Medizinalbedarf GmbH, Hamburg

B. Braun Melsungen AG, Melsungen

B. Braun Melsungen AG, Melsungen

Weichholzgranulateinstreu 


\subsection{Chemikalien und Bioreagenzien}

Tabelle 8.4: Auflistung der verwendeter Chemikalien und Bioreagenzien

2-Methyl-butan

2-Propanol (Isopropanol, ROTISOLV ${ }^{\circledR}$ ) UV/IR-Grade)

5-Brom-4-chlor-3-indoxylphosphat

4-Toluidin-Salz (BCIP)

5-Bromo-2-Deoxyuridin (BrdU)

ABsolute $^{T M}$ QPCR Seal

ABsolute $^{T M} \quad$ QPCR-SYBR $^{\circledR}$-Green-

ROX-Mix

Acrylamid 2K-Solution (30\%, Mix

Acrylamid: Bisacrylamid; 37,5:1)

Agarose

Aluminiumsulfat-Hexadecahydrat

$\left(\mathrm{Al}_{2} \mathrm{O}_{12} \mathrm{~S}_{3} \times 16 \mathrm{H}_{2} \mathrm{O}\right)$

Ammoniumacetat $\left(\mathrm{CH}_{3} \mathrm{COONH}_{4}\right)$

Azeton

Bepanthen (Augen- und Nasensalbe)

-Mercaptoethanol

Biotherm $^{T M}$ 10x Buffer

Biotherm $^{T M}$ DNA-Polymerase

Calciumchlorid-Dihydrat $\quad\left(\mathrm{CaCl}_{2} \quad \mathrm{x}\right.$ $2 \mathrm{H}_{2} \mathrm{O} ; \quad 99 \%$ )

Citronensäure-Monohydrat $\left(\mathrm{C}_{6} \mathrm{H}_{8} \mathrm{O}_{7} \quad \mathrm{x}\right.$ $\mathrm{H}_{2} \mathrm{O} ; \geq 99,5 \%$ )

Chemilumineszenzsubstrat Chemiglow

Cobaltchlorid $\left(\mathrm{CoCl}_{2}\right)$

Complete@ Proteases-Inhibitor-

Cocktail

$\mathrm{DAB}$
Carl Roth GmbH, Karlsruhe

Carl Roth GmbH, Karlsruhe

Roche Diagnostics, Mannheim

Roche Diagnostics, Mannheim

Sigma-Aldrich, St. Louis, Missouri, USA

Abgene, Epsom, UK

Abgene, Epsom, UK

AppliChem, Darmstadt

Peqlab, Biotechnologie, Erlangen

Carl Roth GmbH, Karlsruhe

Carl Roth GmbH, Karlsruhe

Carl Roth GmbH, Karlsruhe

Bayer Vital, Leverkusen

Fluka (Sigma-Aldrich)

GeneCraft / Ares Bioscience GmbH,

Köln

GeneCraft / Ares Bioscience GmbH, Köln

Sigma-Aldrich, St. Louis, Missouri, USA

Roth, Karlsruhe

Alpha Innotec, San Leandro, USA

Carl Roth GmbH, Karlsruhe

Roche Diagnostics GmbH, Mannheim

Sigma-Aldrich Chemie GmbH, Taufkirchen 
DABCO

Desoxynucleosid-5'-triphosphate dNTP Mix $10 \mathrm{mM}$

Desoxyribonuklease I (DNase I; 3550 $\mathrm{KU} / \mathrm{mg}$ Protein)

Dinatriumhydrogenphosphat-

Heptahydrat $\left(\mathrm{Na}_{2} \mathrm{HPO}_{4} \times 7 \mathrm{H}_{2} \mathrm{O}\right)$

Dimethylsulfoxid (DMSO)

DIG DNA Labeling Mix, 10 x conc.

Dithiothreitol (DTT)

DPX mounting medium

Eosin G (gelblich)

Essigsäure (Eisessig, 100\%)

Ethanol (Rotipuran ${ }^{\circledR} \geq 99,8 \%$, p.a.)

Ethidiumbromid

Ethylendiamintetraessigsäure-

Dinatriumsalz-Dihydrat

$\mathrm{C}_{10} \mathrm{H}_{14} \mathrm{~N}_{2} \mathrm{Na}_{2} \mathrm{O}_{8}$ × $\left.2 \mathrm{H}_{2} \mathrm{O}\right)$

Fetales Kälberserum (Gibco ${ }^{\circledR}$, hitzein- Invitrogen, Carlsbad, Kalifornien, USA aktiviert)

Flüssigstickstoff

Gene Ruler ${ }^{T M}$ (100 bp DNA Ladder)

GeneRuler $^{\circledR}$ (1 kb-DNA-Ladder)

Glucose

Glucoseoxidase

Glycin

Glycerol

Guanidinisothiocyanat

Histoacryl
Sigma-Aldrich Chemie GmbH, Taufkirchen

Invitrogen $\mathrm{GmbH}$, Karlsruhe

Sigma-Aldrich, St. Louis, Missouri, USA

Sigma-Aldrich, St. Louis, Missouri, USA

Sigma-Aldrich Chemie GmbH, Taufkirchen

Roche Diagnostics, Mannheim

Roche Diagnostics, Mannheim

Fluka, Neu-Ulm

Merck KGaA, Darmstadt

Merck KGaA, Darmstadt

Roth, Karlsruhe

Sigma-Aldrich, St. Louis, Missouri, USA

Sigma-Aldrich, St. Louis, Missouri, USA (EDTA,

Linde AG, Pullach

Fermentas, Burlington, Ontario, Kanada

Fermentas Life Sciences, St. Leon-Rot

Sigma-Aldrich Chemie GmbH, Taufkirchen

Sigma-Aldrich Chemie GmbH, Taufkirchen

AppliChem, Darmstadt

Sigma-Aldrich Chemie GmbH, Taufkirchen

Mobitec Molecular Biotechnology, Göttingen

B. Braun, Melsungen 
Hämalaunlösung (sauer nach Mayer)

Hoechst 33258 (Bisbenzimid)

Immersionsöl (für die Mikroskopie)

Isofluran Forene@

Kaliumchlorid ( $\mathrm{KCl}$ )

Kaliumdihydrogenphosphat $\left(\mathrm{KH}_{2} \mathrm{PO}_{4}\right)$

Kernechtrot (für die Mikroskopie)

Ketamin $(10 \% ; 100 \mathrm{mg} / \mathrm{ml})$

Loading Dye (6 x Solution)

Magnesiumchlorid $\left(\mathrm{MgCl}_{2}\right), 25 \mathrm{mM}$

Magnesiumchlorid-Hexahydrat $\quad \mathrm{MgCl}_{2}$ x $\left.6 \mathrm{H}_{2} \mathrm{O}\right)$

Metafectene transfection reagent

Methanol

M-MLV Reverse Transcriptase

NaCl-Lösung (0,9\%)

$\mathrm{NaCl}$ solution $(0,9 \%$, steril, für Injektion)

Natriumchlorid ( $\mathrm{NaCl})$

Natriumcitrat-Dihydrat $\left(\mathrm{C}_{6} \mathrm{H}_{5} \mathrm{Na}_{3} \mathrm{O}_{7} \mathrm{x}\right.$ $\left.2 \mathrm{H}_{2} \mathrm{O}\right)$

Natriumdodecylsulfat

Natriumhydroxid $(\mathrm{NaOH})$

Naturaflor ${ }^{\circledR}$ Milchpulver

Nitroblau-Tetrazoliumchlorid (NBT)

Oligo(dT)15 Primer

Paraformaldehyd PFA (reinst)

Ponceau S

Prestained SDS-PAGE Standard (Broad

Range)

Proteinase K, rekombinant

Proteinase K, aus Tritirachium album $(\geq 30 \mathrm{U} / \mathrm{mg})$
Carl Roth GmbH, Karlsruhe

Invitrogen, Carlsbad, Kalifornien, USA

Merck KGaA, Darmstadt

Abbott GmbH \& Co KG, Wiesbaden

Carl Roth GmbH, Karlsruhe

Merck KGaA, Darmstadt

Merck KGaA, Darmstadt

Pharmanovo GmbH, Hannover

Fermentas, Burlington, Ontario, Kanada

Fermentas, Burlington, Ontario, Kanada

Carl Roth GmbH, Karlsruhe

Biontex Laboratories, Martinsried

Carl Roth GmbH, Karlsruhe

Promega, Madison, Wisconsin, USA

Diaco, Triest, Italien

B. Braun Melsungen AG, Melsungen

Carl Roth GmbH, Karlsruhe

Sigma-Aldrich, St. Louis, Missouri, USA

Sigma-Aldrich, St. Louis, Missouri, USA

Sigma-Aldrich, St. Louis, Missouri, USA

Töpfer GmbH, Dietmannsried

Roche Diagnostics, Mannheim

Promega, Madison, Wisconsin, USA

Carl Roth GmbH, Karlsruhe

Sigma-Aldrich Chemie GmbH, Taufkirchen

Bio-Rad, München

Roche Diagnostics, Mannheim

Carl Roth GmbH, Karlsruhe 
RNase Inhibitor (RNasin)

RNeasy Mini Kit

RQ1 DNase Buffer (10x)

RQ1 RNase Free DNaseI

Salzsäure (HCl; 6 mol/l; 6 N Lösung)

Sauerstoff

Stop Solution

Wasser, Rotisol ${ }^{\circledR}$ HPLC Gradient Grade

Terminale Transferase (rekombinant)

Thermo-Fast ${ }^{\circledR}$ Platte, 96-Well

Tris (PUFFERAN ${ }^{\circledR} \geq 99,3 \%$, Buffer Grade)

Triton X-100

TWEEN ${ }^{\circledR} 20$

Wasser für Injektionszwecke (Ampuwa) Xylazin $(2 \% ; 20 \mathrm{mg} / \mathrm{ml})$

Xylol (Isomere)

Ziegenserum
Promega, Madison, Wisconsin, USA

Qiagen, Hilden

Promega, Madison, Wisconsin, USA

Promega, Madison, Wisconsin, USA

Carl Roth GmbH, Karlsruhe

Linde AG, Pullach

Promega, Madison, Wisconsin, USA

Carl Roth GmbH, Karlsruhe

Roche Diagnostics, Mannheim

Abgene, Epsom, UK

Carl Roth GmbH, Karlsruhe

Sigma-Aldrich Chemie GmbH, Taufkirchen

Sigma-Aldrich, St. Louis, Missouri, USA

Fresenius Kabi, Bad Homburg

Riemser Arzneimittel AG, Greifswald Insel Riems

Carl Roth GmbH, Karlsruhe

PAA Laboratories GmbH, Pasching, Österreich 


\subsection{PCR-Amplifikate zur Genotypisierung von LFGEIIaCre-Versuchstieren}

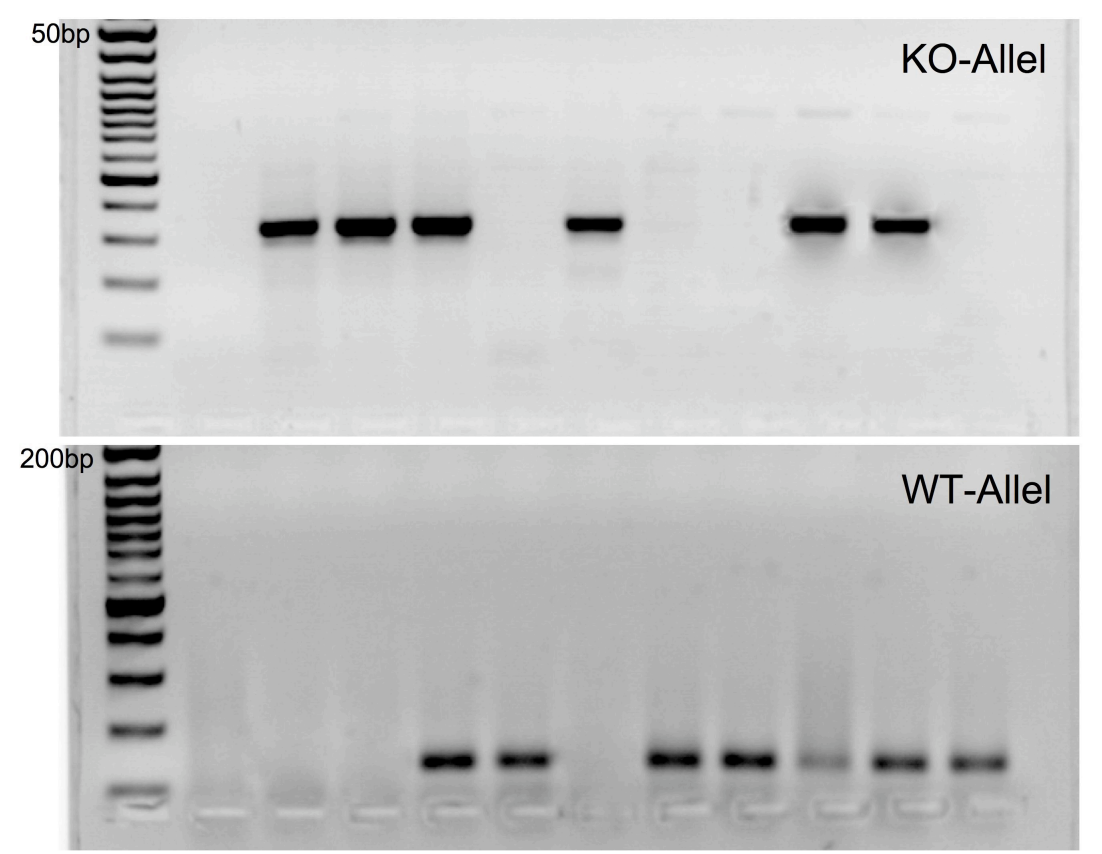

Abbildung 8.1: Agarosegelelektrophorese von PCR-Amplifikaten zur Genotypisierung von LFGEIIaCre-Versuchstieren 


\subsection{Stereotaktische Injektion}

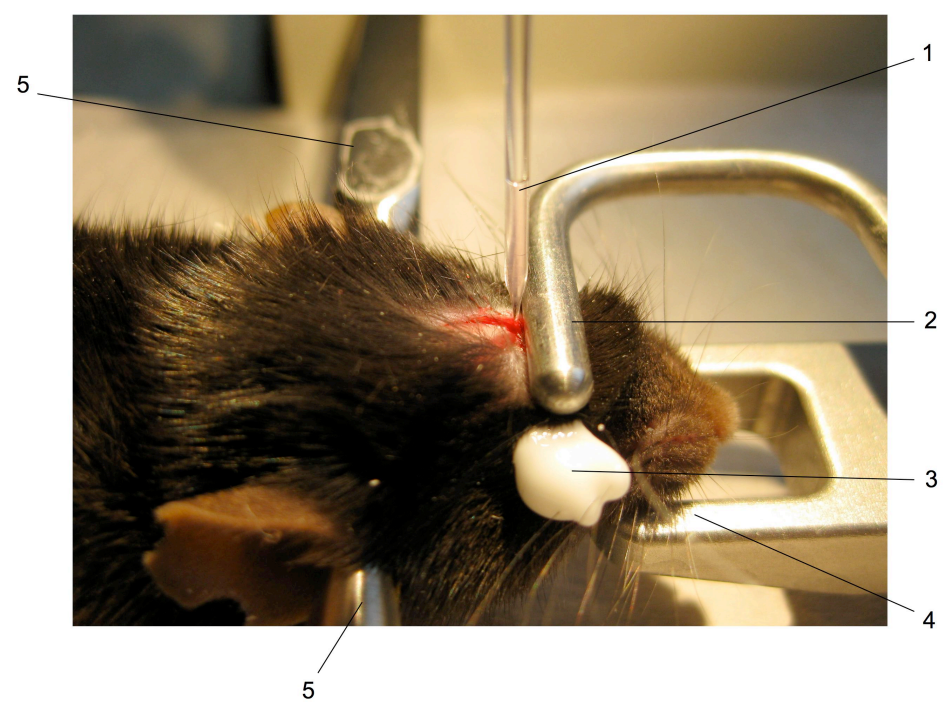

Abbildung 8.2: Versuchsaufbau der stereotaktischen Injektion. (1) Mit Mineralöl und Virus befüllte Glaskapillare; (2) Fixierungsbügel; (3) Auge mit Bepanthen Augen- und Nasensalbe bedeckt; (4) Bügel für Oberkieferauflage; (5) Fixierungsbolzen an den Os mastoidii bds.

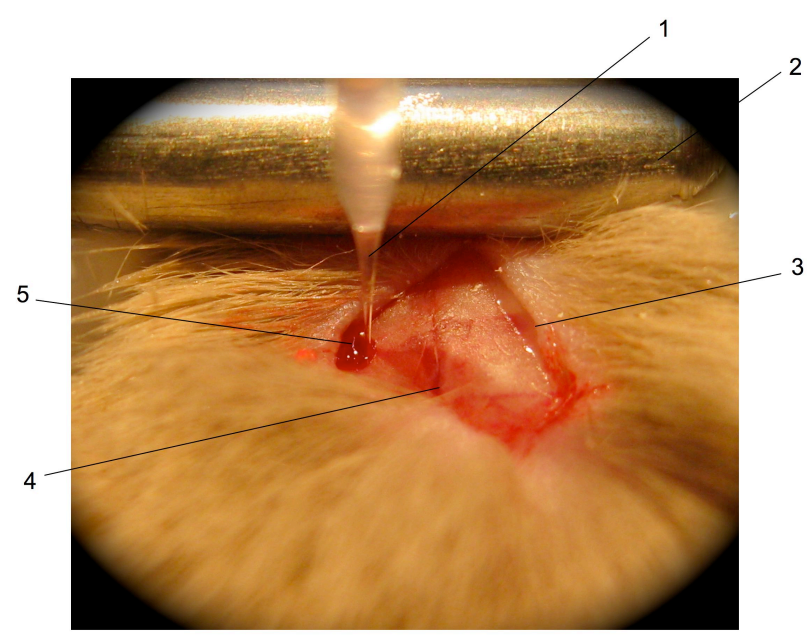

Abbildung 8.3: Anatomische Verhältnisse bei stereoktakischer Injektion mittels Bohrlochtrepanation. (5-fache Vergrößerung) (1) Mit Mineralöl und Virus befüllte Glaskapillare; (2) Fixierungsbügel; (3) Circa 0,5 cm langer Hautschnitt, median; (4) Bregma; (5) Bohrloch. 


\subsection{Position und Anatomie der Hirnsektionen}

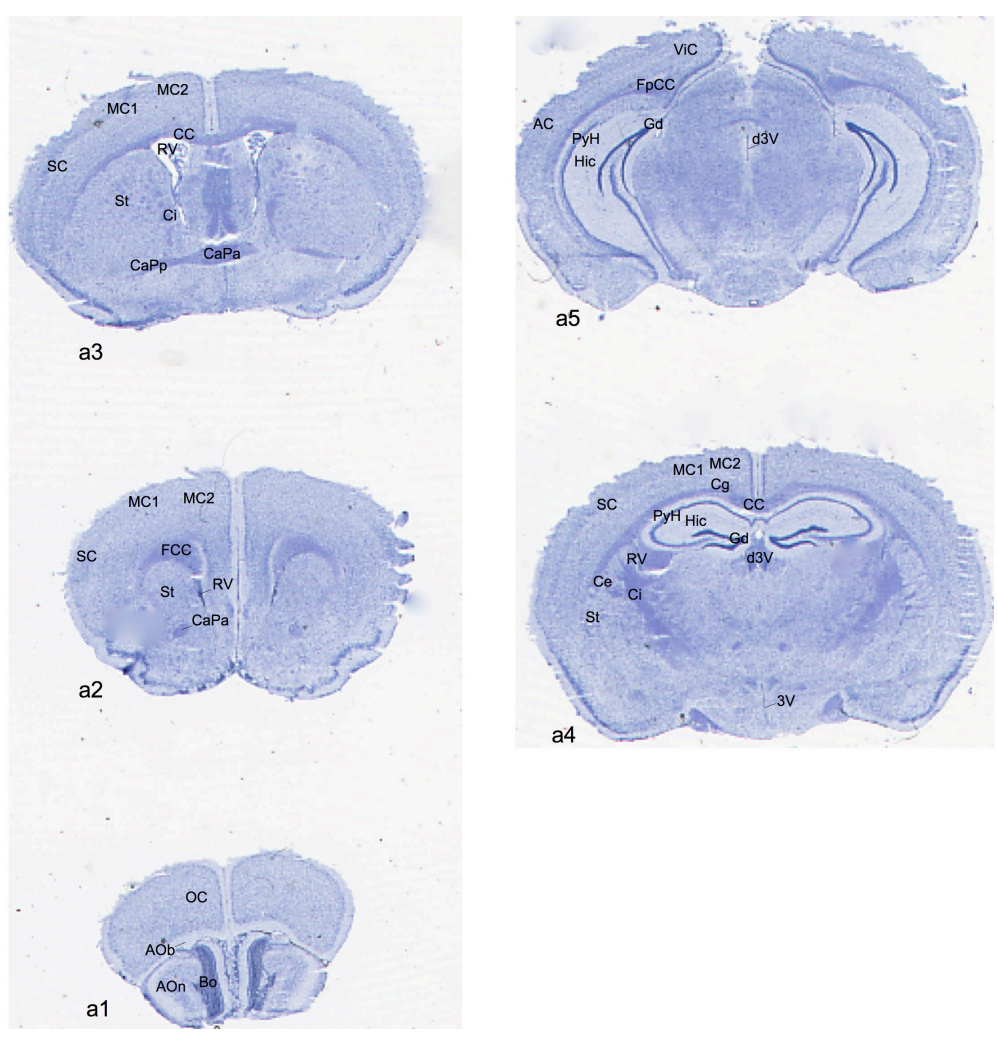

Abbildung 8.4: Position der koronaren Hirnschnitte in einer Kontrolle (sham) ohne Ischämie a1: $+3,14 \mathrm{~mm}$ (Bregma) AOb Accessorischer olfaktorischer Bulbus; AOn Anteriorer olfaktorischer Nukleus; Bo Bulbus olfaktorius; OC Orbitaler Cortex; a2: $+1,70 \mathrm{~mm}$ (Bregma) CaPa Commissura anterior Pars anterior; FCC Forceps anterior des Corpus Callosum; MC1 Primärer motorischer Kortex; MC2 Sekundärer motorischer Kortex; $R V$ Rechter Ventrikel; $S C$ Somatosensorischer Kortex; St Striatum; a3: $0 \mathrm{~mm}$ (Bregma) $\mathrm{CaPa}$ Commissura anterior Pars anterior; CaPp Commissura anterior Pars posterior; $C C$ Corpus callosum; $C i$ Capsula interna; $M C 1$ Primärer motorischer Kortex; MC2 Sekundärer motorischer Kortex; $R V$ Rechter Ventrikel; $S C$ Somatosensorischer Kortex; $S t$ Striatum; a4: -1, $28 \mathrm{~mm}$ (Bregma) 3V Dritter Ventrikel; $C C$ Corpus callosum; Ce Capsula externa; $C g$ Cingulum; $C i$ Capsula interna; $d 3 V$ dorsaler Anteil des dritten Ventrikels; Gd Gyrus dentatus; Hic Hippocampus; MC1 Primärer motorischer Kortex; MC2 Sekundärer motorischer Kortex; PyH Pyramidenzellschicht des Hippokampus; $R V$ Rechter Ventrikel; $S C$ Somatosensorischer Kortex; $S t$ Striatum; a5: $-2,75 \mathrm{~mm}$ (Bregma) $A C$ Auditorischer Kortex; d3V dorsaler Anteil des dritten Ventrikels; FpCC Forceps posterior des Corpus Callosum; Gd Gyrus dentatus; Hic Hippocampus; PyH Pyramidenzellschicht des Hippokampus; ViC Visueller Kortex 


\subsection{SNAP-Score}




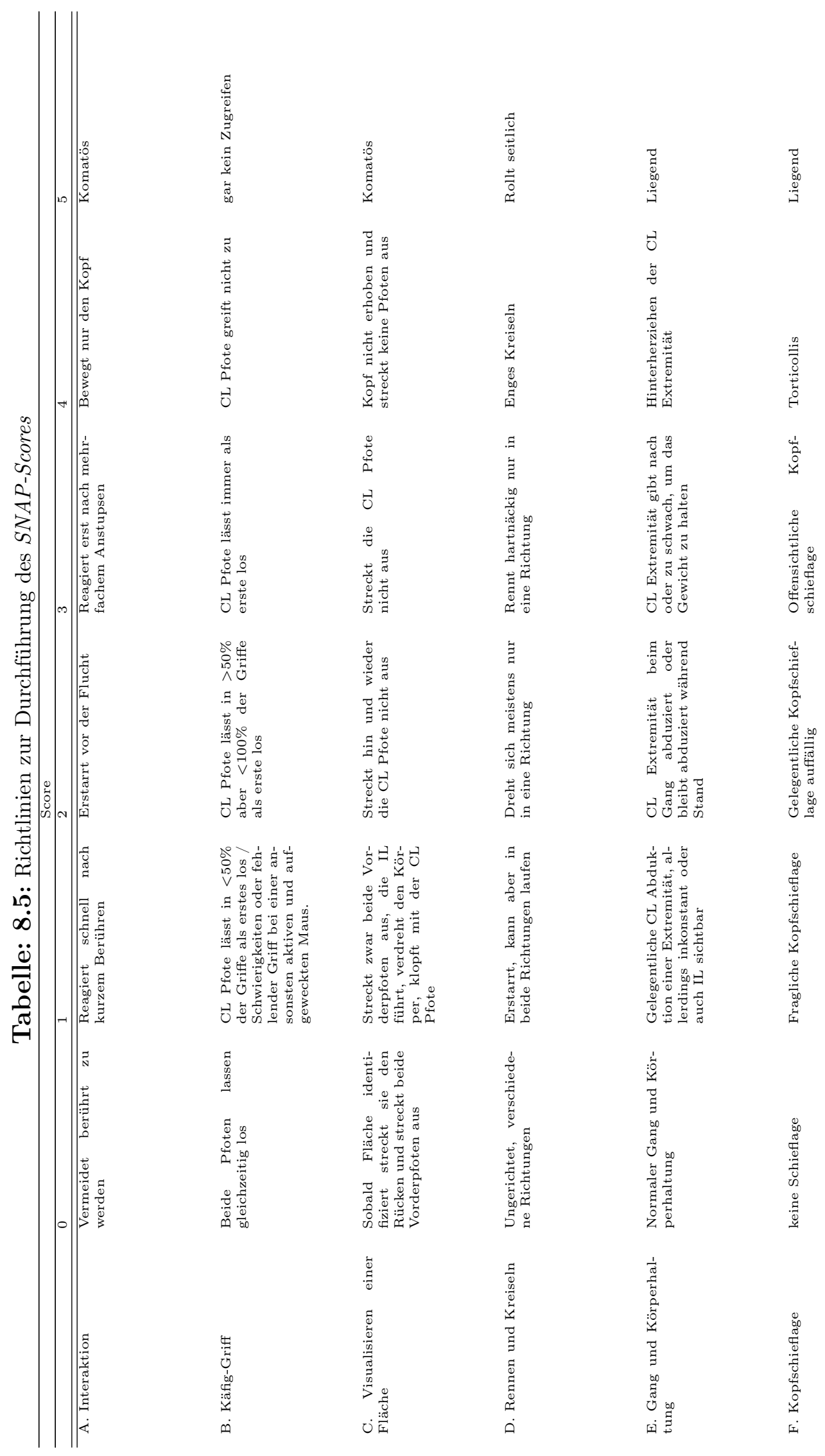




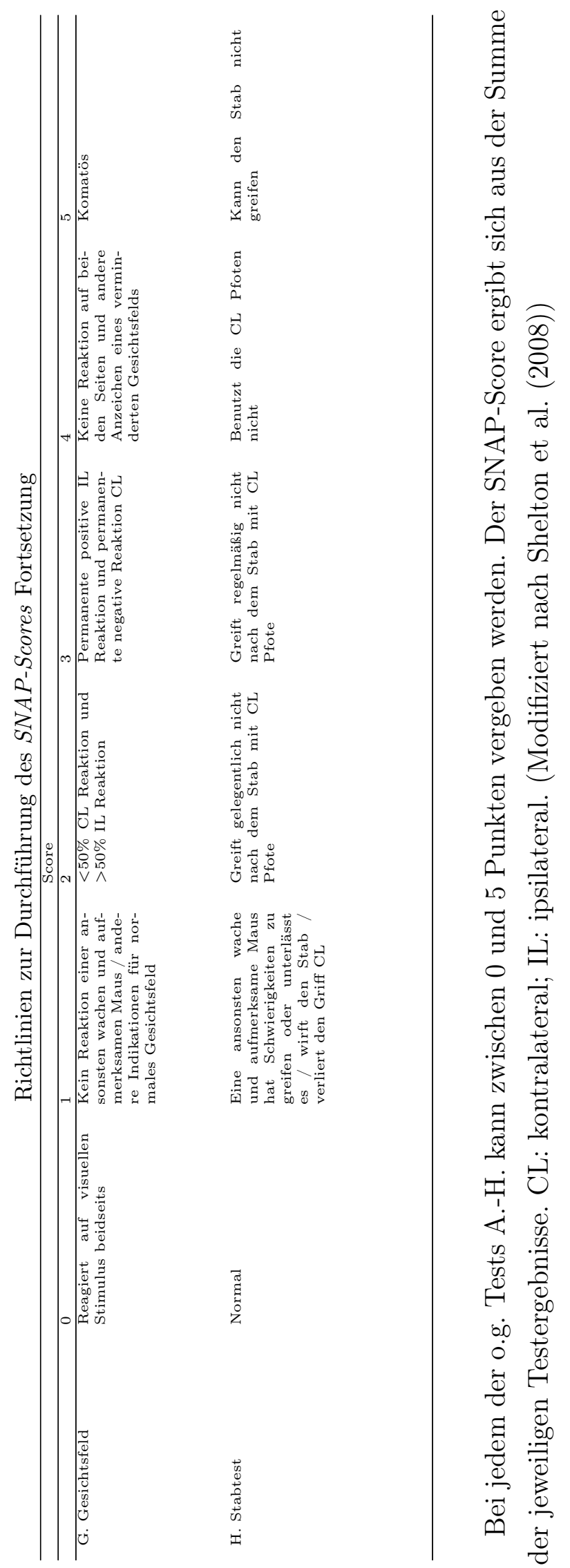




\section{Danksagung}

Ein besonderer Dank gilt meinem Doktorvater Herrn Prof. Dr. med. Jörg B. Schulz für die Bereitstellung der Ressourcen zur Durchführung der vorliegenden Arbeit sowie für die intensive Betreuung und Unterstützung in der Erstellungs- und Versuchsphase. Ebenso gilt mein Dank Herrn Prof. Dr. med. Matthias Endres der Klinik für Neurologie der Charité Universitätsmedizin Berlin für die freundliche und hochkompetente Zusammenarbeit in den Räumen seines Labors am Campus Mitte und Charlottenburg.

Dr. med. Arno Reich, möchte ich für seine engagierte Betreuung während der Anlernphase von wissenschaftlichen Grundlagen und den Vorversuchen ebenso danken, wie für die Begleitung während der Versuchsdurchführung und Auswertung sowie der Strategieplanung und Erarbeitung der aus der vorliegenden Arbeit entstandenen Publikationen, welche diese Promotion sehr bereichert haben.

Ebenfalls gilt mein besonderer Dank Frau Dr. med. Karen Gertz und Herrn Prof. Dr. med. Golo Kronenberg der Klinik für Neurologie der Charité Universitätsmedizin Berlin für ihr überaus großes Engagement in der Einarbeitung in die Versuchsmethodik der Middle Cerebral Artery Occlusion und die darauf folgende Aufarbeitung und molekularbiologische Auswertung der Ischämieversuche.

Ein weiterer Dank gilt Herrn Dr. med. Christoph Harms (in-vitro-Versuche), Dr. rer. nat. Anja Drinkut (stereotaktische Injektionen) und Dr. rer. nat. Ellen Gerhard (lentiviraler Vektor) für die intensive Einarbeitung und Unterstützung bzw. enge Kooperation. 
Ohne die große Unterstützung durch die Medizinisch Technischen Assistenten wäre die vorliegende Arbeit nicht möglich gewesen. Dafür einen herzlichen Dank an die beteiligten MTAs der ehemaligen Abteilung für Neurodegenerations- und Neurorestaurationsforschung der Georg-August-Universität Göttingen, der Neurologischen Klinik des Universitätsklinikums Aachen und der Klinik für Neurologie der Charité Universitätsmedizin Berlin.

Nicht zuletzt möchte ich dem ehemaligen Studiendekan der medizinischen Fakultät der Georg-August-Universät Göttingen, Herrn Prof. Dr. med. Gerhard Hellige, und dem amtierenden Studiendekan der medizinischen Fakultät, Herrn Prof. Dr. med. Gerhard Burckhardt, für die Breitstellung der finanziellen Unterstützung im Rahmen des aus Studienbeiträgen finanzierten Exzellenzförderungsstipendiums Gö4med danken. Ebenso gilt mein Dank der Studienstiftung des Deutschen Volkes für die jahrelange finanzielle und inhaltliche Unterstützung meiner Studien- und Forschungstätigkeiten. 